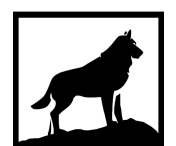

1885

\title{
AN EXPERIMENTAL INVESTIGATION OF THE EFFECT OF TEMPERATURE AND SPACE VELOCITY ON THE PERFORMANCE OF A CU-ZEOLITE FLOW-THROUGH SCR AND A SCR CATALYST ON A DPF WITH AND WITHOUT PM LOADING
}

Vaibhav Kadam

Michigan Technological University, vkadam@mtu.edu

Copyright 2016 Vaibhav Kadam

\section{Recommended Citation}

Kadam, Vaibhav, "AN EXPERIMENTAL INVESTIGATION OF THE EFFECT OF TEMPERATURE AND SPACE VELOCITY ON THE PERFORMANCE OF A CU-ZEOLITE FLOW-THROUGH SCR AND A SCR CATALYST ON A DPF WITH AND WITHOUT PM LOADING", Open Access Master's Thesis, Michigan Technological University, 2016.

https://doi.org/10.37099/mtu.dc.etdr/271

Follow this and additional works at: https://digitalcommons.mtu.edu/etdr

Part of the Automotive Engineering Commons, Energy Systems Commons, and the Heat Transfer, Combustion Commons 


\title{
AN EXPERIMENTAL INVESTIGATION OF THE EFFECT OF TEMPERATURE AND SPACE VELOCITY ON THE PERFORMANCE OF A CU-ZEOLITE FLOW- THROUGH SCR AND A SCR CATALYST ON A DPF WITH AND WITHOUT PM LOADING
}

\author{
By \\ Vaibhav Kadam
}

\begin{abstract}
A THESIS
Submitted in partial fulfillment of the requirements for the degree of MASTER OF SCIENCE

In Mechanical Engineering
\end{abstract}

MICHIGAN TECHNOLOGICAL UNIVERSITY

2016

(C) 2016 Vaibhav Kadam 

This thesis has been approved in partial fulfillment of the requirements for the Degree of MASTER OF SCIENCE in Mechanical Engineering.

Department of Mechanical Engineering - Engineering Mechanics

Thesis Co-Advisor: Dr. Jeffrey Naber

Thesis Co-Advisor: $\quad$ Dr. John Johnson

Committee Member: $\quad$ Dr. David Shonnard

Department Chair: Dr. William Predebon 



\section{Table of Contents}

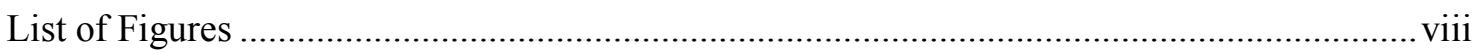

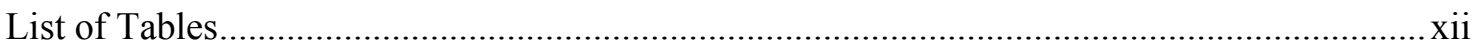



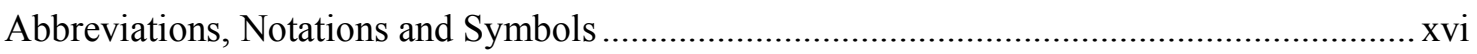

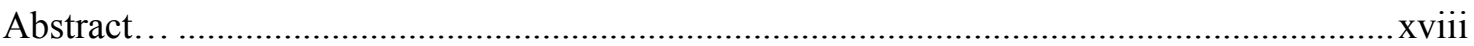

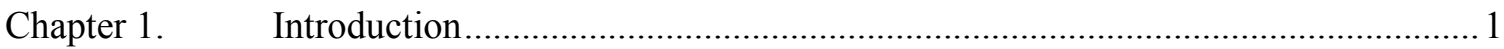

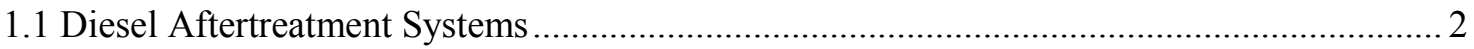

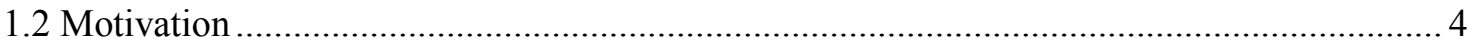

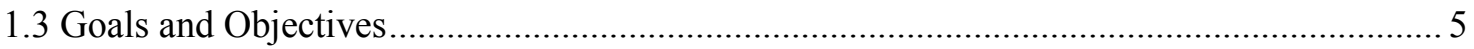



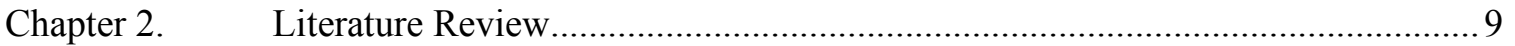

2.1 SCR Catalyst Formulations and Experimental Studies .................................................... 9

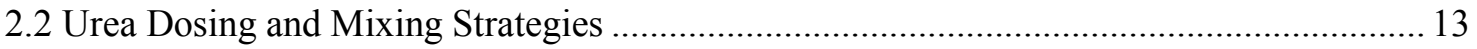

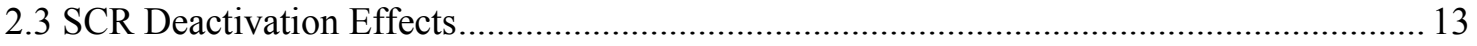

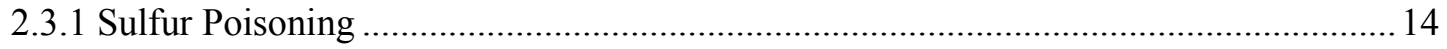

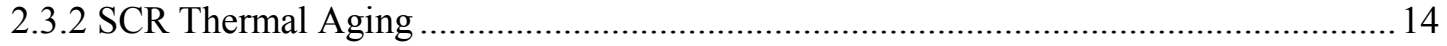

2.3.3 Hydrocarbon and Chemical Poisoning …................................................................. 15

2.4 Modeling the Kinetics of the SCR Reactions................................................................... 15

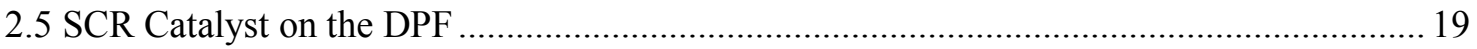



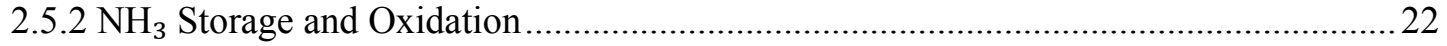

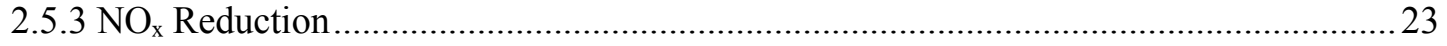

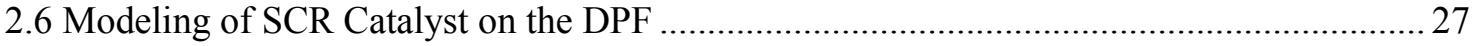

Chapter 3. Experimental Setup, Instrumentation and Test Procedures .............................. 30

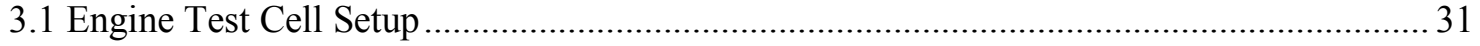

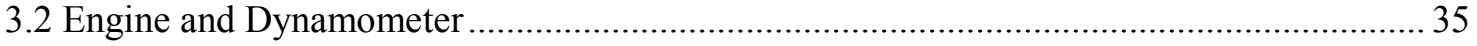

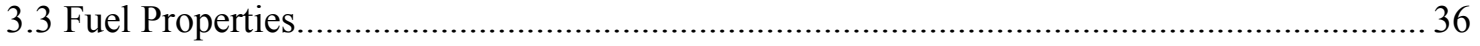

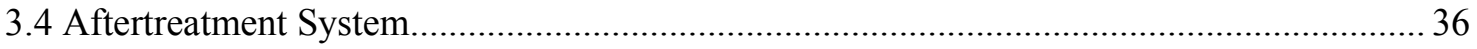

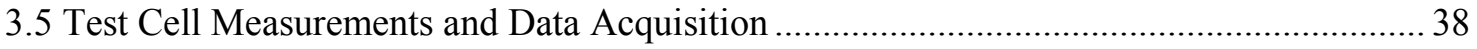

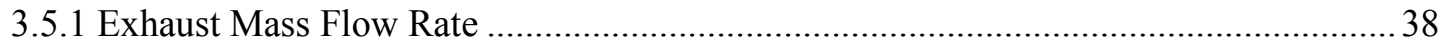

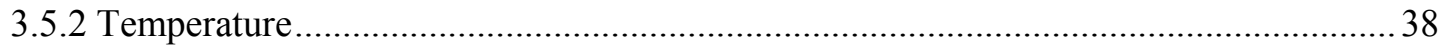

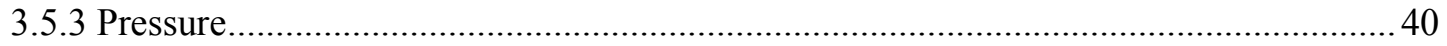

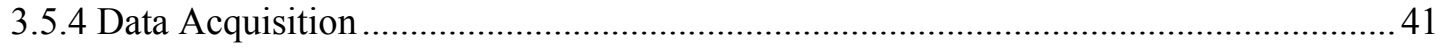




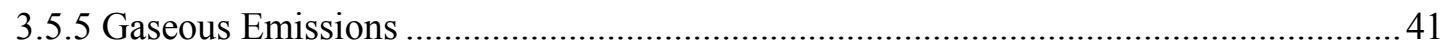



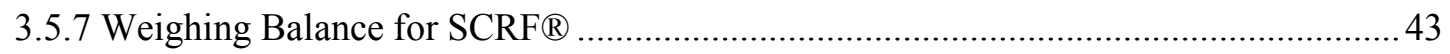

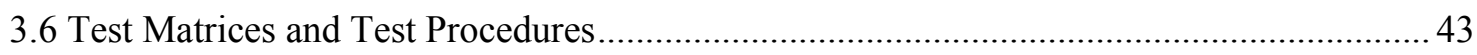

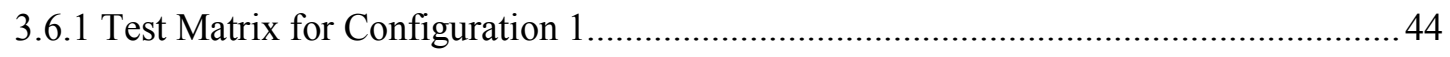

3.6.2 Test Matrix for $\mathrm{NO}_{\mathrm{x}}$ Experimental Tests (Production-2013-SCR and

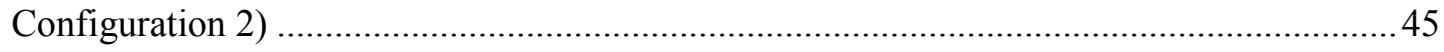

3.6.3 Baseline Condition and Aftertreatment Clean-out....................................................... 46

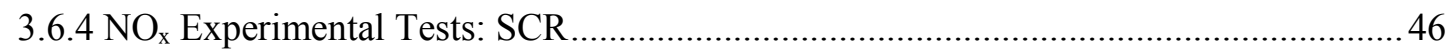

3.6.5 $\mathrm{NO}_{\mathrm{x}}$ Experimental Tests: SCRF® - without PM Loading - Configuration 2 2................ 47

3.6.6 $\mathrm{NO}_{\mathrm{x}}$ Experimental Tests: SCRF® - with PM Loading (2 g/L) - Configuration 2......... 49

3.6.7 $\mathrm{NO}_{\mathrm{x}}$ Experimental Tests: SCRF® - with PM Loading (4 g/L) - Configuration 2.........52

3.6.8 Calculation of PM Mass Retained and Nitrogen Balance .............................................53

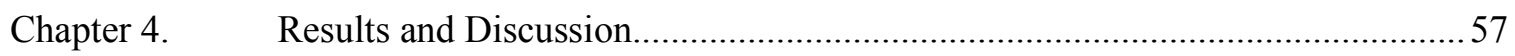

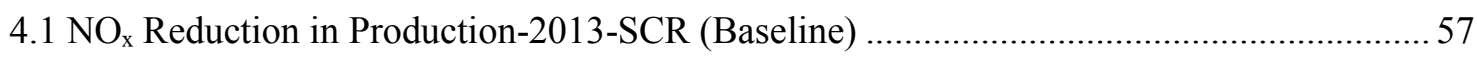



4.3 SCRF® Experimental Data: Configuration 1 (Passive Oxidation with Urea Injection) ...... 72

4.4 SCRF® Experimental Data: Configuration $2\left(\mathrm{NO}_{x}\right.$ Reduction with 0, 2 and 4 g/L PM

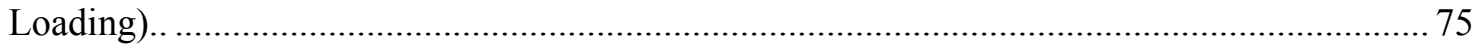

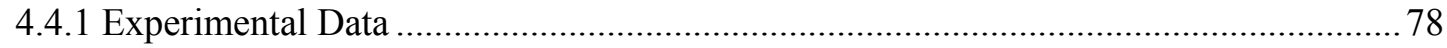

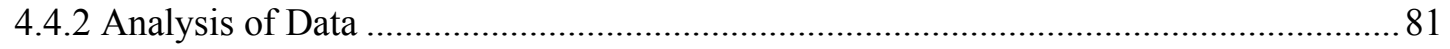

4.5 Comparison of $\mathrm{NO}_{\mathrm{x}}$ Reduction: SCRF ${ }^{\circledR}$ to Production-2013-SCR …................................ 97

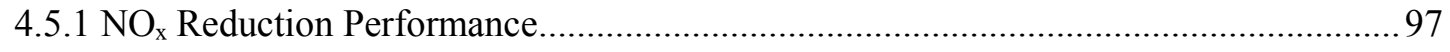

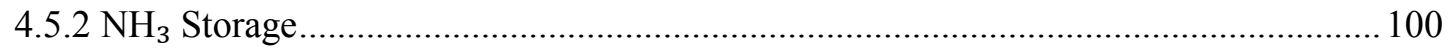

4.6 Calculation of ANR's for Configuration 3: SCRF® + SCR …...................................... 103

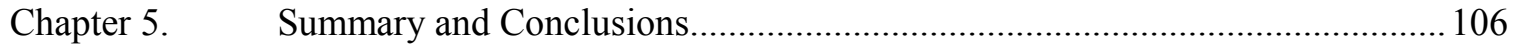

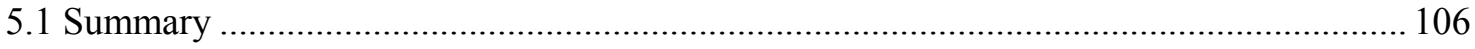



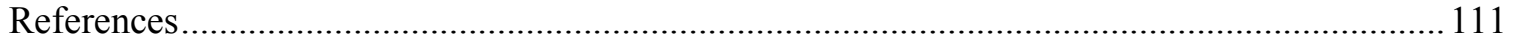

Appendix A. MS Start up, Shut down and Calibration Procedures ..................................... 120

Appendix B. Calibration of $\mathrm{NH}_{3}$ Sensor using the MS ...................................................... 122

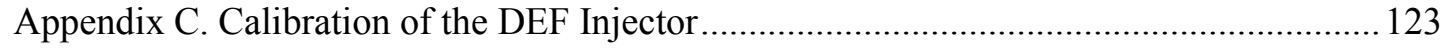

Appendix D. Production-2013-SCR Experimental Results, 1-D SCR Model Calibration




Appendix E. Engine, Exhaust conditions and PM Mass Balance for each Stage Configuration 2 (with PM loading)

Appendix F. Gaseous Emissions by Stage

Appendix G. Pressure Drop Across the SCRF® - Configuration 2 (with and without PM loading)

Appendix H. Temperature Distribution in the SCRF®) - Configuration 2 (with and without PM loading).

Appendix I. Permissions to Use Copyrighted Material 


\section{List of Figures}

Figure 1.1: Overall schematic of the Cummins ISB 2013 production aftertreatment system [3]

Figure 2.1: $\mathrm{NO}_{\mathrm{x}}$ conversion of a cerium oxide based $\mathrm{SCR}$ as a function of

temperature [27]

Figure 2.2: $\mathrm{NO}_{\mathrm{x}}$ conversion of a $\mathrm{Mn}(0.25) / \mathrm{Ti}$ based $\mathrm{SCR}$ as a function of

temperature [33].

Figure 2.3: Schematic of conventional DPF, SCR and SCR-on-filter [11]

Figure 2.4: Effect of $\mathrm{NH}_{3}$ and $\mathrm{NO}_{x}$ on the passive oxidation. GHSV $=15 \mathrm{k} / \mathrm{hr}$, $\mathrm{H}_{2} \mathrm{O}=5 \%, \mathrm{O}_{2}=8 \%$ when $\mathrm{NH}_{3}$ is present, $\mathrm{NH}_{3}=500$ ppm. a $\mathrm{NO}_{\mathrm{x}}=0$ ppm, b $\mathrm{NO}_{\mathrm{x}}=500$ ppm, $\mathrm{NO}_{2} / \mathrm{NO}_{\mathrm{x}}=0[64]$.....

Figure 2.5: Competition between passive oxidation and SCR reactions [64]

Figure 2.6: $\mathrm{NO}_{\mathrm{x}}$ conversions for $\mathrm{V}-\mathrm{DPF}$ and $\mathrm{Cu}-\mathrm{DPF}$ compared to $\mathrm{V}-\mathrm{ft}$ and $\mathrm{Cu}-\mathrm{ft}$

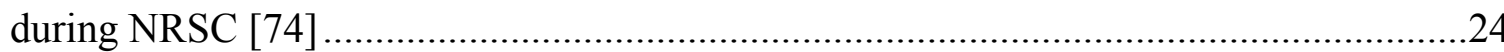

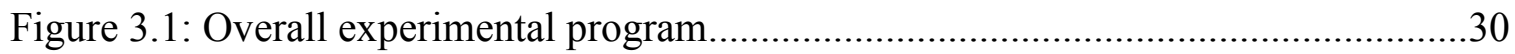

Figure 3.2: A picture from the heavy duty diesel lab at MTU .....................................32

Figure 3.3: Schematic of test cell with the production engine and aftertreatment system and the instrumentation [3]

Figure 3.4: Schematic of test cell with the production engine and the SCRF® and the instrumentation for configuration-1 [3]

Figure 3.5: Schematic of test cell with the production engine and the SCRF® (with and without the upstream CPF) and the instrumentation for configuration-2 [3] ............34

Figure 3.6: Thermocouple arrangement in the CPF (adapted from reference [13]) ..........39

Figure 3.7: Thermocouple arrangement in the SCRF®.

Figure 3.8: Stages of a passive oxidation test with urea dosing with configuration 1

[1]

Figure 3.9: Urea dosing cycle for the production-2013-SCR

Figure 3.10: Schematic for $\mathrm{NO}_{\mathrm{x}}$ reduction test on $\mathrm{SCRF}{ }^{\circledR}$ without PM Loading.............48

Figure 3.11: Modified urea dosing cycle for the SCRF®.

Figure 3.12: Schematic for effect of PM Loading on SCRF® $\mathrm{NO}_{\mathrm{x}}$ reduction.

Figure 3.13: Delta Pressure across the SCRF® for Configuration 2 - Test Point 1 with PM

Figure 3.14: Delta Pressure across the SCRF® for Configuration 2 - Test Point 1 with PM

Figure 4.1: $\mathrm{NO}_{\mathrm{x}}$ conversion efficiency of production-2013-SCR for steady state conditions at target ANR 1.0 and 1.2.

Figure 4.2: $\mathrm{NH}_{3}$ slip in production-2013-SCR for steady state conditions at target ANR 1.0 and 1.2

Figure 4.3: Comparison of SCR outlet NO concentrations for various Test Points .........67

Figure 4.4: Comparison of SCR outlet $\mathrm{NO}_{2}$ concentrations for various Test Points ........68 
Figure 4.5: Comparison of $\mathrm{NH}_{3}$ slip concentrations for various Test Points

Figure 4.6: Comparison of the SCR outlet gaseous concentrations between simulation results and experimental measurements for Test Point 4 (SCR inlet temperature $327^{\circ} \mathrm{C}, \mathrm{SV} 26.7 \mathrm{k} / \mathrm{hr}$ ) using urea dosing cycle (Figure 3.9) .70

Figure 4.7: Comparison of the SCR outlet gaseous concentrations between simulation results and experimental measurements for Test Point 1 (SCR inlet temperature $218^{\circ} \mathrm{C}, \mathrm{SV} 12.0 \mathrm{k} / \mathrm{hr}$ ) using urea dosing cycle (Figure 3.9) .71 Figure 4.8: Comparison of the SCR outlet gaseous concentrations between simulation results and experimental measurements for Test Point 1 (SCR inlet temperature $218^{\circ} \mathrm{C}, \mathrm{SV} 12.0 \mathrm{k} / \mathrm{hr}$ ), using different parameters as shown in Table $4.5 \ldots . .72$ Figure 4.9: $\mathrm{NO}_{\mathrm{x}}$ conversion efficiency of the SCRF ${ }^{\circledR}-$ Configuration 1 ........................75 Figure 4.10: $\mathrm{NO}, \mathrm{NO}_{2} \mathrm{NH}_{3}$ slip downstream of the $\mathrm{SCRF}{ }^{\circledR}$ and $\mathrm{NO}_{\mathrm{x}}$ conversion efficiency at various ANR for Test Point 1 , with and without PM in the SCRF® $\left(\mathrm{SCRF} \circledast\right.$ inlet temperature $=201{ }^{\circ} \mathrm{C}$ and $\left.\mathrm{SV}=13.7 \mathrm{k} / \mathrm{hr}\right)$...

Figure 4.11: $\mathrm{NO}, \mathrm{NO}_{2} \mathrm{NH}_{3}$ slip downstream of the $\mathrm{SCRF}{ }^{\circledR}$ and $\mathrm{NO}_{\mathrm{x}}$ conversion efficiency at various ANR for Test Point 3, with and without PM in the SCRF® $\left(\mathrm{SCRF}{ }^{\circledR}\right.$ inlet temperature $=304{ }^{\circ} \mathrm{C}$ and $\mathrm{SV}=29.1 \mathrm{k} / \mathrm{hr}$ ).

Figure 4.12: $\mathrm{NO}, \mathrm{NO}_{2} \mathrm{NH}_{3}$ slip downstream of the $\mathrm{SCRF}{ }^{\circledR}$ and $\mathrm{NO}_{\mathrm{x}}$ conversion efficiency at various ANR for Test Point 6, with and without PM in the SCRF® (SCRF® inlet temperature $=345^{\circ} \mathrm{C}$ and $\mathrm{SV}=18.8 \mathrm{k} / \mathrm{hr}$ ).

Figure 4.13: $\mathrm{NO}, \mathrm{NO}_{2} \mathrm{NH}_{3}$ slip downstream of the $\mathrm{SCRF} \AA$ and $\mathrm{NO}_{\mathrm{x}}$ conversion efficiency at various ANR for Test Point 8 , with and without PM in the SCRF®

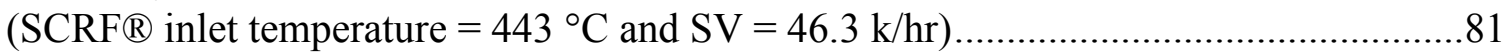

Figure 4.14: $\mathrm{NO}_{2} / \mathrm{NO}_{\mathrm{x}}$ ratios at the inlet and outlet of the SCRF® at $0 \mathrm{ANR}$.................84 Figure 4.15: $\mathrm{NO}_{\mathrm{x}}$ conversion efficiency of the $\mathrm{SCRF}{ }^{\circledR}$ with and without $\mathrm{PM}$ at ANR 0.8 .86

Figure 4.16: $\mathrm{NH}_{3}$ Slip from the SCRF® with and without PM at ANR 0.8 .86 Figure 4.17: $\mathrm{NO}_{\mathrm{x}}$ conversion efficiency of the $\mathrm{SCRF}{ }^{\circledR}$ with and without PM at ANR 1.0

Figure 4.18: $\mathrm{NH}_{3}$ Slip from the SCRF® with and without PM at ANR 1.0 ....

Figure 4.19: $\mathrm{NO}_{\mathrm{x}}$ conversion efficiency of the $\mathrm{SCRF}{ }^{\circledR}$ with and without PM at

ANR 1.2

Figure 4.20: $\mathrm{NH}_{3}$ Slip from the SCRF® with and without PM at ANR 1.2

Figure 4.21: Pressure drop across the SCRF® for the Test Point 1, with PM loading $2 \mathrm{~g} / \mathrm{L}$

Figure 4.22: Pressure drop across the SCRF® for the Test Point 6, with PM loading $2 \mathrm{~g} / \mathrm{L}$

Figure 4.23: Temperature distribution in the SCRF® during $\mathrm{NO}_{\mathrm{x}}$ reduction stage for Test Point 6 without PM loading, without urea injection .... .94 Figure 4.24: Temperature distribution in the $\mathrm{SCRF}{ }^{\circledR}$ during $\mathrm{NO}_{\mathrm{x}}$ reduction stage for Test Point 6 without PM loading, at ANR 1.0. .95 
Figure 4.25: SCRF® inlet and axial temperatures relative to ANR for Test Point 6 without PM loading

Figure 4.26: Temperature distribution in the SCRF® during $\mathrm{NO}_{\mathrm{x}}$ reduction stage for

Test Point 6 with $2 \mathrm{~g} / \mathrm{L}$ PM loading, at ANR 1.0 ..................................................96

Figure 4.27: Temperature distribution in the $\mathrm{SCRF} \AA$ during $\mathrm{NO}_{\mathrm{x}}$ reduction stage for

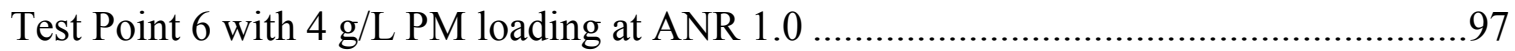

Figure 4.28: $\mathrm{NO}_{\mathrm{x}}$ conversion efficiency of the production-2013-SCR and the

$\mathrm{SCRF} \circledast$ at various inlet temperatures

Figure 4.29: $\mathrm{NH}_{3}$ slip out of the production-2013-SCR/SCRF® during $\mathrm{NO}_{\mathrm{x}}$

reduction and passive oxidation with urea injection tests at ANR 1.0

Figure 4.30: Inlet $\mathrm{NH}_{3}$ and $\mathrm{NH}_{3}$ stored in the SCRF® at Test Point 1 at ANR 1.2

repeat, without and with PM loading in the $\operatorname{SCRF}{ }^{\circledR}(0$ and $2 \mathrm{~g} / \mathrm{L}), \mathrm{SV}=13.7 \mathrm{k} / \mathrm{hr}$,

$\mathrm{SCRF}{ }^{\circledR}$ inlet temperature $=210^{\circ} \mathrm{C}$

Figure 4.31: Fraction of Urea thermolyzed at various locations, $\mathrm{SV}=30 \mathrm{k} / \mathrm{hr}[85] \ldots \ldots .102$

Figure 4.32: $\mathrm{NH}_{3}$ storage in the production-SCR and the SCRF® at various

temperatures....

Figure 4.33: Sample calculations to estimate the targeted ANR for Test Point A

Figure 4.34: Sample calculations to estimate the targeted ANR for Test Point E.

Figure C.1: Calibration curve for the DEF injection

Figure D.1: Flow chart of manual optimization procedure to calibrate 1-D SCR

model.

Figure D.2: Arrhenius plots of reaction rate constants for reactions R1, R2, R7 and R9

Figure D.3: Comparison of the SCR outlet gaseous concentrations between

simulation results and experimental measurements for Test Point 2 (SCR inlet temperature $235^{\circ} \mathrm{C}, \mathrm{SV} 17.2 \mathrm{k} / \mathrm{hr}$

Figure D.4: Comparison of the SCR outlet gaseous concentrations between

simulation results and experimental measurements for Test Point 3 (SCR inlet

temperature $307^{\circ} \mathrm{C}$, SV $26.4 \mathrm{k} / \mathrm{hr}$

Figure D.5: Comparison of the SCR outlet gaseous concentrations between

simulation results and experimental measurements for Test Point 5 (SCR inlet

temperature $355^{\circ} \mathrm{C}, \mathrm{SV} 21.6 \mathrm{k} / \mathrm{hr}$.

Figure D.6: Comparison of the SCR outlet gaseous concentrations between

simulation results and experimental measurements for Test Point 6 (SCR inlet

temperature $351^{\circ} \mathrm{C}, \mathrm{SV} 16.9 \mathrm{k} / \mathrm{hr}$

Figure D.7: Comparison of the SCR outlet gaseous concentrations between

simulation results and experimental measurements for Test Point 8 (SCR inlet

temperature $447^{\circ} \mathrm{C}, \mathrm{SV} 44.7 \mathrm{k} / \mathrm{hr}$.

Figure F. $1 \mathrm{NO}_{\mathrm{x}}$ conversion efficiency of the SCRF® with and without PM at ANR

-1.2 Repeat

Figure G.1: Pressure drop across the SCRF® for the Test Point 1, PM loading $0 \mathrm{~g} / \mathrm{L} \ldots 151$

Figure G.2: Pressure drop across the SCRF® for the Test Point 3, PM loading $0 \mathrm{~g} / \mathrm{L} \ldots 152$ 
Figure G.3: Pressure drop across the SCRF® for the Test Point 6, PM loading $0 \mathrm{~g} / \mathrm{L} \ldots 152$ Figure G.4: Pressure drop across the SCRF® for the Test Point 8, PM loading $0 \mathrm{~g} / \mathrm{L} \ldots 153$ Figure G.5: Pressure drop across the SCRF® for the Test Point 3, with PM loading $2 \mathrm{~g} / \mathrm{L}$

Figure G.6: Pressure drop across the SCRF® for the Test Point 8, with PM loading $2 \mathrm{~g} / \mathrm{L}$

Figure G.7: Pressure drop across the SCRF® for the Test Point 1, with PM loading $4 \mathrm{~g} / \mathrm{L}$

Figure G.8: Pressure drop across the SCRF® for the Test Point 3, with PM loading $4 \mathrm{~g} / \mathrm{L}$

Figure G.9: Pressure drop across the SCRF® for the Test Point 6, with PM loading $4 \mathrm{~g} / \mathrm{L}$

Figure G.10: Pressure drop across the SCRF® for the Test Point 8, with PM loading $4 \mathrm{~g} / \mathrm{L}$

Figure H.1: Thermocouple arrangement in the SCRF® (all dimensions in $\mathrm{mm}$ )....

Figure H.2: Temperature distribution in the SCRF® during $\mathrm{NO}_{\mathrm{x}}$ reduction stage for

Test Point 1 without PM loading, at ANR 1.0

Figure H.3: Temperature distribution in the $\mathrm{SCRF}{ }^{\circledR}$ during $\mathrm{NO}_{\mathrm{x}}$ reduction stage for

Test Point 1 with $2 \mathrm{~g} / \mathrm{L}$ PM loading, at ANR 1.0 ...

Figure H.4: Temperature distribution in the $\mathrm{SCRF}{ }^{\circledR}$ during $\mathrm{NO}_{\mathrm{x}}$ reduction stage for Test Point 1 with $4 \mathrm{~g} / \mathrm{L}$ PM loading, at ANR 1.0

Figure H.5: Temperature distribution in the SCRF® during $\mathrm{NO}_{\mathrm{x}}$ reduction stage for Test Point 3 without PM loading, at ANR 1.0

Figure H.6: Temperature distribution in the $\mathrm{SCRF}{ }^{\circledR}$ during $\mathrm{NO}_{\mathrm{x}}$ reduction stage for Test Point 3 with $2 \mathrm{~g} / \mathrm{L}$ PM loading, at ANR 1.0

Figure H.7: Temperature distribution in the $\mathrm{SCRF}{ }^{\circledR}$ during $\mathrm{NO}_{\mathrm{x}}$ reduction stage for Test Point 3 with $4 \mathrm{~g} / \mathrm{L}$ PM loading, at ANR 1.0 162

Figure H.8: Temperature distribution in the SCRF® during $\mathrm{NO}_{\mathrm{x}}$ reduction stage for Test Point 8 without PM loading, at ANR 1.0

Figure H.9: Temperature distribution in the SCRF® during $\mathrm{NO}_{\mathrm{x}}$ reduction stage for Test Point 8 with $2 \mathrm{~g} / \mathrm{L}$ PM loading, at ANR 1.0

Figure H.10: Temperature distribution in the SCRF® during $\mathrm{NO}_{\mathrm{x}}$ reduction stage for Test Point 8 with $4 \mathrm{~g} / \mathrm{L}$ PM loading at ANR 1.0.

Figure H.11: Temperature factor profile at the SCRF® inlet during $\mathrm{NO}_{\mathrm{x}}$ reduction stage without PM loading, at ANR 1.0

Figure H.12: Temperature factor profile at the $\mathrm{SCRF}{ }^{\circledR}$ inlet during $\mathrm{NO}_{\mathrm{x}}$ reduction stage with $2 \mathrm{~g} / \mathrm{L}$ PM loading, at ANR 1.0.

Figure H.13: Temperature factor profile at the SCRF® inlet during $\mathrm{NO}_{\mathrm{x}}$ reduction stage with 4g/L PM loading, at ANR 1.0. 


\section{List of Tables}

Table 1.1: US EPA \& California Emission Standards for Heavy-Duty CI Engines, $\mathrm{g} / \mathrm{bhp} \cdot \mathrm{hr}[2]$

Table 2.1: Reactions included in the 1-D SCR model from reference [9] ........................18

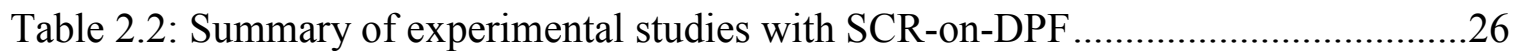

Table 2.3: Summary of modeling studies on SCR-on-filter ..............................................29

Table 3.1: Specifications of the Cummins ISB 2013 engine ...............................................35

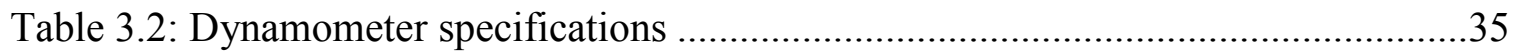

Table 3.3: Specifications of the fuel used for engine testing from reference [3]................36

Table 3.4: Specifications of the ISB 2013 production aftertreatment system and the



Table 3.5: Diesel engine aftertreatment de-greening procedure ........................................37

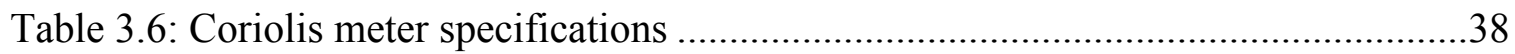

Table 3.7: Specifications of the thermocouples used in the aftertreatment system............39

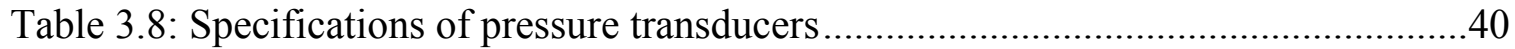

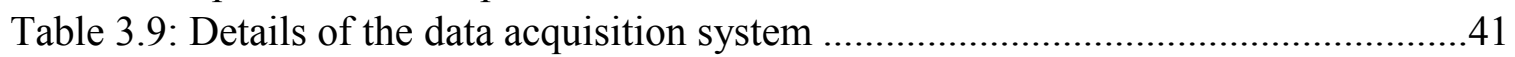

Table 3.10: Specifications of IMR-MS and calibration gases ..........................................42

Table 3.11: Specification $\mathrm{NO}_{\mathrm{x}}$ and $\mathrm{NH}_{3}$ sensor on production aftertreatment system......42

Table 3.12: Specifications of the weighing balance used to weigh the SCRF ${ }^{\circ}$................43

Table 3.13: Test matrix for passive oxidation with urea dosing with configuration 1

[1]

Table 3.14: Test matrix for $\mathrm{NO}_{\mathrm{x}}$ reduction tests for the production-2013-SCR and

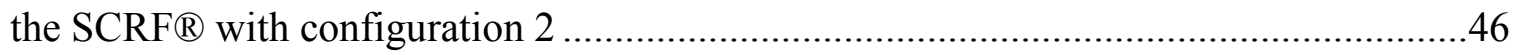

Table 3.15: Exhaust parameters during the Loading Condition ........................................50

Table 3.16: Engine and exhaust parameters of the Loading Condition ...............................52

Table 4.1: Engine and exhaust conditions at SCR inlet for $\mathrm{NO}_{\mathrm{x}}$ reduction tests ................58

Table 4.2: $\mathrm{NO}$ and $\mathrm{NO}_{2}$ concentrations across the production-2013-SCR without

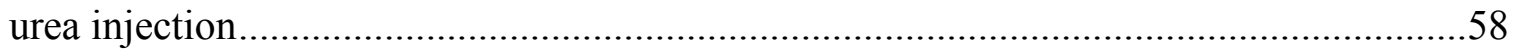

Table 4.3: $\mathrm{NO}_{\mathrm{x}}$ reduction performance of the production-2013-SCR at target ANR of 1.0

Table 4.4: $\mathrm{NO}_{\mathrm{x}}$ reduction performance of the production-2013-SCR at target ANR

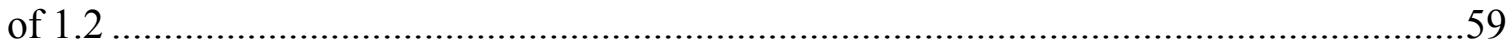

Table 4.5: 1-D SCR model calibration parameters ..........................................................62

Table 4.6: Results from calibrated model - NO concentration at SCR outlet (ppm) ........64

Table 4.7: Results from calibrated model $-\mathrm{NO}_{2}$ concentration at SCR outlet (ppm) ......64

Table 4.8: Results from calibrated model $-\mathrm{NH}_{3}$ concentration at SCR outlet (ppm) ......65

Table 4.9: Emission concentrations and $\mathrm{NO}_{x}$ conversion efficiency during passive oxidation tests with urea injection - Configuration 1 [1] ...............................................74

Table 4.10: Engine exhaust conditions at $\mathrm{SCRF}{ }^{\circledR}$ inlet for $\mathrm{NO}_{\mathrm{x}}$ reduction Test Points 
Table 4.11: $\mathrm{NO}$ and $\mathrm{NO}_{2}$ concentration at the inlet and outlet of DOC during $\mathrm{NO}_{\mathrm{x}}$

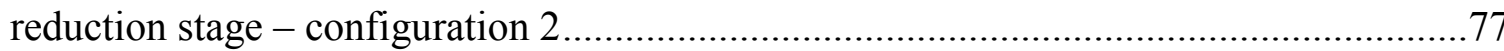

Table 4.12: DOC exhaust conditions and NO conversion efficiency during $\mathrm{NO}_{\mathrm{x}}$

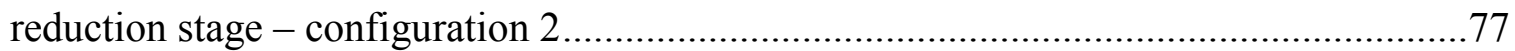

Table 4.13: $\mathrm{NO}$ and $\mathrm{NO}_{2}$ concentrations at the inlet and outlet of the SCRF® at 0 ANR without PM loading in the SCRF® ................................................................82

Table 4.14: $\mathrm{NO}$ and $\mathrm{NO}_{2}$ concentrations at the inlet and outlet of the SCRF® at 0



Table 4.15: $\mathrm{NO}$ and $\mathrm{NO}_{2}$ concentrations at the inlet and outlet of the SCRF® at 0

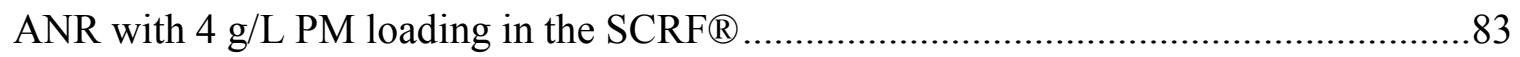

Table 4.16: $\mathrm{NO}_{2} / \mathrm{NO}_{\mathrm{x}}$ ratios at the inlet and outlet of the SCRF® ${ }^{\circ}$ at 0 ANR ...................84

Table 4.17: $\mathrm{NO}, \mathrm{NO}_{2}$ and $\mathrm{NH}_{3}$ concentrations at inlet and outlet of the SCRF® at

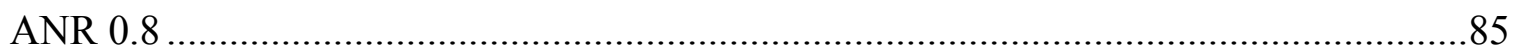

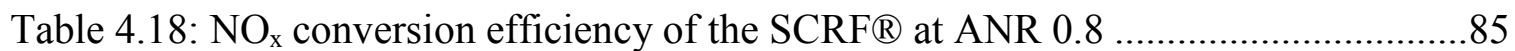

Table 4.19: $\mathrm{NO}, \mathrm{NO}_{2}$ and $\mathrm{NH}_{3}$ concentrations at inlet and outlet of the SCRF® at

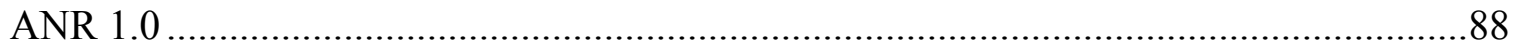

Table 4.20: $\mathrm{NO}_{\mathrm{x}}$ conversion efficiency of the SCRF® at ANR 1.0 ................................8

Table 4.21: $\mathrm{NO}, \mathrm{NO}_{2}$ and $\mathrm{NH}_{3}$ concentrations at inlet and outlet of the SCRF® at

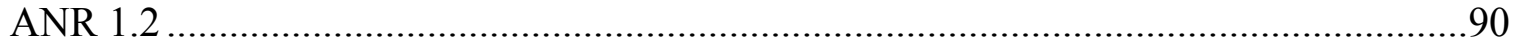

Table 4.22: $\mathrm{NO}_{\mathrm{x}}$ conversion efficiency of the SCRF® at ANR 1.2 ................................90

Table 4.23: Performance of the SCRF® during the passive oxidation tests with urea

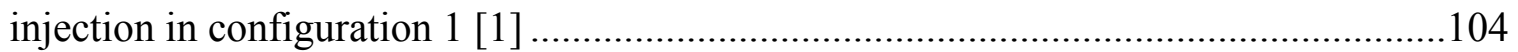

Table B.1: Results of $\mathrm{NH}_{3}$ sensor calibration ............................................................122

Table D.1: $\mathrm{NO}_{\mathrm{x}}$ reduction performance of the production-2013-SCR at target ANR

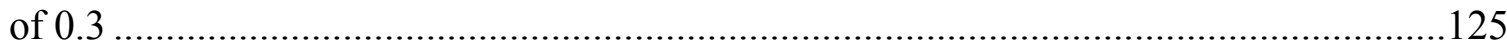

Table D.2: $\mathrm{NO}_{\mathrm{x}}$ reduction performance of the production-2013-SCR at target ANR of 0.5

Table D.3: $\mathrm{NO}_{\mathrm{x}}$ reduction performance of the production-2013-SCR at target ANR of 0.8

Table D.4: $\mathrm{NO}_{\mathrm{x}}$ reduction performance of the production-2013-SCR at target ANR

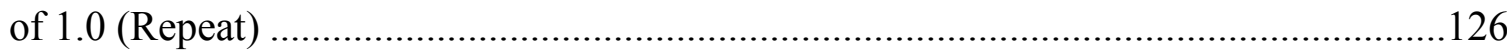

Table D.5: $\mathrm{NO}_{\mathrm{x}}$ reduction performance of the production-2013-SCR at target ANR of 0.8 (repeat).

Table E.1: Engine and exhaust conditions for the SCRF® during stage 1 Configuration 2 (PM loading $2 \mathrm{~g} / \mathrm{L}$ )

Table E.2: Engine and exhaust conditions for the SCRF® during stage 2 Configuration 2 (PM loading $2 \mathrm{~g} / \mathrm{L}$ )

Table E.3: Particulate matter mass balance during stage 1 - Configuration 2 (PM loading $2 \mathrm{~g} / \mathrm{L}$ ).

Table E.4: Particulate matter mass balance during stage 2 - Configuration 2 (PM loading $2 \mathrm{~g} / \mathrm{L}$ ). 
Table E.5: Engine and exhaust conditions for the SCRF® during stage 1 -

Configuration 2 (PM loading $4 \mathrm{~g} / \mathrm{L}$ )

Table E.6: Engine and exhaust conditions for the SCRF® during stage 2 -

Configuration 2 (PM loading $4 \mathrm{~g} / \mathrm{L}$ )

Table E.7: Particulate matter mass balance during stage 1 - Configuration 2 (PM

loading $4 \mathrm{~g} / \mathrm{L}$ ).

Table E.8: Particulate matter mass balance during stage 2 - Configuration 2 (PM

loading $4 \mathrm{~g} / \mathrm{L})$.....

Table E.9: $\mathrm{PM}_{\text {Retained }}$ in the SCRF® at the end of the stage 1, stage 2 and $\mathrm{NO}_{\mathrm{x}}$

reduction stage for Test Points in configuration 2

Table E.10: $\mathrm{NH}_{3}$ stored (grams) in the SCRF® for various Test Points in

configuration 2

Table F.1: $\mathrm{NO}, \mathrm{NO}_{2}, \mathrm{NO}_{\mathrm{x}}$ concentrations at inlet and outlet of the DOC and

SCRF® during stage 1 - Configuration 2 (PM loading at $2 \mathrm{~g} / \mathrm{L}$ ).

Table F.2: NO, $\mathrm{NO}_{2}, \mathrm{NO}_{\mathrm{x}}$ concentrations at inlet and outlet of the DOC and

SCRF® during Stage 2 - Configuration 2 (PM loading at $2 \mathrm{~g} / \mathrm{L}$ )

Table F.3: NO, $\mathrm{NO}_{2}, \mathrm{NO}_{\mathrm{x}}$ concentrations at inlet and outlet of the DOC and

SCRF® during Stage 1 - Configuration 2 (PM loading at $4 \mathrm{~g} / \mathrm{L}$ )

Table F.4: NO, $\mathrm{NO}_{2}, \mathrm{NO}_{\mathrm{x}}$ concentrations at inlet and outlet of the DOC and

SCRF® during Stage 2 - Configuration 2 (PM loading at $4 \mathrm{~g} / \mathrm{L}$ ).....

Table F.5: $\mathrm{NO}$ and $\mathrm{NO}_{2}$ concentrations at inlet and outlet of the SCRF® for $\mathrm{NO}_{\mathrm{x}}$ reduction Test Points, at ANR - 0

Table F.6: $\mathrm{NO}, \mathrm{NO}_{2}$ and $\mathrm{NH}_{3}$ concentrations at inlet and outlet of the SCRF® at

ANR 1.2 Repeat

Table F.7: $\mathrm{NO}_{\mathrm{x}}$ conversion efficiency of the SCRF® at ANR-1.2 Repeat.

Table H.1: Thermocouple temperatures during $\mathrm{NO}_{\mathrm{x}}$ reduction stage for Test Point 1 , with and without PM loading - Configuration 2

Table H.2: Thermocouple temperatures during $\mathrm{NO}_{\mathrm{x}}$ reduction stage for Test Point 3, with and without PM loading - Configuration 2

Table H.3: Thermocouple temperatures during $\mathrm{NO}_{\mathrm{x}}$ reduction stage for Test Point 6 , with and without PM loading - Configuration 2

Table H.4: Thermocouple temperatures during $\mathrm{NO}_{\mathrm{x}}$ reduction stage for Test Point 8 , with and without PM loading - Configuration 2 


\section{Acknowledgements}

I would like to thank every individual and institution that supported and assisted me in any way during this research and helped me complete this thesis.

Foremost, I would like to express my sincere gratitude to my advisors, Dr. Jeffrey Naber and Dr. John Johnson for providing the opportunity and continuous guidance, without which this thesis would not have been possible. Dr. Jeffrey Naber helped me understand and analyze the experimental data, as well as troubleshoot the problems in the test cell. Dr. John Johnson was supportive in understanding the experimental data critically to ensure data integrity and provided continuous guidance during my efforts to write this thesis. I would like to thank Dr. David Shonnard for being on my research committee.

I would like to thank my past and present colleagues at Michigan Tech, Erik Gustafson, Krishnan Raghavan, Saksham Gupta and Sagar Sharma for their assistance during the engine testing and Rajesh Chundru for providing me necessary information to perform the modeling work. I would like to thank Paul Dice, Steve Lehmann and Christopher Pinnow who helped me in various ways during the course of this research. I would also like to thank Krishna Chilumukuru from Cummins for providing information and support for the experimental work of the research.

I would like to thank the MTU Diesel Engine Aftertreatment Research Consortium for providing me the financial support during this research. Cummins has also provided the ISB 2013 engine, the production aftertreatment system and the supporting hardware and the software used in this research. Johnson Matthey and Corning provided the SCRF®, which was studied in this research.

Last but not the least, I would like to thank my family and friends for their constant encouragement and support during the course of this research. 


\section{Abbreviations, Notations and Symbols}

\begin{tabular}{|c|c|}
\hline EPA & Environmental Protection Agency \\
\hline $\mathrm{DOC}$ & Diesel Oxidation Catalyst \\
\hline DPF & Diesel Particulate Filter \\
\hline SCR & Selective Catalytic Reduction \\
\hline SCR-on-filter & Diesel Particulate Filter coated with SCR Catalyst \\
\hline $\mathrm{SCRF} \circledast$ & SCR-on-filter developed by Johnson Matthey \\
\hline $\mathrm{NO}_{\mathrm{x}}$ & Oxides of Nitrogen (Usually $\mathrm{NO}$ and $\mathrm{NO}_{2}$ ) \\
\hline PM & Particulate Matter \\
\hline $\mathrm{CO}$ & Carbon Monoxide \\
\hline NO & Nitrogen Oxide \\
\hline $\mathrm{CO}_{2}$ & Carbon Dioxide \\
\hline $\mathrm{NO}_{2}$ & Nitrogen Dioxide \\
\hline $\mathrm{NH}_{3}$ & Ammonia \\
\hline $\mathrm{HC}$ & Hydrocarbons \\
\hline $\mathrm{CPF}$ & Catalyzed Particulate Filter \\
\hline AR & Active Regeneration \\
\hline $\mathrm{PO}$ & Passive Oxidation \\
\hline $\mathrm{DEF}$ & Diesel Exhaust Fluid \\
\hline $\mathrm{H}_{2} \mathrm{O}$ & Dihydrogen Monoxide (Water) \\
\hline MTU & Michigan Technological University \\
\hline
\end{tabular}


SCR-F

A

$E_{a}$

$\mathrm{R}$

$\mathrm{T}$

RR

HD

ANR

UDOC

DDOC

DCPF

USCRF®

DSCRF®

ECM

$\mathrm{H} / \mathrm{C}$
SCR on a DPF model

Pre Exponential Factor

Activation Energy

Universal Gas Constant

Temperature

Reaction Rate

Heavy Duty

Ammonia to $\mathrm{NO}_{\mathrm{x}}$ Ratio

Upstream of the DOC

Downstream of the DOC

Downstream of the CPF

Upstream of the SCRF®

Downstream of the SCRF®

Engine Control Module

Hydrogen to Carbon Ratio 


\begin{abstract}
The heavy-duty diesel (HDD) engines use the diesel oxidation catalyst (DOC), catalyzed particulate filter (CPF) and urea injection based selective catalytic reduction (SCR) systems in sequential combination, to meet the US EPA 2010 PM and $\mathrm{NO}_{\mathrm{x}}$ emission standards. The SCR along with a $\mathrm{NH}_{3}$ slip control catalyst (AMOX) offer $\mathrm{NO}_{\mathrm{x}}$ reduction $>90 \%$ with $\mathrm{NH}_{3}$ slip $<20 \mathrm{ppm}$. However, there is a strong desire to further improve the $\mathrm{NO}_{\mathrm{x}}$ reduction performance of such systems, to meet the 2015 California Optional Low $\mathrm{NO}_{\mathrm{x}}$ Standard. Integrating SCR functionality into a diesel particulate filter (DPF), by coating the SCR catalyst on the DPF, offers potential to reduce the system cost and packaging weight/ volume. It also provides opportunity to increases the SCR volume without affecting the overall packaging, to achieve $\mathrm{NO}_{\mathrm{x}}$ reduction efficiencies $>95 \%$.
\end{abstract}

In this research, the $\mathrm{NO}_{\mathrm{x}}$ reduction and $\mathrm{NH}_{3}$ storage performance of a $\mathrm{Cu}$-zeolite $\mathrm{SCR}$ and $\mathrm{Cu}$-zeolite SCR catalyst on a DPF (SCRF®) were experimentally investigated based on the engine experimental data at steady state conditions. The experimental setup and test procedures for evaluation of $\mathrm{NO}_{\mathrm{x}}$ gaseous emissions and $\mathrm{PM}$ oxidation performance of the SCRF®, including pressure drop and the temperature distribution with and without PM loading in the SCRF ${ }^{\circledR}$ are described. The experimental data for the production-2013SCR and the SCRF® were collected (with and without PM loading in the SCRF®) on a Cummins ISB 2013 engine, at varying inlet temperatures, space velocities, inlet $\mathrm{NO}_{\mathrm{x}}$ concentrations and $\mathrm{NO}_{2} / \mathrm{NO}_{\mathrm{x}}$ ratios, to evaluate the $\mathrm{NO}_{\mathrm{x}}$ reduction, $\mathrm{NH}_{3}$ storage and $\mathrm{NH}_{3}$ slip characteristics of the SCR catalyst. The SCRF® was loaded with 2 and $4 \mathrm{~g} / \mathrm{L}$ of PM prior to the $\mathrm{NO}_{\mathrm{x}}$ reduction tests to study the effect of $\mathrm{PM}$ loading on the $\mathrm{NO}_{\mathrm{x}}$ reduction and $\mathrm{NH}_{3}$ storage performance of the $\mathrm{SCRF}$.

The 1-D SCR model developed at MTU was calibrated to the engine experimental data obtained from the seven $\mathrm{NO}_{\mathrm{x}}$ reduction tests conducted with the production-2013-SCR. The performance of the 1-D SCR model was validated by comparing the simulation and experimental data for $\mathrm{NO}, \mathrm{NO}_{2}$ and $\mathrm{NH}_{3}$ concentrations at the outlet of the SCR. The $\mathrm{NO}$ and $\mathrm{NO}_{2}$ concentrations were calibrated to $\pm 20 \mathrm{ppm}$ and $\mathrm{NH}_{3}$ was calibrated to $\pm 20 \mathrm{ppm}$. 
The experimental results for the production-2013-SCR indicate that the $\mathrm{NO}_{\mathrm{x}}$ reduction of $80-85 \%$ can be achieved for the inlet temperatures below $250^{\circ} \mathrm{C}$ and above $450^{\circ} \mathrm{C}$ and $\mathrm{NO}_{\mathrm{x}}$ reduction of $90-95 \%$ can be achieved for the inlet temperatures between $300-$ $350^{\circ} \mathrm{C}$, at ammonia to $\mathrm{NO}_{\mathrm{x}}$ ratio (ANR) 1.0 , while the $\mathrm{NH}_{3}$ slip out of the SCR was $<75$ ppm. Conversely, the SCRF® showed $90-95 \% \mathrm{NO}_{\mathrm{x}}$ reduction at ANR of 1.0, while the $\mathrm{NH}_{3}$ slip out of the SCRF® was $>50 \mathrm{ppm}$, with and without PM loading in the SCRFc, for the inlet temperature range of $200-450{ }^{\circ} \mathrm{C}$, space velocity in the range of 13 to 48 $\mathrm{k} / \mathrm{hr}$ and inlet $\mathrm{NO}_{2} / \mathrm{NO}_{\mathrm{x}}$ in the range of 0.2 to 0.5 . The $\mathrm{NO}_{\mathrm{x}}$ reduction in the SCRF® increases to $>98 \%$ at ANR 1.2. However, the $\mathrm{NH}_{3}$ slip out of the SCRF® increases significantly at ANR 1.2.

The effect of PM loading at 2 and $4 \mathrm{~g} / \mathrm{L}$ on the $\mathrm{NO}_{\mathrm{x}}$ reduction performance of the SCRF® was negligible below $300{ }^{\circ} \mathrm{C}$. However, with PM loading in the SCRF®, the $\mathrm{NO}_{\mathrm{x}}$ reduction decreased by $3-5 \%$ when compared to the clean $\mathrm{SCRF} \AA$, for inlet temperature $>350{ }^{\circ} \mathrm{C}$. Experimental data were also collected by reference [1] to investigate the $\mathrm{NO}_{2}$ assisted PM oxidation in the SCRF® for the inlet temperature range of $260-370{ }^{\circ} \mathrm{C}$, with and without urea injection and thermal oxidation of PM in the SCRF® during active regeneration for the inlet temperature range of $500-600{ }^{\circ} \mathrm{C}$, without urea injection. The experimental data obtained from this study and [1] will be used to develop and calibrate the SCR-F model at Michigan Tech. The $\mathrm{NH}_{3}$ storage for the production-2013-SCR and the $\mathrm{SCRF}{ }^{\circledR}$ (with and without PM loading) were determined from the steady state engine experimental data. The $\mathrm{NH}_{3}$ storage for the production-2013-SCR and the SCRF® (without PM loading) were within $\pm 5 \mathrm{gmol} / \mathrm{m}^{3}$ of the substrate, with maximum $\mathrm{NH}_{3}$ storage of $75-80 \mathrm{gmol} / \mathrm{m} 3$ of the substrate, at the SCR/SCRF® inlet temperature of $200^{\circ} \mathrm{C}$. The $\mathrm{NH}_{3}$ storage in the SCRF®, with $2 \mathrm{~g} / \mathrm{L}$ PM loading, decreased by $30 \%$, when compared to the $\mathrm{NH}_{3}$ storage in the $\mathrm{SCRF}{ }^{\circledR}$, without PM loading. The further increase in the PM loading in the $\mathrm{SCRF}{ }^{\circledR}$, from 2 to $4 \mathrm{~g} / \mathrm{L}$, had negligible effect on $\mathrm{NH}_{3}$ storage. 



\section{Chapter 1. Introduction}

Heavy duty diesel engines are used as the power plants in stationery applications, on-road and off-road vehicles. They can significantly reduce $\mathrm{CO}_{2}$ emissions, but they produce mainly emissions of nitrogen oxides $\left(\mathrm{NO}_{\mathrm{x}}\right)$ and particulate matter $(\mathrm{PM})$ that need to be controlled to meet the emission standards. Various agencies around the world have been working to regulate the emissions. The tail pipe emission standards for heavy duty diesel engines have been regulated since 1974 by the Environmental Protection Agency (EPA) in the U.S. The evolution of emission standards in the U.S. from year $2004-2015$ is shown in Table 1.1.

Diesel engine emissions are controlled with technologies such as high pressure fuel injection system, turbocharging, cooled exhaust gas recirculation (EGR) and multiple fuel injections using piezo injectors. Diesel engine manufacturers of heavy-duty on-road vehicles implemented the usage of Diesel Particulate Filter (DPF) in 2007 to meet the standards for PM. Present aftertreatment systems typically consists of a Diesel Oxidation Catalyst (DOC), a Catalyzed Particulate Filter (CPF), Selective Reduction Catalyst (SCR) with the urea injection assembly and Ammonia Oxidation Catalyst (AMOX) to meet the gaseous and PM emissions, post 2010.

Table 1.1: US EPA \& California Emission Standards for Heavy-Duty CI Engines, $\mathrm{g} / \mathrm{bhp} \cdot \mathrm{hr}[2]$

\begin{tabular}{|l|l|l|l|l|}
\hline \multirow{2}{*}{$\begin{array}{l}\text { Emission } \\
\text { Gases }\end{array}$} & \multicolumn{5}{|l|}{ EPA Standard - Implementation Year } \\
\cline { 2 - 5 } & $\mathbf{2 0 0 4}$ & $\mathbf{2 0 0 7 - 0 9}$ & $\mathbf{2 0 1 0}$ & $\mathbf{2 0 1 5}$ \\
\hline NO & $2.00^{*}$ & 1.2 & 0.2 & $0.02 * *$ \\
\hline NMHC & $0.5^{*}$ & 0.14 & 0.14 & 0.14 \\
\hline CO & 15.5 & 15.5 & 15.5 & 15.5 \\
\hline PM & 0.1 & 0.01 & 0.01 & 0.01 \\
\hline NOTE: “*” - Alternative standard: NMHC+NO \\
“**” - Manufactures may choose California Optional Low $\mathrm{NO}_{\mathrm{x}}$ Standard
\end{tabular}




\subsection{Diesel Aftertreatment Systems}

A typical arrangement of components in the aftertreatment system for a heavy duty diesel engine is shown in the Figure 1.1.

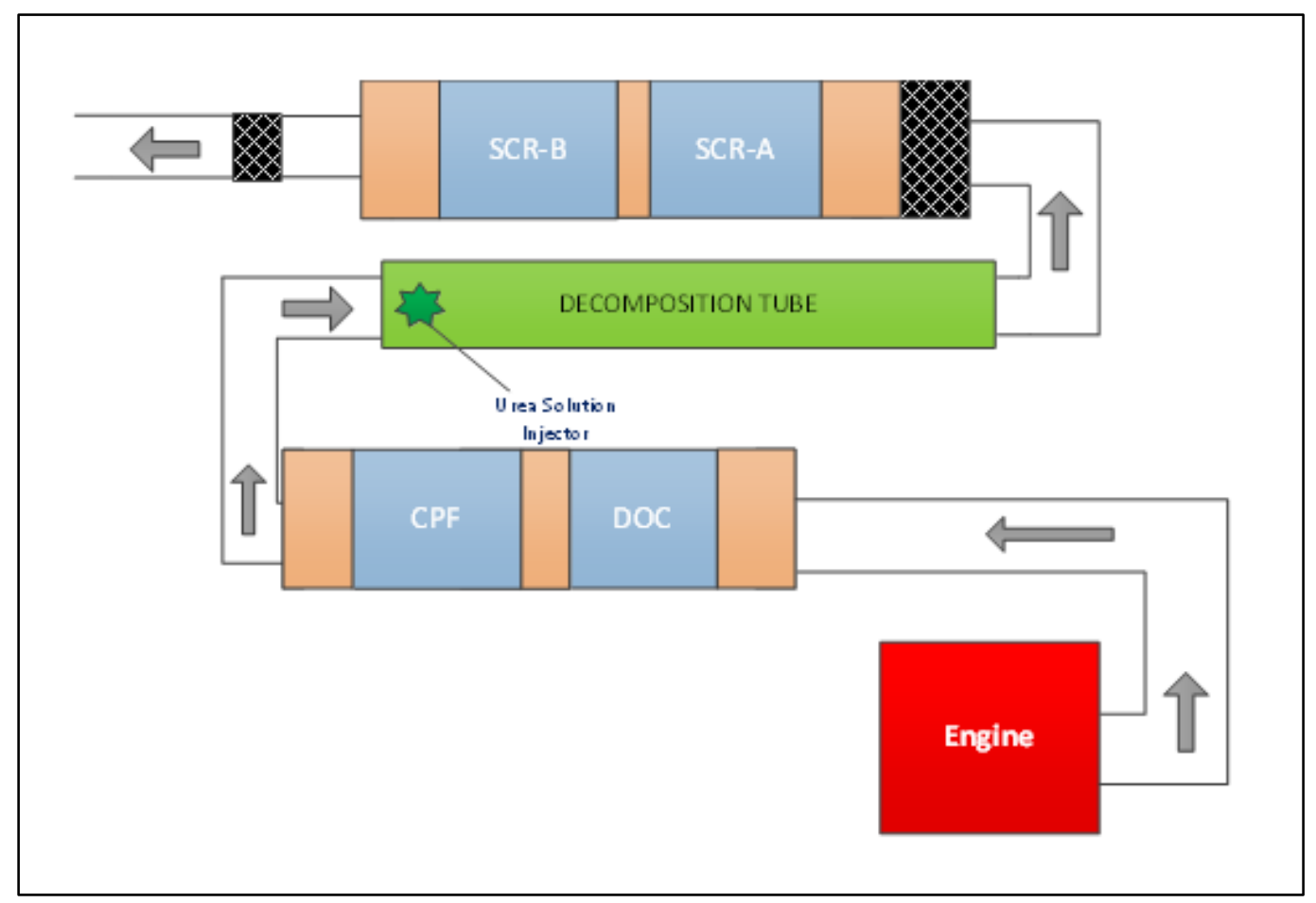

Figure 1.1: Overall schematic of the Cummins ISB 2013 production aftertreatment system [3]

The first component is a DOC, which is a flow through catalyst that oxidizes the $\mathrm{HC}, \mathrm{CO}$ and $\mathrm{NO}$ in the exhaust stream into $\mathrm{H}_{2} \mathrm{O}, \mathrm{CO}_{2}$ and $\mathrm{NO}_{2}$. For diesel engines, the proportion of $\mathrm{NO}_{2}$ in total engine-out $\mathrm{NO}_{\mathrm{x}}$ is typically $5-15 \%$. The oxidation of $\mathrm{NO}$ to $\mathrm{NO}_{2}$ provides an increased rate of $\mathrm{NO}_{2}$ assisted oxidation of PM in the CPF and helps in maintaining higher $\mathrm{NO}_{2} / \mathrm{NO}_{\mathrm{x}}$ ratio needed for better $\mathrm{NO}_{\mathrm{x}}$ reduction in the SCR [4]. The $\mathrm{HC}$ conversion efficiency increases with an increase in exhaust temperature, whereas the $\mathrm{NO}$ to $\mathrm{NO}_{2}$ conversion efficiency is maximum at $340{ }^{\circ} \mathrm{C}$ DOC inlet temperature, and decreases for temperatures less or more than $340{ }^{\circ} \mathrm{C}[5]$. 
The CPF is a wall flow device, with every other channel open at the inlet but closed at the outlet end. The CPF filters the PM in the exhaust gas and oxidizes the PM accumulated in the filter either by passive oxidation or active regeneration. The $\mathrm{NO}_{2}$ assisted oxidation occurs due to reaction between the PM accumulated in the CPF and the $\mathrm{NO}_{2}$ present in the exhaust gases, at temperatures between $250-400{ }^{\circ} \mathrm{C}$. The thermal oxidation occurs due to reaction between PM accumulated in the CPF and the $\mathrm{O}_{2}$ present in the exhaust gases, at exhaust temperatures higher than $400^{\circ} \mathrm{C}$. Both the mechanisms of PM oxidation occur simultaneously. These mechanisms are explained in detail in reference $[3,6,7]$.

The SCR system is a flow through substrate which reduces the $\mathrm{NO}_{\mathrm{x}}$ in the exhaust gas into $\mathrm{N}_{2}$ and $\mathrm{H}_{2} \mathrm{O}$ using the urea solution injected in the decomposition tube. The urea solution with $32.5 \%$ urea concentration by weight, also known as diesel exhaust fluid (DEF) is used as the reducing agent. The DEF is dosed into the exhaust gases using an injector into the decomposition tube. The decomposition tube helps in mixing the DEF spray with the exhaust flow and also accelerates the urea hydrolysis and thermolysis process [8]. The urea decomposes into $\mathrm{NH}_{3}$ and isocyanic acid. The isocyanic acid further decomposes into $\mathrm{NH}_{3}$ and $\mathrm{CO}_{2}$ on the SCR catalytic surface [8]. The $\mathrm{NH}_{3}$ produced by decomposition of the urea is adsorbed and stored on the SCR catalytic surface. The $\mathrm{NO}_{\mathrm{x}}$ in the exhaust gases is reduced by the $\mathrm{NH}_{3}$ stored on the SCR catalyst.

The SCR substrate is a honeycomb structure with a typical channel density of 400 cells per square inch (CPSI). The substrate is made from the ceramic material such as cordierite and titanium oxide. The catalytic components such as oxides of vanadium and tungsten, iron $(\mathrm{Fe})$ or copper $(\mathrm{Cu})$ zeolites and precious metals are coated on the channels of the SCR. The performance of various catalysts, based on the published literature will be discussed in the next chapter.

The AMOX is placed after the SCR substrates or on the back of a substrate to oxidize the $\mathrm{NH}_{3}$ that slips out of the SCR due to various reasons including over injection of DEF, low exhaust temperatures and the effect of an aged $\mathrm{SCR}$ catalyst. $\mathrm{NH}_{3}$ is oxidized to $\mathrm{N}_{2}$ and $\mathrm{H}_{2} \mathrm{O}$. Figure 1.1 shows a SCR-A substrate that just has a SCR catalyst and SCR-B 
represents a substrate coated with the SCR catalyst in the front and the AMOX on the back of the substrate.

\subsection{Motivation}

The California optional emission regulations for 2015 require high $\mathrm{NO}_{\mathrm{x}}$ reduction $(>95 \%)$ and low $\mathrm{NH}_{3}$ slip $(<10 \mathrm{ppm})$. Hence, it is important to understand the $\mathrm{NO}_{\mathrm{x}}$ reduction performance of the SCR catalyst and the effect of various inlet temperatures, space velocities, inlet $\mathrm{NO}_{\mathrm{x}}$ concentrations and $\mathrm{NO}_{2} / \mathrm{NO}_{\mathrm{x}}$ ratios on the $\mathrm{NO}_{\mathrm{x}}$ reduction performance of the SCR catalyst. In order to change the SCR design to achieve improved performance and reduced complexity of the SCR systems, extensive studies along with modeling efforts are required. An SCR model calibrated to experimental data provides possibilities to estimate the SCR states which cannot be directly measured [9].

The diesel engine aftertreatment catalysts can be arranged either in DOC + CPF + SCR or $\mathrm{DOC}+\mathrm{SCR}+\mathrm{CPF}$, although each configuration has advantages and disadvantages; the selection of configuration will depend on issues such as the need for rapid light-off of the $\mathrm{SCR}$, for maximizing passive regeneration, for adequate urea mixing, and for packaging space [10]. Furthermore, the California optional emission standards for year 2015 will require even lower tailpipe $\mathrm{NO}_{\mathrm{x}}$ emissions when compared to year 2010. One potential approach would be increasing the catalyst volume, but it will increase the cost of the system due to the precious metals involved and could cause packaging problems.

The SCR catalyst on a DPF is also known as a SDPF and SCR-in-DPF is an upcoming technology in the field of diesel aftertreatment systems which provides a cost-effective solution to reduce $\mathrm{NO}_{\mathrm{x}}$ and $\mathrm{PM}$ using a single aftertreatment device [11]. One way to make the SCR on a DPF is by coating the SCR catalyst on the DPF substrate. The reduced aftertreatment volume achieved by the integration of SCR and DPF provides opportunity for packaging flexibility and improved thermal management [12].

The SCR catalyst on a DPF used in this study is known as the SCRF®, and it was developed and supplied by Johnson Matthey and Corning. The SCRF® is a wall flow device (DPF) in which the substrate is coated with a $\mathrm{Cu}$-zeolite based SCR catalyst. Thus, 
the $\mathrm{NO}_{\mathrm{x}}$ and $\mathrm{PM}$ can be controlled using a single device. The substrate of the SCRF® used in this study is made from cordierite and was supplied by Corning. The PM accumulated in the SCRF® is oxidized by $\mathrm{NO}_{2}$ assisted oxidation and thermal oxidation. The $\mathrm{NO}_{\mathrm{x}}$ in the exhaust gas is reduced by the SCR reactions occurring on the SCR catalyst.

The total volume of the production aftertreatment components and the SCRF® is given in Table 1.2. It can be observed that the volume of the production aftertreatment is almost 10 liters higher than the DOC + SCRF®. This indicates that an additional SCR brick could be used and still maintain the weight to volume ratio similar to the production aftertreatment system. The additional $\mathrm{NO}_{\mathrm{x}}$ reduction catalyst would help to achieve the 2015 emission standards shown in Table 1.1.

Table 1.2: Volume comparison of the Production and DOC-SCRF® systems [3]

\begin{tabular}{|l|c|c|c|}
\hline \multirow{2}{*}{ Component } & \multicolumn{3}{|c|}{ Volume (L) } \\
\cline { 2 - 4 } & Production & $\begin{array}{l}\text { DOC } \\
\text { SCRF® }\end{array}$ & $\begin{array}{l}\text { DOC + SCRF® + } \\
\text { SCR-B }\end{array}$ \\
\cline { 2 - 4 } & (Present) & (Option 1) & (Option 2) \\
\hline DOC & 4.2 & 4.2 & 4.2 \\
\hline CPF & 10.4 & - & - \\
\hline SCRF® & - & 17.0 & 17.0 \\
\hline SCR-A & 8.52 & - & - \\
\hline SCR-B & 11.4 & - & 11.4 \\
\hline AMOX & - & 2.9 & - \\
\hline Total & $\mathbf{3 4 . 5}$ & $\mathbf{2 4 . 1}$ & $\mathbf{3 2 . 6}$ \\
\hline
\end{tabular}

\subsection{Goals and Objectives}

One of the goals of this research is to investigate with the experimental data the $\mathrm{NO}_{\mathrm{x}}$ reduction performance of the production-2013-SCR, calibrate the high fidelity MTU 1-D SCR model developed by Dr. Song [9] to simulate the SCR outlet gaseous concentrations $\left(\mathrm{NO}, \mathrm{NO}_{2}\right.$ and $\mathrm{NH}_{3}$ ), investigate the $\mathrm{NO}_{\mathrm{x}}$ reduction and $\mathrm{NH}_{3}$ storage performance of the $\mathrm{SCRF}{ }^{\circledR}$ and compare it with the performance of the production-2013-SCR. 
The production-2013-SCR from the Cummins ISB 2013 diesel engine aftertreatment system and the SCRF® will be used to conduct experiments as a part of the Diesel Engine Aftertreatment Consortium efforts at MTU. The experimental data will be collected by varying the SCR and the SCRF ${ }^{\circledR}$ inlet temperature, space velocity, $\mathrm{NO}_{\mathrm{x}}$ concentration and $\mathrm{NO}_{2} / \mathrm{NO}_{\mathrm{x}}$ ratio. Experimental data for the $\mathrm{SCRF}{ }^{\circledR}$ will be collected from configuration 1, 2 and 3, which will be used to determine the PM oxidation, PM loading, PM filtration, pressure drop and temperature distribution characteristics of the SCRF ${ }^{\circledR}$ with and without urea injection and the NOx reduction and $\mathrm{NH}_{3}$ storage in the SCRF®, with 0, 2 and $4 \mathrm{~g} / \mathrm{L}$ PM loading in the SCRF®. Configuration 1 and 2 consist of a DOC and a SCRF®. However, in configuration 2, a CPF will be placed upstream of the SCRF ${ }^{\circledR}$ during the tests designed to collect experimental data without PM loading in the SCRF®. Configuration 3 consists of a DOC, a SCRF® and a SCR downstream of the SCRF®. A SCR-F model will be developed from the MPF model for the CPF [13], with the addition of the SCR equations from the MTU 1-D SCR model [9] and the experimental data from the SCRF® will be utilized to validate and calibrate the SCR-F model.

The following objectives were developed to meet the research goals:

1) Develop the procedures and identify the test conditions for steady state testing of the Cummins ISB 2013 engine and the aftertreatment system to characterize the $\mathrm{NO}_{\mathrm{x}}$ gaseous emissions performance of the production-2013-SCR and the SCRF® including the pressure drop and temperature distribution data needed for calibrating the SCR-F model.

2) Conduct the $\mathrm{NO}_{\mathrm{x}}$ experimental tests as a function of ANR to evaluate the $\mathrm{NO}_{\mathrm{x}}$ emission performance of the ISB 2013 production-2013-SCR and the SCRF® and collect data for the 1-D SCR and the SCR-F models. The procedures developed in Objective 1 will be used to collect the experimental data. The data from the production-2013-SCR will be considered as the baseline SCR performance and will be used to compare to the SCRF® data and the SCRF® data will be used to develop and calibrate the SCR-F model. 
3) Analyze the data for the production-2013-SCR and the SCRF® to determine the $\mathrm{NO}_{x}$ conversion efficiency, $\mathrm{NH}_{3}$ slip and $\mathrm{NH}_{3}$ storage. The effect of parameters such as space velocity, SCR and SCRF® inlet temperature, SCR and SCRF® inlet $\mathrm{NO}, \mathrm{NO}_{2}$ and $\mathrm{NO}_{\mathrm{x}}$ concentrations, $\mathrm{ANR}$ and $\mathrm{NO}_{2} / \mathrm{NO}_{\mathrm{x}}$ ratios will be used to explain the outlet gaseous concentrations $\left(\mathrm{NO}, \mathrm{NO}_{2}\right.$ and $\mathrm{NH}_{3}$ ) and the $\mathrm{NO}_{\mathrm{x}}$ conversion efficiency. The data consistency will be checked based on nitrogen balance across the SCR and SCRF®. These data will be used for determining the ANR for the experimental tests with a SCRF® plus SCR system.

4) Calibrate the 1-D SCR model using the engine experimental data by determining the storage parameters and the pre-exponential factors for the SCR reactions. Validate the model performance by comparing the simulation results and the experimental data.

5) The SCRF® performance will be determined with 2 and $4 \mathrm{~g} / \mathrm{L}$ of PM and without $\mathrm{PM}$ in the $\mathrm{SCRF}{ }^{\circledR}(0 \mathrm{~g} / \mathrm{L})$ and the SCR and the SCRF® performance, with and without PM in the SCRF® will be analyzed and compared to the published literature.

\subsection{Thesis Outline}

The thesis discusses the $\mathrm{NO}_{\mathrm{x}}$ reduction performance of the SCR and the SCRF® based on the experimental study conducted on the Cummins ISB 2013 engine with the production-2013-SCR and the SCRF®. This chapter presented the brief introduction and the motivation for the research. The importance of the aftertreatment system was explained, followed by the goals and objectives of the research.

Chapter 2 provides a literature review of the published papers relating to the SCR and the SCR catalyst on the DPF systems. Information regarding the performance of the components, based on the experimental and modeling studies were collected from the previous technical papers from different organizations.

Chapter 3 discusses the test cell layout and the experimental procedures used for collecting the experimental data. The testing facilities and specific instruments are 
introduced. The various test procedures and the test matrices are discussed. The important modifications in the test procedure are explained.

Chapter 4 presents the results of this study. The data analysis and implementation of nitrogen balance methodology to validate the data consistency are explained. The $\mathrm{NO}_{\mathrm{x}}$ reduction and $\mathrm{NH}_{3}$ storage characteristics of the production-2013-SCR and the SCRF®, with and without PM loading in the SCRF® are discussed. Performance of the calibrated 1-D SCR model are explained by comparing the simulated and experimental results.

Chapter 5 summarizes the analyzed results from the experimental and the modeling studies and the conclusions of the research. Recommendations for future work are proposed. 


\section{Chapter 2. Literature Review}

The urea-SCR technology has been the most effective solution to control $\mathrm{NO}_{\mathrm{x}}$ emissions from diesel exhaust gas. The SCR technology was first applied in thermal power plants in 1970s and was commercially adopted for diesel engines about a decade ago [2]. The current hardware commonly uses a $\mathrm{DOC}+\mathrm{CPF}+\mathrm{SCR}$ system configuration to meet the heavy-duty emission regulations. Recently developed diesel engines are calibrated to produce high engine-out $\mathrm{NO}_{\mathrm{x}}(1500-2000 \mathrm{ppm})$ to facilitate passive oxidation of $\mathrm{PM}$ in the $\mathrm{DPF} / \mathrm{CPF}$. This change in engine calibration further increases the demand for high $\mathrm{NO}_{\mathrm{x}}$ conversion efficiency from the SCR system. Combining the functions of the SCR and the DPF (SCR-on-filter) provides the opportunity for design and packaging flexibility, improved thermal management and reduced aftertreatment volume in heavy duty diesel engine applications. Due to closer placement of the SCR-on-filter than the SCR, SCR-on-filter can operate at higher temperatures and hence achieve higher NOx conversion [12]. A literature review of the aspects related to the SCR and the SCR-onfilter from the published research are presented in the following sections of this chapter.

\subsection{SCR Catalyst Formulations and Experimental Studies}

The major SCR catalysts that are used and studied include Cu-zeolite, Fe-zeolite, vanadia and cerium based composite oxides. The vanadia SCR (V-SCR) catalysts consist of $\mathrm{V}_{2} \mathrm{O}_{5}$ as the active component impregnated on $\mathrm{TiO}_{2}$. Barium (Ba), cerium $(\mathrm{Ce})$, zirconium $(\mathrm{Zr})$, terbium $(\mathrm{Tb})$ and erbium $(\mathrm{Er})$ are used to stabilize vanadium $[14,15] . \mathrm{SiO}_{2}$ and $\mathrm{WO}_{3}$ are used to increase the thermal durability. The V-SCR has demonstrated maximum $\mathrm{NO}_{\mathrm{x}}$ conversion between 300 to $450^{\circ} \mathrm{C}$ and superior resistance to sulfur poisoning [16]. Hence vanadia SCR is preferred in markets with high sulfur fuel.

The low melting of $\mathrm{V}_{2} \mathrm{O}_{5}$ leads to thermal deactivation of V-SCR and loss in $\mathrm{NO}_{\mathrm{x}}$ conversion above $550^{\circ} \mathrm{C}[9,17]$. The maximum $\mathrm{NO}_{\mathrm{x}}$ conversion efficiency for $\mathrm{V}-\mathrm{SCR}$ after a 64 hours hydrothermal aging at $670^{\circ} \mathrm{C}$ was only about $20 \%$, while for $\mathrm{Fe}$ and $\mathrm{Cu}$ zeolite $\mathrm{SCR}, \mathrm{NO}_{\mathrm{x}}$ conversion efficiency was $>90 \%$ after the same hydrothermal aging 
procedure. A significant improvement in the durability of V-SCR after 100 hours of exposure at $650^{\circ} \mathrm{C}$ was reported by Spenglet et al. [16]. They found that the $\mathrm{NO}_{\mathrm{x}}$ conversion efficiency, increased from $30 \%$ at $300^{\circ} \mathrm{C}$ catalyst temperature to $95 \%$, by stabilizing the titania support and then immobilizing the vanadia catalyst on the titania. However, the V-SCR also releases toxic vanadium compounds such as $\mathrm{V}_{2} \mathrm{O}_{5}$, from the catalysts at temperatures beyond $600{ }^{\circ} \mathrm{C}$. Hence, a formulation is needed which is efficient in $\mathrm{NO}_{\mathrm{x}}$ conversion, thermally stable and more environmental friendly than the V-SCR.

The new generation SCR catalyst technologies also include $\mathrm{Cu}$ and Fe based zeolites. The characteristic of the $\mathrm{Cu}$-zeolite and Fe-zeolite SCR from various references $[4,18,19,20$, $21,22,23]$ are compared and summarized below.

- $\mathrm{Cu}$-zeolite SCR demonstrates higher $\mathrm{NO}_{\mathrm{x}}$ conversion efficiency than the Fezeolite SCR below SCR inlet temperatures of $350{ }^{\circ} \mathrm{C}$, while Fe-zeolite SCR provides better $\mathrm{NO}_{\mathrm{x}}$ conversion at temperatures $>400{ }^{\circ} \mathrm{C}$.

- $\mathrm{Cu}$-zeolite $\mathrm{SCR}$ has higher $\mathrm{NH}_{3}$ storage capacity than the Fe-zeolite SCR, which may be the main reason for higher $\mathrm{NO}_{\mathrm{x}}$ reduction in $\mathrm{Cu}$-zeolite SCR than the Fezeolite SCR at low temperatures. The $\mathrm{NH}_{3}$ storage capacity and $\mathrm{NO}_{\mathrm{x}}$ reduction performance is significantly affected by the catalyst aging.

- Both the catalysts exhibit a tendency to oxidize $\mathrm{NH}_{3}$ above $300{ }^{\circ} \mathrm{C}$ with high selectivity to $\mathrm{N}_{2}(>95 \%)$. However, higher surface oxidation was observed in $\mathrm{Cu}-$ zeolite SCR than the Fe-zeolite SCR, reducing the effective amount of $\mathrm{NH}_{3}$ available for $\mathrm{NO}_{\mathrm{x}}$ reduction reactions.

- The $\mathrm{NO}_{\mathrm{x}}$ reduction performance of Cu-zeolite SCR is less dependent on the $\mathrm{NO}_{2} / \mathrm{NO}_{\mathrm{x}}$ ratio, compared to that of Fe-zeolite SCR. This is due to the ability of the $\mathrm{Cu}$-zeolite SCR to oxidize the surface $\mathrm{NO}$ to $\mathrm{NO}_{2}$ in situ. However, Fe-Zeolite provides better $\mathrm{NO}_{\mathrm{x}}$ reduction than the $\mathrm{Cu}$-zeolite $\mathrm{SCR}$ at an optimal $\mathrm{NO}_{2} / \mathrm{NO}_{\mathrm{x}}$ ratio of 0.5 .

- $\mathrm{Cu}$-zeolite shows lower $\mathrm{NH}_{3}$ slip due to its higher $\mathrm{NH}_{3}$ storage and $\mathrm{NH}_{3}$ oxidation than the Fe-zeolite SCR. 
- $\mathrm{Cu}$ and Fe-zeolite catalysts are thermally more stable than the vanadia based SCR at temperatures typical of diesel application with active regeneration. However, their performance can deteriorate irreversibly over time as a result of high temperature thermal deactivation.

- $\mathrm{Cu}$-zeolite SCR exhibits less tolerance to sulfur poisoning than the Fe-zeolite $\mathrm{SCR}$. The low temperature $\left(<300{ }^{\circ} \mathrm{C}\right)$ performance of $\mathrm{Cu}$-zeolite SCR decreased significantly upon exposure to $\mathrm{SO}_{2}$. However, the sensitivity to $\mathrm{SO}_{2}$ reduced at high temperatures, indicating occurrence of desulfation phenomenon.

- The Cu-zeolite produces higher concentration of $\mathrm{N}_{2} \mathrm{O}$ than the Fe-zeolite SCR. $\mathrm{N}_{2} \mathrm{O}$ formation could be regulated by optimizing the catalyst's oxidizing performance, the urea injection strategy and the $\mathrm{NH}_{3}$ storage onto the catalyst to decrease the $\mathrm{NH}_{3}$ slip.

Studies were performed to combine the Cu-zeolite and Fe-zeolite systems to obtain better performance when compared to individual catalysts. The simulation results of a combined system were presented in reference [24]. They concluded that the dual-brick configuration performs better than the dual-layer configuration in the temperature window of 100 to $600^{\circ} \mathrm{C}$. The overall NO conversion reduces in the dual-layer catalyst due to the diffusional limitations at the intermediate temperature when compared to the dual-brick catalyst. The experimental results of combined $\mathrm{Cu}$ and Fe-zeolite SCR catalysts were presented in reference [22]. They observed that the combined-SCR catalysts achieved higher $\mathrm{NO}_{\mathrm{x}}$ reduction during the WHTC and are capable of reducing $\mathrm{NO}_{\mathrm{x}}$ over a wider range of operating temperature than achieved using either of the individual systems. The best $\mathrm{NO}_{\mathrm{x}}$ reduction was achieved using a combined system with a Fe: $\mathrm{Cu}$ catalyst ratio of 1:2. To meet the challenge of high $\mathrm{NO}_{\mathrm{x}}$ conversion at low temperature, a high porosity substrate which minimizes the pressure drop impact was studied in references [25, 26]. Hirose et al. [25] studied the effect of cell structure, $\mathrm{Cu}$ zeolite amount, high porosity and high cell density on $\mathrm{NO}_{\mathrm{x}}$ reduction and pressure drop. They concluded that increasing cell density, porosity and catalyst amount results in $10-$ 
$15 \%$ increase in $\mathrm{NO}_{\mathrm{x}}$ conversion at high and low temperatures. The improved $\mathrm{NO}_{\mathrm{x}}$ conversion efficiency also helps in downsizing the SCR substrate volume by $40-50 \%$.

Recently, many types of doped cerium oxide based catalysts were also studied, such as Ce-Ta [27], Ce-Ti [28], Ce-Mo [29] and Ce-Cu-Ti [30], which demonstrated $\mathrm{NO}_{x}$ reduction similar to Cu-zeolite or Fe-zeolite catalysts as shown in Figure 2.1. These Cebased composite oxide catalysts exhibit excellent oxygen storage-release capacity, redox properties in the $\mathrm{NH}_{3}$-SCR reaction and increased area per gram of catalyst. Tao Zhang et al. [27] studied the novel $\mathrm{Ce}_{\mathrm{a}} \mathrm{Ta}_{b} \mathrm{O}_{\mathrm{x}}$ series catalysts prepared by co-precipitation method. The test results indicated that water vapor and $\mathrm{SO}_{2}(150 \mathrm{ppm})$ inhibits the catalytic activity slightly at $300{ }^{\circ} \mathrm{C}$ which may be attributed to the competitive adsorption of $\mathrm{H}_{2} \mathrm{O}$ and $\mathrm{NH}_{3}$ molecules on the acid sites and deposition of ammonium sulfate on the surface of the catalyst which blocked the active sites [31, 32]. However, the $\mathrm{NO}_{\mathrm{x}}$ conversion was still maintained at approximately $80 \%$.

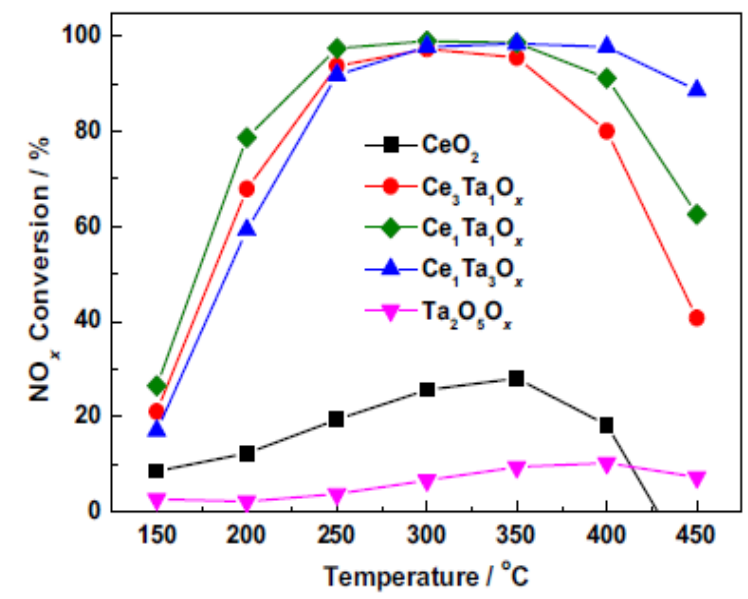

Figure 2.1: $\mathrm{NO}_{\mathrm{x}}$ conversion of a cerium oxide based SCR as a function of temperature [27]

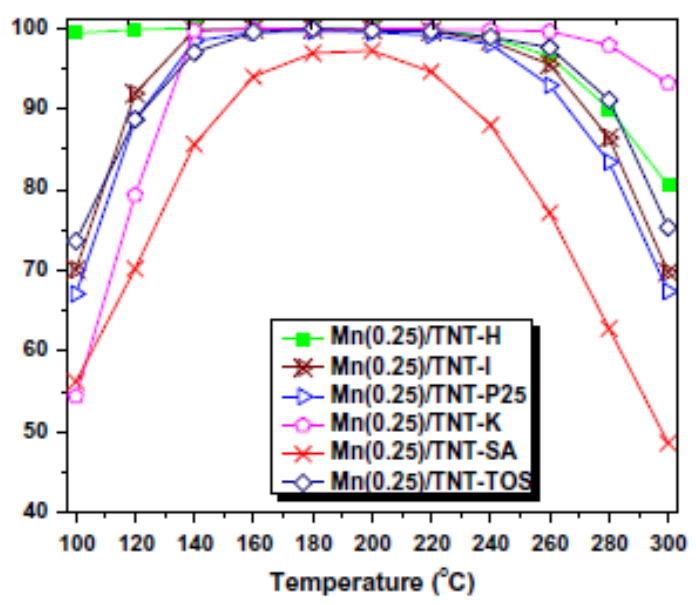

Figure 2.2: $\mathrm{NO}_{\mathrm{x}}$ conversion of a $\mathrm{Mn}(0.25) /$ Ti based SCR as a function of temperature [33]

A series of manganese oxide based catalysts, supported on $\mathrm{TiO}_{2}$ nanoparticles were also studied by references $[33,34,35]$ since the manganese oxide based catalysts exhibit high $\mathrm{NO}_{\mathrm{x}}$ reduction in the low temperature region. Pappas et al. [33] conducted reactor based experiments to study the optimal content of manganese oxide supported on titania 
nanotubes and concluded that with the $\mathrm{Mn} / \mathrm{Ti}$ atomic ratio of 0.25 , maximum $\mathrm{NO}_{\mathrm{x}}$ conversion efficiency can be achieved in the temperature range of $100-300^{\circ} \mathrm{C}$. They also observed that the $\mathrm{NO}_{\mathrm{x}}$ conversion efficiency greater than $95 \%$ can be achieved in the temperature range of $100-300^{\circ} \mathrm{C}$ by using the Hombikat type $\mathrm{Mn} / \mathrm{Ti} \mathrm{SCR}$ catalyst as shown in Figure 2.2. The catalyst exhibited high activity and resistance to steam deactivation.

\subsection{Urea Dosing and Mixing Strategies}

Due to the complexity of the urea-SCR system and stringent standards for $\mathrm{NH}_{3}$ slipping out of the catalyst, the optimized urea dosing in the SCR becomes important. In today's applications, urea dosing is controlled using control algorithms that work on strategies including feed-forward control, closed-loop feedback and neutral network model to optimize the availability of $\mathrm{NH}_{3}$ on the catalytic surface $[36,37,38]$. It is also important to understand how DEF sprays interact with changing exhaust conditions. Gaynor et al. [39] studied a range of dosing strategies in both, ambient air flow $\left(25-30{ }^{\circ} \mathrm{C}\right)$ and hotair flow $\left(200-350{ }^{\circ} \mathrm{C}\right)$ to simulate the real world exhaust conditions. They observed that the strategy used to inject DEF has significant impact on spray deflection, spray atomization, droplet distribution and spray-wall impingement within the system. Dong et al. [40] observed that the low quality spray from an injector which used a single hole of $0.9 \mathrm{~mm}$ and 0.2 $\mathrm{MPa}$ assisted air pressure, leads to deposit formation within the pipe and the SCR catalyst inlet surface and decrease the $\mathrm{NO}_{x}$ conversion efficiency of the SCR. However, a high quality spray from an injector with four holes of diameter $0.25 \mathrm{~mm}$ and $0.8 \mathrm{MPa}$ assisted air pressure can avoid the deposit formation.

\subsection{SCR Deactivation Effects}

The $\mathrm{Cu}$-zeolite and Fe-zeolite based SCR catalysts have exhibited good $\mathrm{NO}_{\mathrm{x}}$ reduction performance and durability. However, the catalysts may become deactivated after being exposed to sulfur or hydrocarbon (HC) compounds, prolonged high temperature thermal deactivation and Pt-Pd poisoning. The adverse effect of these factors on the SCR will be discussed in this section. 


\subsubsection{Sulfur Poisoning}

Ultra-low sulfur diesel (ULSD with sulfur less than $15 \mathrm{ppm}$ ) has been used in the US since 2006. However, even with the use of ULSD, sulfur poisoning can negatively impact the overall SCR performance [41]. The impact of sulfur poisoning was more significant in $\mathrm{Cu}$-zeolite than Fe-zeolite catalyst and the damaging effect was noted mainly below $300{ }^{\circ} \mathrm{C}[42,43]$. Theis et al. [43] found that for $\mathrm{Cu}$-zeolite, the effect of continued exposure to $\mathrm{SO}_{2}$ was significant and more sensitive at low temperatures than at the high temperatures, indicating that desulfation may occur at higher temperatures. For the Fezeolite catalysts, there was little impact of $\mathrm{SO}_{2}$ on the $\mathrm{NO}_{\mathrm{x}}$ conversion at low temperatures. It was concluded that the $\mathrm{NO}_{\mathrm{x}}$ reduction performance of poisoned catalyst could be fully recovered after desulfation for 5-10 minutes of lean operation at $650{ }^{\circ} \mathrm{C}$ for $\mathrm{Cu}$-zeolite and $750{ }^{\circ} \mathrm{C}$ for Fe-zeolite. It was also noticed that the $\mathrm{NO}_{\mathrm{x}}$ reduction sensitivity to the presence of $\mathrm{SO}_{2}$ at low temperature was reduced after multiple poisoning and desulfation cycles. Cavataio et al. [19] found similar results for desulfation of $\mathrm{Cu}$-zeolite and Fe-zeolite catalyst. However, they concluded that the relatively hightemperature necessary for desulfation was related to the decomposition of sulfates, rather than a simple desorption of adsorbed $\mathrm{SO}_{2}$.

\subsubsection{SCR Thermal Aging}

Aftertreatment systems exposed to high temperatures $\left(>600^{\circ} \mathrm{C}\right)$, may cause irreversible damages to the catalysts and deteriorate the $\mathrm{NO}_{\mathrm{x}}$ reduction performance of the SCR. Hence, it becomes important to understand the thermal aging and hydrothermal deactivation of the SCR catalyst. The hydrothermal aging effects were studied by references [44, 45, 46, 47]. In general, deactivation of zeolite catalysts by hydrothermal aging can occur by can occur through three mechanisms, i.e. dealumination, sintering and thermal collapse $[48,49]$. When a zeolite is heated to elevated temperatures, its structure changes to denser crystalline phases, such as quartz [50]. The presence of water further accelerates this phase transition by attacking the aluminum site through a dealumination process causing loss of $\mathrm{NH}_{3}$ storage capacity of the catalyst. The copper sintering 
contributes to a loss of catalytic active sites, since the copper can be sequestered into large particles or removed from the catalyst [44]. Luo et al. [46] observed $10-15 \%$ loss in $\mathrm{NO}_{\mathrm{x}}$ conversion efficiency at low and high SCR inlet temperatures, when hydrothermal temperatures were increased from $550-850^{\circ} \mathrm{C} . \mathrm{NH}_{3}$ storage at $200^{\circ} \mathrm{C}$ decreases from 2.4 to $1.8 \mathrm{~g} / \mathrm{L}$ upon aging from $550^{\circ} \mathrm{C}$ to $850^{\circ} \mathrm{C}[51]$.

\subsubsection{Hydrocarbon and Chemical Poisoning}

It is well known that zeolites can absorb and store a considerable amount of hydrocarbons (HCs). HCs may reach the SCR catalyst, block the active sites and degrade the performance of the SCR causing a HC poisoning effect. Some HCs may get polymerized and form carbonaceous deposits on the catalyst. To regenerate the active sites, exposure to high temperatures will be required [52]. During the cold start conditions or when the upstream DOC is aged, significant amounts of HC can be stored on the SCR catalyst. The stored $\mathrm{HC}$ will be oxidized based on subsequent stages of operation and raising the temperature of the SCR causes thermal deactivation of the SCR [53]. It has been reported that the propylene has a negative effect on the zeolite and vanadia-based SCR, due to HC deposits inhibiting the formation of $\mathrm{NO}_{2}$ and adversely affecting the standard and fast SCR reactions [51, 54, 55].

Chemical poison from engine oil and bio-diesel such K, P, Na and Ca have been reported to have negative impact on the performance of the SCR catalysts. The phosphorous poisoning causes metaphosphates to replace hydroxyl groups on the active isolated iron species on Fe-BEA zeolites [56]. Results show that the increased amount of $\mathrm{K}$ and $\mathrm{Na}$ contamination resulted in a linear decline of BET surface area, $\mathrm{NH}_{3}$ storage capacity, acid sites and the subsequent $\mathrm{NO}_{\mathrm{x}}$ reduction [57].

\subsection{Modeling the Kinetics of the SCR Reactions}

A numerical model aims at simulating the performance of the SCR including $\mathrm{NO}_{\mathrm{x}}$ reduction, $\mathrm{NH}_{3}$ storage, $\mathrm{NH}_{3}$ slip and $\mathrm{SCR}$ outlet temperature in a wide range of scenarios. Models includes SCR reaction kinetics, $\mathrm{NH}_{3}$ adsorption and desorption kinetics and the mass and heat transfer process. This section will explain the SCR 
reaction mechanisms and estimation of kinetics for SCR reactions for the 1-D flow through SCR model developed at MTU by reference [9]. The 1-D SCR model considers one single channel, which is discretized into 10 finite elements from inlet to outlet. The model consists of two sites $\mathrm{S}_{1}$ and $\mathrm{S}_{2}$. The $1^{\text {st }}$ site $\mathrm{S}_{1}$, supports $\mathrm{NH}_{3}$ adsorption, desorption and all the SCR reactions. Whereas, the $2^{\text {nd }}$ site $\mathrm{S}_{2}$, supports only $\mathrm{NH}_{3}$ adsorption and desorption. $\mathrm{NH}_{3}$ is the only species that is assumed to be stored on the catalyst surface. The exhaust flowing through the channel is known as gas phase or bulk phase. The species are transported from the gas phase to the surface phase. The SCR reactions between the stored $\mathrm{NH}_{3}$ and the species occur on the catalyst surface. Assuming all the reactions occur on the catalyst surface, mass transfer between gas phase and the surface phase are included in the model. The equations are described in section 4.1.1 in reference [9]. Heat transfer between the bulk flow and the substrate and between the substrate and the ambient is included to simulate the SCR outlet temperatures under transient conditions [9]. However, the heat release due to the SCR reactions is negligible and was set to zero in the model.

The global chemical reactions for the urea-SCR system include urea decomposition reactions and the SCR reactions that occur on the catalytic surface [9]. A numerical model simulating the spray interaction with the exhaust gas is presented in references [58, $59,60,61]$. The injected urea goes through a 4-step mechanism of decomposition to produce $\mathrm{NH}_{3}$ [58] . The first step is injection of atomized, aqueous urea solution into the hot exhaust stream as shown in equation 2.1. This is followed by evaporation of water from the droplets, yielding molten urea. In the third step, pure urea thermally decomposes to equimolar amounts of ammonia and isocyanic acid as shown in equation 2.3. In the last step, isocyanic acid is hydrolyzed to $\mathrm{NH}_{3}$ and $\mathrm{CO}_{2}$ on the catalyst surface as given in equation 2.4. Isocyanic acid is stable in the gas phase and requires a catalytic surface to accelerate the hydrolysis reaction $[9,62]$ 
$\mathrm{NH}-\mathrm{CO}-\mathrm{NH}_{2}$ (sol) $\rightarrow$ NH-CO-NH (droplets) $^{-}$

Eqn. 2.1

$\mathrm{NH}-\mathrm{CO}-\mathrm{NH}_{2}(\mathrm{aq}) \rightarrow \mathrm{NH}_{2}-\mathrm{CO}-\mathrm{NH}_{2}$ (molten) $+\mathrm{xH}_{2} \mathrm{O}($ gas)

Eqn. 2.2

$\mathrm{NH}-\mathrm{CO}-\mathrm{NH}_{2}$ (molten) $\rightarrow \mathrm{NH}_{3}$ (gas) $+\mathrm{HNCO}$ (gas)

Eqn. 2.3

$\mathrm{HCNO}($ gas $)+\mathrm{H}_{2} \mathrm{O}($ gas $) \rightarrow \mathrm{NH}_{3}$ (gas) $+\mathrm{CO}_{2}$ (gas)

Eqn. 2.4

The four steps correspond to the overall urea decomposition shown in reaction 2.5.

NH-CO-NH $\mathrm{N}_{2}$ (aq) $+\mathrm{H}_{2} \mathrm{O}($ gas $) \rightarrow 2 \mathrm{NH}_{3}($ gas $)+\mathrm{CO}_{2}($ gas $)$

Eqn. 2.5

However, due to complexity of the decomposition process, it was not included in the numerical simulations of the SCR chemistry. It was assumed that the urea was completely converted to $\mathrm{NH}_{3}$ and the conversion occurred in the decomposition tube and in the first substrate of the SCR system. The stored $\mathrm{NH}_{3}$ reacts with the species in the surface phase [9]. The $\mathrm{NH}_{3}$ storage equations for the two sites are described in the equation 4.5 in reference [9]. $\mathrm{NH}_{3(\mathrm{ads}), 1}$ and $\mathrm{NH}_{3(\mathrm{ads}), 2}$ are the $\mathrm{NH}_{3}$ molecules adsorbed on the catalytic surface of each site.

The global SCR reactions taking place on the surface phase consists of 12 reactions as shown in Table 2.1 (Table 4.1 from reference [9]). R1 and R2 represent the $\mathrm{NH}_{3}$ adsorption and desorption on the surface of the catalyst on the $1^{\text {st }}$ site. R3 and R4 represent the $\mathrm{NH}_{3}$ adsorption and desorption on the surface of the catalyst on the $2^{\text {nd }}$ site. Reactions $\mathrm{R} 5$ to $\mathrm{R} 12$ are the $\mathrm{SCR}$ reaction mechanisms than take place on the $1^{\text {st }}$ site. R5 and $\mathrm{R} 6$ are the oxidation reaction of adsorbed $\mathrm{NH}_{3}$, selectively oxidized to $\mathrm{NO}$ or $\mathrm{N}_{2}$. R7 and $\mathrm{R} 8$ are the standard reactions which have different $\mathrm{NH}_{3} / \mathrm{NO}_{\mathrm{x}}$ stoichiometry ratio. The higher $\mathrm{NH}_{3} / \mathrm{NO}_{\mathrm{x}}$ stoichiometry ratio for $\mathrm{R} 8$ explains the overconsumption of $\mathrm{NH}_{3}$. The fast and slow reactions are given in $\mathrm{R} 9$ and $\mathrm{R} 10$ respectively. $\mathrm{R} 11$ is a reversible reaction which considers oxidation of $\mathrm{NO}$ and decomposition of $\mathrm{NO}_{2}$. $\mathrm{R} 12$ is $\mathrm{N}_{2} \mathrm{O}$ formation reaction. 
The reaction rate constants for the twelve reactions are described by the Arrhenius equation shown in equation 2.6. The equations for all reactions are provided in Table 2.1.

$$
k=A e^{-\frac{E a}{R T}}
$$

Where $A$ is the pre-exponential factor, $E_{a}$ is the activation energy $(\mathrm{J} / \mathrm{mol}), \mathrm{R}$ is the universal gas constant $(8.314 \mathrm{~J} / \mathrm{mol} \mathrm{K})$ and $\mathrm{T}$ is the temperature $(\mathrm{K})$.

Table 2.1: Reactions included in the 1-D SCR model from reference [9]

\begin{tabular}{|c|c|c|}
\hline No. & Description & Reaction Equation \\
\hline R1 & Adsorption (Site1) & $\mathrm{NH}_{3}+\mathrm{S} 1 \rightarrow \mathrm{NH}_{3}(\mathrm{ads}), 1$ \\
\hline R2 & Desorption (Site 1) & $\mathrm{NH}_{3(\mathrm{ads}), 1} \rightarrow \mathrm{NH}_{3}+\mathrm{S} 1$ \\
\hline R3 & Adsorption (Site 2) & $\mathrm{NH}_{3}+\mathrm{S} 2 \rightarrow \mathrm{NH}_{3}(\mathrm{ads}), 2$ \\
\hline R4 & Desorption (Site 2) & $\mathrm{NH}_{3(\mathrm{ads}), 2} \rightarrow \mathrm{NH}_{3}+\mathrm{S} 2$ \\
\hline R5 & $\mathrm{NH}_{3}$ Oxidation 1 (Site 1) & $4 \mathrm{NH}_{3(\mathrm{ads}), 1}+3 \mathrm{O}_{2} \rightarrow 2 \mathrm{~N}_{2}+6 \mathrm{H}_{2} \mathrm{O}$ \\
\hline R6 & $\mathrm{NH}_{3}$ Oxidation 2 (Site 1) & $4 \mathrm{NH}_{3(\mathrm{ads}), 1}+5 \mathrm{O}_{2} \rightarrow 4 \mathrm{NO}+6 \mathrm{H}_{2} \mathrm{O}$ \\
\hline R7 & Standard SCR 1 (Site 1) & $4 \mathrm{NH}_{3(\mathrm{ads}), 1}+4 \mathrm{NO}+\mathrm{O}_{2} \rightarrow 4 \mathrm{~N}_{2}+6 \mathrm{H}_{2} \mathrm{O}$ \\
\hline R8 & Standard SCR 2 (Site 1) & $5 \mathrm{NH}_{3}(\mathrm{ads}), 1+3 \mathrm{NO}+9 / 4 \mathrm{O}_{2} \rightarrow 4 \mathrm{~N}_{2}+15 / 2 \mathrm{H}_{2} \mathrm{O}$ \\
\hline R9 & Fast SCR (Site 1) & $4 \mathrm{NH}_{3(\text { ads }), 1}+2 \mathrm{NO}+2 \mathrm{NO}_{2} \rightarrow 4 \mathrm{~N}_{2}+6 \mathrm{H}_{2} \mathrm{O}$ \\
\hline R10 & Slow SCR (Site 1) & $4 \mathrm{NH}_{3(\mathrm{ads}), 1}+3 \mathrm{NO}_{2} \rightarrow 7 / 2 \mathrm{~N}_{2}+6 \mathrm{H}_{2} \mathrm{O}$ \\
\hline R11 & $\begin{array}{l}\mathrm{NO} \text { Oxidation and } \mathrm{NO}_{2} \\
\text { Decomposition (Site 1) }\end{array}$ & $2 \mathrm{NO}+\mathrm{O}_{2} \leftrightarrow 2 \mathrm{NO}_{2}$ \\
\hline R12 & $\mathrm{N}_{2} \mathrm{O}$ Formation (Site 1) & $6 \mathrm{NH}_{3(\text { (ads) }, 1}+8 \mathrm{NO}_{2} \rightarrow 7 \mathrm{~N}_{2} \mathrm{O}+9 \mathrm{H}_{2} \mathrm{O}$ \\
\hline
\end{tabular}




\subsection{SCR Catalyst on the DPF}

The sequential arrangement of DOC, DPF and SCR has the following challenges:

1) The volume of the conventional arrangement of DOC, DPF and SCR catalysts is very large $(34.5 \mathrm{~L})$ as shown in Table 1.2. The demand for higher $\mathrm{NO}_{\mathrm{x}}$ reduction may require more SCR catalyst, further increasing the volume of the conventional aftertreatment system.

2) The SCR inlet temperature is insufficient during cold start when the DPF is located upstream of the SCR. This arrangement deteriorates the $\mathrm{NO}_{\mathrm{x}}$ reduction ability of the SCR.

3) The placement of the SCR upstream of the DPF is an unfavorable condition for passive oxidation of PM accumulated in the DPF, due to reduction of $\mathrm{NO}_{2}$ and heat loss to the ambient in the SCR.

The problem can be potentially resolved by integrating the SCR and DPF functions into one single filter, by coating catalysts on or inside the walls of the DPF. The 2-way SCR/DPF reduces the volume and mass of the aftertreatment system when compared with DPF and flow through type SCR [11,63]. Moreover, SCR-on-filter offers potential for higher $\mathrm{NO}_{\mathrm{x}}$ conversion efficiency due to increase in the effective reaction surface for SCR and higher substrate temperature due to passive oxidation of PM. A schematic of conventional DPF, SCR and SCR-on-DPF from reference [11] is shown in Figure 2.3. 

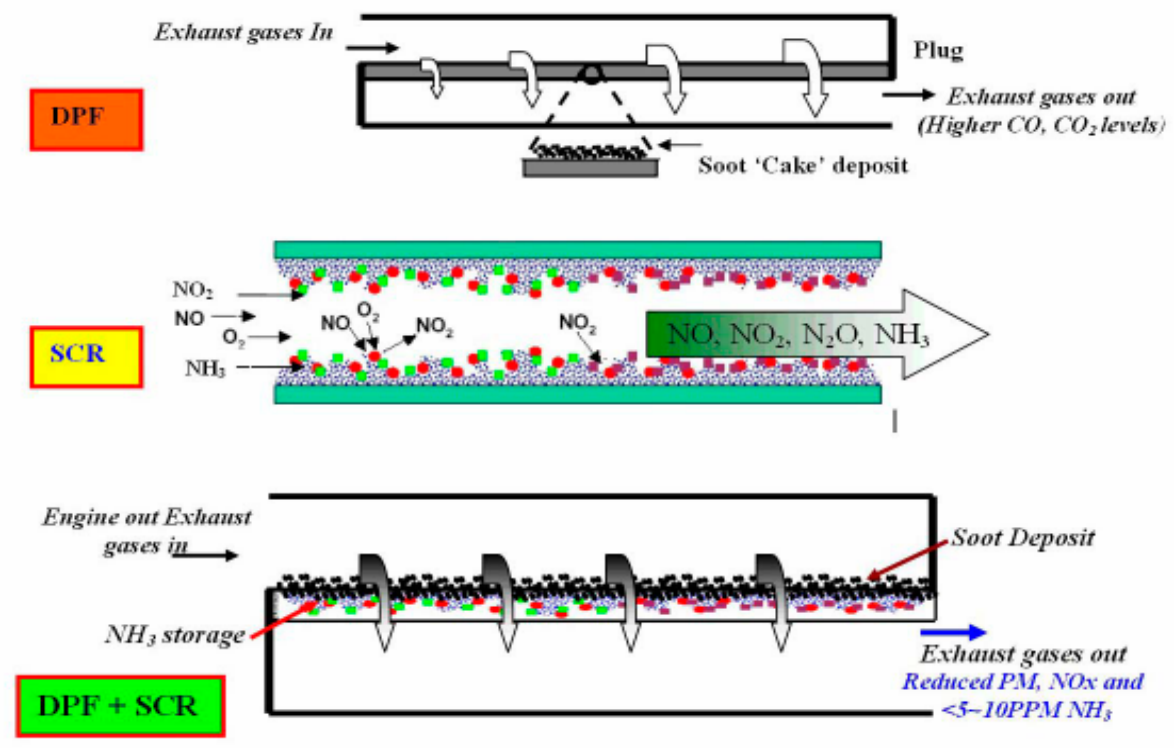

Figure 2.3: Schematic of conventional DPF, SCR and SCR-on-filter [11]

\subsection{PM Oxidation}

Tronconi et al. [64] performed modeling and experimental based studies to evaluate the effect of $\mathrm{NH}_{3}$ on passive oxidation characteristics of a Cu-zeolite SCR-on filter. A comparison of modeling results for passive oxidation in the presence and absence of $\mathrm{NH}_{3}$ is shown in Figure 2.4. The $\mathrm{NO}_{2} / \mathrm{NO}_{\mathrm{x}}$ molar feed ratio was varied from 0 to 1 . In Figure 2.4a, both the $\mathrm{CO}_{2}$ and $\mathrm{CO}$ peaks recorded in the presence of $\mathrm{NH}_{3}$ are shifted to slightly lower temperatures of approximately by $50{ }^{\circ} \mathrm{C}$, which suggests that $\mathrm{NH}_{3}$ had positive effect on active regeneration of PM. Figure $2.4 \mathrm{c}$ and $\mathrm{d}$, confirm that the addition of $\mathrm{NH}_{3}$ significantly reduces the passive oxidation of PM at low temperature, since under these conditions, the fast $\mathrm{SCR}$ reaction ( $\mathrm{R} 9$ in Table 2.1) and $\mathrm{NO}_{2} \mathrm{SCR}$ reaction ( $\mathrm{R} 10$ in Table 2.1) successfully compete with the $\mathrm{PM}$ oxidation and the $\mathrm{NH}_{3}-\mathrm{SCR}$ reactions $(\mathrm{R} 9, \mathrm{R} 10$ and R11 in Table 2.1) are the preferred pathway for $\mathrm{NO}_{2}$ consumption. This phenomenon has to be carefully considered for applications which rely on passive oxidation. 

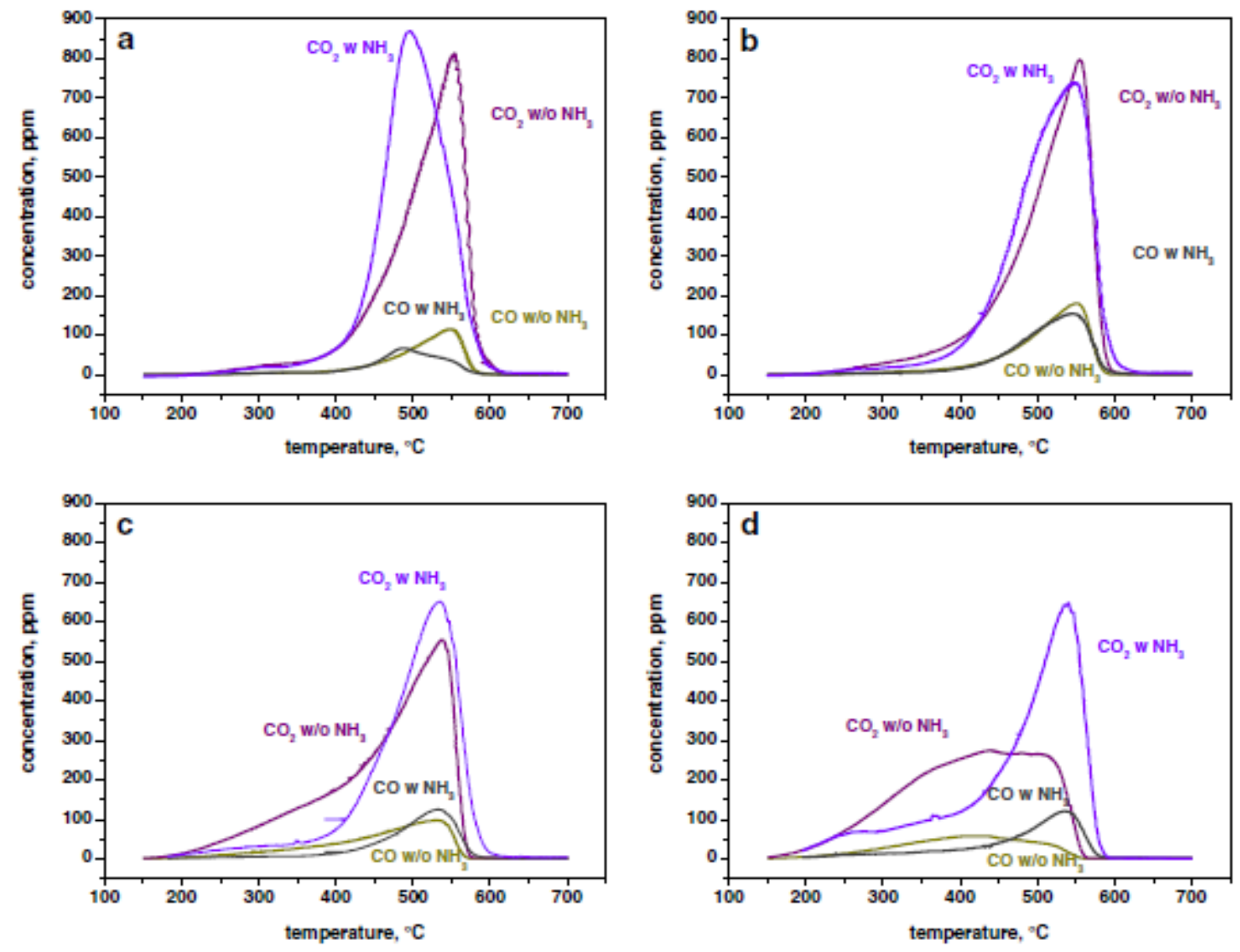

Figure 2.4: Effect of $\mathrm{NH}_{3}$ and $\mathrm{NO}_{x}$ on the passive oxidation. GHSV $=15 \mathrm{k} / \mathrm{hr}, \mathrm{H}_{2} \mathrm{O}=5 \%$, $\mathrm{O}_{2}=8 \%$ when $\mathrm{NH}_{3}$ is present, $\mathrm{NH}_{3}=500$ ppm. a $\mathrm{NO}_{\mathrm{x}}=0$ ppm, b $\mathrm{NO}_{\mathrm{x}}=500$ ppm, $\mathrm{NO}_{2} / \mathrm{NO}_{\mathrm{x}}=0$ [64]

Naseri et al. [65] compared the steady state performance of a Cu-zeolite SCR-on filter with the CPF, after loading both the filters up to $3 \mathrm{~g} / \mathrm{L}$. Passive oxidation experiments were conducted for 30 minutes at a DOC inlet temperature of 300 and $400{ }^{\circ} \mathrm{C}$, using a 2007 MY heavy duty diesel engine. During tests with the SCR-on-filter, the engine out $\mathrm{NO}_{\mathrm{x}}$ was $4.5 \mathrm{~g} / \mathrm{hp}-\mathrm{hr}$, whereas for CPF tests the engine out $\mathrm{NO}_{\mathrm{x}}$ was less than $1.0 \mathrm{gm} / \mathrm{hp}-$ hr. At $300{ }^{\circ} \mathrm{C}$ the $\mathrm{CPF}$ gained $10 \%$ weight $(3.3 \mathrm{~g} / \mathrm{L}$ for initial PM loading of $3 \mathrm{~g} / \mathrm{L})$ at the end of 30 minutes, whereas the SCR-on-filter gained 20\% weight (PM loading $3.6 \mathrm{~g} / \mathrm{L}$ for initial PM loading of $3 \mathrm{~g} / \mathrm{L}$ ) at the end of 30 minutes, with the urea injection during the 30 minutes at ANR of 1.2. The passive oxidation in SCR-on-filter was further studied with and without urea injection at the same DOC inlet temperatures. At $300{ }^{\circ} \mathrm{C}$ the SCR- 
on-filter without urea gained $5 \%$ weight $(3.15 \mathrm{~g} / \mathrm{L}$ for initial PM loading of $3 \mathrm{~g} / \mathrm{L})$ when compared to $20 \%$ weight gain ( $3.6 \mathrm{~g} / \mathrm{L}$ for initial PM loading of $3 \mathrm{~g} / \mathrm{L})$ with urea injection at ANR of 1.2 . At $400^{\circ} \mathrm{C}$ the PM was oxidized by $25 \%(2.25 \mathrm{~g} / \mathrm{L}$ for initial PM loading of $3 \mathrm{~g} / \mathrm{L}$ ) for no urea injection when compared to $19 \%$ PM oxidation (2.43 $\mathrm{g} / \mathrm{L}$ for initial PM loading of $3 \mathrm{~g} / \mathrm{L}$ ) with urea injection at ANR of 1.2.

Czerwinski et al. [66] studied the passive oxidation performance of a SCR-on-filter with PM loading of $3 \mathrm{~g} / \mathrm{L}$. They observed that urea dosing significantly hinders passive oxidation. The passive oxidation efficiency decreased from $81 \%$ without urea injection to $42 \%$ with urea injection at ANR of 1.0. Similar passive oxidation trends for SCR-onfilter were observed by references $[67,68]$. Enhanced PM oxidation can be achieved by calibrating the engine to a higher $\mathrm{NO}_{\mathrm{x}} / \mathrm{PM}$ ratio and designing the $\mathrm{DOC}$ to provide $\mathrm{NO}_{2} / \mathrm{NO}_{\mathrm{x}}$ ratio $>0.5[69]$.

\subsection{2 $\mathrm{NH}_{3}$ Storage and Oxidation}

Tan et al. [70] characterized the $\mathrm{NH}_{3}$ storage in a Cu-zeolite SCR-on-filter and the effects of PM loading and catalyst aging on the $\mathrm{NH}_{3}$ storage through reactor experiments. The PM loading reduced the $\mathrm{NH}_{3}$ storage over degreened SCR-on filter by $30 \%$. However, the impact of aging on $\mathrm{NH}_{3}$ storage was insignificant. The impact on $\mathrm{NH}_{3}$ storage for degreened and aged SCR-on-filter was minimal up to PM loading of $1.2 \mathrm{~g} / \mathrm{L}$.

Schrade et al. [71] performed temperature programmed desorption (TPD) experiments on $\mathrm{Cu}$-zeolite SCR-on-filter, with and without PM loading in the filter. The experiments were conducted for the SCR-on-filter inlet temperature range of $150-250{ }^{\circ} \mathrm{C}$. They observed that the $\mathrm{NH}_{3}$ storage for the SCR-on-filter with PM loading of 2.5 and $9 \mathrm{~g} / \mathrm{L}$ was $12-20 \%$ higher when compared to the $\mathrm{NH}_{3}$ storage for the SCR-on-filter without PM loading.

The presence of $\mathrm{PM}$ has marginal influence on the $\mathrm{NH}_{3}$ oxidation [64]. During the steady state condition, the loaded SCR-on-filter shows slower and reduced $\mathrm{NO}_{\mathrm{x}}$ reduction and higher $\mathrm{NH}_{3}$ slip when compared to empty SCR-on-filter, due to use of some the $\mathrm{NO}_{2}$ for PM oxidation. To avoid $\mathrm{NH}_{3}$ slip, it is recommended to avoid passing ANR of 0.9 [72]. 


\subsubsection{NO Reduction}

Understanding the $\mathrm{NO}_{\mathrm{x}}$ reduction characteristics of the SCR-on-filter is another challenge. In a flow-through SCR, the catalyst is located on the wall while in case of SCR-on-filter, the catalyst is located inside the wall or on the wall of the inlet and outlet channel. Various research groups have concluded that the SCR-on-filter can achieve $\mathrm{NO}_{\mathrm{x}}$ conversion efficiency close to those of flow-through SCR catalysts [10, 65, 73]. However, the PM loading on the filter and decrease in residence time affect the $\mathrm{NO}_{\mathrm{x}}$ reduction performance of the catalyst. PM loading has minimal impact on standard SCR and fast SCR reactions and also improves $\mathrm{NO}_{\mathrm{x}}$ conversion between $250-400{ }^{\circ} \mathrm{C}$ due to oxidation of PM. The competition between SCR and PM oxidation reactions for consumption of $\mathrm{NO}_{2}$ in a SCR-on-filter is schematically illustrated in Figure 2.5 [64]. A summary of published research is described in the following paragraphs.

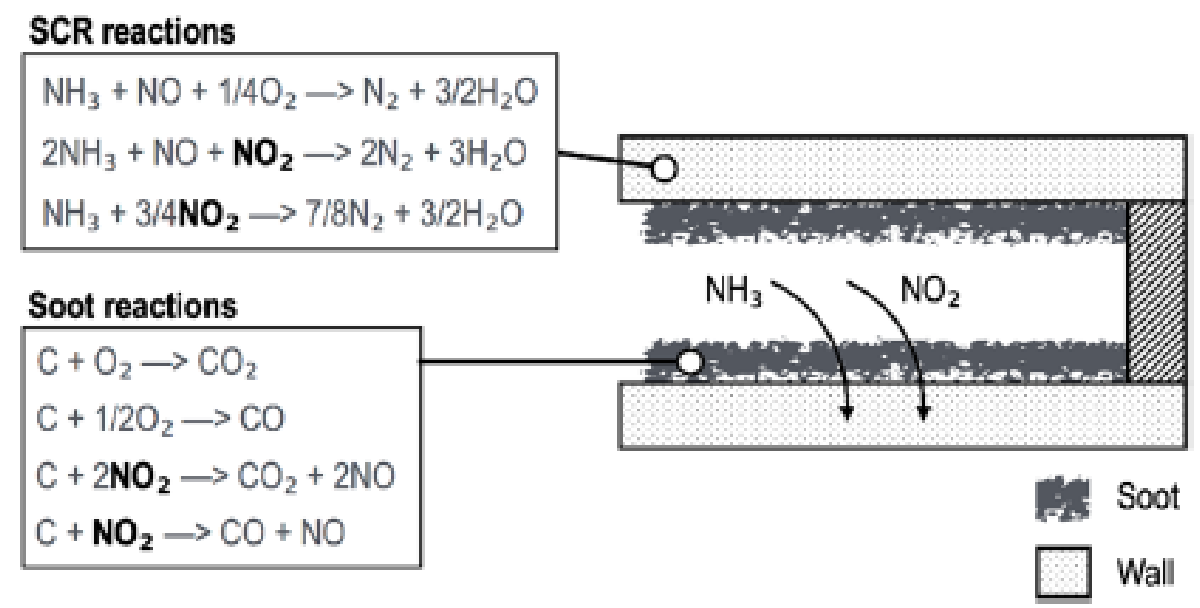

Figure 2.5: Competition between passive oxidation and SCR reactions [64]

Tang et al. [69] conducted steady state and transient tests on a 9.3L 2011MY HDD engine, to investigate the $\mathrm{NO}_{\mathrm{x}}$ reduction performance of Cu-zeolite SCR-on-Filter. During steady state testing, with ANR of 1.0 , a $\mathrm{NO}_{\mathrm{x}}$ conversion efficiency of $90 \%$ was achieved at an exhaust temperature of $465{ }^{\circ} \mathrm{C}$ and $\mathrm{NO}_{2} / \mathrm{NO}_{\mathrm{x}}$ ratio of 0.12 . The $\mathrm{NO}_{\mathrm{x}}$ conversion dropped to $87 \%$ at an exhaust temperature of $250{ }^{\circ} \mathrm{C}$ and unfavorable $\mathrm{NO}_{2} / \mathrm{NO}_{\mathrm{x}}$ ratio of 0.74 . For 1 Cold and 3 Hot NRTC tests, the cumulative $\mathrm{NO}_{\mathrm{x}}$ 
conversion of 92.6 and $95.5 \%$ was observed with a clean and pre-loaded PM to $6.2 \mathrm{~g} / \mathrm{L}$ respectively, at ANR of 1.05. Computational results suggest that the kinetic rates for the SCR reactions are much faster than the NO assisted reactions of PM. This is a result of reduced local $\mathrm{NO}_{2}$ concentrations in the PM cake layer which is due to a strong forward diffusion/flow of $\mathrm{NO}_{2}$ [69].

Johansen et al. [74] investigated the Cu-DPF and V-DPF based SCR-on-filter with material porosity of 73 and $65 \%$, for reactor and engine based experiments respectively. Engine tests indicate that the V-DPF shows better $\mathrm{NO}_{\mathrm{x}}$ conversion than the Cu-DPF during the NRTC, although ammonia slip is lower for $\mathrm{Cu}$-DPF due to its superior ammonia storage capacity. However, the steady state 8-mode test demonstrated that the $\mathrm{Cu}-\mathrm{DPF}$ has better $\mathrm{NO}_{\mathrm{x}}$ conversion than the V-DPF at high temperatures, although at intermediate temperature, the $\mathrm{NO}_{\mathrm{x}}$ conversion was similar for both the catalysts as shown in Figure 2.6. Reactor tests indicate that below $300{ }^{\circ} \mathrm{C}$, the $\mathrm{Cu}$-DPF has a much higher $\mathrm{NO}_{\mathrm{x}}$ conversion than the V-DPF. $\mathrm{N}_{2} \mathrm{O}$ formations are similar and kept low below $450^{\circ} \mathrm{C}$.



Figure 2.6: $\mathrm{NO}_{\mathrm{x}}$ conversions for $\mathrm{V}-\mathrm{DPF}$ and $\mathrm{Cu}-\mathrm{DPF}$ compared to $\mathrm{V}-\mathrm{ft}$ and $\mathrm{Cu}-\mathrm{ft}$ during NRSC [74]

Raymond Conway et al. [75] conducted field trials on a 1998 MY Detroit Diesel S60 engine equipped with a $\mathrm{Cu}$-zeolite SCR-on-filter of $26.1 \mathrm{~L}$ and under floor $\mathrm{Cu}$-zeolite SCR of $21.8 \mathrm{~L}$. They concluded that $\mathrm{NO}_{\mathrm{x}}$ reductions of $95 \%$ can be achieved with ANR close to 1 . They also observed that by reducing the SCR catalyst volume by $27 \%$, the 
$\mathrm{NO}_{\mathrm{x}}$ reduction continued to remain between $90-100 \%$ depending on the inlet temperature. Kojima et al. [76] conducted experiments on a Honda 2.2L i-DTEC engine and compared the $\mathrm{NO}_{\mathrm{x}}$ reduction performance of a $2.5 \mathrm{~L} \mathrm{SCR}$ and SCR-on-filter during the steady state and FTP72. They observed that the $\mathrm{NO}_{\mathrm{x}}$ reduction in the SCR-on-filter was $15-20 \%$ lower than the flow through SCR, below $200{ }^{\circ} \mathrm{C}$. The difference reduced to $10 \%$ at temperatures above $300{ }^{\circ} \mathrm{C}$. This could be attributed to shorter residence time in the SCR-on-filter when compared to the SCR, since the catalyst is coated inside the wall in the case of SCR-on-filter. They also found that at temperatures below $200{ }^{\circ} \mathrm{C}$, the PM loading of $3 \mathrm{~g} / \mathrm{L}$ decreased the $\mathrm{NO}_{\mathrm{x}}$ conversion efficiency of SCR-on-filter by $5-10 \%$ when compared to no PM loading.

Rappe et al. [77] conducted experiments on a Cu-zeolite catalyst based SCR-on-filter with a 2003 VW Jetta TDI engine. They observed that the SCR-on-filter provides $>90 \%$ $\mathrm{NO}_{\mathrm{x}}$ conversion without PM loading in the SCR-on-filter at ANR of 1.0, for inlet temperatures between $250-400{ }^{\circ} \mathrm{C}$ and $\mathrm{NO}_{2} / \mathrm{NO}_{\mathrm{x}}$ ratio between $0.45-0.50$. However, the $\mathrm{NO}_{\mathrm{x}}$ conversion decreased for the $\mathrm{NO}_{2} / \mathrm{NO}_{\mathrm{x}}$ ratios above or below 0.50 . The $\mathrm{NO}_{\mathrm{x}}$ conversion of the SCR-on-filter with PM loading of $4 \mathrm{~g} / \mathrm{L}$ improves by $8-10 \%$ for inlet temperatures below $300^{\circ} \mathrm{C}$ and $\mathrm{NO}_{2} / \mathrm{NO}_{x}$ ratio 0.6. Conversely, for a $\mathrm{NO}_{2} / \mathrm{NO}_{\mathrm{x}}$ ratio of 0.45 , the $\mathrm{NO}_{\mathrm{x}}$ conversion decreases for the inlet temperatures between $250-350^{\circ} \mathrm{C}$. A summary of the representative experimental studies is described in Table 2.2. 


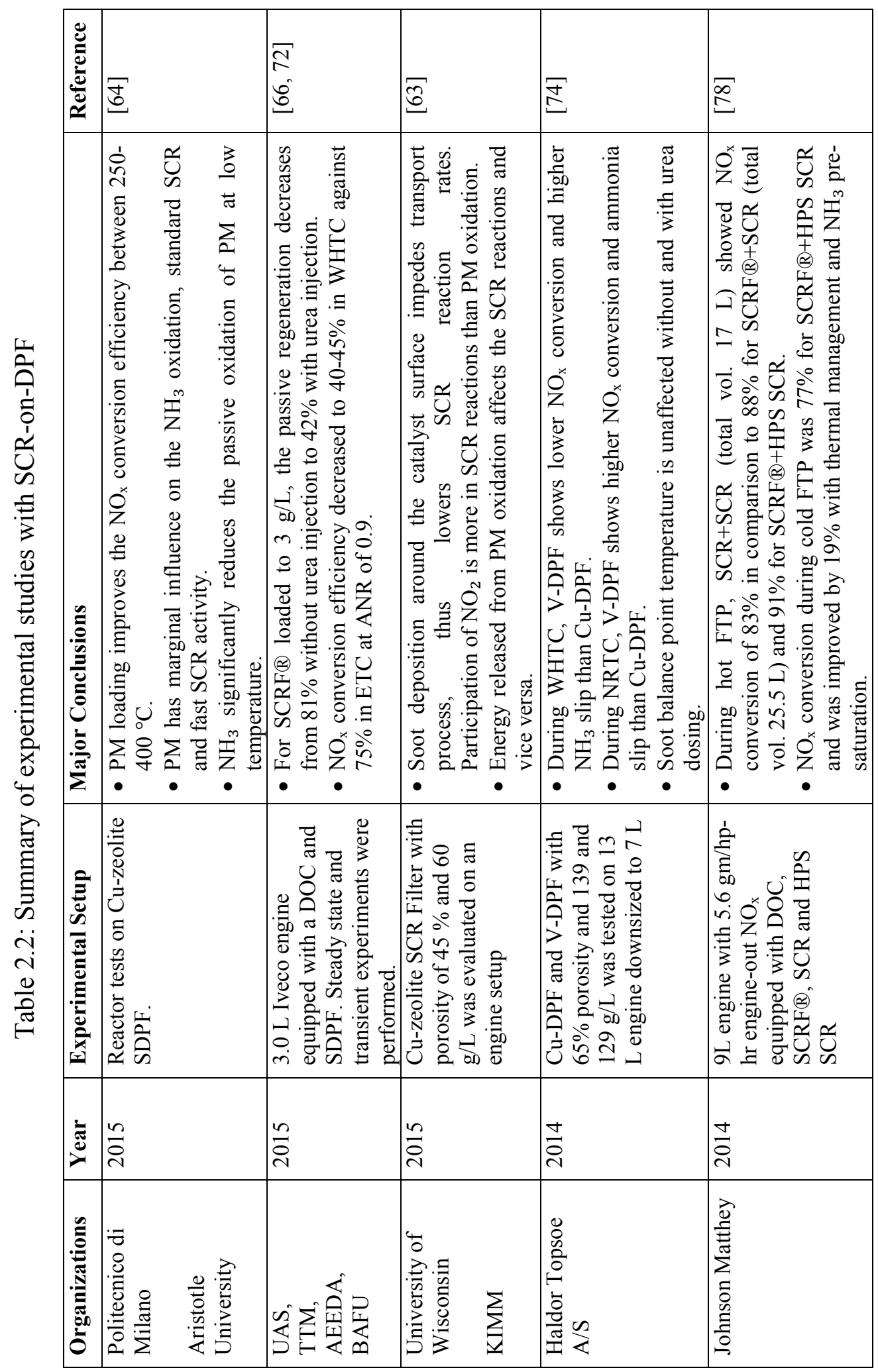




\subsection{Modeling of SCR Catalyst on the DPF}

The simulation model is a useful and reliable tool to design and optimize the aftertreatment devices. It allows investigation of wide range of scenarios in a time and cost effective way. It also provides insight into the kinetics of the reactions and the internal states of the catalyst which cannot be measured using the experimental setup. One of the main objectives of the modeling studies is to understand the interaction between the SCR reactions and the PM oxidation, since SCR reactions occur on the surface, whereas, PM is deposited inside the wall and on the cake layer. There is also the need to understand the temperature and PM distribution along with the filtration efficiency that is related to the PM in the wall and the resulting pressure drop across the filter. A summary of the modeling studies is presented in Table 2.2.

Yang et al. [63] considered that the deposition of PM on the surface deteriorates the mass transport of the species from gas stream to the catalyst surface, which in turn weakens the SCR reactions. The model also assumes that the passive oxidation of PM changes the $\mathrm{NO}_{2} / \mathrm{NO}_{\mathrm{x}}$ ratio, which can have positive or negative impact on SCR reactions, depending on the $\mathrm{NO}_{2} / \mathrm{NO}_{\mathrm{x}}$ ratio being higher or lower than 0.5 respectively. However, if the reaction rate for $\mathrm{NO}_{2}$ assisted oxidation of $\mathrm{PM}$ is much lower than the reaction rate for SCR reactions, then passive oxidation will have minimum impact on the SCR reactions. The energy released by oxidation of PM is another factor that influences the SCR reactions [63]. The substrate temperature increases with the oxidation of PM, which promotes the SCR reactions.

Strots et al. [79] and Schrade et al. [71] demonstrated that the PM reaction model and the SCR kinetics sub-model are sufficient to model the interactions between the SCR and PM oxidation reactions observed in SCR-on-filter substrates. The PM reaction model [71] consists of $\mathrm{PM}$ oxidation by $\mathrm{NO}_{2}$ and oxygen, both pathways producing $\mathrm{CO}$ and $\mathrm{CO}_{2}$. Oxidation of CO on the SCR catalyst is also included in the model. The SCR sub-model includes $\mathrm{NH}_{3}$ storage on two sites, reaction between $\mathrm{NH}_{3}$ stored on the catalyst with the $\mathrm{NO}$ and $\mathrm{NO}_{2}$ in the exhaust stream. The oxidation of $\mathrm{NH}_{3}$ and $\mathrm{NO}$ as well as formation 
and reactions of $\mathrm{N}_{2} \mathrm{O}$ are also included in the SCR in the model. A summary of the representative modeling studies is described in Table 2.3.

The next chapter describes the experimental setup, instrumentation and test matrix used for the experimental study of the $\mathrm{NO}_{\mathrm{x}}$ reduction and $\mathrm{NH}_{3}$ storage in the production-2013SCR and the SCRF®, with and without PM loading in the SCRF®. 


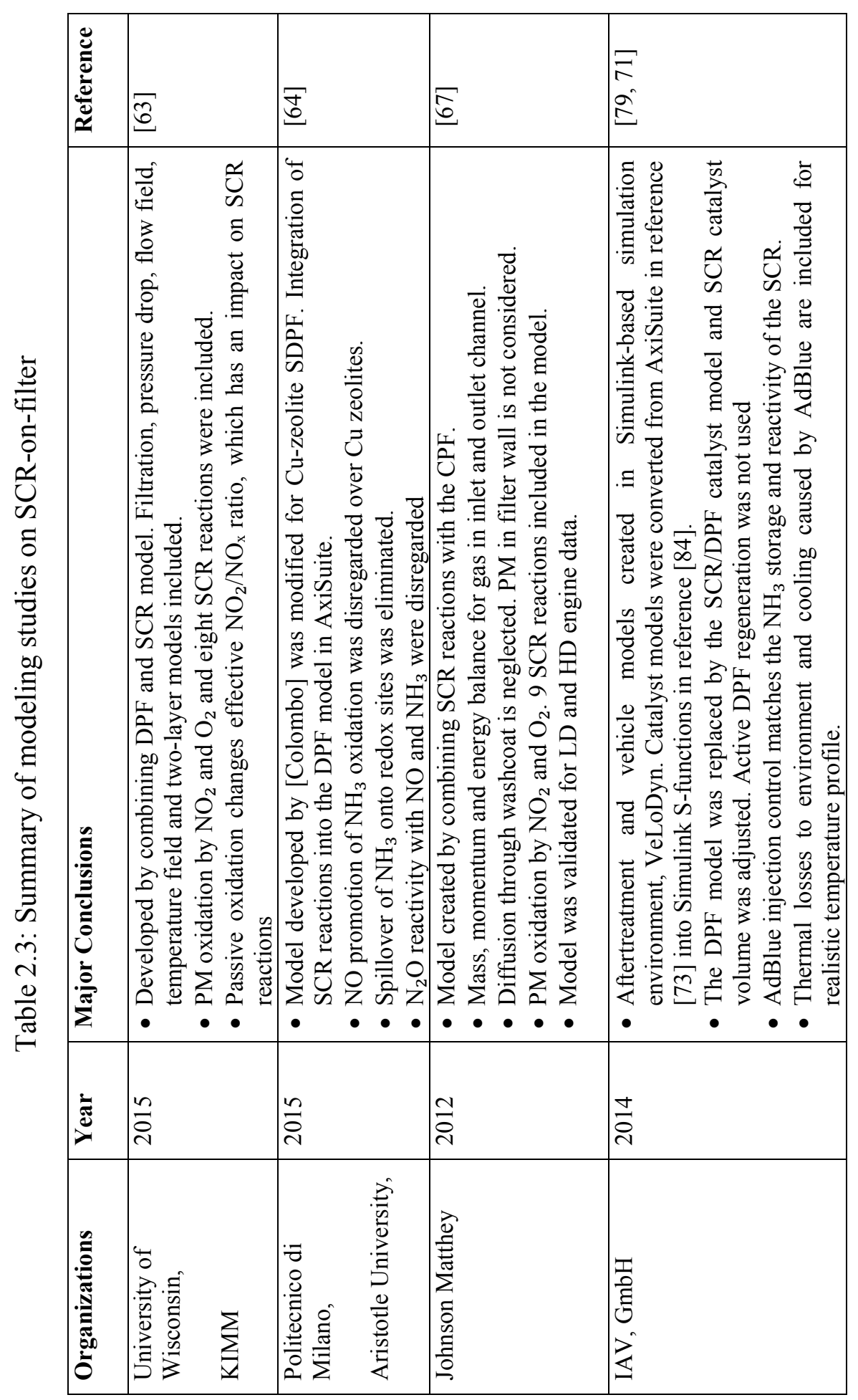




\section{Chapter 3. Experimental Setup, Instrumentation and Test Procedures}

This chapter explains the test cell setup for the ISB 2013 engine, the production aftertreatment system and the SCRF®, including the instrumentation and the test procedures for various aftertreatment configurations. The steady state engine experiments were conducted to evaluate the $\mathrm{NO}_{\mathrm{x}}$ reduction and $\mathrm{NH}_{3}$ storage performance of the production-2013-SCR and the SCRF® in the Heavy Duty Diesel Laboratory on the campus of Michigan Technological University.

The overall experimental program to study the Baseline System and the SCRF® is shown in Figure 3.1. The Baseline System is the production aftertreatment system supplied by Cummins and it consists of a DOC, a CPF and a SCR (production-2013-SCR).

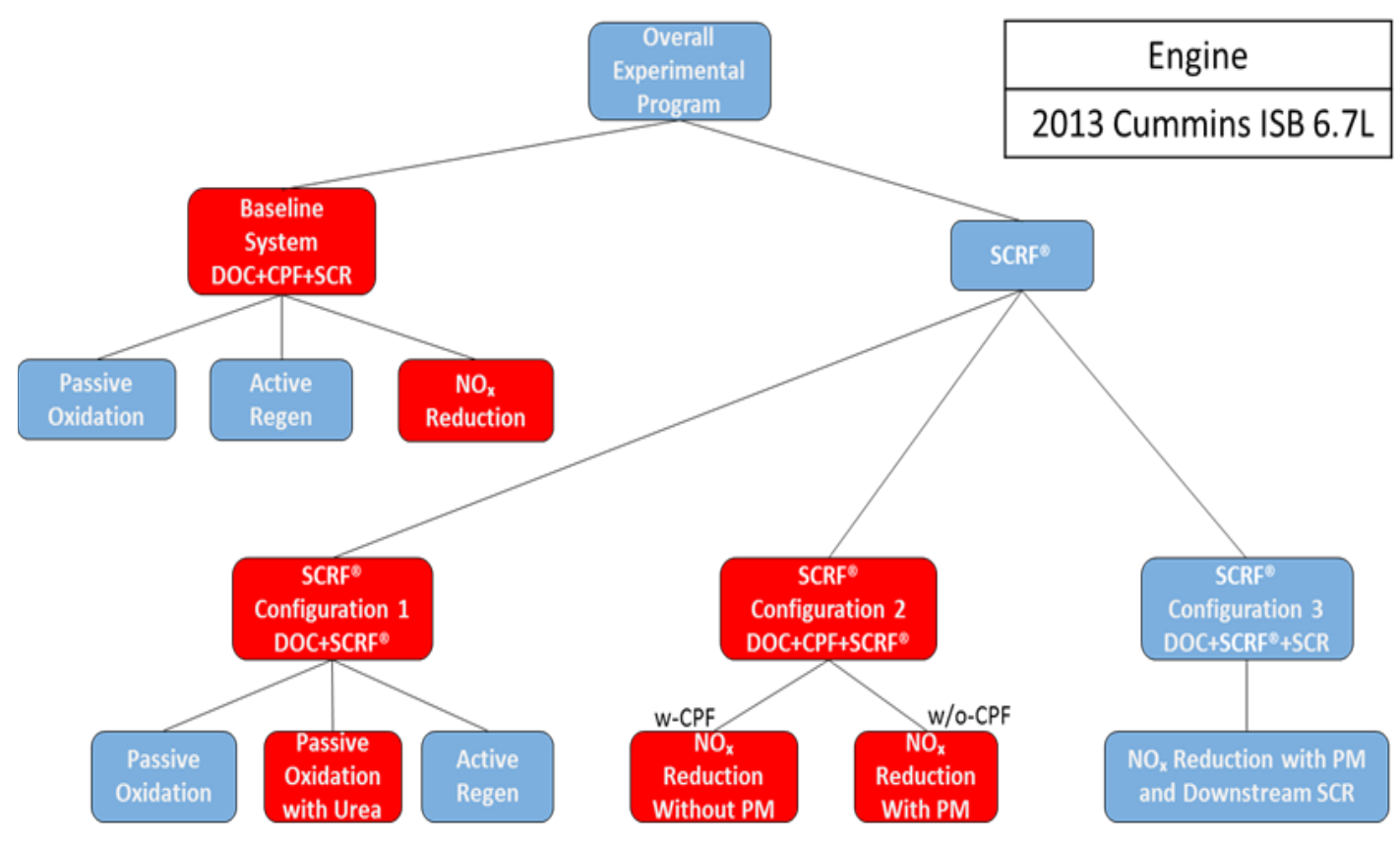

Figure 3.1: Overall experimental program 
The PM oxidation, PM loading and PM filtration performance of the CPF and the $\mathrm{NO}_{\mathrm{x}}$ reduction and $\mathrm{NH}_{3}$ storage performance of the production-2013-SCR were determined from the experiments conducted on the Baseline System. The experimental PM data obtained from the Baseline System, presented in the thesis [3], were used to calibrate the MTU 1-D CPF model [80] and the $\mathrm{NO}, \mathrm{NO}_{2}$ and $\mathrm{NH}_{3}$ data were used to calibrate the MTU 1-D SCR model [9]. The MPF model in reference [13] has been used to develop a SCR-F model and it will be used to calibrate the baseline data and configuration 1,2 and 3 data as shown in Figure 3.1.

The configuration-1 was performed to study the PM oxidation, PM loading and PM filtration performance of the SCRF®, with and without urea injection in the SCRF®. The configuration-2 was performed to study the $\mathrm{NO}_{\mathrm{x}}$ reduction and $\mathrm{NH}_{3}$ storage performance of the SCRF®, without PM and with 2 and $4 \mathrm{~g} / \mathrm{L}$ of PM in the SCRF®. The purpose of configuration-3 is to study the $\mathrm{NO}_{\mathrm{x}}$ reduction performance of the SCRF® and the SCR together and evaluate the effect of ANR $>1.0$ on the $\mathrm{NO}_{2}$ assisted $\mathrm{PM}$ oxidation of the SCRF®. The experimental data collected for the SCRF® will be used to develop and calibrate the SCR-F model being developed at Michigan Tech. The model would be used to simulate the PM filtration efficiency, pressure drop, PM oxidation kinetics, SCR reaction kinetics and substrate temperatures for the SCRF®. The configurations highlighted in red in Figure 3.1 are the main focus of this thesis.

\subsection{Engine Test Cell Setup}

The test cell setup was done to measure, monitor and record the various parameters which determine the performance of the diesel aftertreatment components. A picture of the test cell is shown in Figure 3.2. The layout of the engine, Baseline System (production aftertreatment components), sensors and sampling locations within the test cell are shown in Figure 3.3. The engine exhaust flows through a 4-inch diameter exhaust pipe, from where it can be directed either into the trap line, which has the aftertreatment components, or directly to the building exhaust through the bypass line. The path of exhaust flow is selected by opening or closing the pneumatic butterfly valve mounted in each exhaust line. In the trap line, the exhaust gas flows through a $25 \mathrm{~kW}$ exhaust heater 
which can be used to raise the temperature of the gas entering the aftertreatment system. This enables the evaluation of the aftertreatment system in a controlled and elevated temperature range without changing engine operating conditions [9].

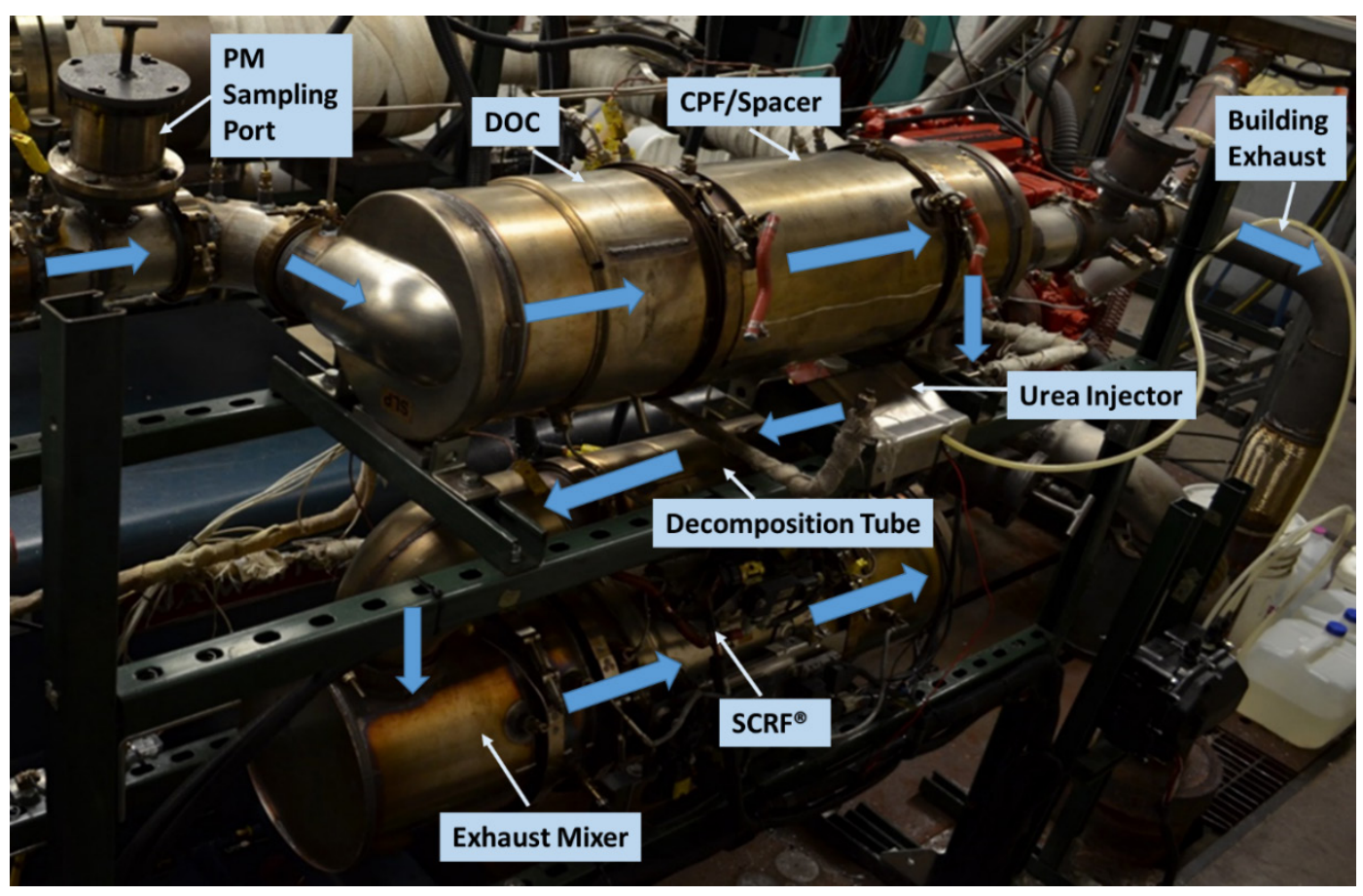

Figure 3.2: A picture from the heavy duty diesel lab at MTU

The exhaust flows through the DOC, where the $\mathrm{HC}, \mathrm{CO}$ and $\mathrm{NO}$ are oxidized to $\mathrm{H}_{2} \mathrm{O}$, $\mathrm{CO}_{2}$ and $\mathrm{NO}_{2}$. The next component in the production set-up is the CPF where PM is filtered and oxidized. Then the exhaust flows through the decomposition tube on which the DEF injector is mounted. The next component is a mixer to ensure homogenous mixing of the DEF decomposition products/droplets and the exhaust gas. After this, exhaust flows through the two SCR-A substrates (production-2013-SCR) and then to the building exhaust through another mixer downstream of the SCR substrates. The mixer downstream of the production-2013-SCR ensured proper mixing for tailpipe emission measurements by the IMR-MS, and the $\mathrm{NO}_{\mathrm{x}}$ and the $\mathrm{NH}_{3}$ sensors. The production aftertreatment system has one SCR-A substrate (only SCR catalyst present) followed by one SCR-B substrate (SCR and oxidation catalyst present). However, the SCR-B substrate was replaced by SCR-A substrate in this experimental study, to obtain the $\mathrm{NH}_{3}$ 
slip data out of the two SCR-A substrates, which was necessary in order to collect data to calibrate the MTU 1-D SCR model.

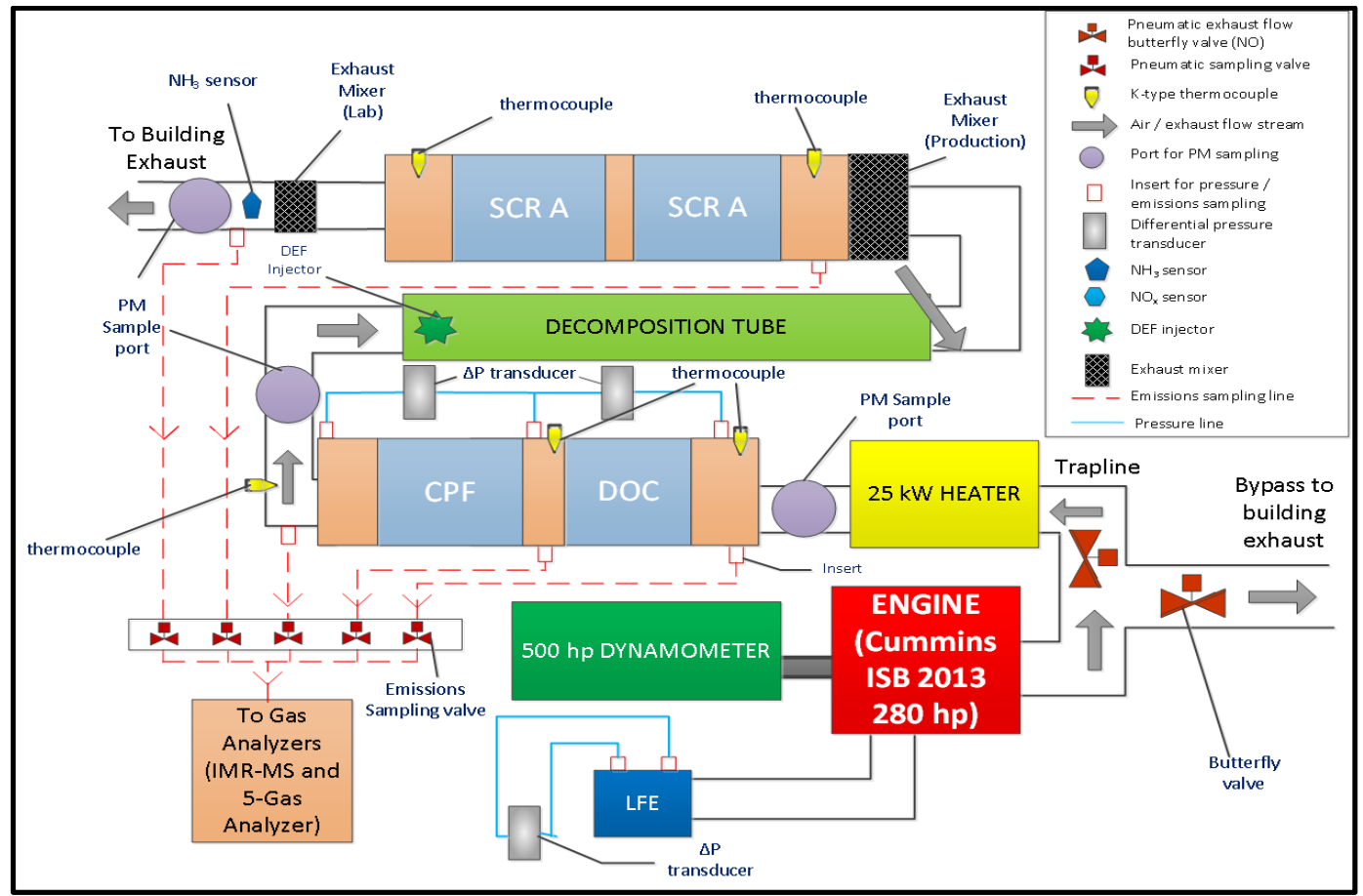

Figure 3.3: Schematic of test cell with the production engine and aftertreatment system and the instrumentation [3]

The passive oxidation experiments with urea injection were performed with the SCRF® in configuration-1 as shown in Figure 3.1. One of the objectives of this configuration was to study the effect of $\mathrm{NO}_{\mathrm{x}}$ reduction in the $\mathrm{SCRF}{ }^{\circledR}$ on the $\mathrm{NO}_{2}$ assisted $\mathrm{PM}$ oxidation kinetics of the SCRF®. During the passive oxidation experiments with urea injection, conducted in configuration-1, the CPF was replaced with the spacer and the two SCR-A substrates were replaced with the SCRF® and the spacer as shown in Figure 3.4. The $\mathrm{NO}_{\mathrm{x}}$ reduction experiments with the $\mathrm{SCRF} \AA$, with and without $\mathrm{PM}$ loading in the $\mathrm{SCRF}{ }^{\circledR}$ were performed in configuraton-2, as shown in Figure 3.1. The schematic for configuration-2 is shown in Figure 3.5. During the $\mathrm{NO}_{\mathrm{x}}$ reduction experiments without PM loading, the CPF was placed upstream of the SCRF®, to filter the PM entering into the SCRF®. During the $\mathrm{NO}_{\mathrm{x}}$ reduction experiments with PM loading, the CPF upstream of the $\mathrm{SCRF}{ }^{\circledR}$ was replaced with the spacer. The test procedures for experiments conducted in configurations 1 and 2 are explained later in the chapter. 


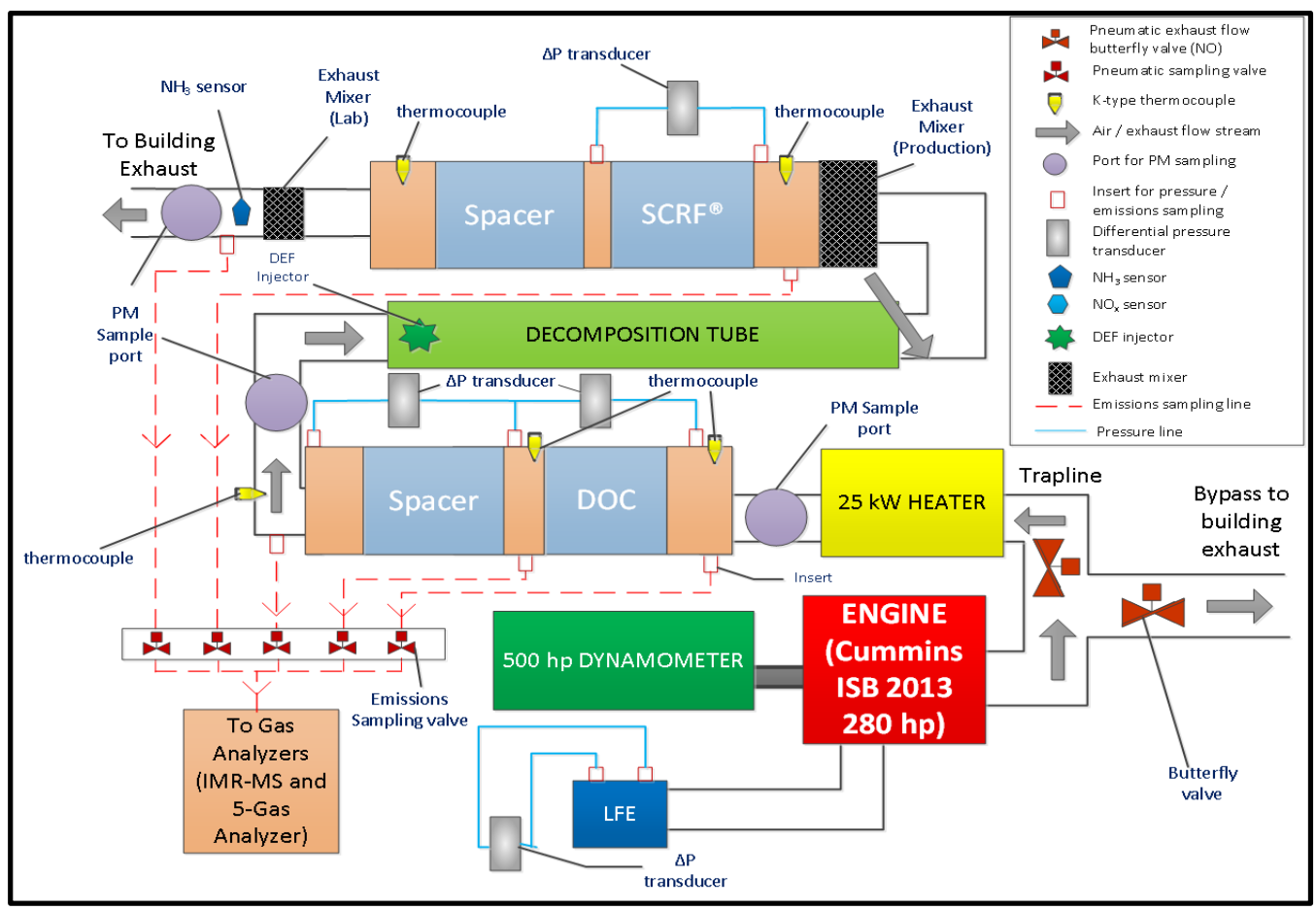

Figure 3.4: Schematic of test cell with the production engine and the SCRF® and the instrumentation for configuration-1 [3]

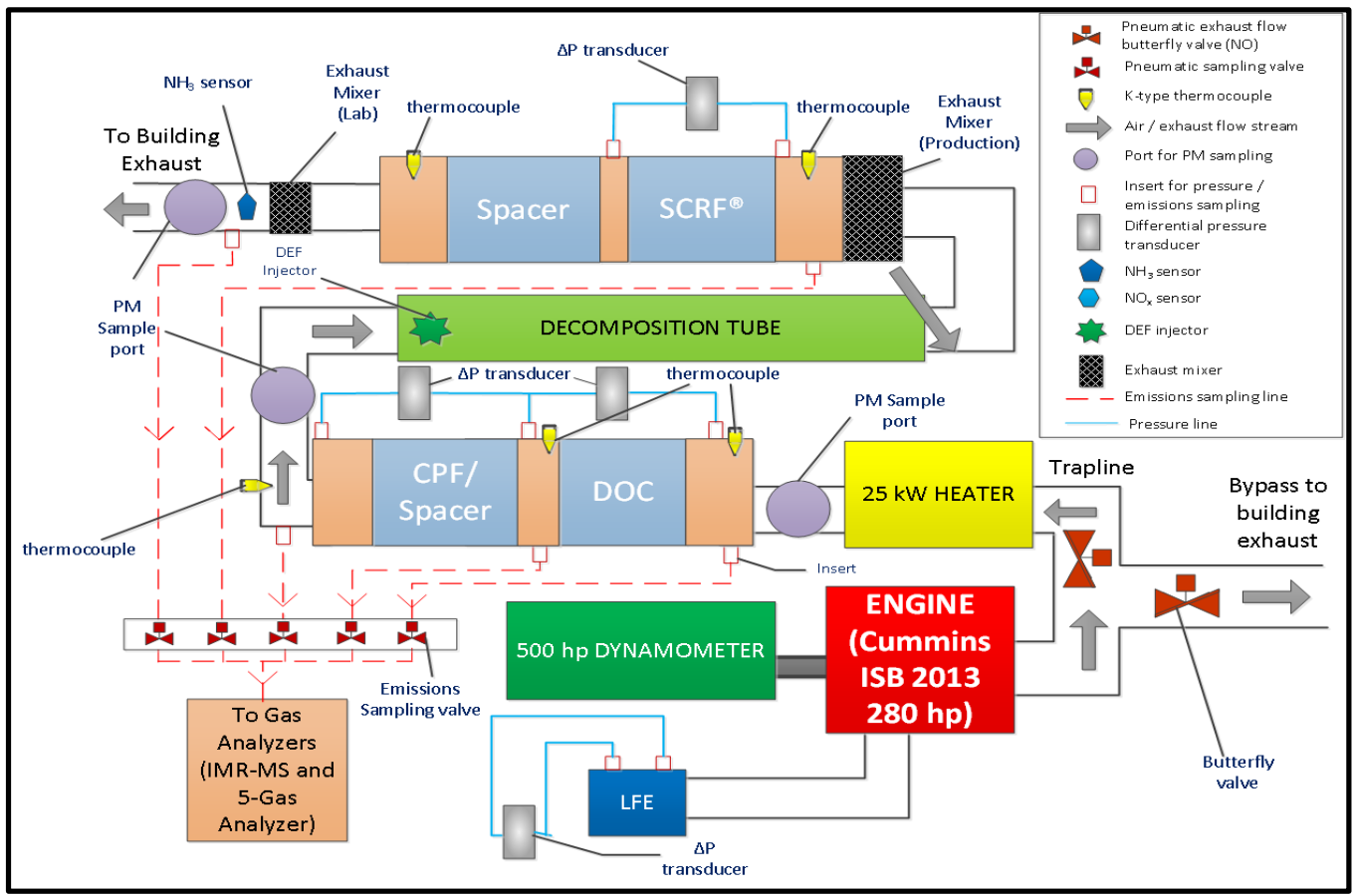

Figure 3.5: Schematic of test cell with the production engine and the SCRF® (with and without the upstream $\mathrm{CPF}$ ) and the instrumentation for configuration-2 [3] 


\subsection{Engine and Dynamometer}

A Cummins 2013 ISB (280 hp) engine that conforms to the U.S EPA 2013 emission regulations was used in the research. The specifications of the engine are provided in Table 3.1. An engine control module governs the engine and sub-systems such as the common rail fuel injection system, the DEF dosing system and the EGR system.

Table 3.1: Specifications of the Cummins ISB 2013 engine

\begin{tabular}{|l|l|}
\hline Model & Cummins ISB $208 \mathrm{~kW}(280 \mathrm{hp})$ \\
\hline Year of Manufacture & 2013 \\
\hline Cylinders & 6, inline \\
\hline Bore \&Stroke & $107 \times 124 \mathrm{~mm}$ \\
\hline Displacement & $409 \mathrm{in}^{3}(6.7 \mathrm{~L})$ \\
\hline Aspiration & Turbocharged \\
\hline Aftercooling & Cummins Charge Air Cooler \\
\hline Turbocharger & Variable Geometry Turbocharger $($ Holset $)$ \\
\hline Rated Speed and Power & $2400 \mathrm{RPM}$ and $209 \mathrm{~kW}$ \\
\hline Peak Torque & $895 \mathrm{~N} \cdot \mathrm{m} @ 1600$ RPM \\
\hline EGR system & Electronically controlled and cooled \\
\hline
\end{tabular}

The engine was coupled to an eddy current dynamometer which regulates the speed and the load on the engine. The specifications are provided in Table 3.2. The dynamometer was controlled by a Digalog Model 1022A controller and can be operated in the 'constant speed' and 'constant load' modes using the controller. However, during the engine testing, the dynamometer controller was set to the 'constant speed' mode and the throttle was operated to regulate the load on the engine. Throttle (rheostat) varies the fuel flow rate supplied to the engine to apply the desired load on the engine.

Table 3.2: Dynamometer specifications

\begin{tabular}{|l|l|}
\hline Manufacturer & Dynamatic \\
\hline Model Number & AD8121 \\
\hline Peak Power (kW) & $373 @ 1750-7000 R P M$ \\
\hline Peak Torque (N-m) & 2035@1750RPM \\
\hline
\end{tabular}




\subsection{Fuel Properties}

The ULSD that conforms to EPA regulations was used to conduct the experimental tests in this research. The fuel properties from reference [3] are reported in Table 3.3, since the same fuel was used for the experiments.

Table 3.3: Specifications of the fuel used for engine testing from reference [3]

\begin{tabular}{|c|c|}
\hline Fuel Type & ULSD -2 \\
\hline API. Gravity at & 35.4 \\
\hline SP. Gravity at & 0.848 \\
\hline Viscosity at & 2.999 \\
\hline Total Sulfur & 7 \\
\hline Initial Boiling & 184 \\
\hline Final Boiling & 363 \\
\hline Cetane Index & 48.7 \\
\hline Water Content & 34 \\
\hline Higher Heating & 45.68 \\
\hline Lower Heating & 42.89 \\
\hline H/C & 1.833 \\
\hline
\end{tabular}

${ }^{1}$ These values were obtained from reference [81], since similar fuel was used

\subsection{Aftertreatment System}

The Cummins production aftertreatment system and the SCRF® from Johnson Matthey and Corning were used to conduct the experiments. The production aftertreatment system included a DOC, a CPF, and two SCR-A substrates. The specifications of the production aftertreatment system and the SCRF® are given in Table 3.4.

To reduce the variation in the performance of the catalysts, a de-greening procedure was performed for all the aftertreatment components, prior to conduction of the reported tests. The test cycle recommended by Cummins was used to perform the de-greening procedure. During the de-greening procedure, the engine was run at 1400 RPM and 820 $\mathrm{N}-\mathrm{m}$ for 12 hours with active regeneration for 30 mins, starting off after 4 hours and recurring every 2 hours after that. The exhaust conditions during the de-greening procedure are given in Table 3.5. 
Table 3.4: Specifications of the ISB 2013 production aftertreatment system and the SCRF®

\begin{tabular}{|c|c|c|c|c|}
\hline Substrate & DOC & CPF & $2 *$ SCR-A & SCRF® \\
\hline Material & Cordierite & Cordierite & Cordierite & Cordierite \\
\hline Diameter (inch) & 9.0 & 9 & 10.5 & 10.5 \\
\hline Length (inch) & 4 & 10 & $12^{1}$ & 12 \\
\hline Cell Geometry & Square & Square & Square & Square \\
\hline Total Volume (L) & 4.17 & 10.40 & 17.04 & 17.04 \\
\hline Open Volume (L) & 3.5 & 7.3 & 14.4 & 10.2 \\
\hline Cell Density /in ${ }^{2}$ & 400 & 200 & 400 & 200 \\
\hline Cell Width (mil) & 46 & 59 & 46 & 55 \\
\hline Filtration Area (in ${ }^{2}$ ) & $\mathrm{NA}$ & 8858 & $\mathrm{NA}$ & 11370 \\
\hline Open Frontal Area (in $\left.{ }^{2}\right)$ & 26.92 & 22.15 & 73.29 & 25.9 \\
\hline Channel Wall Thickness & 4 & 12 & 4 & 16 \\
\hline Wall density $\left(\mathrm{g} / \mathrm{cm}^{3}\right)$ & 0.91 & 1.53 & 0.91 & - \\
\hline Porosity (\%) & 35 & 59 & 35 & 50 \\
\hline Mean Pore Size $(\mu \mathrm{m})$ & NA & 15 & NA & 16 \\
\hline Number of in cells & 25447 & 6362 & 34636 & 8659 \\
\hline Weight of substrate + & 5155 & 14377 & 14088 & 18140 \\
\hline
\end{tabular}

Table 3.5: Diesel engine aftertreatment de-greening procedure

\begin{tabular}{|c|c|c|c|c|c|}
\hline Speed & Load & $\begin{array}{c}\text { Exhaust } \\
\text { Flow } \\
\text { Rate }\end{array}$ & $\begin{array}{c}\text { SCRF® } \\
\text { Inlet } \\
\text { Temp }\end{array}$ & $\begin{array}{l}\text { Post-Fuel } \\
\text { Dosing }\end{array}$ & Duration \\
\hline [RPM] & {$[\mathbf{N}-\mathbf{m}]$} & [kg/min] & {$\left[{ }^{\circ} \mathrm{C}\right]$} & [mg/stroke] & [Hours] \\
\hline \multirow{8}{*}{1400} & \multirow{8}{*}{830} & \multirow{8}{*}{6.5} & 450 & 0.0 & 4.0 \\
\hline & & & 602 & 23.0 & 0.5 \\
\hline & & & 451 & 0.0 & 2.0 \\
\hline & & & 606 & 23.0 & 0.5 \\
\hline & & & 448 & 0.0 & 2.0 \\
\hline & & & 603 & 23.5 & 0.5 \\
\hline & & & 451 & 0.0 & 2.0 \\
\hline & & & 601 & 24.0 & 0.5 \\
\hline & & & & Total Hours & 12.0 \\
\hline
\end{tabular}




\subsection{Test Cell Measurements and Data Acquisition}

\subsubsection{Exhaust Mass Flow Rate}

The exhaust mass flow rate is considered as the sum of air and fuel flow rates. The air flow rate was calculated from the pressure drop (in intake air flow) measured using a pressure transducer across the Meriam Instruments Laminar Flow Element (LFE). The pressure drop value was used to calculate the intake air standard volumetric flow rate which was then converted to the mass flow rate using density of air at the standard conditions $\left(20^{\circ} \mathrm{C}\right.$ and $1 \mathrm{~atm}$ pressure). The fuel mass flow rate was measured by a model CMFS015M319N2BAECZZ Micro Motion Coriolis Meter. The specifications of the flow meter are given in Table 3.6.

Table 3.6: Coriolis meter specifications

\begin{tabular}{|l|l|l|l|}
\hline Manufacturer & \multicolumn{3}{|l|}{ Micro Motion } \\
\hline Model & \multicolumn{2}{l|}{ CMFS015M319N2BAECZZ } \\
\hline Measurement & Flowrate & Density & Temperature \\
\hline Units & {$[\%]$} & {$\left[\mathrm{kg} / \mathrm{m}^{3}\right]$} & {$\left[{ }^{\circ} \mathrm{C}\right]$} \\
\hline Accuracy & \pm 0.10 & \pm 0.5 & \pm 1.0 \\
\hline Repeatability & \pm 0.05 & \pm 0.2 & \pm 0.2 \\
\hline
\end{tabular}

\subsubsection{Temperature}

The temperature sensors were installed at various locations in the exhaust system, and in the $\mathrm{CPF}$ and the SCRF ${ }^{\circledR}$ to record the radial and axial gas temperature distribution. Ktype thermocouples manufactured by Omega were used to measure the temperature. The details of the thermocouples used are given in Table 3.7. The thermocouple layout in the $\mathrm{CPF}$ and the SCRF® are given in Figures 3.6 and 3.7. Twenty thermocouples, namely S1 - S20 were instrumented in the SCRF®. The thermocouples S1 - S10 were inserted into the SCRF ${ }^{\circledR}$ through the inlet channels of the SCRF ${ }^{\circledR}$ and the thermocouples $\mathrm{S} 11-\mathrm{S} 20$ were inserted into the SCRF® through the outlet channels of the SCRF®. 
Table 3.7: Specifications of the thermocouples used in the aftertreatment system

\begin{tabular}{|c|c|c|c|c|c|c|}
\hline Manufacturer & Type & Diameter & Length & Part Number & Accuracy & Location \\
\hline$[-]$ & {$[-]$} & [in.] & [in.] & {$[-]$} & {$[\%]$} & {$[-]$} \\
\hline Omega & $\mathrm{K}$ & 0.020 & 12 & K-MQSS-020-U-12 & $\pm 2.2^{\circ} \mathrm{C}$ & $\mathrm{CPF}$ \\
\hline Omega & $\mathrm{K}$ & 0.020 & 16 & K-MQSS-020-U-16 & $\pm 2.2^{\circ} \mathrm{C}$ & $\mathrm{CPF}$ \\
\hline Omega & $\mathrm{K}$ & 0.020 & 12 & K-MQSS-020-U-12 & $\pm 2.2^{\circ} \mathrm{C}$ & SCRF® \\
\hline Omega & $\mathrm{K}$ & 0.020 & 16 & K-MQSS-020-U-16 & $\pm 2.2^{\circ} \mathrm{C}$ & SCRF® \\
\hline Omega & K & 0.125 & 6 & K-MQSS-125-U-6 & $\pm 2.2{ }^{\circ} \mathrm{C}$ & $\begin{array}{l}\text { Exhaust, } \\
\text { Air } \\
\text { Intake, } \\
\text { Coolant }\end{array}$ \\
\hline
\end{tabular}

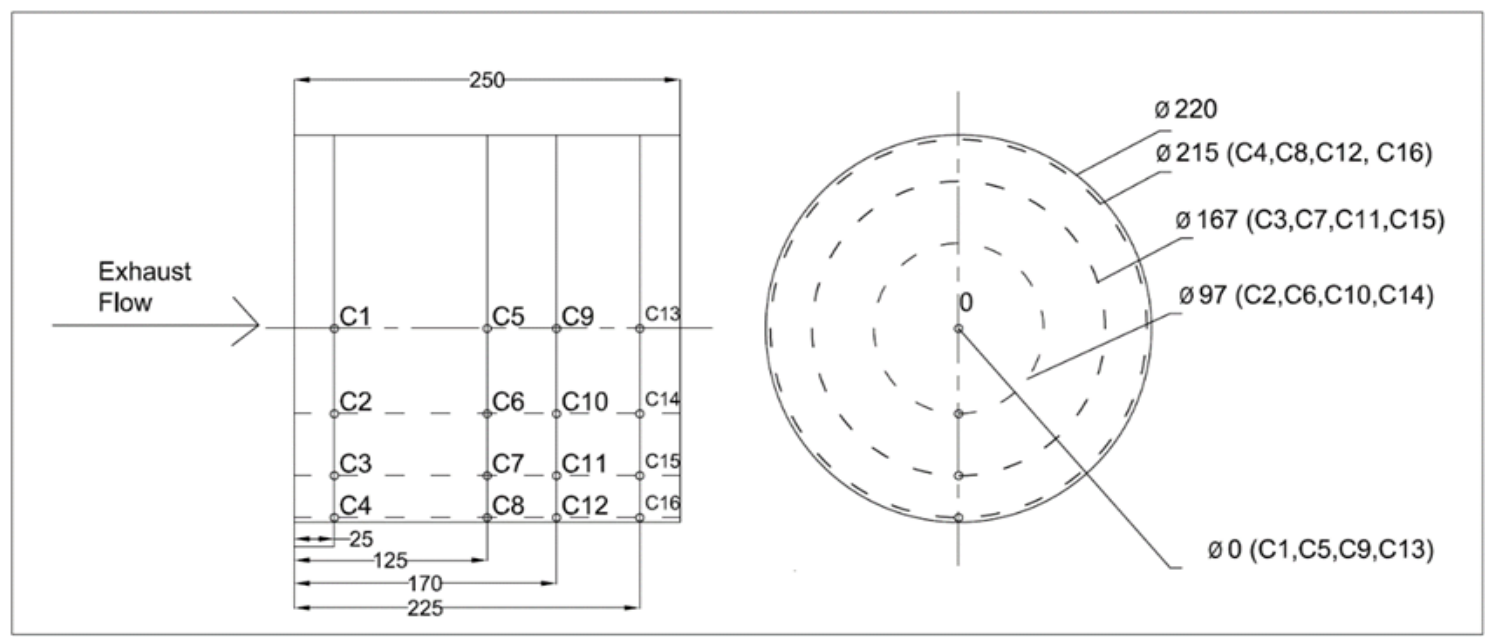

Figure 3.6: Thermocouple arrangement in the CPF (adapted from reference [3]) 


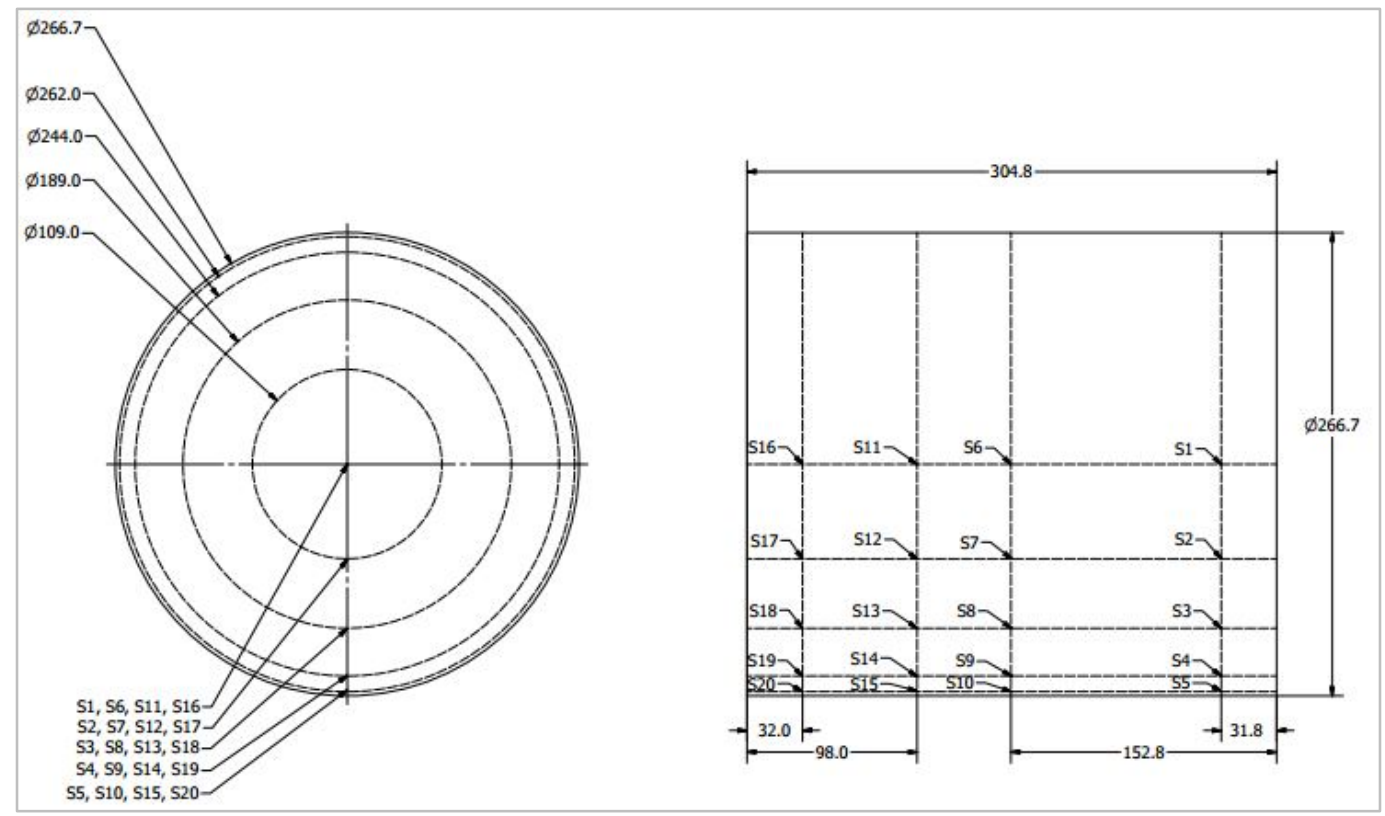

Figure 3.7: Thermocouple arrangement in the SCRF®

\subsubsection{Pressure}

The pressure drop data across the LFE, DOC, CPF, SCR and SCRF® was continuously measured and recorded by several differential pressure transducers. The barometric pressure was measured by an absolute pressure transducer. The specifications of the transducers are given in Table 3.8

Table 3.8: Specifications of pressure transducers

\begin{tabular}{|l|l|l|l|l|l|}
\hline Parameters & $\begin{array}{l}\text { Barometric } \\
\text { Pressure }\end{array}$ & LFE & DOC & CPF & SCRF® \\
\hline $\begin{array}{l}\text { Sensor } \\
\text { Make }\end{array}$ & $\begin{array}{l}\text { Omega } \\
\text { Engineering }\end{array}$ & $\begin{array}{l}\text { Omega } \\
\text { Engineering }\end{array}$ & $\begin{array}{l}\text { Omega } \\
\text { Engineering }\end{array}$ & $\begin{array}{l}\text { Omega } \\
\text { Engineering }\end{array}$ & $\begin{array}{l}\text { Omega } \\
\text { Engineering }\end{array}$ \\
\hline $\begin{array}{l}\text { Model } \\
\text { Number }\end{array}$ & PX419-26B5V & $\begin{array}{l}\text { PX429- } \\
10 \mathrm{DWU}-10 \mathrm{~V}\end{array}$ & $\begin{array}{l}\text { PX429- } \\
2.5 \mathrm{DWU}-10 \mathrm{~V}\end{array}$ & $\begin{array}{l}\text { PX409- } \\
2.5 \mathrm{DWU}- \\
5 \mathrm{~V}\end{array}$ & $\begin{array}{l}\text { PX429- } \\
5 \mathrm{DWU}-10 \mathrm{~V}\end{array}$ \\
\hline Type & Absolute & Differential & Differential & Differential & Differential \\
\hline Range & $26.00-32.00$ & $0-10$ & $0-2.5$ & $0-2.5$ & $0-5$ \\
\hline Units & in. Hg & in. $\mathrm{H}_{2} \mathrm{O}$ & PSID & PSID & PSID \\
\hline $\begin{array}{l}\text { Accuracy, } \\
\text { Linearity, } \\
\text { Hysteresis }\end{array}$ & $\pm 0.08 \% \mathrm{FS}$ & $\pm 0.08 \% \mathrm{FS}$ & $\pm 0.08 \% \mathrm{FS}$ & $\pm 0.08 \% \mathrm{FS}$ & $\pm 0.08 \% \mathrm{FS}$ \\
\hline $\begin{array}{l}\text { Output } \\
\text { Voltage }\end{array}$ & $0-5 \mathrm{Vdc}$ & $0-10 \mathrm{Vdc}$ & $0-5 \mathrm{Vdc}$ & $0-10 \mathrm{Vdc}$ & $0-10 \mathrm{Vdc}$ \\
\hline
\end{tabular}

Note: FS indicates full scale reading 


\subsubsection{Data Acquisition}

The data acquisition hardware consists of two National Instruments (NI) DAC chassis (NI cDAQ-9178). Multiple NI modules were plugged in to collect the engine speed, load, temperature and pressure data from the various locations. The details of data acquisition system are given in Table 3.9. A NI LabVIEW program was used to log the data and display it on the desktop computer for continuous data monitoring during the test. The specifications of the various modules are described in reference $[9,1]$.

Table 3.9: Details of the data acquisition system

\begin{tabular}{|l|l|l|}
\hline Module & Measurement & Quantity \\
\hline NI 9263 & Analog Output \pm 10 V & 1 \\
\hline NI 9239 & Analog Input 10 V range & 2 \\
\hline NI 9237 & Analog Input \pm 25 mV/V (Bridge) & 1 \\
\hline NI 9213 & Thermocouple & 4 \\
\hline NI 9472 & 24 V, Digital Output & 1 \\
\hline NI 9205 & $\begin{array}{l}\text { Analog Input upto } \pm 10 \text { V (Single ended, } \\
\text { differential) }\end{array}$ & 1 \\
\hline NI 9401 & Digital Input / Output & 1 \\
\hline
\end{tabular}

A PCAN service tool was connected to the desktop computer via USB, to obtain the data from the engine via CAN communication (J1939 protocol). The proprietary software from Cummins Inc., Calterm, was used record and monitor the data from the engine ECM. Calterm was also used to control the post-fuel dosing, urea dosing, throttle position and fuel rail pressure.

\subsubsection{Gaseous Emissions}

The gaseous emissions during the $\mathrm{NO}_{\mathrm{x}}$ reduction tests were measured using a V\&F Airsense ion molecule reaction mass spectrometer (IMR-MS). The details of MS and calibration gases used to calibrate the MS are given in Table 3.10. The procedure to operate and calibrate the MS is described in Appendix A. $\mathrm{N}_{2} \mathrm{O}$ measurement is also important for $\mathrm{NO}_{\mathrm{x}}$ reduction experiments on the SCR and the SCRF®, but due to 
interference caused by the same molecular mass of $\mathrm{N}_{2} \mathrm{O}$ and $\mathrm{CO}_{2}$ (44 amu), accurate measurements were not possible with the MS [9].

Table 3.10: Specifications of IMR-MS and calibration gases

\begin{tabular}{|l|l|l|l|l|l|l|}
\hline Components & $\begin{array}{l}\text { Detection } \\
\text { Level at } \\
\mathbf{1 0 0} \mathbf{~ m s}\end{array}$ & $\begin{array}{l}\text { Monitoring } \\
\text { Mass }\end{array}$ & $\begin{array}{l}\text { Ionization } \\
\text { Gas }\end{array}$ & $\begin{array}{l}\text { Span } \\
\text { Gas }\end{array}$ & $\begin{array}{l}\text { Span gas } \\
\text { concentration }\end{array}$ & Accuracy \\
\hline$[-]$ & {$[\mathbf{p p b}]$} & {$[\mathbf{a m u}]$} & {$[-]$} & {$[-]$} & {$[\mathbf{p p m}]$} & {$[\%]$} \\
\hline $\mathrm{NO}$ & 100 & 30 & Mercury & $\mathrm{NO}, \mathrm{N}_{2}$ & 797 & \pm 1 \\
\hline $\mathrm{NO}_{2}$ & 50 & 46 & Mercury & $\mathrm{NO}_{2}, \mathrm{Air}$ & 495 & \pm 2 \\
\hline $\mathrm{NH}_{3}$ & 120 & 17 & Mercury & $\mathrm{NH}_{3}, \mathrm{~N}_{2}$ & 103.8 & \pm 2 \\
\hline
\end{tabular}

The exhaust gases from different locations were sampled by the MS through the stainless steel sampling lines which were heated to $190{ }^{\circ} \mathrm{C}$. Heating the sampling lines avoided the condensation of water vapor in the exhaust gas and the adsorption of gaseous emissions on the sampling lines [9].

Two UniNO ${ }_{x}$-sensors were installed on the production aftertreatment system, one each at the engine outlet and the SCR outlet, which measured $\mathrm{NO}_{\mathrm{x}}$ concentrations in the exhaust gas and the displayed the values through Calterm. The sensor consists of zirconia based multilayer sensing element made by NGK Insulators and a control unit made by Continental. A Delphi make sensor was also installed at the outlet of the SCR/SCRF® to measure $\mathrm{NH}_{3}$ slip. The specifications of the sensors are given in Table 3.11.

Table 3.11: Specification $\mathrm{NO}_{x}$ and $\mathrm{NH}_{3}$ sensor on production aftertreatment system

\begin{tabular}{|l|l|l|l|l|l|}
\hline Component & Range & Resolution & Accuracy & $\begin{array}{l}\text { Voltage } \\
\text { Range }\end{array}$ & $\begin{array}{l}\text { Operating } \\
\text { Temperature }\end{array}$ \\
\hline$[-]$ & {$[-]$} & {$[\mathbf{m s}]$} & {$[\%]$} & {$[\mathbf{V}]$} & {$\left[{ }^{\circ} \mathbf{C}\right]$} \\
\hline $\mathrm{NO}_{\mathrm{x}}$ Sensor & $\begin{array}{l}0-1500 \\
\text { ppm }\end{array}$ & $0.1 \mathrm{ppm}$ & \pm 10 & $12-32$ & $100-800$ \\
\hline $\mathrm{NH}_{3}$ Sensor & $\begin{array}{l}0-1500 \\
\mathrm{ppm}\end{array}$ & $0.1 \mathrm{ppm}$ & \pm 10 & $13.5-32$ & $200-500$ \\
\hline $\begin{array}{l}\lambda \text { Sensor, } \mathrm{O}_{2} \\
(\text { linear })\end{array}$ & $\begin{array}{l}12- \\
21 \%\end{array}$ & $0.10 \%$ & $\begin{array}{l} \pm 0.3- \\
\pm 1.4\end{array}$ & 24 & $100-800$ \\
\hline
\end{tabular}




\subsubsection{Particulate Matter (PM)}

The concentration of PM was measured by performing hot sampling (without dilution) from the engine exhaust flow using a dry gas meter and a manual sampling train (Made by Anderson Instruments Inc.). The PM was deposited by passing the sampled raw exhaust through an $\mathrm{A} / \mathrm{E}$ type glass fiber filter. The $\mathrm{PM}$ concentration in the engine exhaust was determined by recording the pre and post sampling weights of the glass fiber filter. The detailed information about PM sampling procedure and the instrument is given in reference $[3,7]$.

\subsubsection{Weighing Balance for SCRF®}

PM was deposited in the SCRF® during passive oxidation tests (configuration1) and $\mathrm{NO}_{\mathrm{x}}$ experimental tests (configuration 2) with PM loading of 2 and $4 \mathrm{~g} / \mathrm{L}$ in the SCRF®. The PM loading was performed in stages, and to determine the PM retained in the SCRF®, it was weighed four times during a test for configuration 1 and three times for configuration 2, which is discussed in detail in sections 3.6.5 and 3.6.6. The weight of the SCRF® was used to determine the PM mass retained during that stage of the test [3] and the procedure used to calculate the PM mass is described in section 3.6.7. The specifications of the weighing balance are given in Table 3.12. The detailed procedure to weigh the SCRF® is discussed in reference [3].

Table 3.12: Specifications of the weighing balance used to weigh the SCRF®

\begin{tabular}{|c|l|}
\hline Manufacturer & Ohaus \\
\hline Model & Ranger \\
\hline Capacity & $35,000 \mathrm{~g}$ \\
\hline Certified Readability & $\pm 1.0 \mathrm{~g}$ \\
\hline Readability & $\pm 0.1 \mathrm{~g}$ \\
\hline Linearity & $\pm 0.3 \mathrm{~g}$ \\
\hline
\end{tabular}

\subsection{Test Matrices and Test Procedures}

The primary objective of conducting the $\mathrm{NO}_{\mathrm{x}}$ reduction tests on the production-2013$\mathrm{SCR}$ and the $\mathrm{SCRF}{ }^{\circledR}$ is to acquire the data to calibrate the 1-D SCR model (developed at MTU) and the SCR-F model (being developed at MTU). The inlet and outlet 
$\mathrm{SCR} / \mathrm{SCRF}{ }^{\circledR}$ measurements of exhaust temperature, exhaust flow rate, $\mathrm{NO}, \mathrm{NO}_{2}$ and $\mathrm{NH}_{3}$ concentrations at a variety of test conditions were required to calibrate the models. In addition, the gas temperature in the substrate and the pressure drop across the SCRF® were also needed for calibration of the SCR-F model. Hence, the engine test conditions were selected to cover a wide range of $\mathrm{SCR} / \mathrm{SCRF}{ }^{\circledR}$ inlet exhaust temperature, space velocity, $\mathrm{NO}_{\mathrm{x}}$ and $\mathrm{NO}_{2} / \mathrm{NO}_{\mathrm{x}}$ ratio.

\subsubsection{Test Matrix for Configuration 1}

The schematic of several stages in the test procedure of a passive oxidation (PO) test with urea dosing is shown in Figure 3.8. The test procedure was adopted by modifying the procedures developed by references $[3,82]$.

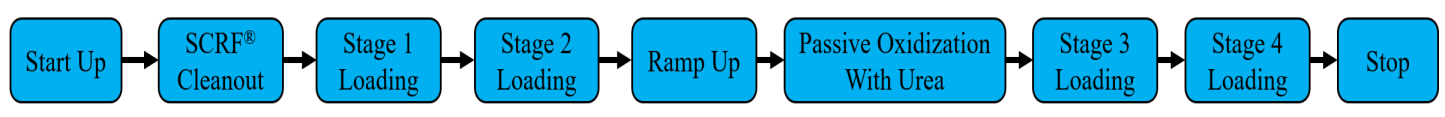

Figure 3.8: Stages of a passive oxidation test with urea dosing with configuration 1 [1]

The first two stages are loading stages where the SCRF® is loaded with PM to a target value of $2 \pm 0.2 \mathrm{~g} / \mathrm{L}$. The loaded PM is oxidized in the PO stage, during which the urea dosing is performed. PO stage is followed by Stage 3 and Stage 4, which provide the post oxidation filter loading characteristics. The detailed procedure for passive oxidation test with urea dosing in described in reference [1]. The passive oxidation with urea dosing was obtained for five different Test Points and two repeat points. The test matrix for passive oxidation with urea injection is given in Table 3.13.

The primary objective of this configuration was to determine the kinetics of $\mathrm{NO}_{2}$ assisted passive oxidation $(\mathrm{PO})$ of $\mathrm{PM}$ in the $\mathrm{SCRF}{ }^{\circ}$, without and with urea dosing during the PO. The urea dosing was performed to study the effect of $\mathrm{NO}_{\mathrm{x}}$ reduction on passive oxidation of PM in the SCRF ${ }^{\circledR}$ and vice-versa. The $\mathrm{NO}_{\mathrm{x}}$ reduction data obtained from the passive oxidation with urea dosing was analyzed and will be discussed in Chapter 4 . 
Table 3.13: Test matrix for passive oxidation with urea dosing with configuration 1 [1]

\begin{tabular}{|c|c|c|c|c|c|c|c|c|}
\hline Test Point & Speed & Load & $\begin{array}{c}\text { Exhaust } \\
\text { Flowrate }\end{array}$ & $\begin{array}{c}\text { SCRF® } \\
\text { Space } \\
\text { Velocity }\end{array}$ & $\begin{array}{c}\text { SCRF® } \\
\text { Inlet } \\
\text { Temp. }\end{array}$ & $\begin{array}{c}\text { PM into } \\
\text { SCRF }\end{array}$ & $\begin{array}{c}\mathbf{N O}_{\mathbf{2}} \\
\text { into } \\
\text { SCRF® }\end{array}$ & $\begin{array}{c}\text { NO } \\
\text { into } \\
\text { SCRF }\end{array}$ \\
\hline$[-]$ & {$[$ RPM] } & {$[$ N.m] } & {$[\mathbf{k g} / \mathbf{m i n}]$} & {$[\mathbf{k} / \mathbf{h r}]$} & {$\left[{ }^{\circ} \mathbf{C}\right]$} & {$[\mathbf{m g} / \mathbf{s c m}]$} & {$[\mathbf{p p m}]$} & {$[\mathbf{p p m}]$} \\
\hline A & 1300 & 302 & 5.6 & 16.8 & 265 & 2.3 & 304 & 590 \\
\hline C & 1402 & 544 & 6.8 & 20.2 & 340 & 2.8 & 301 & 689 \\
\hline E & 1199 & 653 & 7.0 & 20.8 & 344 & 2.2 & 653 & 1635 \\
\hline B & 900 & 456 & 3.6 & 10.6 & 266 & 1.8 & 821 & 1867 \\
\hline B Rpt & 902 & 449 & 3.7 & 11.0 & 256 & 1.7 & 758 & 1798 \\
\hline D & 2099 & 594 & 12.3 & 36.8 & 368 & 3.0 & 171 & 505 \\
\hline D Rpt & 2098 & 594 & 12.5 & 37.4 & 365 & 3.1 & 191 & 497 \\
\hline
\end{tabular}

\subsubsection{Test Matrix for $\mathrm{NO}_{\mathrm{x}}$ Experimental Tests (Production-2013-SCR and Configuration 2)}

Eight Test Points were selected that span the SCR/SCRF® inlet temperature from 200 to $450^{\circ} \mathrm{C}$ with space velocity and $\mathrm{NO}_{\mathrm{x}}$ ranging from 12.0 to $45.2 \mathrm{k} / \mathrm{hr}$ and 300 to $1700 \mathrm{ppm}$ respectively. The Test Points were chosen based on the engine maps for the ISB 2013 engine and were validated by running the engine at the specified speed-load and collecting the exhaust and gaseous emission data. The Test Points and important exhaust parameters for the $\mathrm{NO}_{\mathrm{x}}$ reduction tests with the SCR and the SCRF® in configuration 2 are given in Table 3.14. The Test Points at temperatures lower than $200{ }^{\circ} \mathrm{C}$ were not selected to avoid potential urea deposition on the catalyst and the exhaust pipe. Seven Test Points were completed for the production SCR, excluding Test Point 7 (due to malfunctioning of the urea dosing system). The $\mathrm{NO}_{\mathrm{x}}$ reduction performance of the SCRF® was evaluated without and with 2 and $4 \mathrm{~g} / \mathrm{L}$ PM loading in the SCRF®. The Test Points marked with “*” in Table 3.14 (Test Points 1, 3, 6 and 8) were run and were selected on the basis of the range of the SCRF® inlet temperatures, space velocities and inlet $\mathrm{NO}_{\mathrm{x}}$ concentrations. 
Table 3.14: Test matrix for $\mathrm{NO}_{\mathrm{x}}$ reduction tests for the production-2013-SCR and the $\mathrm{SCRF}{ }^{\circledR}$ with configuration 2

\begin{tabular}{|c|c|c|c|c|c|c|c|c|}
\hline $\begin{array}{c}\text { Test } \\
\text { Point }\end{array}$ & Speed & Torque & $\begin{array}{c}\text { Exhaust } \\
\text { Flow } \\
\text { rate }\end{array}$ & $\begin{array}{c}\text { SCRF }{ }^{\circledR} \text { Inlet } \\
\text { Temperature }\end{array}$ & $\begin{array}{c}\text { SCRF } \\
\text { Std. } \\
\text { Space } \\
\text { Vel. }\end{array}$ & $\begin{array}{c}\text { SCRF } \\
\text { Inlet } \\
\mathbf{N O}_{\mathbf{x}}\end{array}$ & $\begin{array}{c}\text { SCRF® } \\
\text { Inlet } \\
\mathbf{N O}_{\mathbf{2}} / \mathbf{N O}_{\mathbf{x}}\end{array}$ & $\begin{array}{c}\text { SCRF® } \\
\text { Inlet } \\
\mathbf{N O}_{\mathbf{2}}\end{array}$ \\
\hline$[-]$ & {$[\mathbf{R P M}]$} & {$[\mathbf{N}-\mathbf{m}]$} & {$[\mathbf{k g} / \mathbf{m i n}]$} & {$\left[{ }^{\circ} \mathbf{C}\right]$} & {$[\mathbf{k} / \mathbf{h r}]$} & {$[\mathbf{p p m}]$} & {$[-]$} & {$[\mathbf{p p m}]$} \\
\hline $1^{*}$ & 1200 & 203 & 4.9 & 208 & 14.6 & 492 & 0.61 & 301 \\
\hline 2 & 1650 & 203 & 6.5 & 231 & 19.4 & 306 & 0.6 & 184 \\
\hline $3^{*}$ & 2200 & 325 & 10.0 & 310 & 29.9 & 341 & 0.64 & 217 \\
\hline 4 & 2100 & 377 & 0.4 & 331 & 28.1 & 372 & 0.62 & 230 \\
\hline 5 & 1660 & 529 & 7.8 & 353 & 23.3 & 662 & 0.54 & 356 \\
\hline $6^{*}$ & 1200 & 580 & 6.4 & 354 & 19.1 & 1712 & 0.54 & 922 \\
\hline 7 & 2100 & 750 & 13.0 & 404 & 38.8 & 546 & 0.44 & 242 \\
\hline $8^{*}$ & 2400 & 813 & 16.0 & 455 & 47.8 & 596 & 0.39 & 233 \\
\hline
\end{tabular}

\subsubsection{Baseline Condition and Aftertreatment Clean-out}

The engine was run at $1660 \mathrm{RPM}$ and $475 \mathrm{~N}-\mathrm{m}$, hereafter referred as the "baseline condition", to ensure repeatability of the instrumentation and the engine. To start a test, the engine was slowly ramped up from the idling condition to the baseline condition. After the engine had stabilized, exhaust emission samples were collected at UDOC and DDOC to check the repeatability. Then the CPF inlet temperature was raised to $600 \pm 10$ ${ }^{\circ} \mathrm{C}$ by in-cylinder post fuel injection to oxidize PM deposited in the CPF/SCRF® and desorb the $\mathrm{NH}_{3}$ adsorbed on the $\mathrm{SCR} / \mathrm{SCRF}{ }^{\circledR}$ during the previous test. This is called the "aftertreatment clean-out". Fuel dosing was stopped after the pressure drop across the $\mathrm{CPF} / \mathrm{SCRF}{ }^{\circledR}$ had stabilized indicating that the rate of oxidation of PM is equal to the rate of $\mathrm{PM}$ being deposited on the $\mathrm{CPF} / \mathrm{SCRF}{ }^{\circledR}$. This phenomenon is also known as the balance point. A similar procedure was also performed by previous researchers at MTU $[3,9,7,83,84]$.

\subsubsection{NO $\mathrm{N}_{\mathrm{x}}$ Experimental Tests: SCR}

The $\mathrm{NO}_{\mathrm{x}}$ reduction test procedure for the SCR was modified and adapted from reference [9]. It consists of three steps. In the first two steps, baseline condition and aftertreatment cleanout were performed to have a common start state for the experiments. In the third step, the engine was run at the $\mathrm{NO}_{\mathrm{x}}$ reduction Test Point and stabilized. The emission 
samples were collected at UDOC, DDOC, USCR and DSCR to measure $\mathrm{NO}, \mathrm{NO}_{2}$ and $\mathrm{NH}_{3}$. Then the urea dosing cycle was performed and gaseous emission samples were sampled across the SCR to measure the SCR performance. The urea dosing cycle for the production-2013-SCR is shown in Figure 3.9. The urea injection was varied to achieve the targeted ANR of $0.3,0.5,0.8,1.0,1.2,1.0$ repeat, 0.8 repeat and 1.2 repeat. The ANR was varied from 0.3 to 1.2 to collect data to calibrate the SCR kinetics for modeling and predicting $\mathrm{NO}, \mathrm{NO}_{2}$ and $\mathrm{NH}_{3}$ concentrations at the $\mathrm{SCR}$ outlet. The ANR 1.0 repeat and 0.8 repeat were performed to validate the repeatability of the production-2013-SCR performance. The ANR 1.2 repeat was performed to collect data to calculate the $\mathrm{NH}_{3}$ storage on the production-2013-SCR.

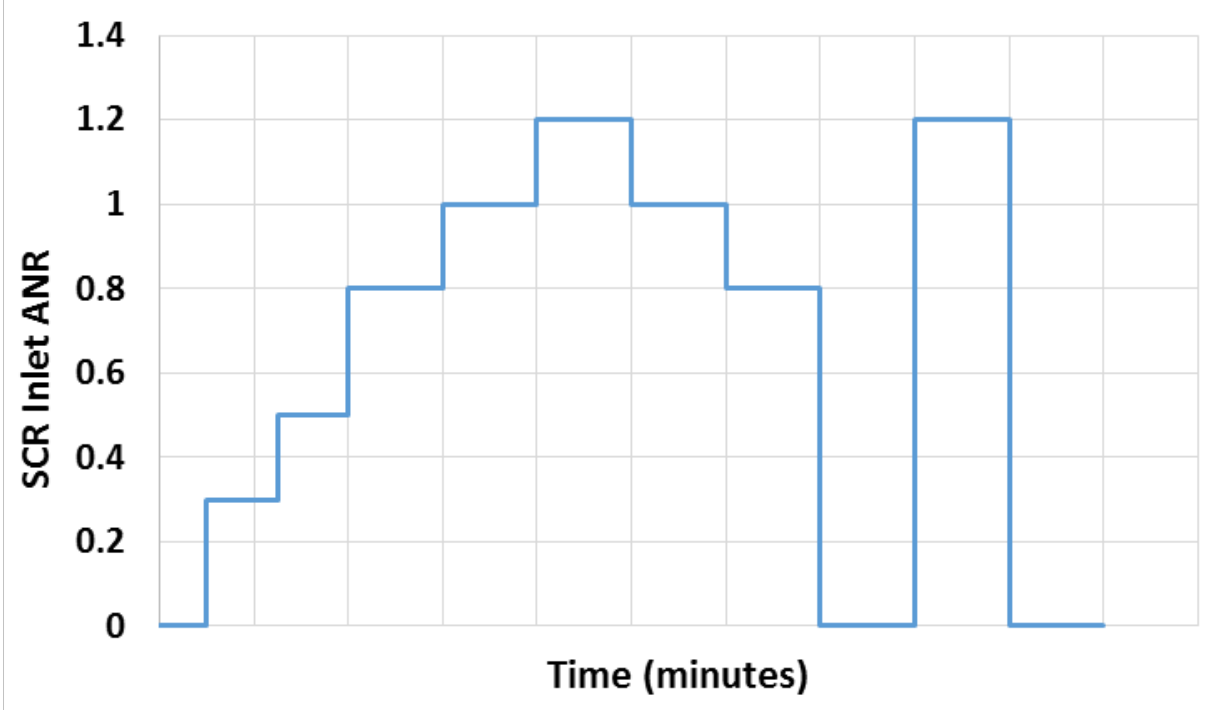

Figure 3.9: Urea dosing cycle for the production-2013-SCR

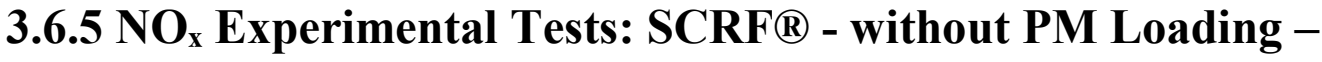 Configuration 2}

The test procedure to perform the $\mathrm{NO}_{\mathrm{x}}$ reduction in the $\mathrm{SCRF}{ }^{\circledR}$, without PM loading, was similar to the test procedure for the production-2013-SCR. The emission data were collected at the baseline condition to check the repeatability and then the aftertreatment clean-out was performed by increasing the SCRF® inlet temperature to $600 \pm 10{ }^{\circ} \mathrm{C}$. 
After that, the engine was stabilized at the $\mathrm{NO}_{\mathrm{x}}$ reduction Test Point. The Test Points in Table 3.11, highlighted with “*” were run for the SCRF®. Then the urea dosing cycle was performed and gaseous emissions were sampled at the inlet and outlet of the SCRF®. The schematic $\mathrm{NO}_{\mathrm{x}}$ reduction tests on the SCRF® without PM loading is shown in Figure 3.10. The production CPF used during the baseline tests was placed upstream of the SCRF® as shown in Figure 3.5, which filtered the PM produced by the engine and ensured minimum PM deposition in the SCRF®.

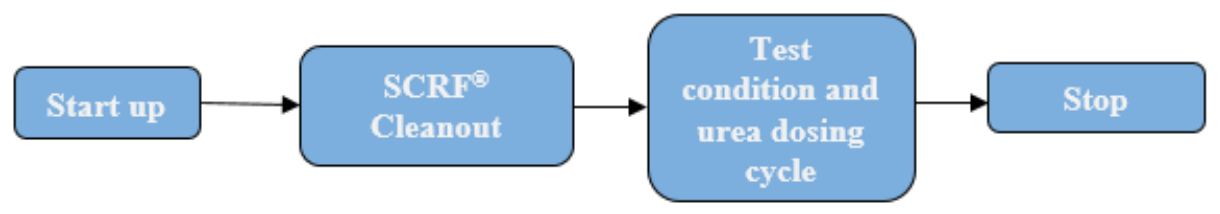

Figure 3.10: Schematic for $\mathrm{NO}_{\mathrm{x}}$ reduction test on $\mathrm{SCRF}{ }^{\circledR}$ without PM Loading

The urea dosing cycle was modified to reduce the test duration. Since 0.3 and 0.5 ANR are not performed during the actual engine operation in a vehicle, they were removed to modify the urea dosing cycle. The modified urea dosing cycle helped to maintain constant PM in the SCRF® during the tests with the target PM loading of 2 and $4 \mathrm{~g} / \mathrm{L}$. The modified urea dosing cycle is shown in Figure 3.11. The urea injection was varied to achieve the targeted ANR of $0.8,1.0,1.2$ and 1.2 repeat. The ANR was varied from 0.8 to 1.2 to collect data to calibrate the SCR kinetics for the SCRF® to be used in the SCRF model calibration. The ANR 1.2 repeat was performed to collect data to calculate the $\mathrm{NH}_{3}$ storage on the SCRF®, with 0,2 and $4 \mathrm{~g} / \mathrm{L}$ PM loading. 


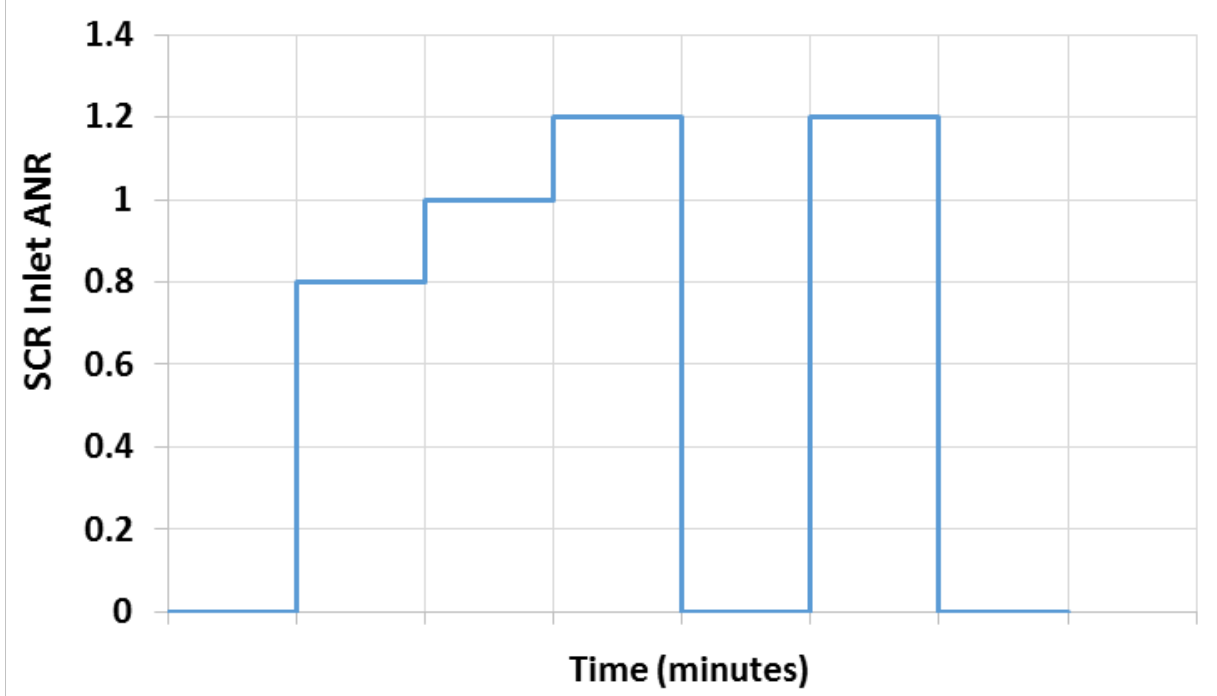

Figure 3.11: Modified urea dosing cycle for the SCRF®

\subsection{6 $\mathrm{NO}_{\mathrm{x}}$ Experimental Tests: SCRF® - with PM Loading (2 g/L) - Configuration 2}

During these tests, the SCRF® was loaded to $2.0 \pm 0.2 \mathrm{~g} / \mathrm{L}$ of PM in two stages, namely Stage 1 and Stage 2. The test procedure started with the baseline condition and the aftertreatment clean-out.

Stage 1 Loading (S1): After the completion of the clean-out procedure, the engine speed and load were changed to $2400 \mathrm{RPM}$ and $200 \mathrm{~N}-\mathrm{m}$ at a fuel rail pressure reduced from 1500 to 1050 bar ( $30 \%$ reduction). This stage is called Stage 1 (S1) and the engine operating point is called Loading condition. The purpose of this stage is to stabilize the SCRF® inlet temperature at the Loading condition, since the weight of the wall flow filter varies with the temperature of the filter. The $\mathrm{S} 1$ was run for 30 minutes and then the engine was shut down to weigh the SCRF®.

Stage 2 Loading (S2): On completion of the SCRF® weighing procedure, aftertreatment components were assembled and the engine was warmed up using the exhaust bypass line (Figure 3.3). After the engine stabilized at the Loading condition, the exhaust flow was 
switched to the trap line (Figure 3.3) and the Stage 2 Loading (S2) duration was started. The purpose of this stage is to load the SCRF® to the targeted PM loading of $2.0 \pm 0.2$ $\mathrm{g} / \mathrm{L}$. The Stage 2 Loading (S2) was run for 330 minutes and at the end the engine was shut down to weigh the SCRF®. The detailed $\mathrm{S} 1$ and $\mathrm{S} 2$ procedures are available in reference $[3,1]$. The exhaust parameters are given in Table 3.15 .

Table 3.15: Exhaust parameters during the Loading Condition

\begin{tabular}{|c|c|c|c|c|c|c|}
\hline Speed & Load & $\begin{array}{c}\text { Exhaust } \\
\text { Flowrate }\end{array}$ & $\begin{array}{c}\text { SCRF® Inlet } \\
\text { Temperature }\end{array}$ & $\begin{array}{c}\text { SCRF }{ }^{\circledR} \\
\text { Inlet } \mathbf{N O}_{2}\end{array}$ & $\begin{array}{c}\text { SCRF }{ }^{\circledR} \\
\text { Inlet PM }\end{array}$ & $\begin{array}{c}\mathrm{NO}_{2}: \text { PM Mass } \\
\text { Ratio }\end{array}$ \\
\hline$[\mathbf{R P M}]$ & {$[\mathbf{N}-\mathbf{m}]$} & {$[\mathrm{kg} / \mathbf{m i n}]$} & {$\left[{ }^{\mathbf{0}} \mathbf{C}\right]$} & {$[\mathbf{p p m}]$} & {$[\mathrm{mg} / \mathbf{s c m}]$} & {$\left[\mathrm{NO}_{\mathbf{2}} / \mathbf{P M}\right]$} \\
\hline 2400 & 200 & 11.2 & 274 & 72 & 11.2 & 11.6 \\
\hline
\end{tabular}

The Test Points 1 and 3 have low SCRF® inlet temperature $\left(218\right.$ and $\left.304^{\circ} \mathrm{C}\right)$, hence less PM would be oxidized during the urea dosing cycle than Test Points 6 and 8 . There will be higher PM oxidation at Test Point 6 and Test Point 8 due to higher SCRF® inlet temperature $\left(350\right.$ to $\left.450^{\circ} \mathrm{C}\right)$. Hence, to accumulate $\mathrm{PM}$ during the $\mathrm{NO}_{\mathrm{x}}$ reduction test condition, the CPF upstream of SCRF® was needed to be replaced with a spacer. To have consistency in the test procedure, the CPF was removed during all the data collection for the Test Points. The schematic diagram for these tests is given in Figure 3.12 .

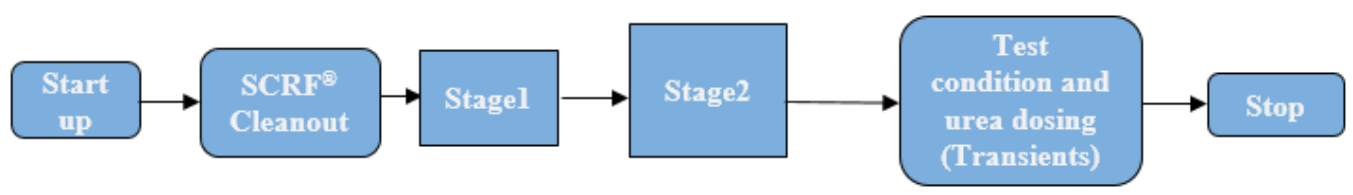

Figure 3.12: Schematic for effect of PM Loading on $\mathrm{SCRF}{ }^{\mathrm{N}} \mathrm{NO}_{\mathrm{x}}$ reduction

Test Point - W/PM Stage: The pressure drop across the SCRF® for the Test Point 1 is plotted in Figure 3.13. The SCRF® was loaded with PM in Loading Stages S1 and S2. Then the test condition for $\mathrm{NO}_{\mathrm{x}}$ reduction is run which is labeled as Test Point 1-W/PM. During the Test Point 1-W/PM the urea dosing cycle (Figure 3.11) was performed continuously and the test condition was completed without adding PM to the SCRF®, 
since the rate of PM addition and the rate of PM oxidation are about equal. It can be observed that the pressure drop is constant during the $\mathrm{NO}_{\mathrm{x}}$ reduction test condition which indicates that the PM in the SCRF ${ }^{\circledR}$ is constant. During the Test Point 1-W/PM stage, emission samples were collected at UDOC and USCRF® in the beginning and then switched to DSCRF ${ }^{\circledR}$ to measure the $\mathrm{NO}, \mathrm{NO}_{2}$ and $\mathrm{NH}_{3}$ concentrations during the urea dosing cycle. The USCRF® and DSCRF® values were used to evaluate the performance of the SCRF®. The same test procedure was followed for Test Point 3-W/PM.

The pressure drop across the Test Point 8 is plotted in Figure 3.14. It can be observed that during Test Point 8-W/PM-I, Test Point 8-W/PM-II and Test Point 8-W/PM-III, the pressure drop curves across the SCRF® is steep, which is due to the high PM oxidation rate. Hence, it was decided to run the loading condition to redeposit PM in the SCRF® to maintain PM loading close to $2 \mathrm{~g} / \mathrm{L}$. These stages are labeled as Repeat Loading-I and Repeat Loading-II. During the Test Point 8-W/PM-I, emission samples were collected at UDOC, DDOC, USCRF® and DSCRF ${ }^{\circledR}$. The same test procedure was followed for Test Point 6 with PM.

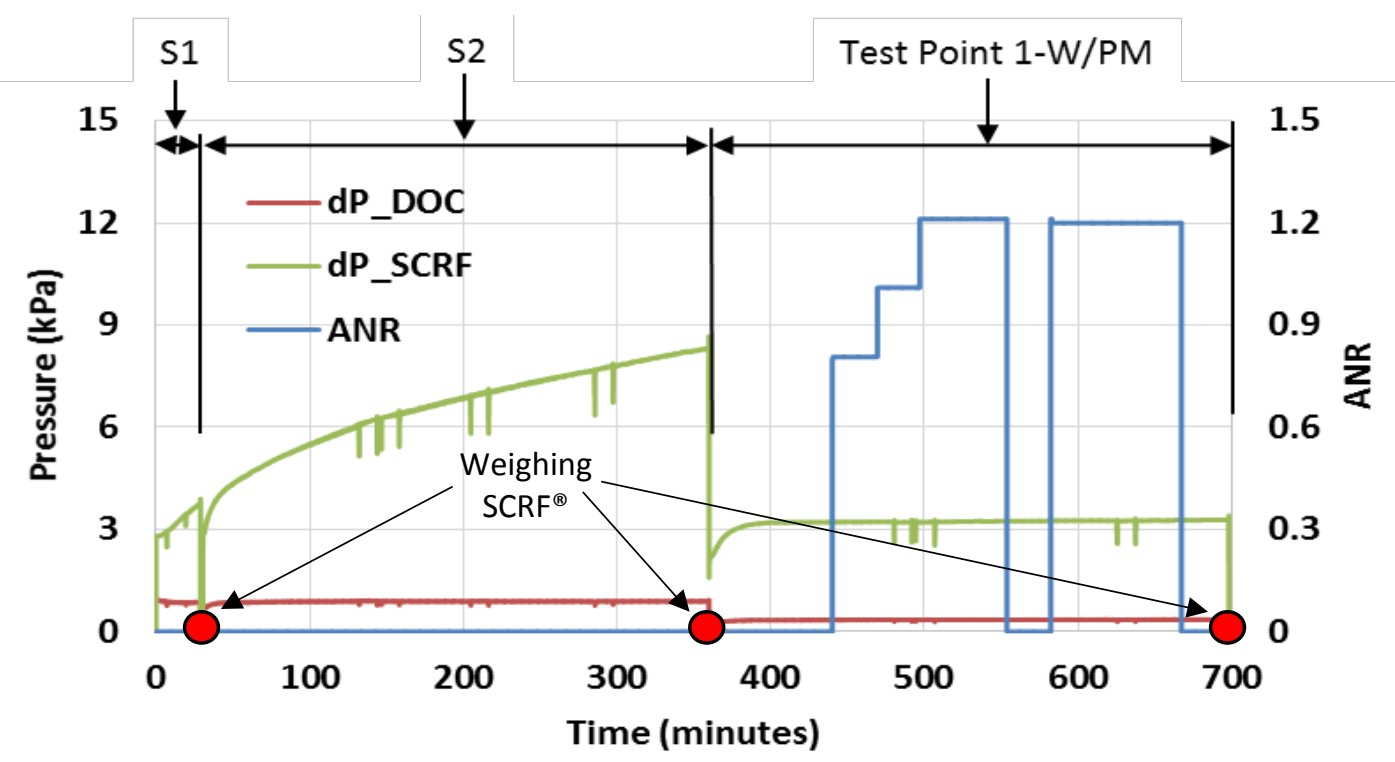

Figure 3.13: Delta Pressure across the SCRF® for Configuration 2 - Test Point 1 with $\mathrm{PM}$ 


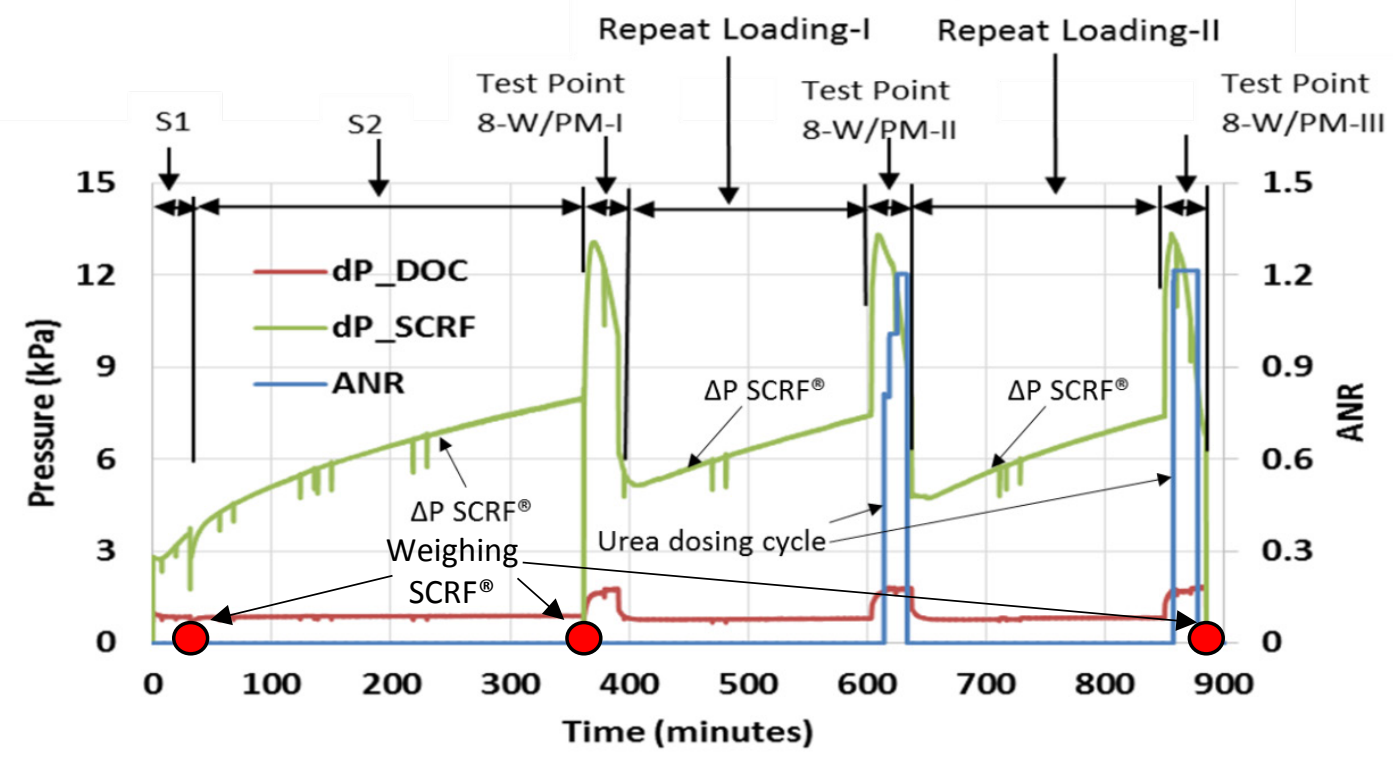

Figure 3.14: Delta Pressure across the SCRF® for Configuration 2 - Test Point 1 with PM

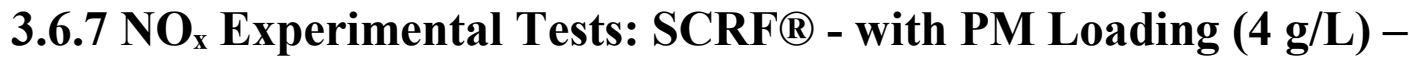 Configuration 2}

The engine operating conditions for the Loading condition were modified to accumulate the targeted PM loading of $4 \mathrm{~g} / \mathrm{L}$ in the SCRF®. The exhaust parameters of the modified loading condition are given in the Table 3.16. The fuel rail pressure was reduced by $50 \%$ for $4 \mathrm{~g} / \mathrm{L}$ of PM loading in comparison to $30 \%$ for $2 \mathrm{~g} / \mathrm{L}$. The reduced rail pressure was 750 bar.

Table 3.16: Engine and exhaust parameters of the Loading Condition

\begin{tabular}{|c|c|c|c|c|c|c|c|}
\hline $\begin{array}{c}\text { PM } \\
\text { Loadin } \\
\text { g }\end{array}$ & Speed & Load & $\begin{array}{c}\text { Exhaust } \\
\text { Flow } \\
\text { Rate }\end{array}$ & $\begin{array}{c}\text { SCRF® Inlet } \\
\text { Temperature }\end{array}$ & $\begin{array}{c}\text { SCRF } \\
\text { ( Inlet } \\
\mathbf{N O}_{\mathbf{2}}\end{array}$ & $\begin{array}{c}\text { SCRF® } \\
\text { Inlet PM }\end{array}$ & $\begin{array}{c}\mathbf{N O}_{\mathbf{2}}: \mathbf{P M} \\
\text { Mass Ratio }\end{array}$ \\
\hline$[\mathbf{g} / \mathbf{L}]$ & {$[\mathbf{R P M}]$} & {$[\mathbf{N} \cdot \mathbf{m}]$} & {$[\mathbf{k g} / \mathbf{m i n}]$} & {$\left[{ }^{\circ} \mathbf{C}\right]$} & {$[\mathbf{p p m}]$} & {$[\mathbf{m g} / \mathbf{s c m}]$} & {$\left[\mathbf{N O}_{\mathbf{2}} / \mathbf{P M}\right]$} \\
\hline 2 & 2400 & 200 & 11.2 & 274 & 72 & 11.2 & 11.6 \\
\hline 4 & 2400 & 201 & 11.1 & 292 & 40 & 20.8 & 3.6 \\
\hline
\end{tabular}


The test procedure for $\mathrm{NO}_{\mathrm{x}}$ reduction tests in $\mathrm{SCRF}{ }^{\circledR}$ with the $\mathrm{PM}$ loading of $4 \mathrm{~g} / \mathrm{L}$ was similar to the tests with the PM loading of $2 \mathrm{~g} / \mathrm{L}$. The Test Points 1 and 3 had two PM loading stages (S1 and S2) followed by the urea dosing cycle. The Test Points 6 and 8 had four PM loading stages (S1, S2, Repeat Loading-I and Repeat Loading-II) with intermediate urea dosing cycle.

\subsubsection{Calculation of PM Mass Retained and Nitrogen Balance}

The following terms and equations are used in the analysis of the data. The terms used in the equations are described below with a brief description.

\section{PM Mass Retained}

The SCRF® substrate was weighed three times during the $\mathrm{NO}_{\mathrm{x}}$ experimental tests with PM loading of 2 and $4 \mathrm{~g} / \mathrm{L}$ in configuration 2 as shown in Figures 3.13 and 3.14. The SCRF ${ }^{\circledR}$ mass measurements include the mass of the substrate and the PM retained in the filter. These mass measurements and PM concentrations at the inlet and outlet of the SCRF® are used to calculate the PM mass retained in the SCRF® $\left(\mathrm{PM}_{\text {Retained }}\right)$ at the end of each stage. The equations used to calculate the $\mathrm{PM}_{\text {Retained }}$ are described in the following section. The equations and assumptions are discussed in more detail in Appendix C of reference [1].

$\mathrm{C}_{\mathrm{in}} \quad$ The average PM concentration in the exhaust in $\mathrm{mg} / \mathrm{scm}$ at the inlet of the $\mathrm{SCRF} \circledast$ for the stage.

$\mathrm{PM}_{\mathrm{In}} \quad$ Mass of PM in grams produced by the engine and flows into the substrate during the stage. The mass of PM that goes into the SCRF® is calculated based on the flowrate of exhaust, PM concentration, and the time of the stage.

$$
P M_{I n}=C_{I n} * \frac{\text { Exhaust Flow Rate }}{\rho_{\text {Std }}} * \frac{\text { Stage Duration }}{1000}
$$

Where $\mathrm{C}_{\text {in }}$ is in $\mathrm{mg} / \mathrm{scm}$, exhaust flow rate is in $(\mathrm{kg} / \mathrm{min})$, stage duration is duration of the stage in (minutes) and $\rho_{\text {std }}$ is exhaust density taken to be $1.18 \mathrm{~kg} / \mathrm{m} 3$ (at $25^{\circ} \mathrm{C}$ and $101.3 \mathrm{kPa}$ ). 
PMout $\quad$ Mass of PM out of the $\mathrm{SCRF}^{\circledR}$ as a result of substrate filtration in grams. This includes PM that was filtered but not oxidized

$$
P M_{\text {Out }}=\left(1-\eta_{f}\right) * P M_{\text {In }}
$$

Where $\eta_{f}$ is the Filtration efficiency of the SCRF®. Only one downstream concentration is taken during the test in stage 2 , so an assumption is made that the filtration efficiency remains roughly constant after the cake layer forms. Appendix C in reference [1] discusses the assumption for filtration efficiency of stage 1 . The efficiency of the stage is given by:

$$
\eta_{f}=\frac{C_{I n}-C_{O u t}}{C_{I n}}
$$

PMstart Mass of PM in the filter at the beginning of the stage in grams.

PMRetained Mass of PM retained in the substrate at the end of the stage in grams. PM retained is a cumulative value, meaning the mass of PM at the end of the stage includes what was loaded from the previous stages.

$\mathrm{PM}_{\text {Available }} \quad$ The theoretical total PM in grams that is or will be available for oxidation during the stage.

$$
P M_{\text {Available }}=m_{\text {Start }}+P M_{\text {In }}
$$

PMoxidized Mass of PM oxidized during the stage in grams. It comes from the overall stage balance.

$$
P M_{\text {oxidized }}=P M_{\text {Start }}+P M_{\text {In }}-P M_{\text {Out }}-P M_{\text {Retained }} \quad \text { Eqn. } 3.5
$$

$\%$ PMOxidized The percentage of mass oxidized during the stage.

$$
\% P M_{\text {Oxidized }}=\frac{P M_{\text {Oxidized }}}{P M_{\text {Available }}} * 100
$$

PMLoading The cumulative loading of PM divided by the open volume of the SCRF ${ }^{\circledR}$ with units of $\mathrm{g} / \mathrm{L}$. The values are considered at the end of the stage.

$$
P M_{\text {Loading }}=\frac{P M_{\text {Retained }}}{V_{\text {Substrate }}}
$$




\section{Nitrogen Balance}

Inlet $\mathrm{NH}_{3} \quad$ The $\mathrm{NH}_{3}$ concentration in ppm at the inlet of the SCRF®.

Inlet $\mathrm{NH}_{3}=\frac{\text { DEF Flow Rate } * \rho_{D E F} * 0.325 * 2 * M W_{\text {Exhaust Gas }} * 1.02}{\text { Exhaust Flow Rate } * M W_{\text {Urea }}} \quad$ Eqn. 3.8

Where, DEF flow rate is obtained from Calterm $(\mathrm{ml} / \mathrm{s}), \rho_{D E F}$ is density of DEF taken to be $1080\left(\mathrm{~kg} / \mathrm{m}^{3)}\right.$ under room condition. The urea concentration of the DEF is $32.5 \%$ by weight. Molecular weight of the urea molecule is $60(\mathrm{~g} / \mathrm{gmol})$ and molecular weight of the exhaust is 28.96 (g/gmol). 1.02 denotes the $2 \%$ correction applied to the DEF flow rate recorded by Calterm, since the actual injection verified by conducting bucket test at various DEF flow rates is $2 \%$ higher than the measurements obtained from Calterm (See Appendix C).

ANR, also described as Target ANR is the ratio of the $\mathrm{NH}_{3}$ concentration (ppm) to the $\mathrm{NO}_{\mathrm{x}}$ concentration (ppm) at the inlet of the SCRF®.

$$
A N R=\frac{\text { Inlet } \mathrm{NH}_{3}}{\operatorname{Inlet} \mathrm{NO}_{\mathrm{x}}}
$$

Inlet $\mathrm{NH}_{3}$ concentration was calculated using Equation 3.8 and inlet $\mathrm{NO}_{\mathrm{x}}$ concentration was obtained by adding inlet $\mathrm{NO}$ and $\mathrm{NO}_{2}$ concentrations measured using $\mathrm{MS}$.

The $\mathrm{NO}_{\mathrm{x}}$ conversion efficiency was calculated using inlet and outlet $\mathrm{NO}_{\mathrm{x}}$ concentrations (ppm) as indicated in equation 3.10.

$N O_{x}$ Conversion efficiency $(\%)=\frac{\text { Inlet } N O_{x}-\text { outlet } N O_{x}}{\text { Inlet } N O_{x}} * 100$

Nitrogen Balance was performed using the $\mathrm{NO}, \mathrm{NO}_{2}$ and $\mathrm{NH}_{3}$ concentrations (ppm) at the inlet and outlet of the SCRF® to validate the data consistency. The nitrogen balance of $100 \pm 10 \%$ was considered to be a good agreement since the concentration of $\mathrm{N}_{2} \mathrm{O}$ and 
isocyanic acid and cyanuric acid (by products of incomplete urea decomposition) were not measured.

Nitrogen Balance $(\%)=\left\{1-\frac{\text { Inlet } \mathrm{NH}_{3}-\left[\left(\text { Inlet NO} \mathrm{O}_{\mathrm{x}}-\text { Outlet } \mathrm{NO}_{\mathrm{x}}\right)+\mathrm{NH}_{3} \text { Slip }\right]}{\text { Inlet } \mathrm{NH}_{3}}\right\} * 100$ Eqn. 3.11

Where all the concentrations are in $\mathrm{ppm}$. The inlet and outlet $\mathrm{NO}_{\mathrm{x}}$ were measured using the MS and the $\mathrm{NH}_{3}$ slip out of the $\mathrm{SCRF}{ }^{\circledR}$ was measured using the sensor.

The values for various parameters such as the emission concentrations, PM concentrations, temperatures and exhaust flow rates recorded during the experiments were analyzed and the results will be discussed in detail in Chapter 4. 


\section{Chapter 4. Results and Discussion}

This chapter discusses the data and the results of the $\mathrm{NO}_{\mathrm{x}}$ reduction tests conducted with the production-2013-SCR and the SCRF®. The $\mathrm{NO}_{\mathrm{x}}$ reduction and $\mathrm{NH}_{3}$ storage performance of the production-2013-SCR was evaluated at seven Test Points (Table 3.14) as discussed in Chapter 3. This chapter also presents the results of 1-D SCR model calibration and comparison of the experimental and the simulation results for the seven test runs with the production-2013-SCR.

The $\mathrm{NO}_{\mathrm{x}}$ reduction performance of the SCRF® was evaluated with 2 and $4 \mathrm{~g} / \mathrm{L}$ PM and without PM at four different Test Points in configuration 2 (total twelve tests) and with PM at five different Test Points (Table 3.13) in configuration 1 (total seven tests including two repeat Test Points. The $\mathrm{NO}_{\mathrm{x}}$ reduction performance and the $\mathrm{NH}_{3}$ storage in the SCRF® and the production SCR are compared to study the difference in the performance of the SCRF® and the production-2013-SCR.

\subsection{NO $\mathrm{N}_{\mathrm{x}}$ Reduction in Production-2013-SCR (Baseline)}

The engine operating conditions and the important exhaust parameters during the seven $\mathrm{NO}_{\mathrm{x}}$ reduction tests for the production-2013-SCR1 are given in Table 4.1. The Test Points are arranged in the increasing order of SCR inlet temperature. It is seen that the Test Point 1 has the lowest SCR inlet temperature and the lowest standard space velocity, while Test Point 8 has the highest SCR inlet temperature and the highest standard space velocity. The $\mathrm{NO}_{2} / \mathrm{NO}_{\mathrm{x}}$ ratio varies between 0.22 and 0.48 .

The analysis of $\mathrm{NO}$ and $\mathrm{NO}_{2}$ values across the production-2013-SCR without urea injection are given in Table 4.2. The delta $\mathrm{NO}$ and $\mathrm{NO}_{2}$ values were calculated by subtracting the SCR outlet from the SCR inlet values as indicated in equations 4.1 and 4.2. Ideally, change in concentration of NO across the SCR (without urea injection) must be equal and opposite to the change in concentration of $\mathrm{NO}_{2}$ across the SCR (without urea injection), i.e. $\Delta \mathrm{NO}=-\left(\Delta \mathrm{NO}_{2}\right)$. In Table 4.2 it is observed that the $\mathrm{SCR}$ outlet $\mathrm{NO}_{2}$ concentration has increased and SCR outlet NO concentration has decreased for all the 
Test Points, which indicates that the Cu-zeolite SCR catalyst has a tendency to oxidize up to $20 \%$ of upstream $\mathrm{NO}$ to $\mathrm{NO}_{2}$.

$$
\begin{array}{lr}
\text { Delta } \mathrm{NO}=\text { SCR Inlet } \mathrm{NO}-\mathrm{SCR} \text { Oulet } \mathrm{NO} & \text { Eqn. } 4.1 \\
\text { Delta } \mathrm{NO}_{2}=\text { SCR Inlet } \mathrm{NO}_{2}-\text { SCR Outlet } \mathrm{NO}_{2} & \text { Eqn. } 4.2
\end{array}
$$

Table 4.1: Engine and exhaust conditions at SCR inlet for $\mathrm{NO}_{\mathrm{x}}$ reduction tests

\begin{tabular}{|c|c|c|c|c|c|c|c|c|}
\hline $\begin{array}{c}\text { Test } \\
\text { Point }\end{array}$ & $\begin{array}{c}\text { SCR } \\
\text { Inlet } \\
\text { Temp. }\end{array}$ & $\begin{array}{c}\text { SCR } \\
\text { Inlet } \\
\text { NO }\end{array}$ & $\begin{array}{c}\text { SCR } \\
\text { Outlet } \\
\text { NO }\end{array}$ & $\Delta \mathrm{NO}$ & $\begin{array}{l}\text { SCR } \\
\text { Inlet } \\
\mathrm{NO}_{2}\end{array}$ & $\begin{array}{c}\mathrm{SCR} \\
\text { Outlet } \\
\mathrm{NO}_{2}\end{array}$ & $\begin{array}{c}\Delta \\
\mathbf{N O}_{2}\end{array}$ & $\begin{array}{c}\text { Out } / \text { In } \\
\mathrm{NO}_{2}\end{array}$ \\
\hline$[-]$ & {$\left[{ }^{\circ} \mathbf{C}\right]$} & [ppm] & [ppm] & [ppm] & [ppm] & [ppm] & [ppm] & {$[-]$} \\
\hline 1 & 219 & 470 & 439 & 31 & 178 & 189 & -11 & 1.06 \\
\hline 2 & 238 & 177 & 173 & 3 & 102 & 107 & -4 & 1.04 \\
\hline 3 & 307 & 199 & 184 & 16 & 91 & 109 & -17 & 1.19 \\
\hline 4 & 327 & 185 & 172 & 12 & 158 & 173 & -15 & 1.10 \\
\hline 5 & 354 & 325 & 286 & 40 & 227 & 253 & -27 & 1.12 \\
\hline 6 & 352 & 1045 & 926 & 119 & 685 & 847 & -162 & 1.24 \\
\hline 8 & 447 & 443 & 416 & 26 & 99 & 115 & -16 & 1.17 \\
\hline
\end{tabular}

\begin{tabular}{|c|c|c|c|c|c|c|c|}
\hline \multirow{2}{*}{$\begin{array}{c}\text { Test } \\
\text { Point }\end{array}$} & Speed & Load & $\begin{array}{c}\text { Exhaust } \\
\text { Flow } \\
\text { Rate }\end{array}$ & $\begin{array}{c}\text { SCR } \\
\text { Inlet } \\
\text { Temp. }\end{array}$ & $\begin{array}{c}\text { Std. } \\
\text { Space } \\
\text { velocity }\end{array}$ & $\begin{array}{c}\text { SCR } \\
\text { Inlet } \\
\mathbf{N O}_{\mathbf{x}}\end{array}$ & $\begin{array}{c}\text { SCR } \\
\text { Inlet } \\
\mathbf{N O}_{\mathbf{2}} / \mathbf{N O}_{\mathbf{x}}\end{array}$ \\
\cline { 2 - 8 }$[\mathbf{[ R P M}]$ & {$[\mathbf{N m}]$} & {$[\mathbf{k g} / \mathbf{m i n}]$} & {$\left[{ }^{\circ} \mathbf{C}\right]$} & {$[\mathbf{k} / \mathbf{h r}]$} & {$[\mathbf{p p m}]$} & {$[-]$} \\
\hline $\mathbf{1}$ & 1200 & 204 & 4.4 & 219 & 12.0 & 648 & 0.27 \\
\hline $\mathbf{2}$ & 1650 & 189 & 6.3 & 238 & 17.1 & 279 & 0.37 \\
\hline $\mathbf{3}$ & 2201 & 324 & 9.7 & 307 & 26.4 & 291 & 0.31 \\
\hline $\mathbf{4}$ & 2100 & 376 & 9.7 & 327 & 26.5 & 342 & 0.46 \\
\hline $\mathbf{5}$ & 1659 & 531 & 7.8 & 354 & 21.3 & 552 & 0.41 \\
\hline $\mathbf{6}$ & 1198 & 575 & 6.2 & 352 & 16.9 & 1730 & 0.40 \\
\hline $\mathbf{8}$ & 2400 & 826 & 16.4 & 447 & 44.7 & 542 & 0.18 \\
\hline
\end{tabular}

Table 4.2: $\mathrm{NO}$ and $\mathrm{NO}_{2}$ concentrations across the production-2013-SCR without urea injection 
The $\mathrm{NO}, \mathrm{NO}_{2}$ and $\mathrm{NH}_{3}$ concentrations and the $\mathrm{NO}_{\mathrm{x}}$ reduction performance of the production-2013-SCR at an ANR of 1.0 are given in Table 4.3. It is observed that the $\mathrm{NO}_{\mathrm{x}}$ conversion efficiency increases with increase in the SCR inlet temperature until $350^{\circ} \mathrm{C}$ and decreases thereafter. $\mathrm{NO}_{\mathrm{x}}$ conversion efficiency higher than $95 \%$ was observed in the range of 300 to $350^{\circ} \mathrm{C}$. At temperatures below $250^{\circ} \mathrm{C}$, the urea to $\mathrm{NH}_{3}$ conversion is not complete $(<80 \%)$ and at temperatures above $400^{\circ} \mathrm{C}$, the oxidation of $\mathrm{NH}_{3}$ to $\mathrm{N}_{2}$ and $\mathrm{NO}$ is expected to be significant ( $>50 \%$ ). Since $\mathrm{N}_{2}$ (formed by R5 in Table 2.1), $\mathrm{N}_{2} \mathrm{O}$ and isocyanic acid are not considered in the nitrogen balance equation (calculated using Equation 3.11), nitrogen balance lower than 90\% were observed for Test Points 1 and 8.

Table 4.3: $\mathrm{NO}_{\mathrm{x}}$ reduction performance of the production-2013-SCR at target ANR of 1.0

\begin{tabular}{|c|c|c|c|c|c|c|c|c|c|c|}
\hline \multirow{2}{*}{$\begin{array}{c}\begin{array}{c}\text { Test } \\
\text { Point }\end{array} \\
{[-]}\end{array}$} & \multirow{2}{*}{$\begin{array}{c}\text { SCR } \\
\text { Inlet } \\
\text { Temp. } \\
{\left[{ }^{\circ} \mathrm{C}\right]}\end{array}$} & \multicolumn{2}{|c|}{ NO, [ppm] } & \multicolumn{2}{|c|}{$\mathrm{NO}_{2},[\mathrm{ppm}]$} & \multicolumn{2}{|c|}{$\begin{array}{c}\mathbf{N H}_{3}, \\
\text { [ppm] }\end{array}$} & \multirow{2}{*}{$\begin{array}{c}\text { ANR } \\
{[-]}\end{array}$} & \multirow{2}{*}{$\begin{array}{c}\begin{array}{c}\text { NO } \\
\text { Conv. } \\
\text { Cofficiency }\end{array} \\
{[\%]}\end{array}$} & \multirow{2}{*}{$\begin{array}{c}\begin{array}{c}\text { Nitrogen } \\
\text { Balance }\end{array} \\
{[\%]}\end{array}$} \\
\hline & & In & Out & In & Out & In & Out & & & \\
\hline 1 & 219 & 439 & 116 & 189 & 0 & 604 & 13 & 0.96 & 82 & 87 \\
\hline 2 & 238 & 178 & 50 & 110 & 1 & 268 & 2 & 0.96 & 82 & 86 \\
\hline 3 & 307 & 186 & 23 & 111 & 0 & 332 & 33 & 1.12 & 92 & 93 \\
\hline 4 & 327 & 181 & 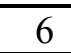 & $10 \%$ & 0 & 31 & 0 & 0.93 & 96 & 106 \\
\hline 5 & 354 & 315 & 6 & 255 & 7 & 546 & 0 & 0.99 & 99 & 99 \\
\hline 6 & 352 & 926 & 69 & 847 & 2 & 1720 & 9 & 0.97 & 96 & 97 \\
\hline 8 & 447 & 425 & 87 & 121 & 0 & 584 & 67 & 1.07 & 84 & 90 \\
\hline
\end{tabular}

Table 4.4: $\mathrm{NO}_{\mathrm{x}}$ reduction performance of the production-2013-SCR at target ANR of 1.2

\begin{tabular}{|c|c|c|c|c|c|c|c|c|c|c|}
\hline \multirow{2}{*}{$\begin{array}{c}\text { Test } \\
\text { Point } \\
{[-]}\end{array}$} & \multirow{2}{*}{$\begin{array}{c}\text { SCR } \\
\text { Inlet } \\
\text { Temp. } \\
{\left[{ }^{\circ} \mathrm{C}\right]} \\
\end{array}$} & \multicolumn{2}{|c|}{ NO, [ppm] } & \multicolumn{2}{|c|}{$\mathrm{NO}_{2},[\mathrm{ppm}]$} & \multicolumn{2}{|c|}{$\mathrm{NH}_{3},[\mathrm{ppm}]$} & \multirow{2}{*}{$\frac{\text { ANR }}{[-]}$} & \multirow{2}{*}{$\begin{array}{c}\begin{array}{c}\text { NO }_{\mathrm{x}} \\
\text { Conv. } \\
\text { Efficiency }\end{array} \\
{[\%]}\end{array}$} & \multirow{2}{*}{$\begin{array}{c}\begin{array}{c}\text { Nitrogen } \\
\text { Balance }\end{array} \\
{[\%]}\end{array}$} \\
\hline & & In & Out & In & Out & In & Out & & & \\
\hline 1 & 219 & 439 & 87 & 189 & 0 & 728 & 177 & 1.16 & 86 & 99 \\
\hline 2 & 238 & 178 & 23 & 110 & $\overline{0}$ & 324 & 44 & 1.16 & 92 & 93 \\
\hline 3 & 307 & 186 & 22 & 111 & $\overline{0}$ & 400 & 107 & 1.34 & 92 & 96 \\
\hline 4 & 327 & 181 & $\overline{0}$ & 167 & 0 & 385 & 61 & 1.13 & 100 & 105 \\
\hline 5 & 354 & 315 & $\overline{0}$ & 255 & 0 & 655 & 91 & 1.19 & 100 & $\overline{98}$ \\
\hline 6 & 352 & 926 & 13 & 847 & 0 & 2078 & 222 & 1.17 & 99 & 95 \\
\hline 8 & 447 & 425 & 75 & 121 & 0 & 704 & 150 & 1.29 & 86 & 88 \\
\hline
\end{tabular}


Similar trends were observed at ANR of 1.2 as given in Table 4.4. The $\mathrm{NO}_{\mathrm{x}}$ conversion efficiency is almost $100 \%$ in the SCR inlet temperature range of $300-350{ }^{\circ} \mathrm{C}$ at ANR of 1.2. The $\mathrm{NO}_{\mathrm{x}}$ conversion efficiency for seven Test Points with the production-2013-SCR, at ANRs of 1.0 and 1.2 are shown in Figure 4.1. 5-10\% improvement in $\mathrm{NO}_{\mathrm{x}}$ conversion efficiency was observed for all the Test Points (except Test Point 3) with an increase in the ANR from 1.0 to 1.2. The $\mathrm{NO}, \mathrm{NO}_{2}$ and $\mathrm{NH}_{3}$ concentrations and the $\mathrm{NO}_{\mathrm{x}}$ reduction performance of the production-2013-SCR at ANR of 0.3, 0.5, 0.8, 1.0-repeat, 0.8-repeat and 1.2-repeat are given in Appendix D.



Figure 4.1: $\mathrm{NO}_{\mathrm{x}}$ conversion efficiency of production-2013-SCR for steady state conditions at target ANR 1.0 and 1.2

The $\mathrm{NH}_{3}$ slip for the seven Test Points with the production-2013-SCR, at ANR 1.0 and 1.2 are shown in Figure 4.2. The $\mathrm{NH}_{3}$ slip for the various Test Points is less than $50 \mathrm{ppm}$ at ANR 1.0, except of the Test Point 8 , which is high space velocity and high temperature test condition. However, the $\mathrm{NH}_{3}$ slip increases significantly at ANR 1.2. The increase in the $\mathrm{NH}_{3}$ slip at ANR 1.2 was observed to be $\sim 20 \%$ of the inlet $\mathrm{NO}_{x}$. 


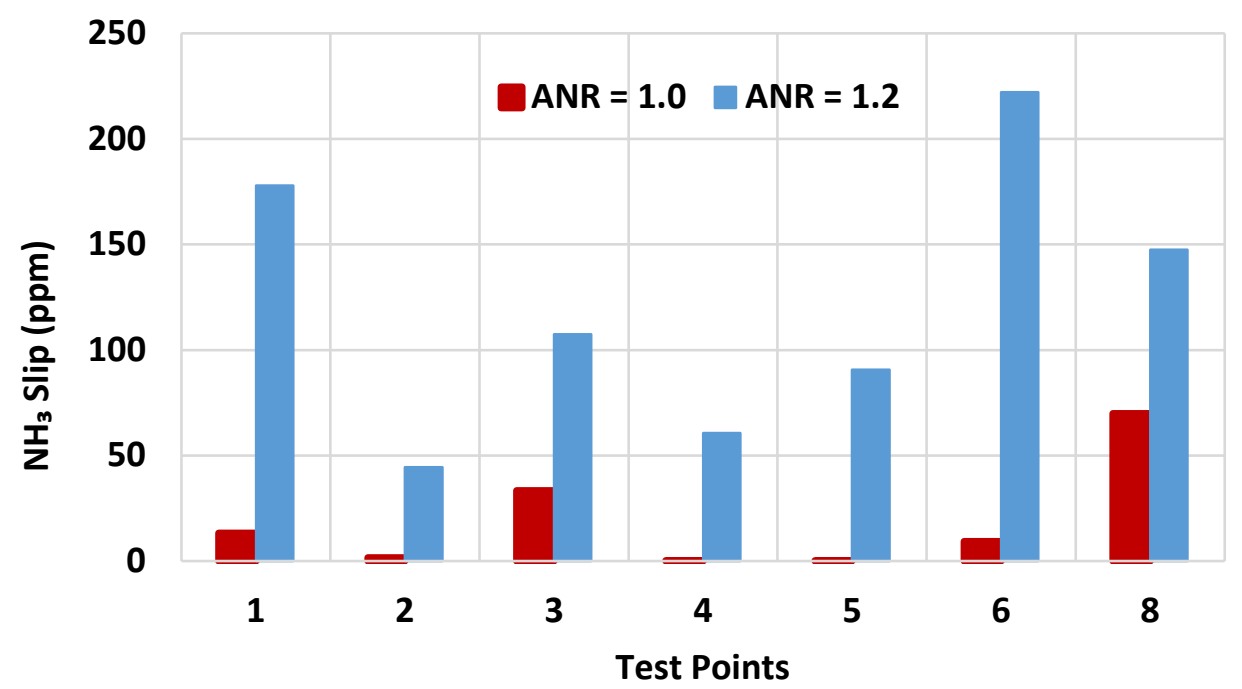

Figure 4.2: $\mathrm{NH}_{3}$ slip in production-2013-SCR for steady state conditions at target ANR 1.0 and 1.2

\subsection{1-D SCR Model Calibration Results}

The experimental data obtained from the seven $\mathrm{NO}_{\mathrm{x}}$ reduction tests with the production2013-SCR were used to calibrate the 1-D SCR model developed by reference [9] and Dr. Parker at Michigan Tech. The 1-D SCR model used in this study is discussed in section 2.4 of this thesis. This section describes the model parameters for the production-2013SCR and the comparison of the simulation of SCR outlet concentrations of $\mathrm{NO}, \mathrm{NO}_{2}$ and $\mathrm{NH}_{3}$ data to the experimental data.

The comparison of the model parameters required to calibrate the model to engine experimental data for the production-2013-SCR and production-2010-SCR [9] is shown in Table 4.5. It can be seen that the storage capacity $\Omega 1$ is comparable for the production2013-SCR and production-2010-SCR. However, the storage capacity $\Omega 2$ for the production-2013-SCR is $\sim 10 \%$ higher than $\Omega 2$ for the production-2010-SCR. The preexponential parameters for R1, R2, R7 and R9 were changed to calibrate the model to the engine experimental data obtained with the production-2013-SCR. The model calibration procedure is described in Appendix D. 
Table 4.5: 1-D SCR model calibration parameters

\begin{tabular}{|c|c|c|c|c|c|}
\hline Parameter & $\begin{array}{c}\text { Calibration } \\
\text { to } \\
\text { ISB2010 } \\
\text { engine data * }\end{array}$ & \begin{tabular}{|c|} 
Calibration \\
to \\
ISB2013 \\
engine data \\
Test Points 2- \\
8
\end{tabular} & $\begin{array}{c}\text { Calibration } \\
\text { to } \\
\text { ISB2013 } \\
\text { engine data } \\
\text { Test Point } 1\end{array}$ & $\begin{array}{c}\text { References * } \\
{[18,43,129,130]}\end{array}$ & Unit \\
\hline$\Omega 1$ & $4.36 \mathrm{E}+01$ & $4.31 \mathrm{E}+01$ & $4.50 \mathrm{E}+01$ & $1.20 \mathrm{E}+02$ & $\mathrm{gmol} / \mathrm{m}^{3}$ \\
\hline$\Omega 2$ & $3.60 \mathrm{E}+01$ & $4.07 \mathrm{E}+01$ & $5.51 \mathrm{E}+01$ & - & $\mathrm{gmol} / \mathrm{m}^{3}$ \\
\hline A_ads1 & $1.08 \mathrm{E}+00$ & $1.18 \mathrm{E}+00$ & $1.01 \mathrm{E}+01$ & - & $\mathrm{m}^{3} / \mathrm{gmol} \cdot \mathrm{s}$ \\
\hline E_ads1 & $-10.2 \pm 4.04$ & $-10.2 \pm 4.04$ & $-10.2 \pm 4.04$ & 0 & $\mathrm{~kJ} / \mathrm{gmol}$ \\
\hline A_des 1 & $3.22 \mathrm{E}+04$ & $5.0 \mathrm{E}+04$ & $3.22 \mathrm{E}+04$ & - & $1 / \mathrm{s}$ \\
\hline E_des 1 & $67.5 \pm 12.1$ & $67.5 \pm 12.1$ & $67.5 \pm 12.1$ & $96.1,97.5$ & $\mathrm{~kJ} / \mathrm{gmol}$ \\
\hline A_ads2 & $2.11 \mathrm{E}+01$ & $2.11 \mathrm{E}+01$ & $2.11 \mathrm{E}+01$ & - & $\mathrm{m}^{3} / \mathrm{gmol} \cdot \mathrm{s}$ \\
\hline E_ads2 & $-7.60 \pm 1.12$ & $-7.60 \pm 1.12$ & $-7.60 \pm 1.12$ & - & $\mathrm{kJ} / \mathrm{gmol}$ \\
\hline A_des 2 & $9.58 \mathrm{E}+05$ & $9.58 \mathrm{E}+05$ & $9.58 \mathrm{E}+05$ & - & $1 / \mathrm{s}$ \\
\hline E_des2 & $72.4 \pm 10.9$ & $72.4 \pm 10.9$ & $72.4 \pm 10.9$ & - & $\mathrm{kJ} / \mathrm{gmol}$ \\
\hline A_ $\mathrm{NH}_{3} \mathrm{Oxi1}$ & $2.33 \mathrm{E}+05$ & $2.33 \mathrm{E}+05$ & $2.33 \mathrm{E}+05$ & - & $1 / \mathrm{s}$ \\
\hline E_ $\mathrm{NH}_{3} \mathrm{Oxil}$ & $91.1 \pm 9.18$ & $91.1 \pm 9.18$ & $91.1 \pm 9.18$ & $177,63.8$ & $\mathrm{~kJ} / \mathrm{gmol}$ \\
\hline A_std & $7.18 \mathrm{E}+07$ & $1.23 \mathrm{E}+08$ & $9.08 \mathrm{E}+07$ & - & $\mathrm{m}^{3} / \mathrm{gmol} \cdot \mathrm{s}$ \\
\hline E_std & $77.3 \pm 7.92$ & $77.3 \pm 7.92$ & $77.3 \pm 7.92$ & $48.7,88.0,89.1$ & $\mathrm{~kJ} / \mathrm{gmol}$ \\
\hline A_std2 & $6.17 \mathrm{E}+06$ & $6.17 \mathrm{E}+06$ & $6.17 \mathrm{E}+06$ & - & $\mathrm{m}^{3} / \mathrm{gmol} \cdot \mathrm{s}$ \\
\hline E_std2 & $68.4 \pm 7.28$ & $68.4 \pm 7.28$ & $68.4 \pm 7.28$ & - & $\mathrm{kJ} / \mathrm{gmol}$ \\
\hline A_slo & $7.13 \mathrm{E}+09$ & $7.13 \mathrm{E}+09$ & $7.13 \mathrm{E}+09$ & - & $\mathrm{m}^{3} / \mathrm{gmol} \cdot \mathrm{s}$ \\
\hline E_slo & $109 \pm 9.21$ & $109 \pm 9.21$ & $109 \pm 9.21$ & $58.3,136.3$ & $\mathrm{~kJ} / \mathrm{gmol}$ \\
\hline A_fst & $1.76 \mathrm{E}+08$ & $1.55 \mathrm{E}+08$ & $9.50 \mathrm{E}+06$ & - & $\mathrm{m}^{6} / \mathrm{gmol}^{2} \cdot \mathrm{s}$ \\
\hline E_fst & $45.2 \pm 9.55$ & $45.2 \pm 9.55$ & $45.2 \pm 9.55$ & $113,32.1,77.1$ & $\mathrm{~kJ} / \mathrm{gmol}$ \\
\hline
\end{tabular}


The results from calibrated model were compared with the experimental data. The comparison of $\mathrm{NO}$ and $\mathrm{NO}_{2}$ concentrations at SCR outlet is given in the Table 4.6 and 4.7 respectively. The model has been calibrated to within $\pm 20 \mathrm{ppm}$ for both the gases. The values highlighted in green have high difference due to inconsistency in the experimental data. The comparison of $\mathrm{NH}_{3}$ concentration at SCR outlet is given in the Table 4.8. The model has been calibrated to within $\pm 30 \mathrm{ppm}$ for $\mathrm{NH}_{3}$ slip (measured using $\mathrm{NH}_{3}$ sensor). 







Comparison of the simulation results and experimental measurements for $\mathrm{NO}, \mathrm{NO}_{2}$ and $\mathrm{NH}_{3}$ concentrations at the SCR outlet are shown in Figure 4.3, 4.4 and 4.5 respectively. From Figures 4.3 and 4.4 it is observed that the difference between the simulation results and experimental measurements for $\mathrm{NO}$ and $\mathrm{NO}_{2}$ concentration is less than $20 \mathrm{ppm}$ for all the Test Points at ANR 0.8, 1.0 and 1.2. From Figure 4.5 it can be observed that the measured (using $\mathrm{NH}_{3}$ sensor) and simulated values are in good agreement for $\mathrm{NH}_{3}$ slip out of the SCR, as the difference between the simulation results and experimental measurements is less than $30 \mathrm{ppm}$ for all the Test Points at ANR 1.0 and 1.2. 

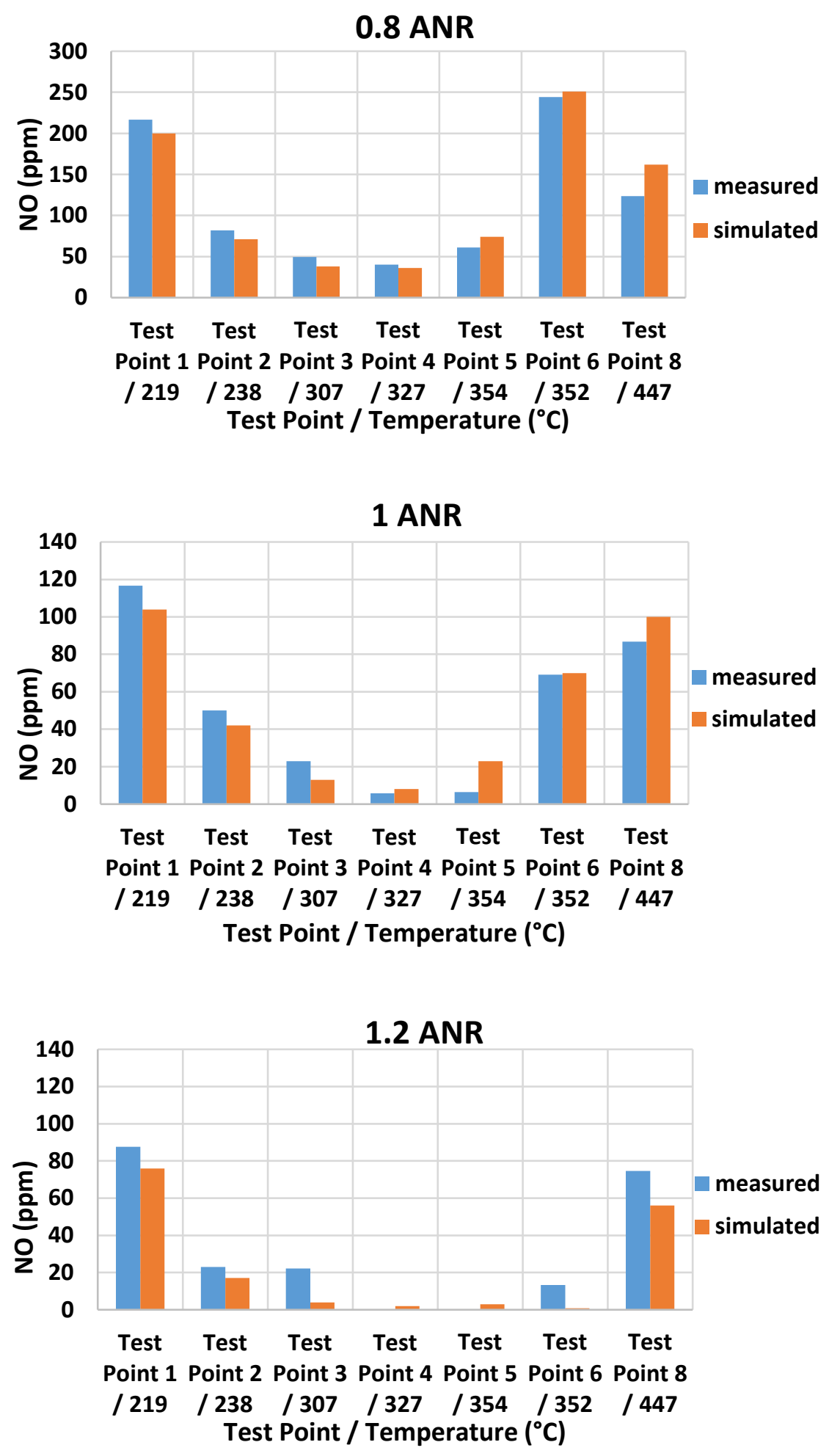

Figure 4.3: Comparison of SCR outlet NO concentrations for various Test Points 

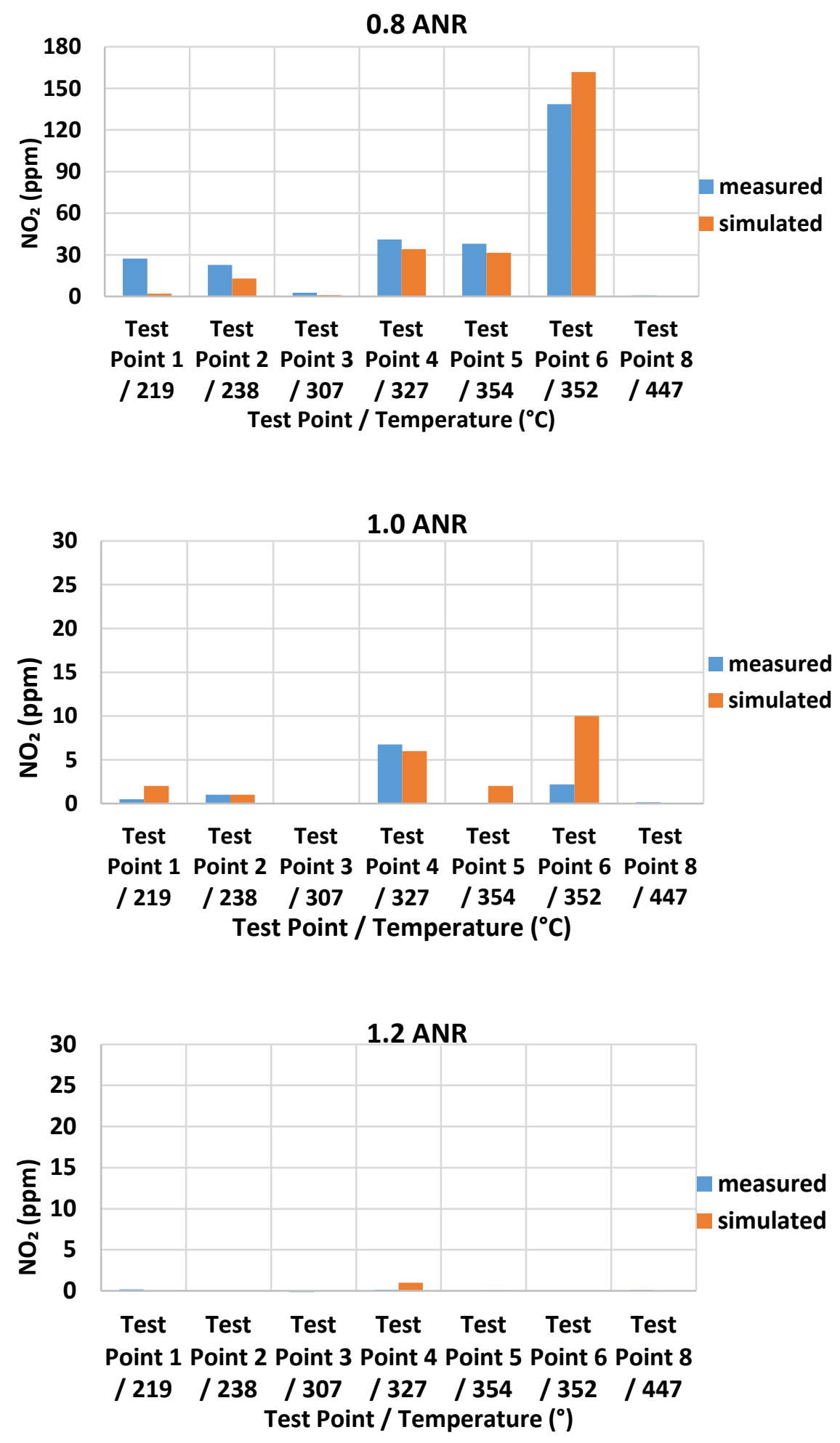

Figure 4.4: Comparison of SCR outlet $\mathrm{NO}_{2}$ concentrations for various Test Points 
1 ANR


Figure 4.5: Comparison of $\mathrm{NH}_{3}$ slip concentrations for various Test Points 
Comparison the simulation of SCR outlet concentrations of $\mathrm{NO}, \mathrm{NO}_{2}$ and $\mathrm{NH}_{3}$ data to the experimental data for the Test Point 4 (SCR inlet temperature of $327^{\circ} \mathrm{C}$, SV of 26.7 $\mathrm{k} / \mathrm{hr}$ ) and Test Point 1 (SCR inlet temperature of $218^{\circ} \mathrm{C}, \mathrm{SV}$ of $12.0 \mathrm{k} / \mathrm{hr}$ ) are given in Figures 4.6 and 4.7. The simulation results for the other Test Points are described in Appendix D.

The top plot of the Figure 4.6 shows the SCR inlet concentrations of $\mathrm{NO}, \mathrm{NO}_{2}$ and $\mathrm{NH}_{3}$. The bottom three plots of the Figure 4.6 show the SCR outlet concentrations of $\mathrm{NO}, \mathrm{NO}_{2}$, $\mathrm{NO}_{\mathrm{x}}$ and $\mathrm{NH}_{3}$ compared between the model simulation and the experimental results. The bottommost plot of the Figure 4.6 compares the $\mathrm{NH}_{3}$ measured using the MS, the production sensor and the simulated values from the SCR model. Since there was a delay in the measurement of $\mathrm{NH}_{3}$ slip using the MS and disagreement in the nitrogen balance during a few test runs, $\mathrm{NH}_{3}$ values measured using the sensor were used for all the calculations.

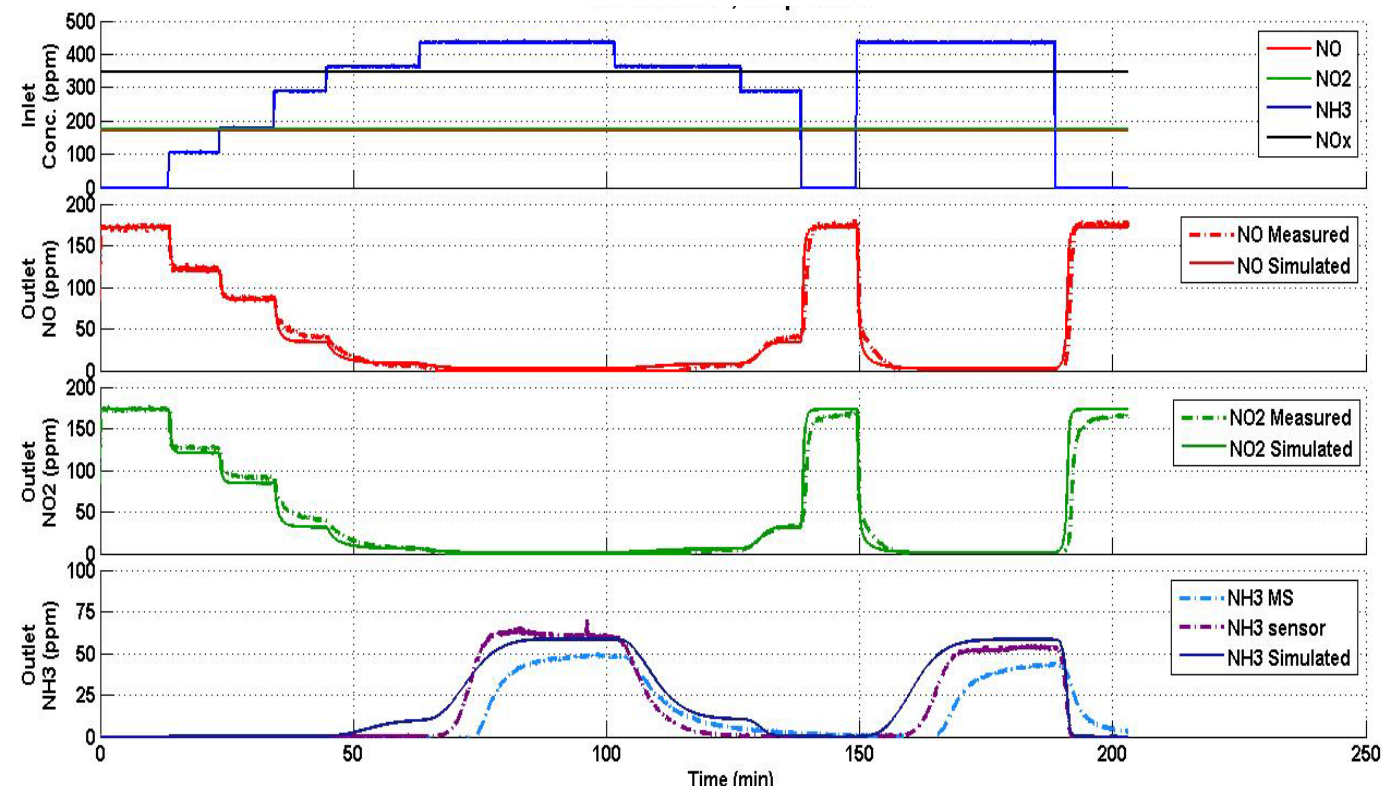

Figure 4.6: Comparison of the SCR outlet gaseous concentrations between simulation results and experimental measurements for Test Point 4 (SCR inlet temperature $327^{\circ} \mathrm{C}$, SV $26.7 \mathrm{k} / \mathrm{hr}$ ) using urea dosing cycle (Figure 3.9) 
It can be observed that for Test Point 4, the maximum simulation error under the steady state urea injection condition is less than 10 ppm for $\mathrm{NO}$ and $\mathrm{NO}_{2}$ and less than $15 \mathrm{ppm}$ for $\mathrm{NH}_{3}$. The simulation results follow the overall trend of the experimental measurements for $\mathrm{NO}$ and $\mathrm{NO}_{2}$, under both steady state and transient urea injection.

However, from Figure 4.7 it can be observed that with the unique set of model parameters, $\mathrm{NO}_{2}$ values simulated by the model are significantly lower than the $\mathrm{NO}_{2}$ values measured during the experiment. Hence, for Test Point 1, a different set of parameters was used which is described in Table 4.5. The comparison of results with different parameters for Test Point 1 are shown in Figure 4.8. It can be observed that the difference for $\mathrm{NO}$ and $\mathrm{NO}_{2}$ species has decreased during the steady state and the transient urea dosing conditions.



Figure 4.7: Comparison of the SCR outlet gaseous concentrations between simulation results and experimental measurements for Test Point 1 (SCR inlet temperature $218^{\circ} \mathrm{C}$, $\mathrm{SV} 12.0 \mathrm{k} / \mathrm{hr}$ ) using urea dosing cycle (Figure 3.9 ) 




Figure 4.8: Comparison of the SCR outlet gaseous concentrations between simulation results and experimental measurements for Test Point 1 (SCR inlet temperature $218^{\circ} \mathrm{C}$, SV $12.0 \mathrm{k} / \mathrm{hr}$ ), using different parameters as shown in Table 4.5

\subsection{SCRF® Experimental Data: Configuration 1 (Passive Oxidation with Urea Injection)}

This section discusses the results and analysis of the experimental data obtained from seven passive oxidation tests conducted with urea injection as a part of the configuration 1. The purpose of the passive oxidation tests was to study the effect of the $\mathrm{NO}_{\mathrm{x}}$ reduction reactions on the kinetics of the $\mathrm{NO}_{2}$ assisted passive oxidation and to obtain experimental data for calibrating the SCR-F model.

The $\mathrm{NO}, \mathrm{NO}_{2}$ and $\mathrm{NO}_{\mathrm{x}}$ concentrations at the inlet and outlet of the $\mathrm{SCRF} \AA$ and the $\mathrm{NO}_{\mathrm{x}}$ conversion efficiency for the seven passive oxidation tests with urea dosing are given in Table 4.9. In Table 4.9, $\mathrm{PM}_{\text {Start }}$ is the PM deposited in the SCRF® at the beginning of passive oxidation stage, $\mathrm{PM}_{\text {Available }}$ is the total $\mathrm{PM}$ mass available for oxidation during passive oxidation stage and PMRetained is the PM retained in the SCRF® at the end of the passive oxidation stage, as discussed in section 3.6.7 and reference [1]. $\mathrm{PM}_{\text {Start }}$, 
$\mathrm{PM}_{\text {Available, }} \mathrm{PM}_{\text {Retained }}$ for stage 1, stage 3 and stage 4 are given in reference [1]. From Table 4.9 it is observed that for Test Points A, B and B Rpt, PMOxidized (explained in section 3.6.7) is less than $30 \%$ and for Test Points C, D, D Rpt and E, PM Oxidized is less than $50 \%$. Hence, during the seven passive oxidation tests with urea injection conducted in configuration 1, the $\mathrm{NO}_{\mathrm{x}}$ reduction performance of the SCRF ${ }^{\circledR}$ was studied with $\mathrm{PM}$ in the SCRF® varying between $2-1 \mathrm{~g} / \mathrm{L}$ (calculated using $\mathrm{PM}_{\text {start }}$ and $\mathrm{PM}_{\text {Retained }}$ in Table 4.9). The $\mathrm{NO}_{\mathrm{x}}$ conversion efficiency for Test Point $\mathrm{A}$ and $\mathrm{B}$ is approximately $90 \%$ and for Test Points D, D-repeat and E, it is approximately 95\% as shown in Figure 4.9. These results are in agreement with the results obtained from the production-2013-SCR (discussed in section 4.1). The nitrogen balance for Test Points A, B and B-repeat are around $90 \%$ since all the urea is not converted to ammonia at $250-260^{\circ} \mathrm{C}$. The Test Point B-repeat has $\mathrm{NO}_{\mathrm{x}}$ conversion efficiency of 99\%, since 1.10 ANR was maintained instead of 1.0. Similarly, the Test Point $\mathrm{C}$ has $\mathrm{NO}_{\mathrm{x}}$ conversion efficiency of $88 \%$, since 0.89 ANR was maintained during the test instead of 1.0. The $\mathrm{NH}_{3}$ slip for all the Test Points is below 20 ppm. It can be concluded that the SCRF® with PM loading of $2 \mathrm{~g} / \mathrm{L}$, has $\mathrm{NO}_{\mathrm{x}}$ conversion efficiency comparable to the production-2013-SCR in the temperature range of 250 to $350^{\circ} \mathrm{C}$. The Test Point B-repeat also indicates that the SCRF ${ }^{\circledR}$ has the potential to achieve high $\mathrm{NO}_{\mathrm{x}}$ conversion efficiency $(98-99 \%)$ at ANR greater than 1.0, with $\mathrm{NH}_{3}$ slip less than $20 \mathrm{ppm}$. The additional data needed to calibrate the SCR-F model, pressure drop across the SCRF® and temperature distribution in the SCRF®, obtained from configuration 1 (passive oxidation with urea injection) are discussed in the reference [1]. 


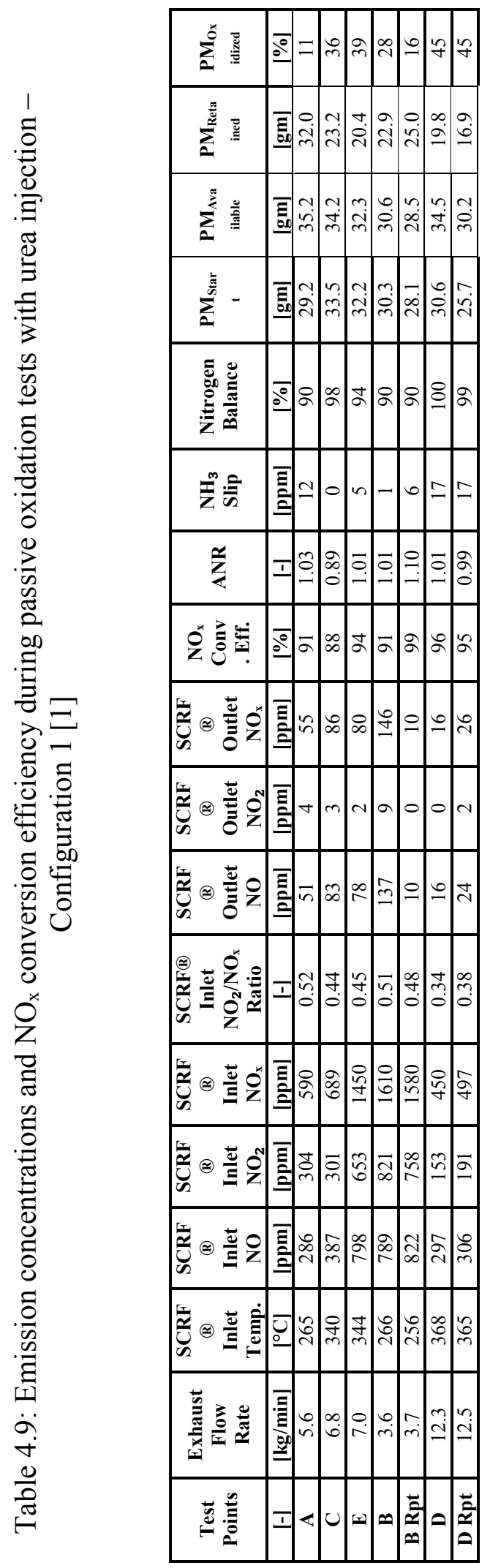




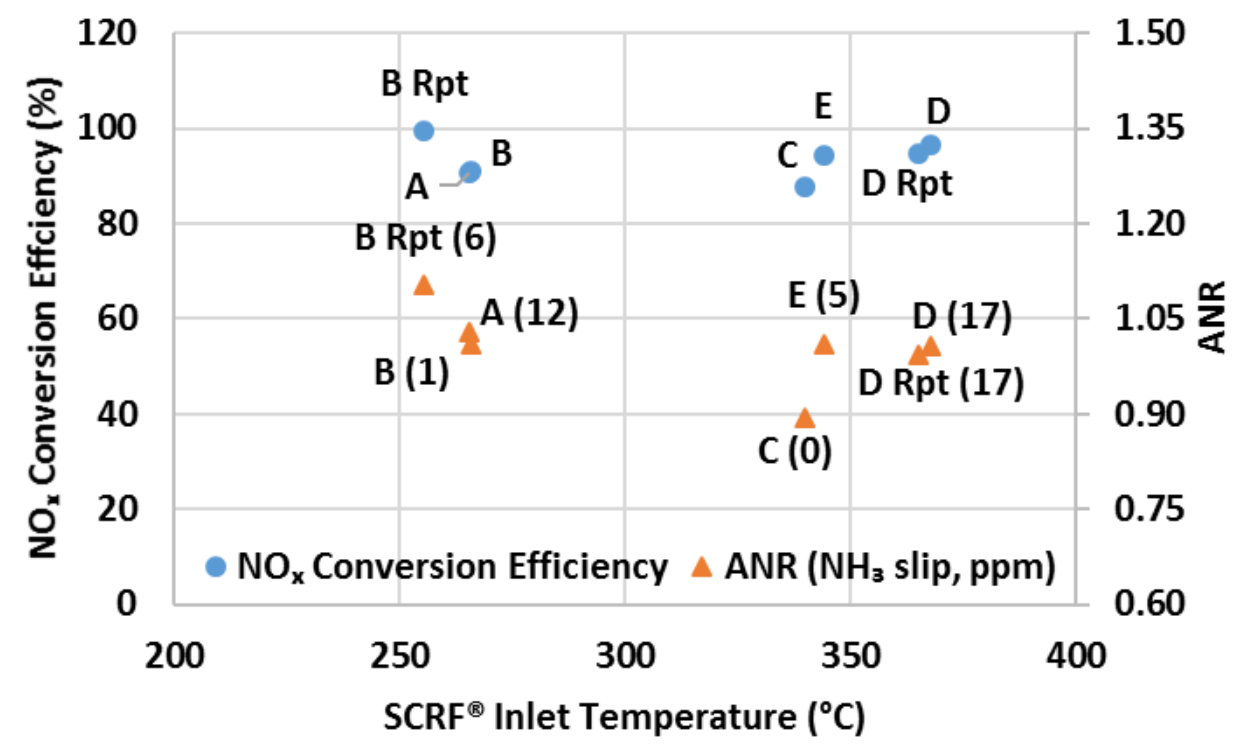

Figure 4.9: $\mathrm{NO}_{\mathrm{x}}$ conversion efficiency of the SCRF® - Configuration 1

\subsection{SCRF® Experimental Data: Configuration $2\left(\mathrm{NO}_{\mathrm{x}}\right.$ Reduction with 0 , 2 and $4 \mathrm{~g} / \mathrm{L}$ PM Loading)}

The purpose of these tests was to determine the $\mathrm{NO}_{\mathrm{x}}$ reduction performance, $\mathrm{NH}_{3}$ slip and $\mathrm{NH}_{3}$ storage for the SCRF® with and without PM in the SCRF® as a function of ANR. The engine conditions and the exhaust parameters at the inlet of the SCRF®, for the twelve $\mathrm{NO}_{\mathrm{x}}$ reduction tests with the SCRF® are given in Table 4.10. It can be observed that the engine speed and load were consistent during the four Test Points without PM and with 2 and $4 \mathrm{~g} / \mathrm{L} \mathrm{PM}$ in the SCRF®. Hence the space velocities, SCRF® inlet temperatures, $\mathrm{NO}_{2} / \mathrm{NO}_{\mathrm{x}}$ ratios were also consistent at the SCRF® inlet. The four Test Points represent the range of SCRF ${ }^{\circledR}$ inlet temperatures from 200 to $450^{\circ} \mathrm{C}$, space velocities from 13 to $48 \mathrm{k} / \mathrm{hr}, \mathrm{NO}_{\mathrm{x}}$ concentration from 300 to $1600 \mathrm{ppm}$ and $\mathrm{NO}_{2} / \mathrm{NO}_{\mathrm{x}}$ ratio from 0.2 to 0.5 . The $\mathrm{SCRF} \AA$ inlet conditions described in Table 4.10 are also in agreement with the production-2013-SCR inlet conditions given in Table 4.1. 
Table 4.10: Engine exhaust conditions at $\mathrm{SCRF}{ }^{\circledR}$ inlet for $\mathrm{NO}_{\mathrm{x}}$ reduction Test Points

\begin{tabular}{|c|c|c|c|c|c|}
\hline \multirow{2}{*}{ Parameter } & \multirow{2}{*}{ PM Loading } & \multicolumn{4}{|c|}{ Test Point } \\
\hline & & 1 & 3 & 6 & 8 \\
\hline \multirow{3}{*}{$\begin{array}{c}\text { Speed } \\
\text { [RPM] }\end{array}$} & $\mathrm{SCRF}{ }^{\circledR}-0 \mathrm{~g} / \mathrm{L}$ & 1199 & 2200 & 1202 & 2401 \\
\hline & $\mathrm{SCRF} \AA-2 \mathrm{~g} / \mathrm{L}$ & 1200 & 2101 & 1200 & 2398 \\
\hline & $\mathrm{SCRF}{ }^{\circledR}-4 \mathrm{~g} / \mathrm{L}$ & 1200 & 2203 & 1200 & 2401 \\
\hline \multirow{3}{*}{$\begin{array}{l}\text { Load } \\
{[\mathrm{Nm}]}\end{array}$} & $\mathrm{SCRF}{ }^{\circ}-0 \mathrm{~g} / \mathrm{L}$ & 201 & 330 & 580 & 826 \\
\hline & $\mathrm{SCRF} \otimes-2 \mathrm{~g} / \mathrm{L}$ & 208 & 329 & 588 & 820 \\
\hline & $\mathrm{SCRF} \AA-4 \mathrm{~g} / \mathrm{L}$ & 203 & 331 & 587 & 818 \\
\hline \multirow{3}{*}{$\begin{array}{c}\text { Exhaust Flow } \\
{[\mathrm{kg} / \mathrm{min}]}\end{array}$} & $\mathrm{SCRF} \AA-0 \mathrm{~g} / \mathrm{L}$ & 5.0 & 10.7 & 6.9 & 17.0 \\
\hline & $\mathrm{SCRF} \AA-2 \mathrm{~g} / \mathrm{L}$ & 5.0 & 9.9 & 6.8 & 17.6 \\
\hline & $\mathrm{SCRF} \circledast \mathrm{R}-4 \mathrm{~g} / \mathrm{L}$ & 5.0 & 10.9 & 6.8 & 17.7 \\
\hline \multirow{3}{*}{$\begin{array}{c}\text { SCRF® Inlet } \\
\text { Temperature } \\
{\left[{ }^{\circ} \mathrm{C}\right]}\end{array}$} & $\mathrm{SCRF} \AA-0 \mathrm{~g} / \mathrm{L}$ & 218 & 304 & 345 & 443 \\
\hline & $\mathrm{SCRF} \AA-2 \mathrm{~g} / \mathrm{L}$ & 206 & 305 & 340 & 438 \\
\hline & $\mathrm{SCRF} \otimes-4 \mathrm{~g} / \mathrm{L}$ & 207 & 302 & 343 & 446 \\
\hline \multirow{3}{*}{$\begin{array}{c}\text { SCRF® Std. } \\
\text { Space Vel. } \\
{[\mathrm{k} / \mathrm{hr}]} \\
\end{array}$} & $\mathrm{SCRF} \AA-0 \mathrm{~g} / \mathrm{L}$ & 13.7 & 29.1 & 18.8 & 46.3 \\
\hline & $\mathrm{SCRF} \otimes-2 \mathrm{~g} / \mathrm{L}$ & 13.7 & 27.0 & 18.6 & 48.0 \\
\hline & $\mathrm{SCRF} \circledast \mathrm{R}-4 \mathrm{~g} / \mathrm{L}$ & 13.5 & 29.8 & 18.6 & 48.2 \\
\hline \multirow{3}{*}{$\begin{array}{c}\text { SCRF® Act. } \\
\text { Space Vel. } \\
\text { [k/hr] }\end{array}$} & $\mathrm{SCRF}{ }^{\circ}-0 \mathrm{~g} / \mathrm{L}$ & 24.5 & 60.2 & 42.0 & 115.2 \\
\hline & $\mathrm{SCRF}{ }^{\circ}-2 \mathrm{~g} / \mathrm{L}$ & 22.6 & 53.8 & 39.3 & 117.9 \\
\hline & $\mathrm{SCRF}{ }^{\circledR}-4 \mathrm{~g} / \mathrm{L}$ & 22.7 & 56.4 & 35.7 & 99.6 \\
\hline \multirow{3}{*}{$\begin{array}{c}\text { SCRF® Inlet } \\
\text { NO [ppm] }\end{array}$} & $\mathrm{SCRF}{ }^{\circ}-0 \mathrm{~g} / \mathrm{L}$ & 345 & 158 & 795 & 411 \\
\hline & $\mathrm{SCRF} \AA-2 \mathrm{~g} / \mathrm{L}$ & 403 & 161 & 844 & 424 \\
\hline & $\mathrm{SCRF}{ }^{\circledR}-4 \mathrm{~g} / \mathrm{L}$ & 452 & 198 & 793 & 415 \\
\hline \multirow{3}{*}{$\begin{array}{c}\text { SCRF }{ }^{\circledR} \text { Inlet } \\
\mathrm{NO}_{2}[\mathrm{ppm}]\end{array}$} & $\mathrm{SCRF} \AA-0 \mathrm{~g} / \mathrm{L}$ & 213 & 121 & 674 & 140 \\
\hline & $\mathrm{SCRF} \AA-2 \mathrm{~g} / \mathrm{L}$ & 203 & 131 & 744 & 125 \\
\hline & $\mathrm{SCRF} \circledast-4 \mathrm{~g} / \mathrm{L}$ & 141 & 143 & 588 & 115 \\
\hline \multirow{3}{*}{$\begin{array}{c}\text { SCRF® } \\
\text { Inlet NO } \\
\text { [ppm] }\end{array}$} & $\mathrm{SCRF} \AA-0 \mathrm{~g} / \mathrm{L}$ & 558 & 279 & 1468 & 551 \\
\hline & $\mathrm{SCRF} \otimes-2 \mathrm{~g} / \mathrm{L}$ & 607 & 292 & 1588 & 548 \\
\hline & $\mathrm{SCRF} \AA-4 \mathrm{~g} / \mathrm{L}$ & 594 & 341 & 1381 & 530 \\
\hline \multirow{3}{*}{$\begin{array}{l}\text { Upstream } \\
\mathrm{NO}_{2} / \mathrm{NO}_{\mathbf{x}}\end{array}$} & $\mathrm{SCRF}{ }^{\circledR}-0 \mathrm{~g} / \mathrm{L}$ & 0.38 & 0.43 & 0.46 & 0.25 \\
\hline & $\mathrm{SCRF} \AA-2 \mathrm{~g} / \mathrm{L}$ & 0.34 & 0.45 & 0.47 & 0.23 \\
\hline & $\mathrm{SCRF}{ }^{\circledR}-4 \mathrm{~g} / \mathrm{L}$ & 0.26 & 0.42 & 0.43 & 0.22 \\
\hline \multirow{3}{*}{$\begin{array}{c}\text { Engine Out PM } \\
{[\mathrm{mg} / \mathrm{scm}]}\end{array}$} & $\mathrm{SCRF} \otimes-0 \mathrm{~g} / \mathrm{L}$ & $\mathrm{N} / \mathrm{A}$ & $\mathrm{N} / \mathrm{A}$ & $\mathrm{N} / \mathrm{A}$ & $\mathrm{N} / \mathrm{A}$ \\
\hline & $\mathrm{SCRF} \AA-2 \mathrm{~g} / \mathrm{L}$ & 2.14 & 4.30 & 3.59 & 7.39 \\
\hline & $\mathrm{SCRF} \circledast \mathrm{R}-4 \mathrm{~g} / \mathrm{L}$ & 1.97 & 4.93 & 2.85 & 4.97 \\
\hline
\end{tabular}

N/A - Engine out PM concentrations not measured for tests without PM in the SCRF®

The $\mathrm{NO}_{2} / \mathrm{NO}_{\mathrm{x}}$ ratio at the inlet of the SCRF® is dependent on the $\mathrm{NO}$ to $\mathrm{NO}_{2}$ conversion efficiency of the DOC, which in turn is dependent on the DOC inlet temperature and 
space velocity of the exhaust, flowing through the DOC. The NO conversion efficiency of the DOC is defined in equation 4.3.

NO Conversion Efficiency $(\%)=\frac{\text { DOC Inlet NO- DOC Outlet NO }}{\text { DOC Inlet NO }} * 100 \quad$ Eqn. 4.3

The $\mathrm{NO}$ and $\mathrm{NO}_{2}$ concentrations at the inlet and outlet of the DOC during the twelve $\mathrm{NO}_{\mathrm{x}}$ reduction tests are given in Table 4.11. The exhaust conditions and the NO conversion efficiency of the DOC are given in the Table 4.12. The NO conversion efficiency was maximum in the range of 300 to $350^{\circ} \mathrm{C}$ which is in agreement with the trend for $\mathrm{NO}$ conversion efficiency observed by reference [7]. However, the NO conversion efficiency for Test Point 1, without PM in the SCRF®, was observed to be $40 \%$, which is $10-20$ $\%$ higher than the results obtained from the Test Point 1 with PM loading in the SCRF®. This could be due to inconsistency in the NO data obtained from the mass spectrometer.

Table 4.11: $\mathrm{NO}$ and $\mathrm{NO}_{2}$ concentration at the inlet and outlet of DOC during $\mathrm{NO}_{\mathrm{x}}$ reduction stage - configuration 2

\begin{tabular}{|c|c|c|c|c|c|c|c|c|c|c|c|c|}
\hline \multirow{3}{*}{$\begin{array}{l}\text { Test } \\
\text { Point }\end{array}$} & \multicolumn{6}{|c|}{ NO [ppm] } & \multicolumn{6}{|c|}{$\mathrm{NO}_{2}[\mathrm{ppm}]$} \\
\hline & \multicolumn{2}{|c|}{$\begin{array}{c}\text { SCRF® }-0 \\
\text { g/L }\end{array}$} & \multicolumn{2}{|c|}{$\begin{array}{c}\text { SCRF® }-2 \\
\text { g/L }\end{array}$} & \multicolumn{2}{|c|}{$\begin{array}{c}\text { SCRF } ®-4 \\
\text { g/L }\end{array}$} & \multicolumn{2}{|c|}{$\begin{array}{c}\text { SCRF® }-0 \\
\text { g/L }\end{array}$} & \multicolumn{2}{|c|}{$\begin{array}{c}\text { SCRF® }-2 \\
\text { g/L }\end{array}$} & \multicolumn{2}{|c|}{$\begin{array}{c}\text { SCRF }{ }^{\circledR}-4 \\
\mathrm{~g} / \mathrm{L}\end{array}$} \\
\hline & In & Out & In & Out & In & Out & In & Out & In & Out & In & Out \\
\hline 1 & 575 & 345 & 581 & 403 & 515 & 411 & 5 & 213 & 2 & 203 & 37 & 141 \\
\hline 3 & 257 & 160 & 288 & 161 & 324 & 198 & 18 & 120 & 0 & 131 & 1 & 124 \\
\hline 6 & 1336 & 795 & 1484 & 743 & 1483 & 793 & 18 & 674 & 4 & 644 & 14 & 588 \\
\hline 8 & 542 & 411 & 556 & 424 & 507 & 415 & 1 & 140 & 2 & 125 & 8 & 115 \\
\hline
\end{tabular}

Table 4.12: DOC exhaust conditions and $\mathrm{NO}$ conversion efficiency during $\mathrm{NO}_{\mathrm{x}}$ reduction stage - configuration 2

\begin{tabular}{|c|c|c|c|c|c|c|c|c|c|}
\hline \multirow{2}{*}{$\begin{array}{l}\text { Test } \\
\text { Point }\end{array}$} & \multicolumn{3}{|c|}{ DOC Inlet Temperature $\left[{ }^{\circ} \mathrm{C}\right]$} & \multicolumn{3}{|c|}{ SCRF® Space Velocity [k/hr] } & \multicolumn{3}{|c|}{ NO Conversion Efficiency [\%] } \\
\hline & $\begin{array}{c}\mathrm{SCRF}^{\circledR}- \\
\mathbf{0}\end{array}$ & $\begin{array}{c}\mathrm{SCRF}^{\circledR}- \\
\mathbf{2}\end{array}$ & $\begin{array}{c}\mathrm{SCRF} \circledast- \\
{ }^{\circledR}-\end{array}$ & $\begin{array}{c}\mathrm{SCRF} \circledast- \\
\mathbf{0}\end{array}$ & $\underset{2}{\mathrm{SCRF}}{ }^{\circledR}-$ & $\begin{array}{c}\mathrm{SCRF} \circledast- \\
4\end{array}$ & $\begin{array}{c}\mathrm{SCRF}^{\circledR}- \\
0\end{array}$ & $\begin{array}{c}\mathrm{SCRF} 囚- \\
\quad\end{array}$ & $\begin{array}{c}\mathrm{SCRF} \circledast- \\
4\end{array}$ \\
\hline 1 & 221 & 218 & 214 & $\overline{56}$ & $\overline{56}$ & $\overline{55}$ & 40 & 31 & 20 \\
\hline 3 & 306 & 315 & 316 & 119 & 111 & 121 & 38 & 44 & 39 \\
\hline 6 & 346 & 355 & 362 & 77 & 76 & 76 & 40 & 43 & 46 \\
\hline 8 & 439 & 442 & 449 & 189 & 196 & 197 & 24 & 24 & 18 \\
\hline
\end{tabular}




\subsubsection{Experimental Data}

The $\mathrm{NO}, \mathrm{NO}_{2}$ and $\mathrm{NH}_{3}$ slip concentrations downstream of the SCRF® and $\mathrm{NO}_{\mathrm{x}}$ conversion efficiency of the SCRF® relative to the ANR for various Test Points, with and without PM loading in the SCRF® are shown in Figures 4.10, 4.11, 4.12 and 4.13. From Figure 4.10 it can be observed that for Test Point 1, with and without PM loading, $<10 \mathrm{ppm}$ of $\mathrm{NO}_{2}$ is remaining downstream of the SCRF® at ANR $>0.8$. The NO concentrations decrease from $\sim 130 \mathrm{ppm}$ to $<20 \mathrm{ppm}$ when ANR is increased from 0.8 to 1.2. The $\mathrm{NO}_{\mathrm{x}}$ conversion efficiency of the SCRF® increases from $\sim 75 \%$ at ANR 0.8 to $\sim 90 \%$ at ANR 1.0 due to availability of more ammonia to react with $\mathrm{NO}_{\mathrm{x}}$ in the exhaust gases. The $\mathrm{NO}_{\mathrm{x}}$ conversion efficiency of the SCRF ${ }^{\circledR}$ with 2 and $4 \mathrm{~g} / \mathrm{L}$ of PM loading was observed to be $2-3 \%$ higher than the $\mathrm{NO}_{\mathrm{x}}$ conversion efficiency of the SCRF® without PM loading, at ANR 0.8 and 1.0.
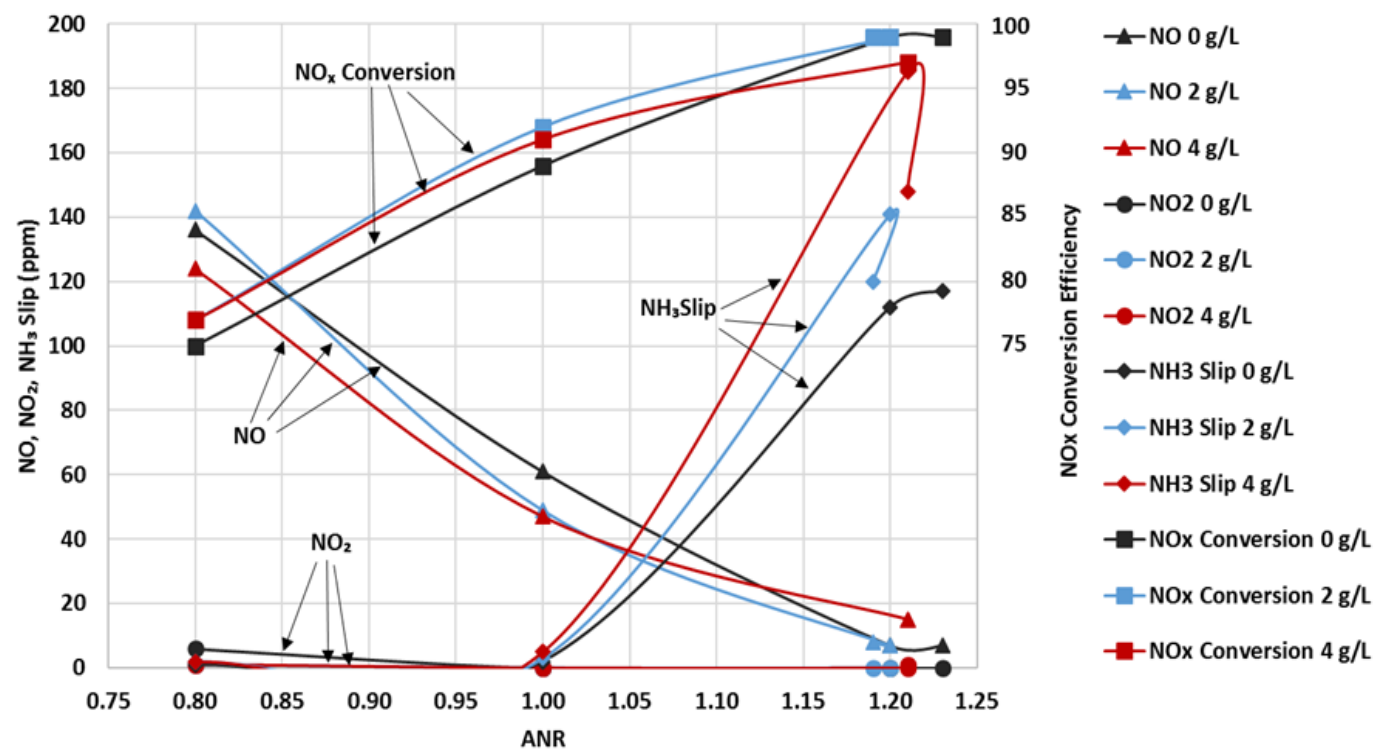

Figure 4.10: $\mathrm{NO}, \mathrm{NO}_{2} \mathrm{NH}_{3}$ slip downstream of the $\mathrm{SCRF} \AA$ and $\mathrm{NO}_{\mathrm{x}}$ conversion efficiency at various ANR for Test Point 1 , with and without PM in the SCRF® (SCRF® inlet temperature $=201{ }^{\circ} \mathrm{C}$ and $\mathrm{SV}=13.7 \mathrm{k} / \mathrm{hr}$ )

The $\mathrm{NH}_{3}$ slip $<10$ ppm was observed up to ANR 1.0, with and without PM loading in the SCRF®. However, the $\mathrm{NH}_{3}$ slip increased to $100-150$ ppm at ANR 1.2 due to excess ammonia availability in the SCRF®. A reduction in the $\mathrm{NO}_{\mathrm{x}}$ conversion efficiency of the 
SCRF® with PM loading was observed at ANR 1.2. This is evident from the change in the slope of the $\mathrm{NO}_{\mathrm{x}}$ conversion trend of the SCRF® with PM loading (Blue and Red lines). The $\mathrm{NO}_{\mathrm{x}}$ conversion efficiency at ANR 1.2 was the least for the SCRF® with PM loading of $4 \mathrm{~g} / \mathrm{L}$. Hence, at ANR 1.2, the SCRF® with PM loading of $4 \mathrm{~g} / \mathrm{L}$ had the highest $\mathrm{NH}_{3}$ slip from the $\mathrm{SCRF}{ }^{\circledR}$.

The trends for $\mathrm{NO}$ and $\mathrm{NO}_{2}$ concentrations downstream of the SCRF® for Test point 3 with and without PM loading were similar to Test Point 1 . The $\mathrm{NO}$ and $\mathrm{NO}_{2}$ concentrations decreased to $<20 \mathrm{ppm}$ with increase in ANR from 0.8 to 1.0. The $\mathrm{NO}_{\mathrm{x}}$ conversion efficiency increased from $\sim 82 \%$ at ANR 0.8 to $\sim 96 \%$ at ANR 1.0. The actual ANR for the test with $4 \mathrm{~g} / \mathrm{L}$ PM loading was higher than the targeted ANR, as indicated by the red line $(0.8,1.0$ and 1.2$)$. Hence, $2-3 \%$ higher $\mathrm{NO}_{\mathrm{x}}$ conversion efficiency was observed. The $\mathrm{NH}_{3}$ slip $<10$ ppm were observed at ANR 1.0. However, the $\mathrm{NH}_{3}$ slip increased to $60 \mathrm{ppm}$ at ANR 1.2.

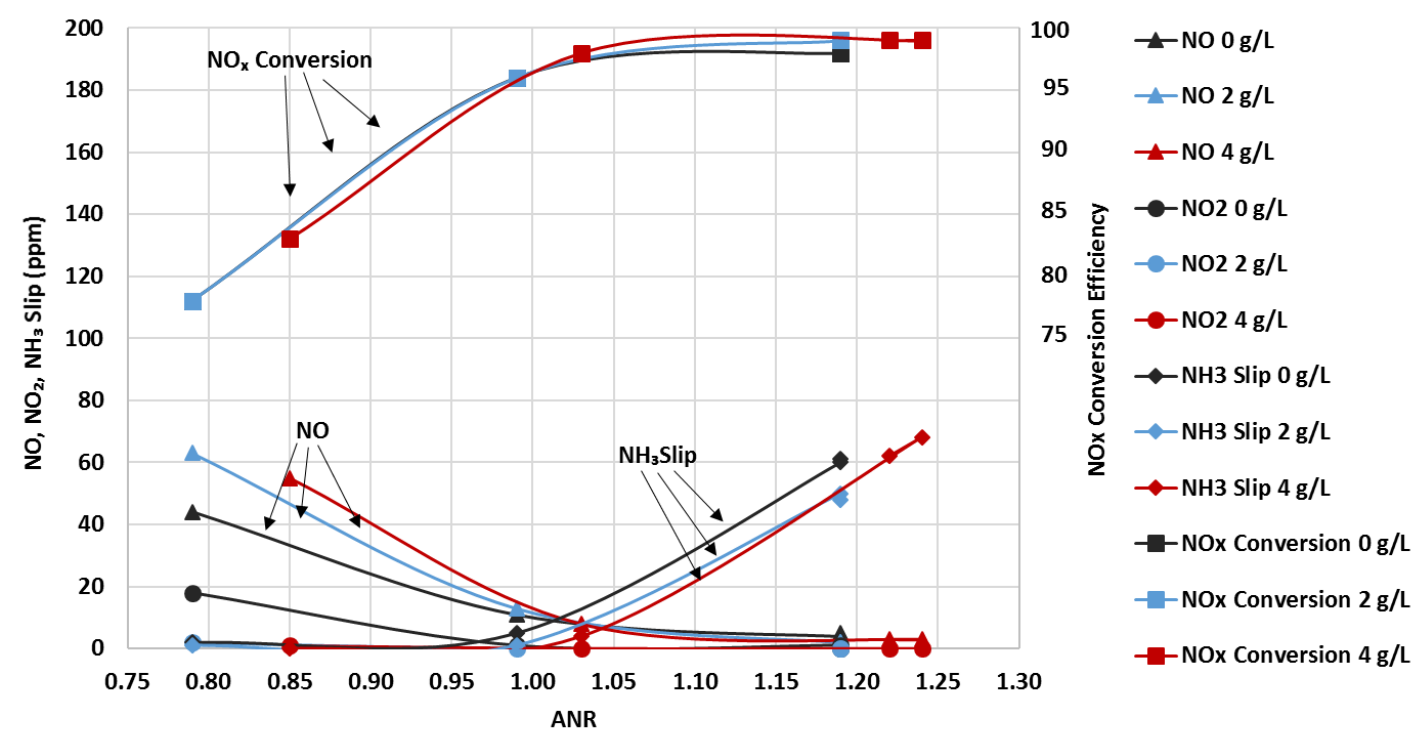

Figure 4.11: $\mathrm{NO}, \mathrm{NO}_{2} \mathrm{NH}_{3}$ slip downstream of the $\mathrm{SCRF}{ }^{\circledR}$ and $\mathrm{NO}_{\mathrm{x}}$ conversion efficiency at various ANR for Test Point 3, with and without PM in the SCRF® (SCRF® inlet temperature $=304{ }^{\circ} \mathrm{C}$ and $\mathrm{SV}=29.1 \mathrm{k} / \mathrm{hr}$ ) 
Figures 4.12 and 4.13 show the $\mathrm{NO}, \mathrm{NO}_{2}$ and $\mathrm{NH}_{3}$ slip concentrations downstream of the SCRF ${ }^{\circledR}$ and $\mathrm{NO}_{\mathrm{x}}$ conversion efficiency of the SCRF® relative to the ANR for Test Points 6 and 8 respectively, with and without PM loading in the SCRF®. From Figure 4.12 it is observed that $\sim 100 \mathrm{ppm} \mathrm{NO}$ and $\sim 150 \mathrm{ppm} \mathrm{NO} \mathrm{NO}_{2}$ concentrations were present downstream of the SCRF at ANR 0.8 for Test Point 6 without PM loading. However, the concentrations decreased to $<10 \mathrm{ppm}$ for Test Point 6 with 2 and $4 \mathrm{~g} / \mathrm{L}$ PM loading at ANR 0.8. This is due to the consumption of $\mathrm{NO}_{2}$ via $\mathrm{NO}_{2}$ assisted oxidation of PM. From Figures 4.12 and 4.13 it is observed that the $\mathrm{NO}_{\mathrm{x}}$ conversion for the test without $\mathrm{PM}$ loading (black line) is $3-4 \%$ higher that the tests with 2 and $4 \mathrm{~g} / \mathrm{L}$ PM loading in the SCRF®. This could be attributed to decrease in the effective $\mathrm{NO}_{2} / \mathrm{NO}_{\mathrm{x}}$ ratios on the SCRF ${ }^{\circledR}$ catalyst due to consumption of $\mathrm{NO}_{2}$ via $\mathrm{NO}_{2}$ assisted oxidation of PM. The $\mathrm{NO}_{\mathrm{x}}$ conversion efficiency for Test point 8 with PM loading is observed to be $\sim 87 \%$ at ANR 1.0 and $\sim 92 \%$ at ANR 1.2, which is $6-7 \%$ lower than the corresponding NOx conversion efficiency for Test Points 3 and 6.

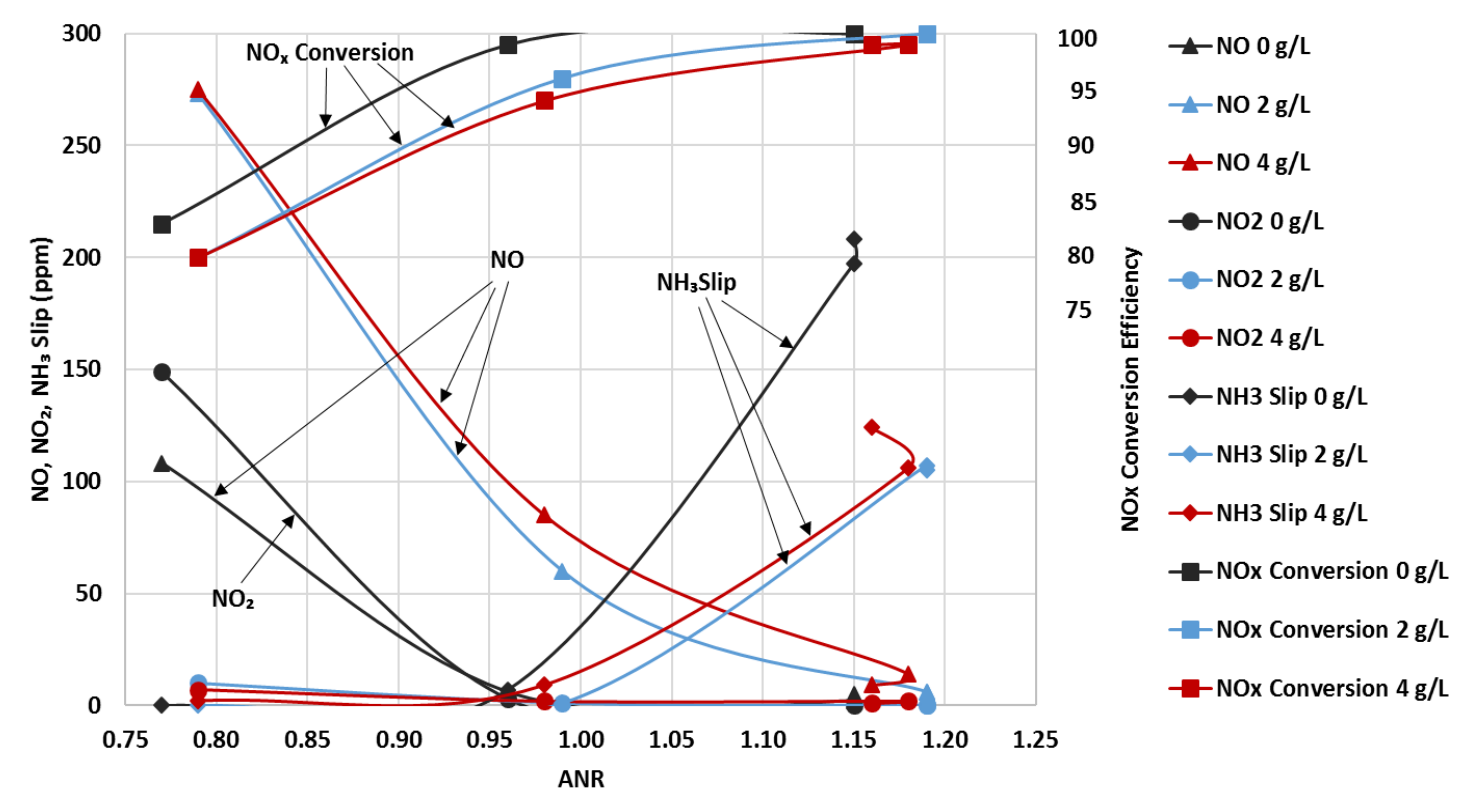

Figure 4.12: $\mathrm{NO}, \mathrm{NO}_{2} \mathrm{NH}_{3}$ slip downstream of the $\mathrm{SCRF}{ }^{\circledR}$ and $\mathrm{NO}_{\mathrm{x}}$ conversion efficiency at various ANR for Test Point 6, with and without PM in the SCRF® $\left(\mathrm{SCRF}{ }^{\circledR}\right.$ inlet temperature $=345^{\circ} \mathrm{C}$ and $\mathrm{SV}=18.8 \mathrm{k} / \mathrm{hr}$ ) 

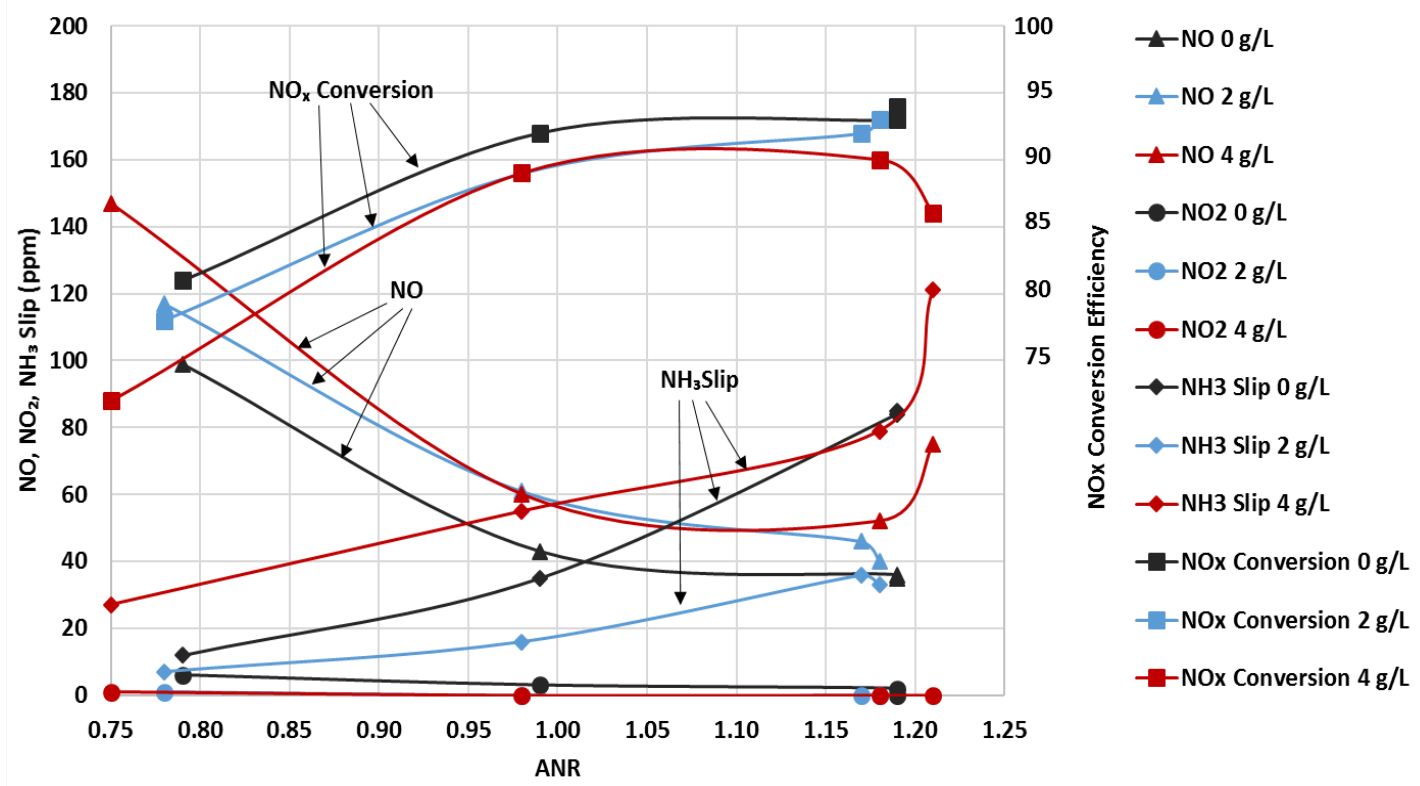

Figure 4.13: $\mathrm{NO}, \mathrm{NO}_{2} \mathrm{NH}_{3}$ slip downstream of the $\mathrm{SCRF} \AA$ and $\mathrm{NO}_{\mathrm{x}}$ conversion efficiency at various ANR for Test Point 8 , with and without PM in the SCRF® (SCRF®) inlet temperature $=443{ }^{\circ} \mathrm{C}$ and $\mathrm{SV}=46.3 \mathrm{k} / \mathrm{hr}$ )

\subsubsection{Analysis of Data}

The analysis of $\mathrm{NO}$ and $\mathrm{NO}_{2}$ concentrations at 0 ANR (without urea injection) for the SCRF® without PM loading and with 2 and $4 \mathrm{~g} / \mathrm{L}$ of PM loading are given in Tables $4.13,4.14$ and 4.15 respectively. From Table 4.13 it can be observed that the NO and $\mathrm{NO}_{2}$ concentrations at the $\mathrm{SCRF}{ }^{\circ}$ inlet and outlet remain unchanged for all the Test Points, without PM loading in the SCRF®. This indicates that the SCRF® has negligible tendency to oxidize $\mathrm{NO}$ to $\mathrm{NO}_{2}$. However, the production-2013-SCR showed up to $20 \%$ conversion of $\mathrm{NO}$ to $\mathrm{NO}_{2}$ across the two SCR-A brick, without urea injection. 
Table 4.13: $\mathrm{NO}$ and $\mathrm{NO}_{2}$ concentrations at the inlet and outlet of the SCRF® at 0 ANR without PM loading in the SCRF®

\begin{tabular}{|c|c|c|c|c|c|c|c|c|c|c|}
\hline $\begin{array}{l}\text { Test } \\
\text { Point }\end{array}$ & $\begin{array}{c}\text { SCRF® } \\
\text { Inlet } \\
\text { Temp. }\end{array}$ & $\begin{array}{c}\text { SCRF® } \\
\text { Inlet } \\
\text { NO }\end{array}$ & $\begin{array}{c}\text { SCRF® } \\
\text { Outlet } \\
\text { NO }\end{array}$ & $\begin{array}{c}\text { Delta } \\
\text { NO }\end{array}$ & $\begin{array}{c}\mathrm{SCRF}{ }^{\circledR} \\
\text { Inlet } \\
\mathrm{NO}_{2}\end{array}$ & $\begin{array}{c}\mathrm{SCRF}{ }^{\circledR} \\
\text { Outlet } \\
\mathrm{NO}_{2}\end{array}$ & $\begin{array}{l}\text { Delta } \\
\mathrm{NO}_{2}\end{array}$ & $\begin{array}{c}\text { SCRF® } \\
\text { Inlet } \\
\text { NO }_{x}\end{array}$ & $\begin{array}{c}\text { SCRF® } \\
\text { Outlet } \\
\text { NO }_{x}\end{array}$ & $\begin{array}{c}\text { Ratio } \\
\text { of } \\
\text { In/Out } \\
\mathrm{NO}_{2}\end{array}$ \\
\hline$[-]$ & {$\left[{ }^{\circ} \mathrm{C}\right]$} & [ppm] & [ppm] & [ppm] & [ppm] & [ppm] & [ppm] & [ppm] & [ppm] & {$[-]$} \\
\hline 1 & 213 & 345 & 352 & -7 & 213 & 200 & 13 & 558 & 552 & 0.94 \\
\hline 3 & 301 & 158 & 160 & -2 & 121 & 116 & 5 & 279 & 276 & 0.96 \\
\hline 6 & 345 & 795 & 808 & -13 & 674 & 688 & -14 & 1469 & 1496 & 1.02 \\
\hline 8 & 443 & 411 & 415 & -4 & 140 & 139 & 1 & 551 & 554 & 0.99 \\
\hline
\end{tabular}

From Table 4.14 and 4.15 it can be observed that the ratio of the $\mathrm{SCRF}{ }^{\circledR}$ outlet $\mathrm{NO}_{2}$ to the $\mathrm{SCRF} \circledast$ inlet $\mathrm{NO}_{2}$ decreases with the increase in the SCRF® inlet temperature (Test Points are arranged in the increasing order of the SCRF® inlet temperature) and increase in PM loading in the SCRF®. This can be attributed to the consumption of $\mathrm{NO}_{2}$ via $\mathrm{NO}_{2}$ assisted oxidation of PM, as indicated by the reactions in equations 4.4 and 4.5. The higher proportion of $\mathrm{NO}_{2}$ available at the SCRF® inlet is consumed through the $\mathrm{NO}_{2}$ assisted oxidation of PM, as the substrate temperature and PM in the filter increases. The $\mathrm{NO}_{2}$ is converted to $\mathrm{NO}$ by oxidation of $\mathrm{PM}$, hence the coherent increase of $\mathrm{NO}$ concentration at the SCRF® outlet was also observed as indicated in Table 4.12 and 4.13.

$$
\begin{array}{ll}
\mathrm{C}+\mathrm{NO}_{2} \rightarrow \mathrm{CO}+\mathrm{NO} & \text { Eqn. } 4.4 \\
\mathrm{C}+2 \mathrm{NO}_{2} \rightarrow \mathrm{CO}_{2}+2 \mathrm{NO} & \text { Eqn. } 4.5
\end{array}
$$

\begin{tabular}{|c|c|c|c|c|c|c|c|c|c|c|}
\hline $\begin{array}{l}\text { Test } \\
\text { Point }\end{array}$ & $\begin{array}{c}\text { SCRF® } \\
\text { Inlet } \\
\text { Temp. }\end{array}$ & $\begin{array}{c}\text { SCRF® } \\
\text { Inlet } \\
\text { NO } \\
\end{array}$ & $\begin{array}{c}\text { SCRF® } \\
\text { Outlet } \\
\text { NO } \\
\end{array}$ & $\begin{array}{c}\text { Delta } \\
\text { NO }\end{array}$ & $\begin{array}{c}\mathrm{SCRF} \circledast \\
\text { Inlet } \\
\mathrm{NO}_{2} \\
\end{array}$ & $\begin{array}{c}\mathrm{SCRF} \circledast \\
\text { Outlet } \\
\mathrm{NO}_{2} \\
\end{array}$ & $\begin{array}{c}\text { Delta } \\
\mathrm{NO}_{2} \\
\end{array}$ & $\begin{array}{c}\text { SCRF® } \\
\text { Inlet } \\
\text { NO }_{x} \\
\end{array}$ & $\begin{array}{c}\text { SCRF } ® \\
\text { Outlet } \\
\text { NO } \\
\end{array}$ & $\begin{array}{c}\text { Ratio } \\
\text { of } \\
\mathrm{In} / \text { Out } \\
\mathrm{NO}_{2} \\
\end{array}$ \\
\hline$[-]$ & {$\left[{ }^{\circ} \mathbf{C}\right]$} & [ppm] & [ppm] & [ppm] & [ppm] & [ppm] & [ppm] & [ppm] & [ppm] & {$[-]$} \\
\hline 1 & 206 & 403 & 387 & 16 & 203 & 205 & -2 & 606 & 592 & 1.01 \\
\hline 3 & 305 & 161 & 198 & -37 & 131 & 88 & 43 & 292 & 286 & 0.67 \\
\hline 6 & 340 & 743 & 963 & -220 & 644 & 424 & 220 & 1387 & 1387 & 0.66 \\
\hline 8 & 438 & 424 & 457 & -33 & 125 & 52 & 73 & 549 & 509 & 0.42 \\
\hline
\end{tabular}

Table 4.14: $\mathrm{NO}$ and $\mathrm{NO}_{2}$ concentrations at the inlet and outlet of the SCRF® at 0 ANR with $2 \mathrm{~g} / \mathrm{L}$ PM loading in the SCRF® 
Table 4.15: $\mathrm{NO}$ and $\mathrm{NO}_{2}$ concentrations at the inlet and outlet of the SCRF® at 0 ANR with $4 \mathrm{~g} / \mathrm{L}$ PM loading in the SCRF®

\begin{tabular}{|c|c|c|c|c|c|c|c|c|c|c|}
\hline $\begin{array}{l}\text { Test } \\
\text { Point }\end{array}$ & $\begin{array}{c}\text { SCRF® } \\
\text { Inlet } \\
\text { Temp. }\end{array}$ & $\begin{array}{c}\text { SCRF® } \\
\text { Inlet } \\
\text { NO }\end{array}$ & $\begin{array}{c}\text { SCRF® } \\
\text { Outlet } \\
\text { NO }\end{array}$ & $\begin{array}{c}\text { Delta } \\
\text { NO }\end{array}$ & $\begin{array}{c}\mathrm{SCRF}{ }^{\circledR} \\
\text { Inlet } \\
\mathrm{NO}_{2} \\
\end{array}$ & $\begin{array}{c}\mathrm{SCRF} ® \\
\text { Outlet } \\
\mathrm{NO}_{2} \\
\end{array}$ & $\begin{array}{l}\text { Delta } \\
\mathrm{NO}_{2}\end{array}$ & $\begin{array}{c}\text { SCRF® } \\
\text { Inlet } \\
\text { NOx } \\
\end{array}$ & $\begin{array}{c}\text { SCRF }{ }^{\circledR} \\
\text { Outlet } \\
\text { NOx } \\
\end{array}$ & $\begin{array}{c}\text { Ratio } \\
\text { of } \\
\text { In/Out } \\
\mathrm{NO}_{2}\end{array}$ \\
\hline$[-]$ & {$\left[{ }^{\circ} \mathbf{C}\right]$} & [ppm] & [ppm] & [ppm] & [ppm] & [ppm] & [ppm] & [ppm] & [ppm] & {$[-]$} \\
\hline 1 & 207 & 452 & 401 & 51 & 141 & 116 & 25 & 593 & 517 & 0.82 \\
\hline 3 & 302 & 198 & 249 & -51 & 124 & 75 & 49 & 322 & 324 & 0.60 \\
\hline 6 & 341 & 793 & 1151 & -358 & 588 & 231 & 357 & 1381 & 1382 & 0.39 \\
\hline 8 & 446 & 415 & 502 & -87 & 115 & 22 & 93 & 530 & 524 & 0.19 \\
\hline
\end{tabular}

The consumption of $\mathrm{NO}_{2}$, through $\mathrm{NO}_{2}$ assisted oxidation of $\mathrm{PM}$, changes the $\mathrm{NO}_{2} / \mathrm{NO}_{\mathrm{x}}$ ratio across the catalyst. The $\mathrm{NO}_{2} / \mathrm{NO}_{\mathrm{x}}$ ratios at the inlet and outlet of the SCRF® without urea injection ( 0 ANR) are given in Table 4.16. Since the ANR is $0, \mathrm{NO}_{2}$ consumption through SCR reactions is zero and the changes in the $\mathrm{NO}_{2} / \mathrm{NO}_{\mathrm{x}}$ ratios are only due to consumption of $\mathrm{NO}_{2}$ through $\mathrm{NO}_{2}$ assisted oxidation of PM. Figure 4.14 shows the $\mathrm{NO}_{2} / \mathrm{NO}_{\mathrm{x}}$ ratios at the inlet and outlet of the SCRF® at 0 ANR. It can be observed that the SCRF® inlet and outlet $\mathrm{NO}_{2} / \mathrm{NO}_{\mathrm{x}}$ ratio remains unchanged for Test Point 1 , since the SCRF® inlet temperature is approximately $200^{\circ} \mathrm{C}$ and $\mathrm{NO}_{2}$ assisted oxidation of PM is negligible at that temperature. However, as the SCRF® inlet temperature increases for 2 and $4 \mathrm{~g} / \mathrm{L}$ data, the difference between the inlet and outlet $\mathrm{NO}_{2} / \mathrm{NO}_{\mathrm{x}}$ ratios increases due to consumption of $\mathrm{NO}_{2}$ through $\mathrm{NO}_{2}$ assisted oxidation of PM. As the PM loading in the SCRF® increases from 2 to $4 \mathrm{~g} / \mathrm{L}$ for the same Test Point, the difference between the inlet and outlet $\mathrm{NO}_{2} / \mathrm{NO}_{\mathrm{x}}$ ratios increases further indicating higher proportion of $\mathrm{NO}_{2}$ being consumed through $\mathrm{NO}_{2}$ assisted oxidation of $\mathrm{PM}$, with increase in PM loading from 2 to $4 \mathrm{~g} / \mathrm{L}$. Due to $\mathrm{NO}_{2}$ consumption, the effective $\mathrm{NO}_{2} / \mathrm{NO}_{\mathrm{x}}$ ratio at the reaction site on the substrate of the SCRF® could be much lower than the $\mathrm{NO}_{2} / \mathrm{NO}_{\mathrm{x}}$ ratios at the SCRF® inlet. Hence, effective $\mathrm{NO}_{2} / \mathrm{NO}_{\mathrm{x}}$ ratio should be considered while analyzing the $\mathrm{NO}_{\mathrm{x}}$ reduction performance of the $\mathrm{SCRF}$. 
Table 4.16: $\mathrm{NO}_{2} / \mathrm{NO}_{\mathrm{x}}$ ratios at the inlet and outlet of the SCRF® at 0 ANR

\begin{tabular}{|c|c|c|c|c|c|c|c|}
\hline \multirow{2}{*}{$\begin{array}{l}\text { Test } \\
\text { Point }\end{array}$} & \multirow{2}{*}{$\begin{array}{c}\text { SCRF }{ }^{\circledR} \\
\text { Inlet } \\
\text { Temp. } \\
{\left[{ }^{\circ} \mathrm{C}\right]}\end{array}$} & \multicolumn{2}{|c|}{ SCRF® ${ }^{\circledR} 0 \mathrm{~g} / \mathrm{L}$} & \multicolumn{2}{|c|}{ SCRF® $-2 \mathrm{~g} / \mathrm{L}$} & \multicolumn{2}{|c|}{ SCRF ${ }^{\circledR}-4 \mathrm{~g} / \mathrm{L}$} \\
\hline & & $\begin{array}{c}\text { Inlet } \\
\mathrm{NO}_{2} / \mathrm{NO}_{\mathrm{x}}\end{array}$ & $\begin{array}{c}\text { Outlet } \\
\mathrm{NO}_{2} / \mathrm{NO}_{\mathrm{x}}\end{array}$ & $\begin{array}{c}\text { Inlet } \\
\mathrm{NO}_{2} / \mathrm{NO}_{\mathrm{x}}\end{array}$ & $\begin{array}{c}\text { Outlet } \\
\mathrm{NO}_{2} / \mathrm{NO}_{\mathrm{x}}\end{array}$ & $\begin{array}{c}\text { Inlet } \\
\mathrm{NO}_{2} / \mathrm{NO}_{\mathrm{x}}\end{array}$ & $\begin{array}{c}\text { Outlet } \\
\mathrm{NO}_{2} / \mathrm{NO}_{\mathrm{x}}\end{array}$ \\
\hline 1 & 213 & 0.38 & 0.36 & 0.34 & 0.35 & 0.24 & 0.22 \\
\hline 3 & 301 & 0.43 & 0.42 & 0.45 & 0.31 & 0.42 & 0.23 \\
\hline 6 & 345 & 0.46 & 0.46 & 0.47 & 0.31 & 0.43 & 0.17 \\
\hline 8 & 443 & 0.25 & 0.25 & 0.23 & 0.1 & 0.22 & 0.04 \\
\hline
\end{tabular}

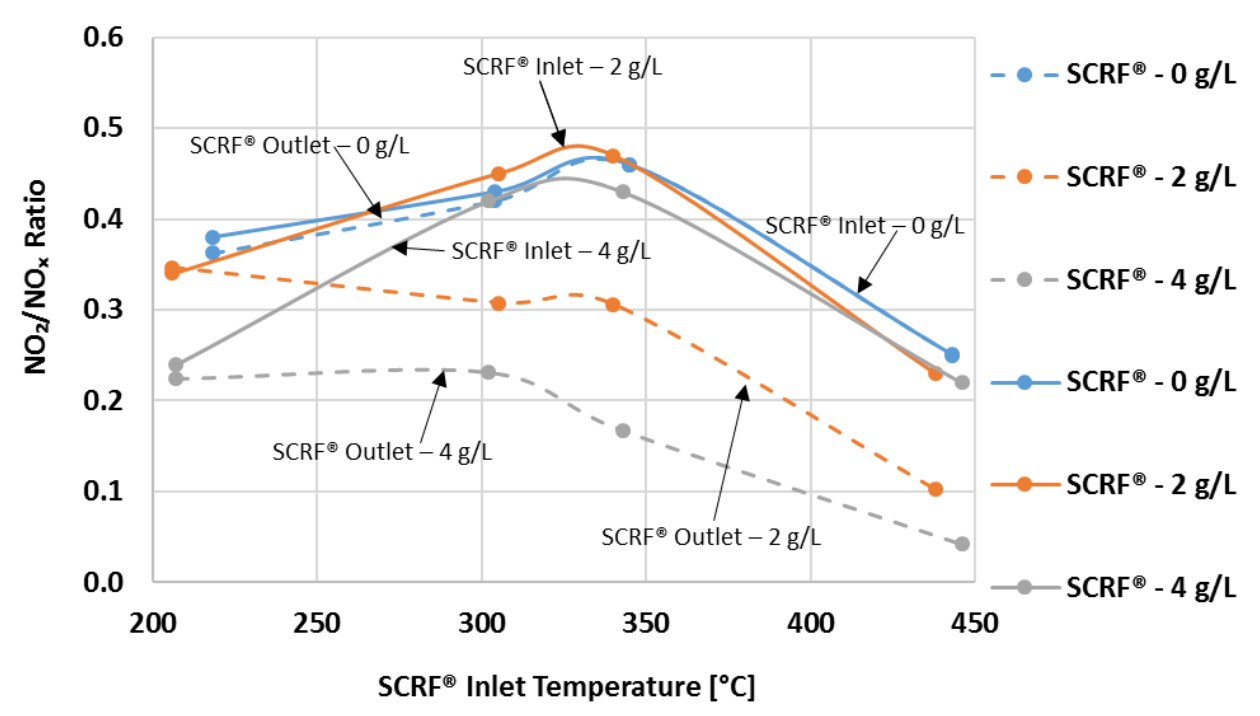

Figure 4.14: $\mathrm{NO}_{2} / \mathrm{NO}_{\mathrm{x}}$ ratios at the inlet and outlet of the SCRF® at 0 ANR

Table 4.17 and 4.18 provide the $\mathrm{NO}, \mathrm{NO}_{2}$ and $\mathrm{NH}_{3}$ concentrations downstream of the SCRF® and the $\mathrm{NO}_{\mathrm{x}}$ conversion efficiency of the SCRF® at ANR of 0.8. It can be observed that the $\mathrm{NO}_{\mathrm{x}}$ conversion efficiency improved by $2-4 \%$ for Test Point 1 and 3 , with increase in the PM loading. However, for Test Point 6 and $8, \mathrm{NO}_{\mathrm{x}}$ conversion efficiency reduced by $5-10 \%$, with increase in $\mathrm{PM}$. The $\mathrm{NO}_{\mathrm{x}}$ conversion efficiency for all the Test Points is shown in Figure 4.15. From Figure 4.16 it can be observed that less than 10 ppm $\mathrm{NH}_{3}$ slip was observed downstream of the SCRF® except for Test Point 8, which is in agreement with the values observed for the production-2013-SCR, described in the section 4.1 . 


\begin{tabular}{|c|c|c|c|c|c|c|}
\hline \multirow{6}{*}{$\begin{array}{l}\bar{\Xi} \\
\underline{z} \\
\mathbf{z}^{m}\end{array}$} & \multirow{2}{*}{ 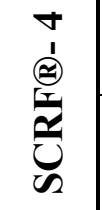 } & 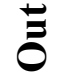 & $N$ & 0 & $\sim$ & $\widehat{\imath}$ \\
\hline & & $\Xi$ & $\underset{\infty}{+\infty}$ & $\underset{\nabla}{\stackrel{\Delta}{N}}$ & 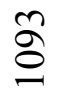 & बे \\
\hline & \multirow{2}{*}{ 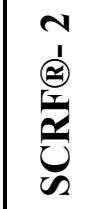 } & 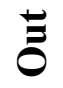 & $\sim$ & - & 0 & $r$ \\
\hline & & $\Xi$ & $\begin{array}{l}\infty \\
+\infty\end{array}$ & $\overrightarrow{\mathrm{n}}$ & 용 & 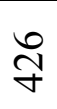 \\
\hline & \multirow{2}{*}{ 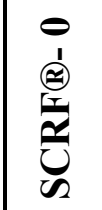 } & 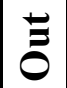 & - & $\sim$ & 0 & $\simeq$ \\
\hline & & $\Xi$ & 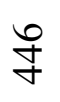 & సి & $\stackrel{\curvearrowleft}{\beth}$ & $\stackrel{\infty}{\underset{\sim}{\sim}}$ \\
\hline \multirow{6}{*}{$\begin{array}{l}\bar{E} \\
\bar{Z} \\
\bar{Z} \\
Z\end{array}$} & \multirow{2}{*}{ 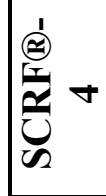 } & 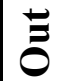 & - & - & $r$ & - \\
\hline & & $\Xi$ & $\Xi$ & $\stackrel{\Xi}{\beth}$ & $\begin{array}{l}\infty \\
\infty \\
\infty\end{array}$ & $\stackrel{n}{\Xi}$ \\
\hline & \multirow{2}{*}{ 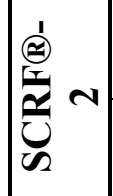 } & $\Xi$ & - & $N$ & $\stackrel{0}{=}$ & - \\
\hline & & $\Xi$ & 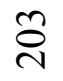 & $\vec{n}$ & $\underset{J}{ষ}$ & $\stackrel{\sim}{\beth}$ \\
\hline & \multirow{2}{*}{ 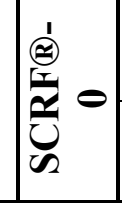 } & 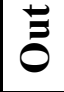 & 6 & $\infty$ & $\stackrel{g}{ \pm}$ & 6 \\
\hline & & $\Xi$ & $\frac{n}{\sim}$ & $\bar{\beth}$ & $\frac{t}{6}$ & $\stackrel{巳}{ \pm}$ \\
\hline \multirow{6}{*}{$\begin{array}{l}\bar{\Xi} \\
\bar{a} \\
0 \\
0 \\
z\end{array}$} & \multirow{2}{*}{ 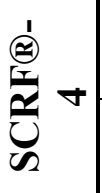 } & $\bar{\Xi}$ & $\stackrel{\Xi}{\beth}$ & $n$ & $\stackrel{n}{\sim}$ & $\stackrel{\Xi}{ \pm}$ \\
\hline & & $\Xi$ & $\bar{\nabla}$ & $\stackrel{\infty}{\stackrel{2}{2}}$ & $\stackrel{2}{2}$ & $\frac{n}{\gamma}$ \\
\hline & \multirow{2}{*}{ 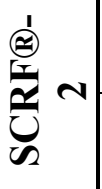 } & 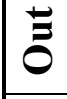 & $\stackrel{\sim}{\Xi}$ & $\hat{\sigma}$ & $\stackrel{m}{\curvearrowright}$ & 三 \\
\hline & & $\Xi$ & O̊g & $\overline{0}$ & $\stackrel{g}{\mathbb{2}}$ & $\underset{\forall}{\stackrel{テ}{\forall}}$ \\
\hline & \multirow{2}{*}{ 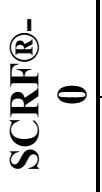 } & $\ddot{\Xi}$ & అ & $\forall$ & $\stackrel{\infty}{0}$ & ลे \\
\hline & & $\Xi$ & $\stackrel{n}{+}$ & $\stackrel{\infty}{n}$ & $\frac{2}{1}$ & $\exists$ \\
\hline \multicolumn{3}{|c|}{ 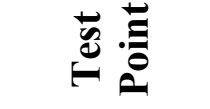 } & - & $m$ & 6 & $\infty$ \\
\hline
\end{tabular}

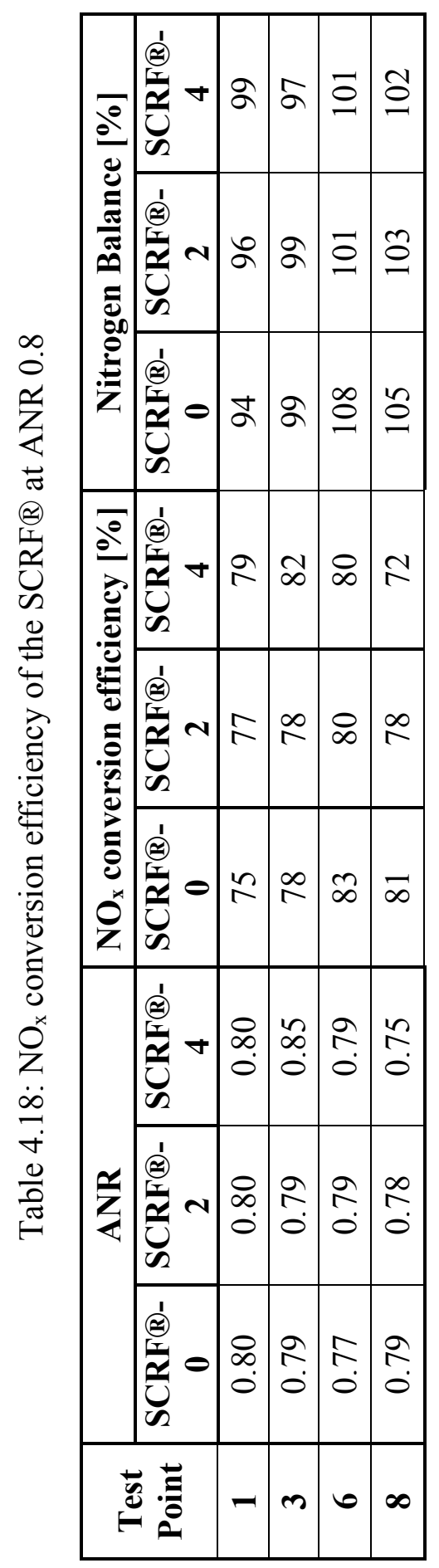




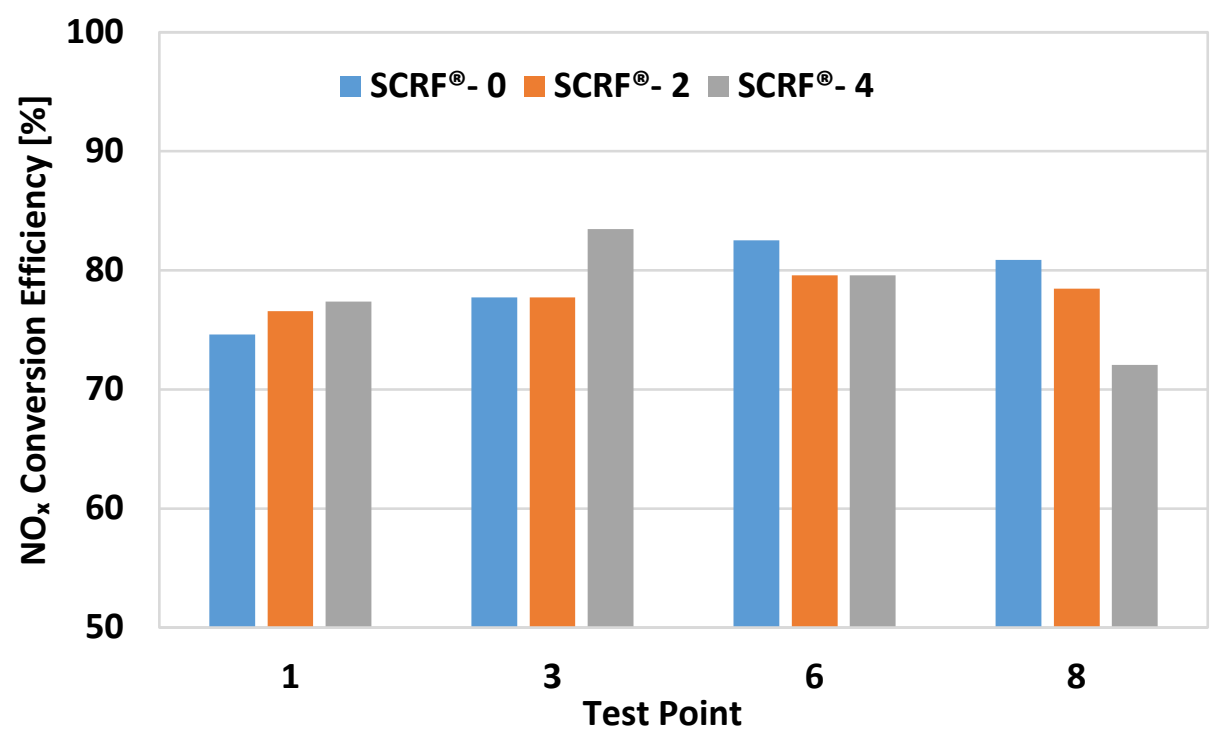

Figure 4.15: $\mathrm{NO}_{\mathrm{x}}$ conversion efficiency of the SCRF® with and without PM at ANR 0.8

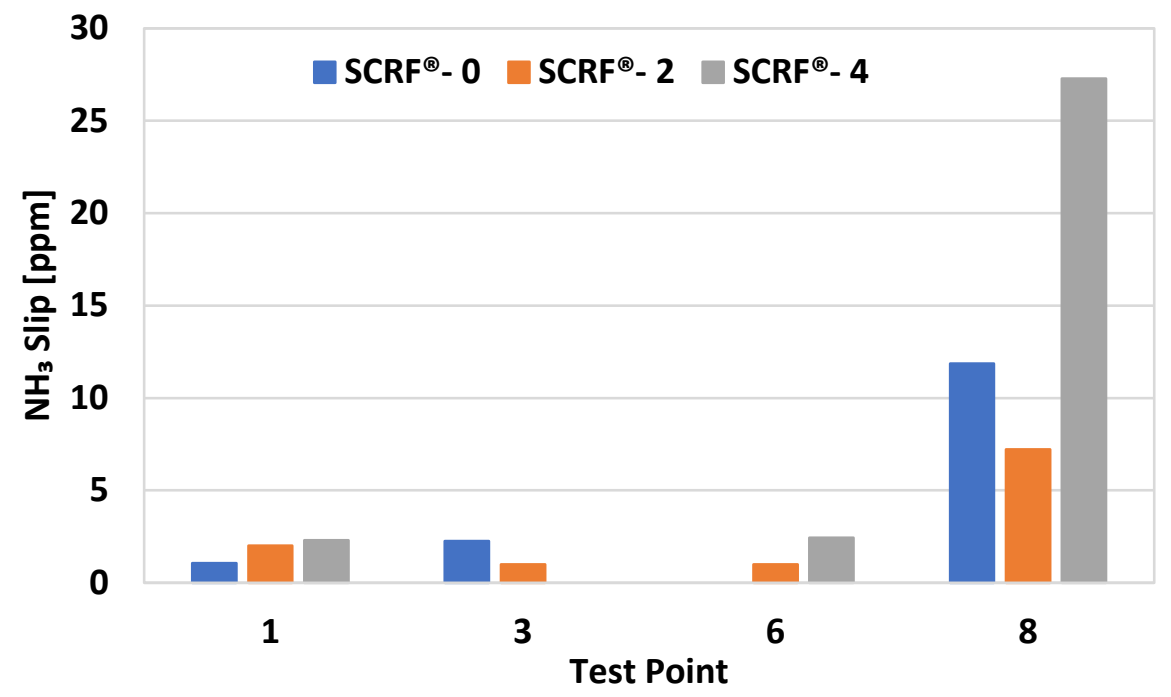

Figure 4.16: $\mathrm{NH}_{3}$ Slip from the SCRF® with and without PM at ANR 0.8 
Table 4.19 and 4.20 provide the $\mathrm{NO}, \mathrm{NO}_{2}$ and $\mathrm{NH}_{3}$ concentrations downstream of the SCRF® and the $\mathrm{NO}_{\mathrm{x}}$ conversion efficiency of the SCRF® at ANR of 1.0. Since the SCRF® inlet $\mathrm{NO}_{2} / \mathrm{NO}_{\mathrm{x}}$ ratios were lower than 0.5 , most of $\mathrm{NO}_{2}$ at the inlet of the $\mathrm{SCRF}{ }^{\circledR}$ is reduced at ANR of 1.0. Table 4.20 and Figure 4.17 indicate that the $\mathrm{NO}_{\mathrm{x}}$ conversion was not affected significantly by PM loading in the SCRF®, at SCRF® inlet temperatures below $300^{\circ} \mathrm{C}$ (Test Point 1 and 3). The $\mathrm{NO}_{\mathrm{x}}$ conversion efficiency for Test Point 1 without PM loading is observed to be lower (89 \%) due to insufficient stabilization time for measurement of the concentrations at the outlet of the SCRF®. The $\mathrm{NO}_{\mathrm{x}}$ conversion efficiency for Test Point 3 with $4 \mathrm{~g} / \mathrm{L}$ PM loading is observed to be higher by $2 \%$ due to higher ANR (1.03). However, increase in the PM deposition affected the $\mathrm{NO}_{\mathrm{x}}$ conversion efficiency of the SCRF®, at SCRF® inlet temperatures above $350^{\circ} \mathrm{C}$ (Test Point 6 and 8). This could be attributed to the reduced effective $\mathrm{NO}_{2} / \mathrm{NO}_{\mathrm{x}}$ ratio in the SCRF®, as described in Table 4.16, since a significant amount of $\mathrm{NO}_{2}$ is consumed through the passive oxidation pathway. Hence, the lower effective $\mathrm{NO}_{2} / \mathrm{NO}_{\mathrm{x}}$ ratio reduces the $\mathrm{NO}_{\mathrm{x}}$ conversion for Test Point 6 and 8. The SCRF® inlet ANR was maintained very close to 1.0 and the nitrogen balance for all the tests is also very close to $100 \%$, indicating that the urea injection, $\mathrm{NO}_{\mathrm{x}}$ conversion and ammonia slip phenomenon are in agreement.

Tables 4.21 and 4.22 provide the $\mathrm{NO}, \mathrm{NO}_{2}$ and $\mathrm{NH}_{3}$ concentrations downstream of the $\mathrm{SCRF}{ }^{\circledR}$ and the $\mathrm{NO}_{x}$ conversion efficiency of the SCRF® at ANR of 1.2. Table 4.22 shows that most of the $\mathrm{NO}_{\mathrm{x}}$ is reduced in the SCRF® at ANR of 1.2 and the $\mathrm{NO}_{\mathrm{x}}$ conversion efficiency is above $99 \%$ for all the Test Points except Test Point 8. As described in Table 4.10, Test Point 8 is a high temperature $\left(450^{\circ} \mathrm{C}\right)$ and high SV and $(48$ $\mathrm{k} / \mathrm{hr}$ ) Test Point. Oxidation of $\mathrm{NH}_{3}$ to $\mathrm{N}_{2}$ and $\mathrm{NO}$ is a dominant reaction at temperatures above $400^{\circ} \mathrm{C}$, the $\mathrm{NO}_{\mathrm{x}}$ conversion efficiency is poor. Also the Nitrogen balance is poor for this condition since $\mathrm{N} 2$ and $\mathrm{N}_{2} \mathrm{O}$ are not considered in the nitrogen balance estimation. 


\begin{tabular}{|c|c|c|c|c|c|c|}
\hline \multirow{6}{*}{$\begin{array}{l}\bar{\Xi} \\
\bar{\Xi} \\
\bar{m} \\
\bar{z}\end{array}$} & \multirow{2}{*}{ 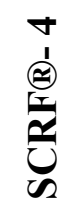 } & $\Xi$ & in & $\nabla$ & $a$ & $i n$ \\
\hline & & $\Xi$ & 8 & $\bar{m}$ & $\begin{array}{l}8 \\
8 \\
0\end{array}$ & ิ \\
\hline & \multirow{2}{*}{ 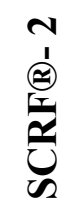 } & $\bar{\Xi}$ & $m$ & - & 一 & 0 \\
\hline & & $\Xi$ & \&े & 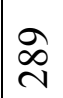 & $\stackrel{?}{m}$ & $\begin{array}{l}0 \\
n \\
n\end{array}$ \\
\hline & \multirow{2}{*}{ 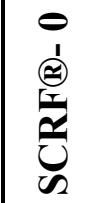 } & $\Xi$ & $N$ & in & $r$ & $n$ \\
\hline & & $\Xi$ & $\begin{array}{l}\infty \\
n \\
n\end{array}$ & $\stackrel{n}{\sim}$ & す & $\stackrel{\infty}{+}$ \\
\hline \multirow{6}{*}{ 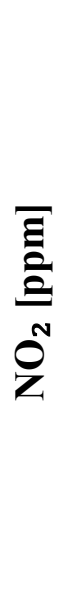 } & \multirow{2}{*}{  } &  & 0 & 0 & N & 0 \\
\hline & & $\Xi$ & す & $\stackrel{\Xi}{\beth}$ & $\begin{array}{l}\infty \\
\infty \\
n\end{array}$ & 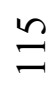 \\
\hline & \multirow{2}{*}{ 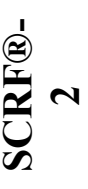 } & 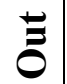 & 0 & 0 & - & 0 \\
\hline & & $\Xi$ & ro & $\bar{m}$ & す & $\stackrel{n}{\simeq}$ \\
\hline & \multirow{2}{*}{ 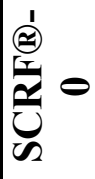 } & $\bar{\Xi}$ & 0 & - & $m$ & $m$ \\
\hline & & $\Xi$ & $\frac{m}{\sim}$ & $\widetilde{\beth}$ & $\frac{+}{6}$ & 욤 \\
\hline \multirow{6}{*}{$\begin{array}{l}\bar{\Xi} \\
\bar{z} \\
\overline{0} \\
\bar{z}\end{array}$} & \multirow{2}{*}{ 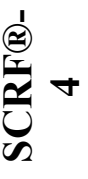 } & $\bar{\Xi}$ & F & $\infty$ & $\infty$ & ○ \\
\hline & & $\Xi$ & $\bar{\gamma}$ & $\stackrel{\infty}{2}$ & হֵ & $\stackrel{n}{\xi}$ \\
\hline & \multirow{2}{*}{ 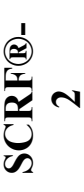 } & $\ddot{\bar{E}}$ & g & 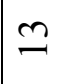 & 8 & $\bar{\sigma}$ \\
\hline & & $\Xi$ & $\hat{o}$ & $\overline{6}$ & $\stackrel{\Re}{\mathbb{I}}$ & $\stackrel{\leftarrow}{+}$ \\
\hline & \multirow{2}{*}{$\underbrace{\Theta}_{\mathscr{S}}$} & $\Xi$ & $\overline{6}$ & $=$ & 6 & $\mathscr{f}$ \\
\hline & & $\Xi$ & $\stackrel{n}{\text { f }}$ & $\stackrel{\infty}{n}$ & 2 & 三 \\
\hline \multicolumn{3}{|c|}{ 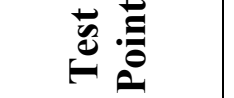 } & - & $m$ & 6 & $\infty$ \\
\hline
\end{tabular}

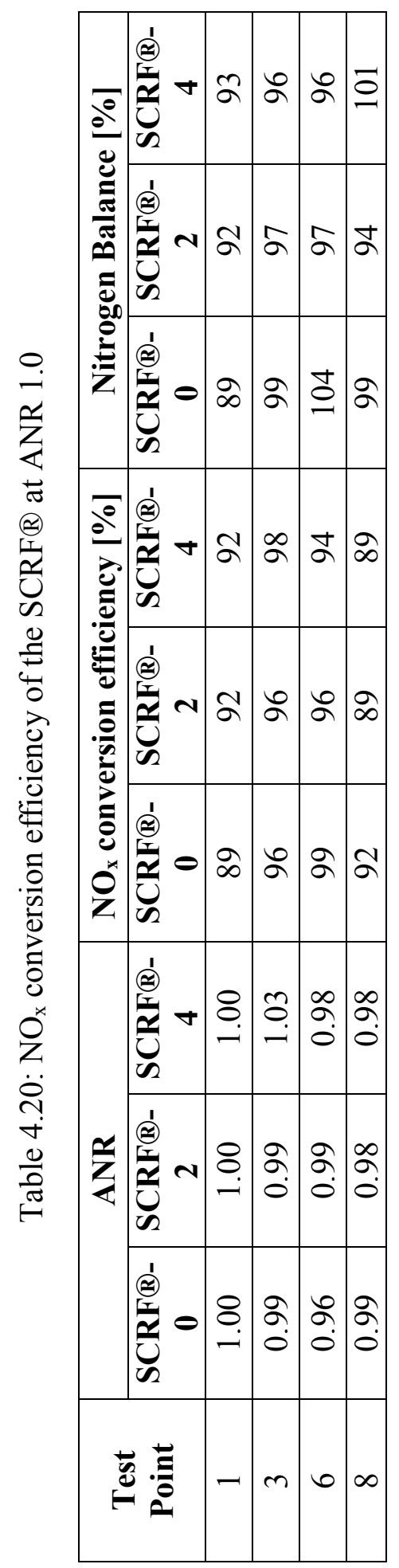




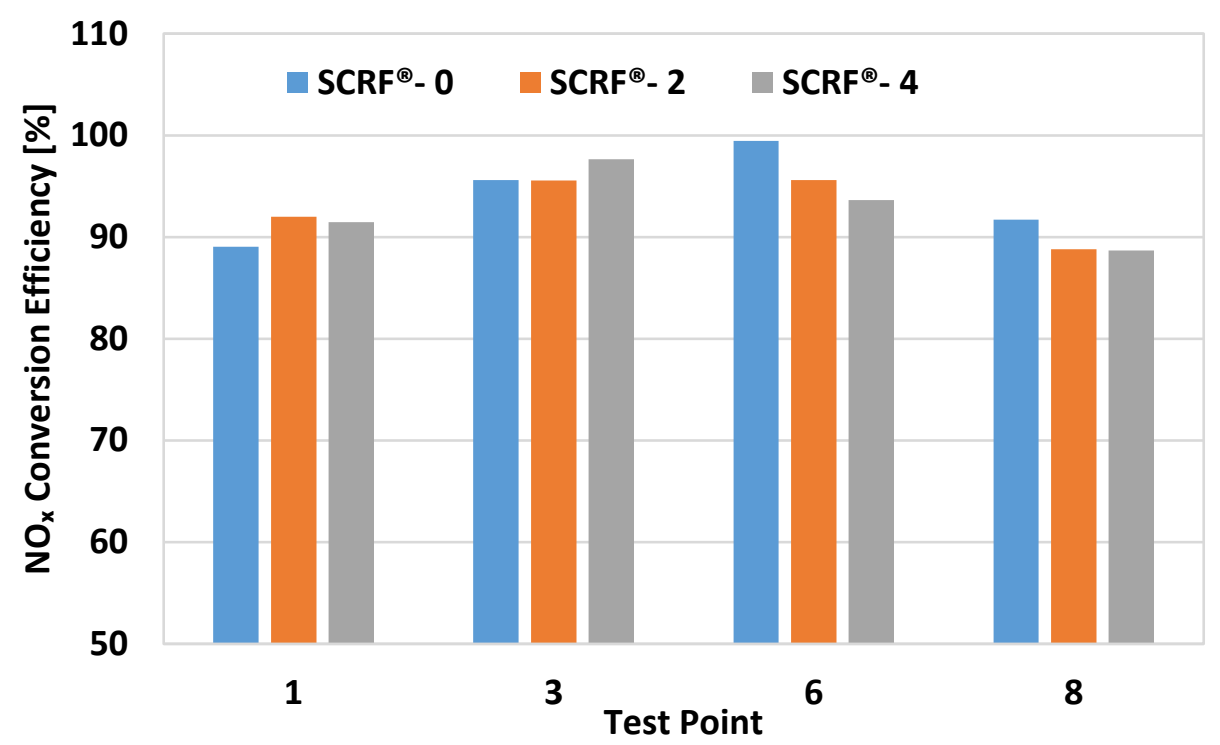

Figure 4.17: $\mathrm{NO}_{\mathrm{x}}$ conversion efficiency of the $\mathrm{SCRF}{ }^{\circledR}$ with and without $\mathrm{PM}$ at $\mathrm{ANR} 1.0$

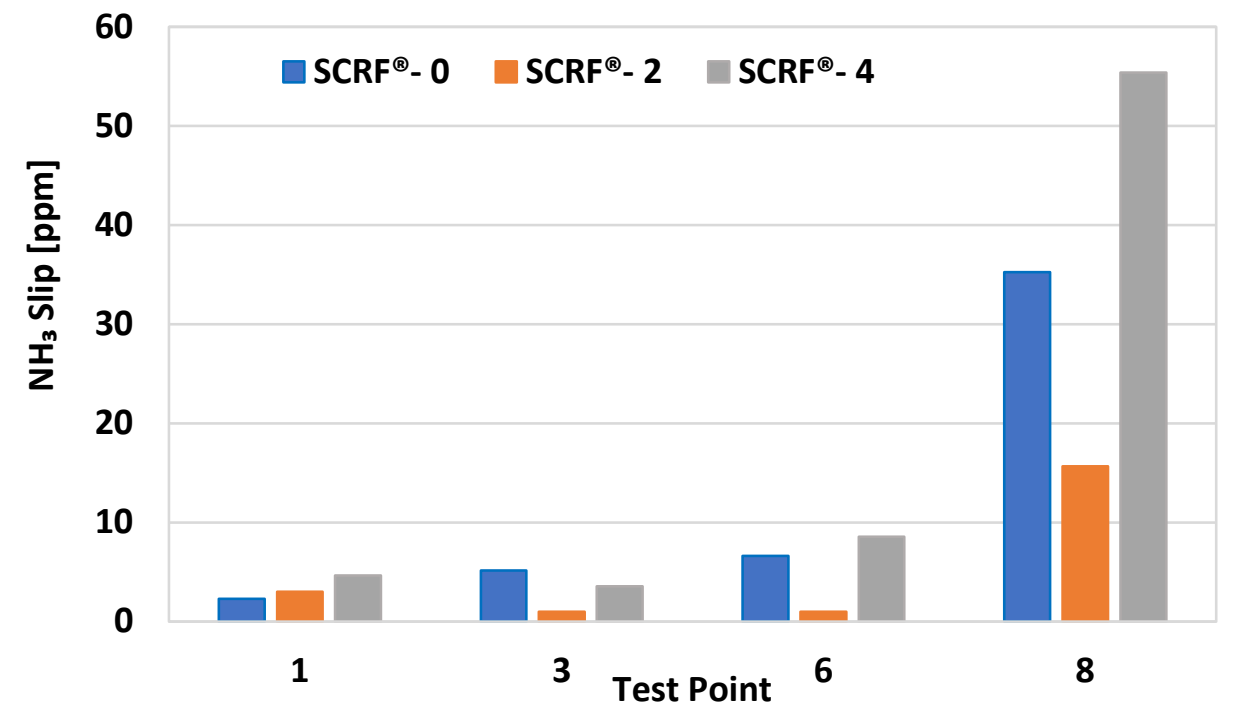

Figure 4.18: $\mathrm{NH}_{3}$ Slip from the $\mathrm{SCRF}{ }^{\circledR}$ with and without PM at ANR 1.0 


\begin{tabular}{|c|c|c|c|c|c|c|}
\hline \multirow{6}{*}{$\begin{array}{l}\bar{\Xi} \\
\bar{z} \\
\bar{z}\end{array}$} & \multirow{2}{*}{  } & $\Xi$ & $\infty$ & $\infty$ & $\stackrel{0}{\circ}$ & 2 \\
\hline & & $\Xi$ & $\underset{N}{ }$ & 文 & (ె) & ำ \\
\hline & \multirow{2}{*}{ 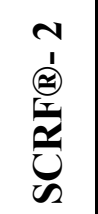 } & $\bar{\Xi}$ & $\exists$ & in & $\hat{0}$ & లి \\
\hline & & $\Xi$ & 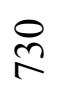 & 守 & 守 & f̊ \\
\hline & \multirow{2}{*}{ 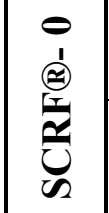 } & 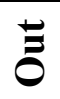 & $\beth$ & 8 & $\hat{a}$ & $\infty_{\infty}^{+}$ \\
\hline & & $\Xi$ & శి & $\bar{n}$ & $\begin{array}{l}n \\
\infty \\
0\end{array}$ & $\hat{6}$ \\
\hline \multirow{6}{*}{ 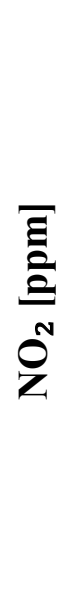 } & \multirow{2}{*}{ 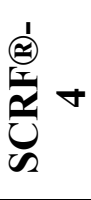 } & $\Xi$ & 0 & 0 & $N$ & 0 \\
\hline & & $\Xi$ & $\Xi$ & $\stackrel{m}{ \pm}$ & $\begin{array}{l}\infty \\
\infty \\
n\end{array}$ & 年 \\
\hline & \multirow{2}{*}{ 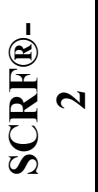 } & $\Xi$ & 0 & 0 & 0 & 0 \\
\hline & & $\Xi$ & $\hat{\text { ஸे }}$ & $\bar{m}$ & J & $\stackrel{\text { I }}{\mathrm{I}}$ \\
\hline & \multirow{2}{*}{ 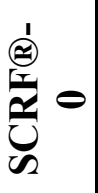 } & $\bar{\Xi}$ & 0 & - & 7 & $N$ \\
\hline & & $\Xi$ & $\frac{m}{\sim}$ & $\vec{\beth}$ & $\frac{\pi}{6}$ & $\stackrel{\text { 巳 }}{ \pm}$ \\
\hline \multirow{6}{*}{$\begin{array}{l}\bar{\Xi} \\
\bar{z} \\
\overline{0} \\
\bar{z}\end{array}$} & \multirow{2}{*}{ 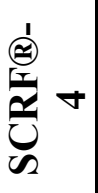 } & $\bar{\Xi}$ & $\stackrel{n}{n}$ & $m$ & $\Xi$ & in \\
\hline & & $\Xi$ & $\bar{\nabla}$ & $\stackrel{\infty}{\stackrel{2}{二}}$ & $\frac{2}{2}$ & $\frac{n}{7}$ \\
\hline & \multirow{2}{*}{ 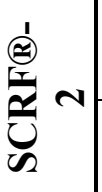 } & 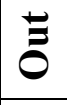 & $r$ & $\sim$ & 6 & \& \\
\hline & & $\Xi$ & ô & 6 & $\stackrel{\mathscr{2}}{\stackrel{2}{+}}$ & $\underset{\sim}{\stackrel{\sim}{\sim}}$ \\
\hline & \multirow{2}{*}{ 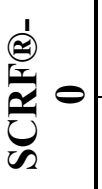 } & $\Xi$ & $r$ & $\nabla$ & $\sim$ & m \\
\hline & & $\Xi$ & $\stackrel{n}{\mathfrak{f}}$ & $\stackrel{\infty}{n}$ & $\frac{n}{2}$ & 三 \\
\hline \multicolumn{3}{|c|}{ 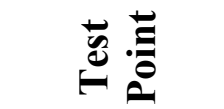 } & - & $m$ & 0 & $\infty$ \\
\hline
\end{tabular}

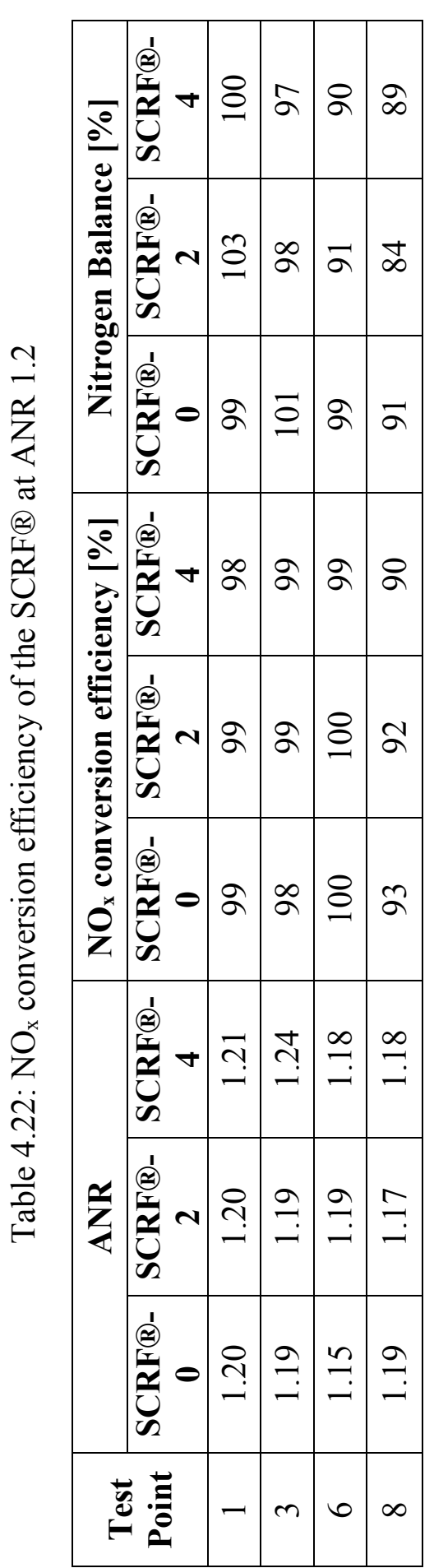




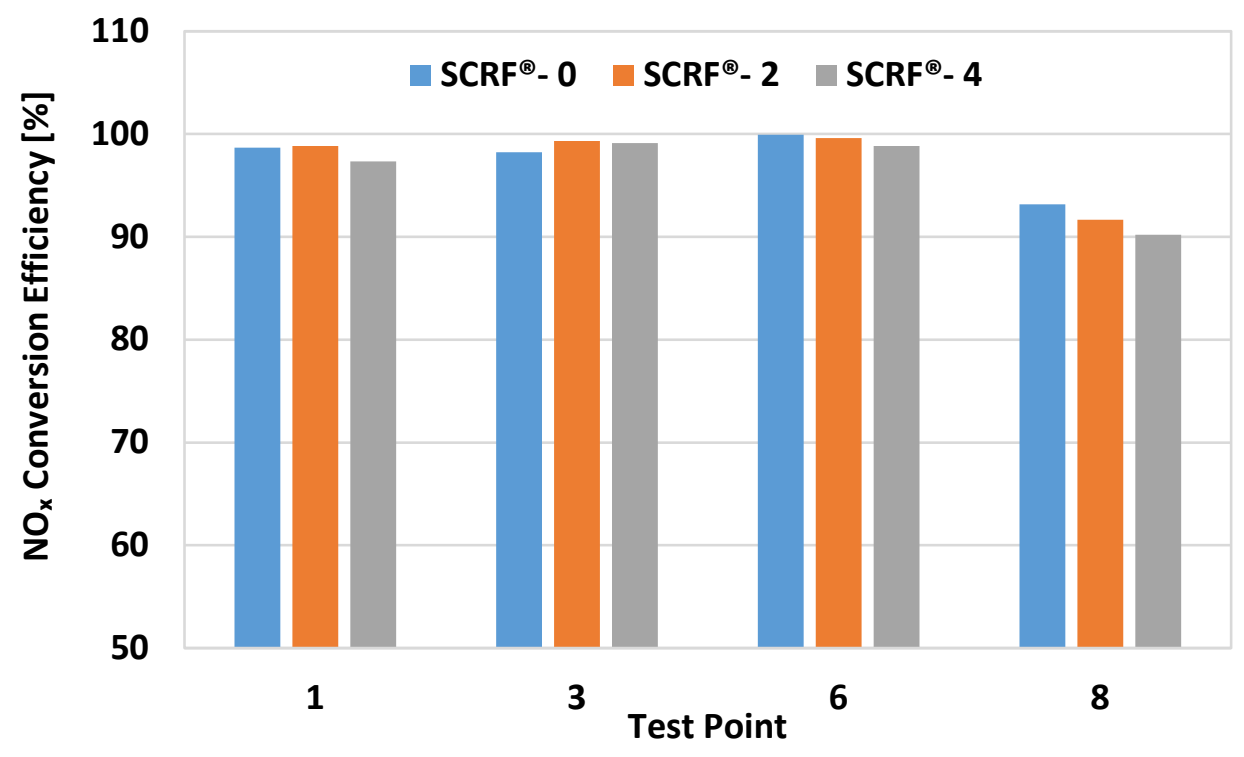

Figure 4.19: $\mathrm{NO}_{\mathrm{x}}$ conversion efficiency of the $\mathrm{SCRF}{ }^{\circledR}$ with and without PM at ANR 1.2

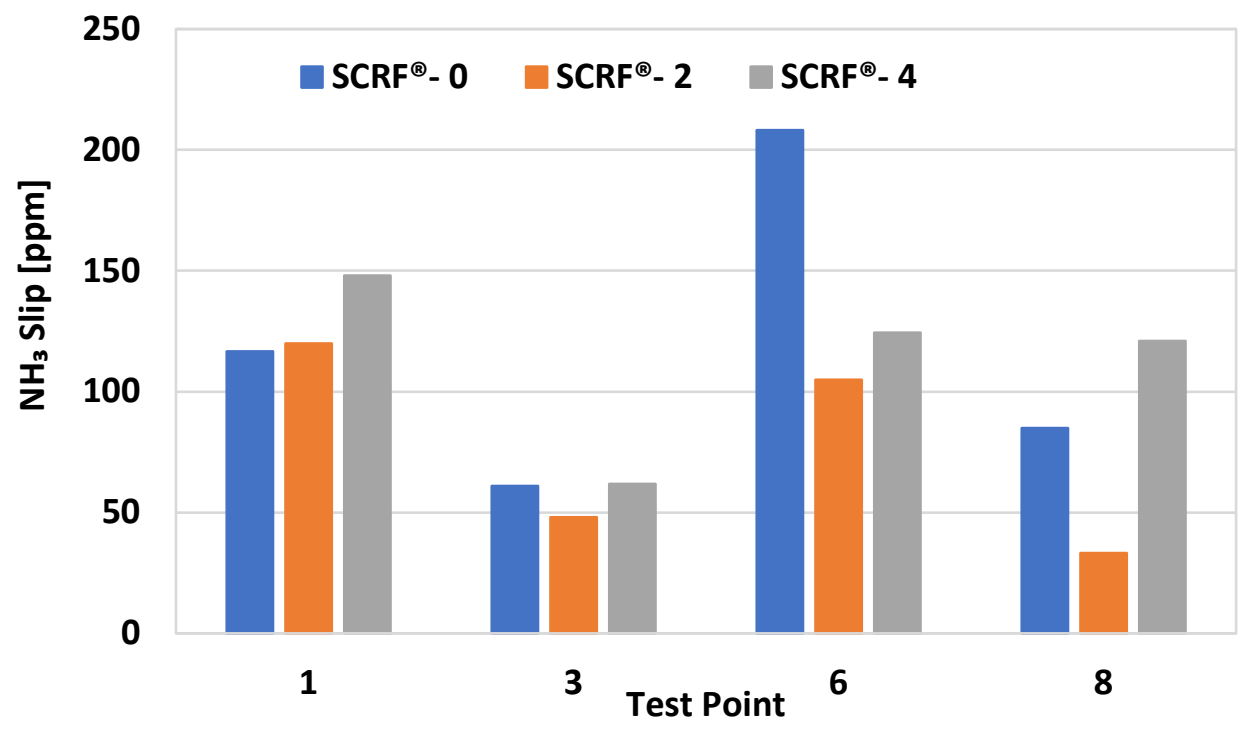

Figure 4.20: $\mathrm{NH}_{3}$ Slip from the $\mathrm{SCRF}{ }^{\circledR}$ with and without PM at ANR 1.2 


\section{Pressure Drop across the SCRF®}

To understand the performance of the SCRF®, the pressure drop across the SCRF® for various tests was investigated. The pressure drop across the SCRF® and $\mathrm{PM}_{\text {Retained }}$ at the end of the stages for Test Point 1 and 6 are shown in Figures 4.21 and 4.22 respectively. From Figure 4.21 it can be observed that the pressure drop is constant during the $\mathrm{NO}_{\mathrm{x}}$ reduction test condition which indicates that the PM in the SCRF® is constant. The pressure drop across the Test Point 8 is plotted in Figure 4.22. It can be observed that during Test Point 8-W/PM-I, Test Point 8-W/PM-II and Test Point 8-W/PM-III, the pressure drop curves across the SCRF® is steep, which is due to the high PM oxidation rate. Hence, the loading condition was repeated during the test to redeposit PM in the SCRF ${ }^{\circledR}$ to maintain PM loading close to $2 \mathrm{~g} / \mathrm{L}$. These stages are indicated as Repeat Loading-I and Repeat Loading-II.

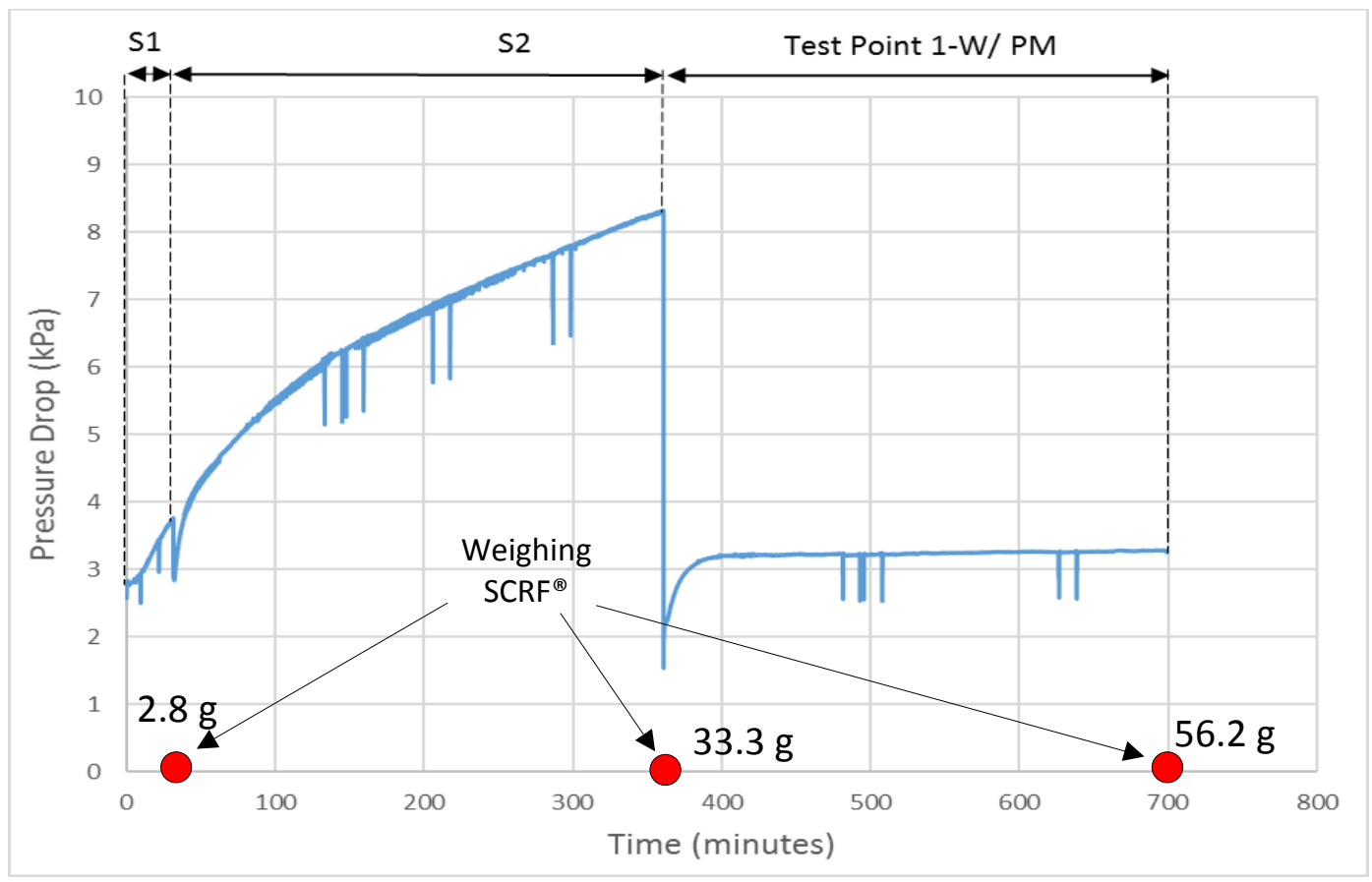

Figure 4.21: Pressure drop across the SCRF® for the Test Point 1, with PM loading 2 g/L 


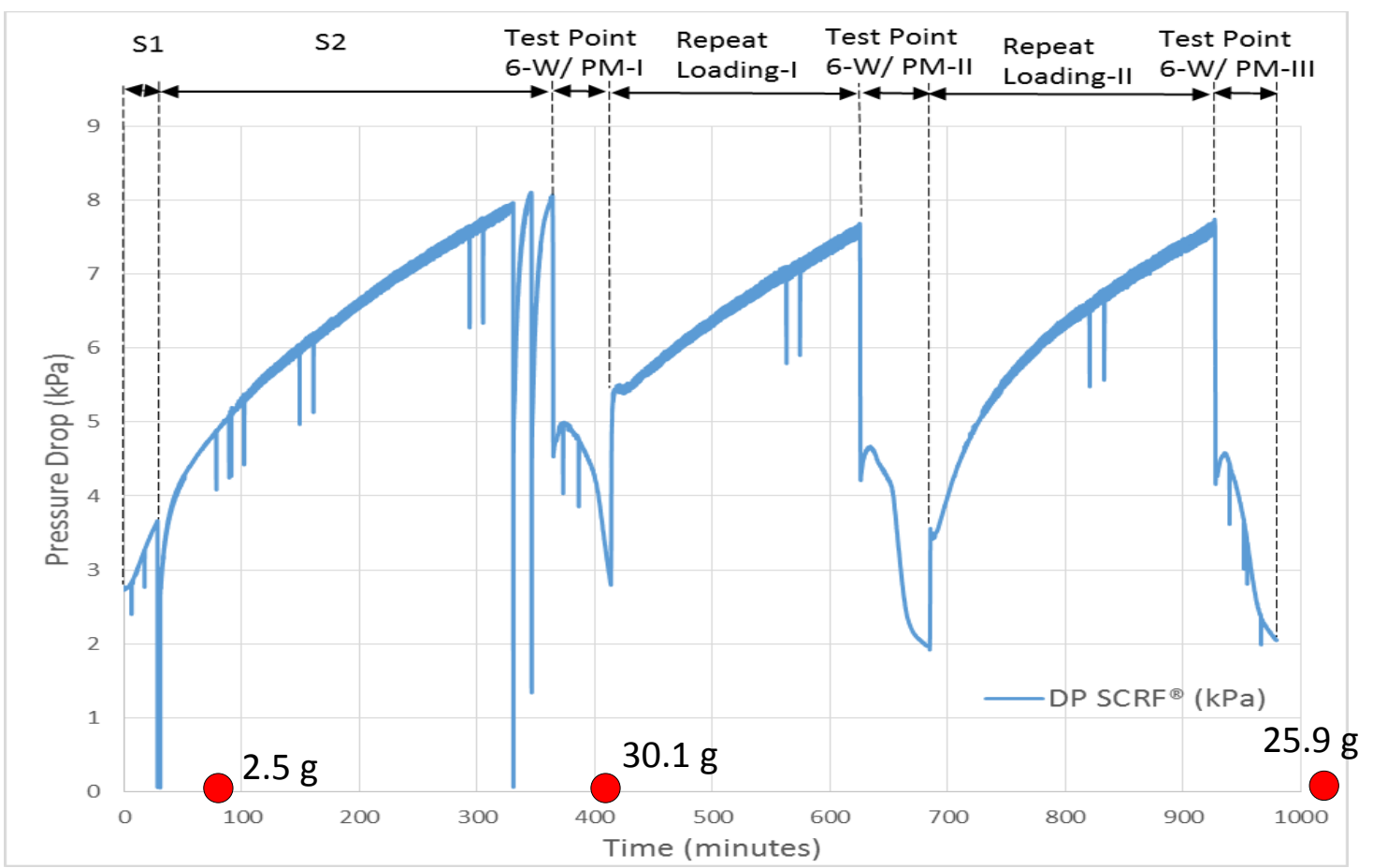

Figure 4.22: Pressure drop across the SCRF® for the Test Point 6, with PM loading $2 \mathrm{~g} / \mathrm{L}$

\section{SCRF® Temperature Distribution}

In this section, the gas temperature distribution in the $\mathrm{SCRF} \circledast$ for the $\mathrm{NO}_{\mathrm{x}}$ experimental tests, with and without PM loading is discussed. The study of the gas temperature distribution obtained from experimental data is critical since the experimental data will be used to calibrate the SCR-F model being developed at MTU. Twenty thermocouples were used in the axial and radial direction of the SCRF® labeled from S1 to S20 to obtain the temperature distribution in the SCRF®. The layout of the thermocouples arrangement is as shown in Figure 3.7. The thermocouples $\mathrm{S} 1$ to $\mathrm{S} 10$ were inserted into the SCRF® through the inlet channels of the SCRF® and the thermocouples S11 to S20 were inserted through the outlet channels of the SCRF®.

The temperature distribution in the SCRF® for Test Point 6 with and without PM loading is shown in Figures 4.23, 4.24, 4.25 and 4.26. Figure 4.23 shows the temperature distribution for Test Point 6, without PM loading in the SCRF®, without urea injection at 4.55 hours ( 5 minutes before the start of the urea dosing cycle). The isothermal lines are almost straight indicating uniform temperature distribution in the substrate, as there is no 
$\mathrm{PM}$ in the substrate and no urea injection to cause exotherm via oxidation of PM or occurrence of SCR reactions. Figure 4.24 shows temperature distribution for Test Point 6, without PM loading, with urea injection at ANR 1.0 at 5.42 hours (15 minutes after the start of ANR 1.0). A drop in the gas temperature is observed in the axial direction before $125 \mathrm{~mm}$, as the temperatures are lower than $350^{\circ} \mathrm{C}$ (in comparison to Figure 4.23). This endotherm could be due to evaporative cooling caused by the evaporation of the urea solution (DEF) injected into the exhaust stream.

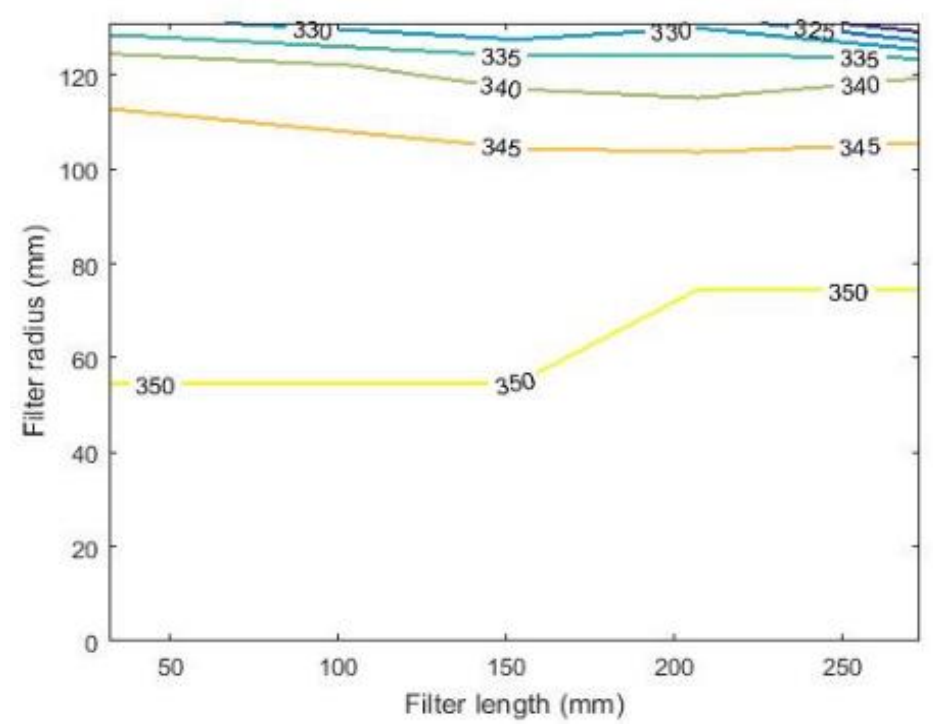

Figure 4.23: Temperature distribution in the $\mathrm{SCRF} \circledast$ during $\mathrm{NO}_{\mathrm{x}}$ reduction stage for Test Point 6 without PM loading, without urea injection

To study the temperature distribution, further analysis was performed by comparing the $\mathrm{SCRF}{ }^{\circledR}$ inlet temperature and temperature distribution in the axial direction at the $\mathrm{SCRF}{ }^{\circledR}$ radius $0 \mathrm{~mm}(\mathrm{~S} 1, \mathrm{~S} 6, \mathrm{~S} 11$ and S16 from Figure 3.7) relative to ANR as shown in Figure 4.25. It is observed that the SCRF® inlet temperature and the temperature measured by $\mathrm{S} 1$ (first thermocouple in the axial direction at radius $0 \mathrm{~mm}$ ) decrease as the urea injection is performed at ANR of 0.8. However, the temperatures measured by S6, S11 and S16 increase as the urea injection is performed at ANR of 0.8. The change in temperature with further increase in ANR is negligible. Further investigation will be performed to study the cause of the trend in the temperature distribution. 


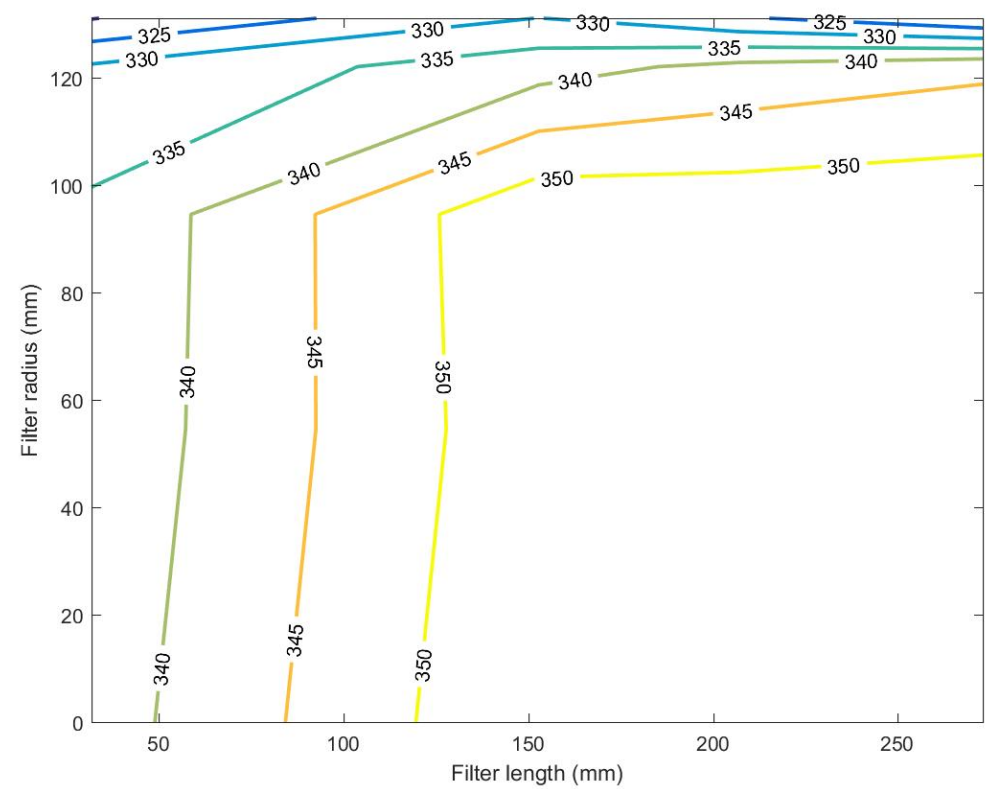

Figure 4.24: Temperature distribution in the $\mathrm{SCRF} \AA$ during $\mathrm{NO}_{\mathrm{x}}$ reduction stage for Test Point 6 without PM loading, at ANR 1.0



Figure 4.25: SCRF® inlet and axial temperatures relative to ANR for Test Point 6 without PM loading 
Figure 4.26 shows temperature distribution for Test Point 6, with 2 g/L PM loading, with urea injection at ANR 1.0 at 13.13 hours (8 minutes after the start of ANR 1.0). A drop in temperature is observed in the axial direction between $0-75 \mathrm{~mm}$ which could be due to the endotherm caused by the evaporative cooling caused by the evaporation of the urea solution (DEF). However, a $10-12{ }^{\circ} \mathrm{C}$ increase in temperature is observed in the axial direction between $100-200 \mathrm{~mm}$ which could be due to exotherm caused via oxidation of PM and occurrence of SCR reactions.

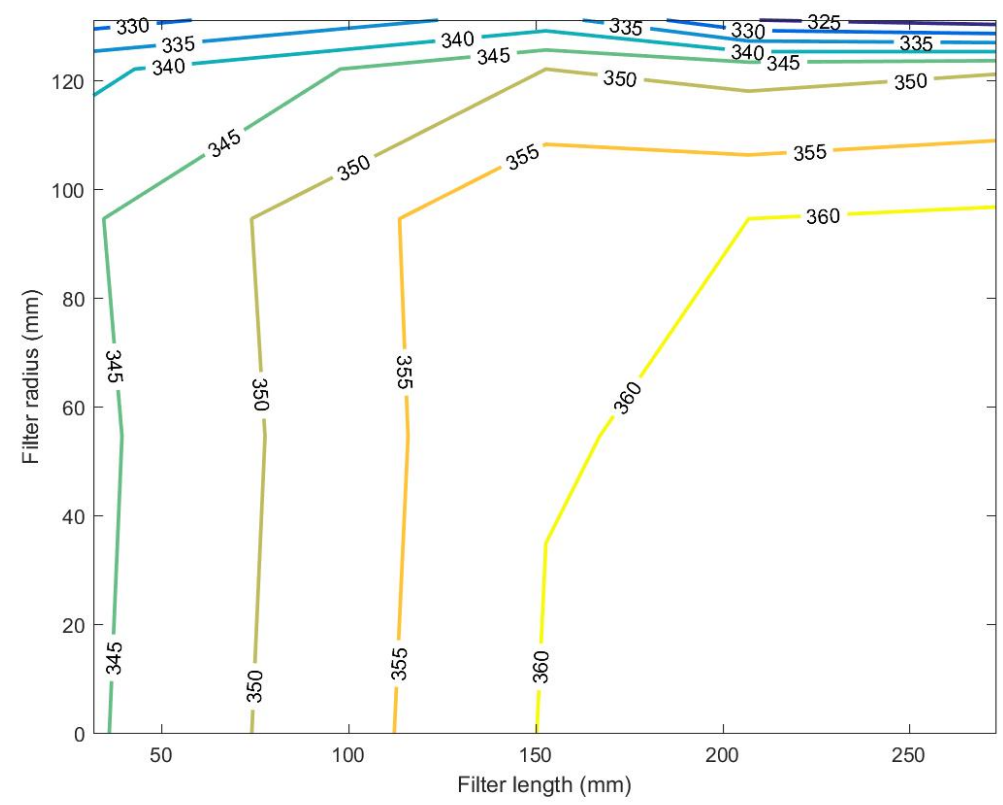

Figure 4.26: Temperature distribution in the $\mathrm{SCRF}{ }^{\circledR}$ during $\mathrm{NO}_{\mathrm{x}}$ reduction stage for Test Point 6 with $2 \mathrm{~g} / \mathrm{L}$ PM loading, at ANR 1.0

Figure 4.27 shows temperature distribution for Test Point 6, with 4 g/L PM loading, with urea injection at ANR 1.0 at 15.92 hours (6 minutes after the start of ANR 1.0). A drop in temperature is observed in the axial direction between $0-50 \mathrm{~mm}$ which could be due to the endotherm caused by the evaporative cooling caused by the evaporation of the urea solution (DEF). However, a $8-12{ }^{\circ} \mathrm{C}$ increase in temperature is observed in the axial direction between $75-200 \mathrm{~mm}$ which could be due to exotherm caused via oxidation of PM and occurrence of SCR reactions. 


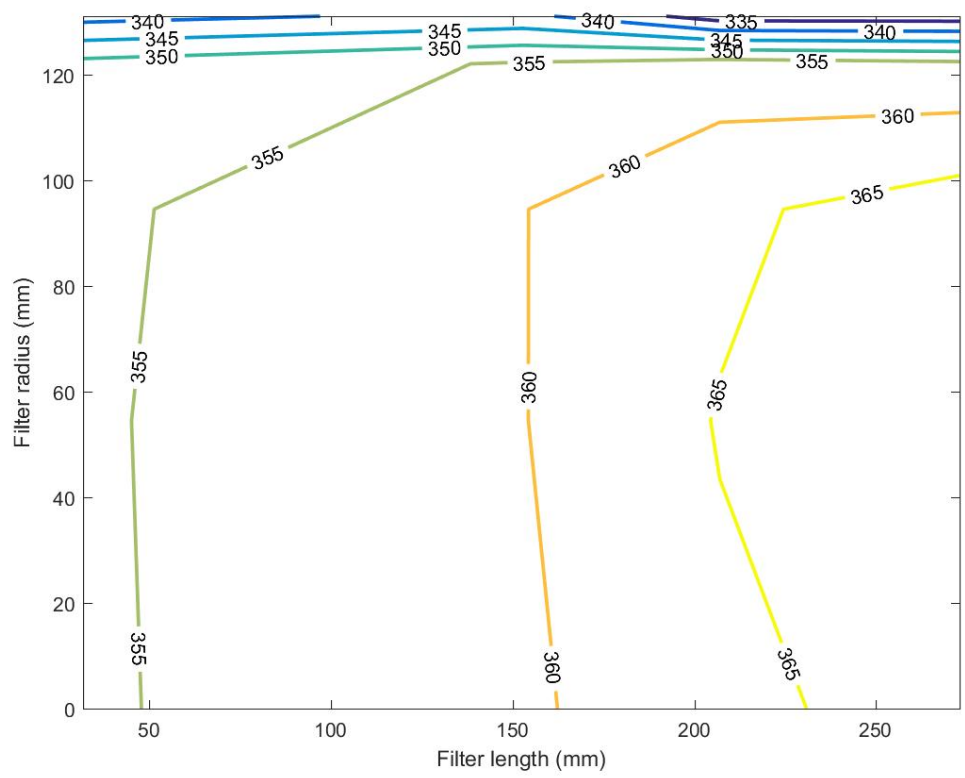

Figure 4.27: Temperature distribution in the $\mathrm{SCRF}{ }^{\circledR}$ during $\mathrm{NO}_{\mathrm{x}}$ reduction stage for Test Point 6 with $4 \mathrm{~g} / \mathrm{L}$ PM loading at ANR 1.0

\subsection{Comparison of $\mathrm{NO}_{\mathrm{x}}$ Reduction: SCRF® to Production-2013-SCR}

In this section, the $\mathrm{NO}_{\mathrm{x}}$ reduction performance and the $\mathrm{NH}$ slip out of the production2013-SCR/SCRF ${ }^{2}$, obtained from the configurations 1 and 2 is compared to the $\mathrm{NO}_{\mathrm{x}}$ reduction performance of the production-2013-SCR (Baseline).

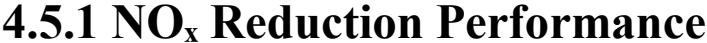

The $\mathrm{NO}_{\mathrm{x}}$ conversion efficiency of the production-2013-SCR and the SCRF ${ }^{\circledR}$ are shown in the Figure 4.27. It can be observed that the production-2013-SCR could achieve $\mathrm{NO}_{\mathrm{x}}$ conversion efficiency of $\leq 85 \%$ in comparison to the $\geq 90 \%$ for the SCRF®, at inlet temperatures below $250{ }^{\circ} \mathrm{C}$ and above $450{ }^{\circ} \mathrm{C}$. The $\mathrm{NO}_{\mathrm{x}}$ conversion efficiency for the $\mathrm{SCRF}{ }^{\circledR}$, with and without $\mathrm{PM}$ in the $\mathrm{SCRF}{ }^{\circledR}$, was $\geq 95 \%$ at the inlet temperature range of $300-400{ }^{\circ} \mathrm{C}$, which is comparable to the production-2013-SCR. 


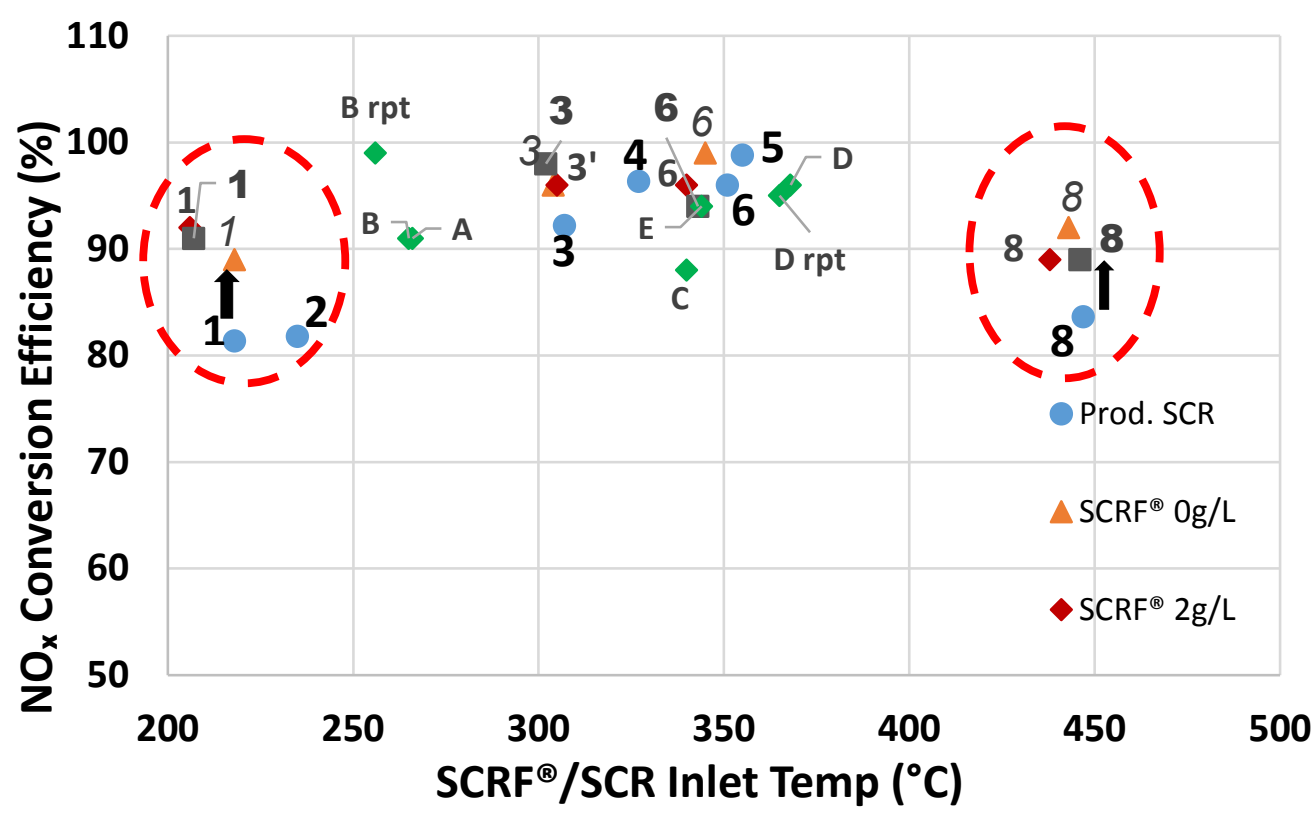

Figure 4.28: $\mathrm{NO}_{\mathrm{x}}$ conversion efficiency of the production-2013-SCR and the SCRF® at various inlet temperatures

The combination of $\mathrm{NO}_{\mathrm{x}}$ conversion efficiency, ANR and $\mathrm{NH}_{3}$ slip out of the production2013-SCR and the $\mathrm{SCRF}{ }^{\circledR}$ during the $\mathrm{NO}_{\mathrm{x}}$ reduction and passive oxidation tests with urea injection (baseline, configuration 2 and configuration 1), at ANR 1.0, are shown in Figure 4.28. The $\mathrm{NH}_{3}$ slip $>50 \mathrm{ppm}$ for the production-2013-SCR and $>20$ ppm for the SCRF ${ }^{\circledR}$, was observed for all the test conditions except Test Point 8 , which is high temperature and high space velocity test condition (refer Table 4.10). The low $\mathrm{NH}_{3}$ slip offers an opportunity to increase the ANR from 1.00 to 1.05 to obtain further improvement in the $\mathrm{NO}_{\mathrm{x}}$ reduction in the $\mathrm{SCRF}{ }^{\circledR}$, below $\mathrm{SCRF}{ }^{\circledR}$ inlet temperatures of $400^{\circ} \mathrm{C}$. Above $400^{\circ} \mathrm{C}$, the oxidation of $\mathrm{NH}_{3}$ is a dominant phenomenon and improvement in $\mathrm{NO}_{\mathrm{x}}$ reduction will be insignificant. The study of the improvement in $\mathrm{NO}_{\mathrm{x}}$ conversion efficiency at ANR $>1.0$ with the SCRF ${ }^{\circledR}$ and a downstream SCR-A brick will be performed in the configuration-3, at a later stage of this research. 


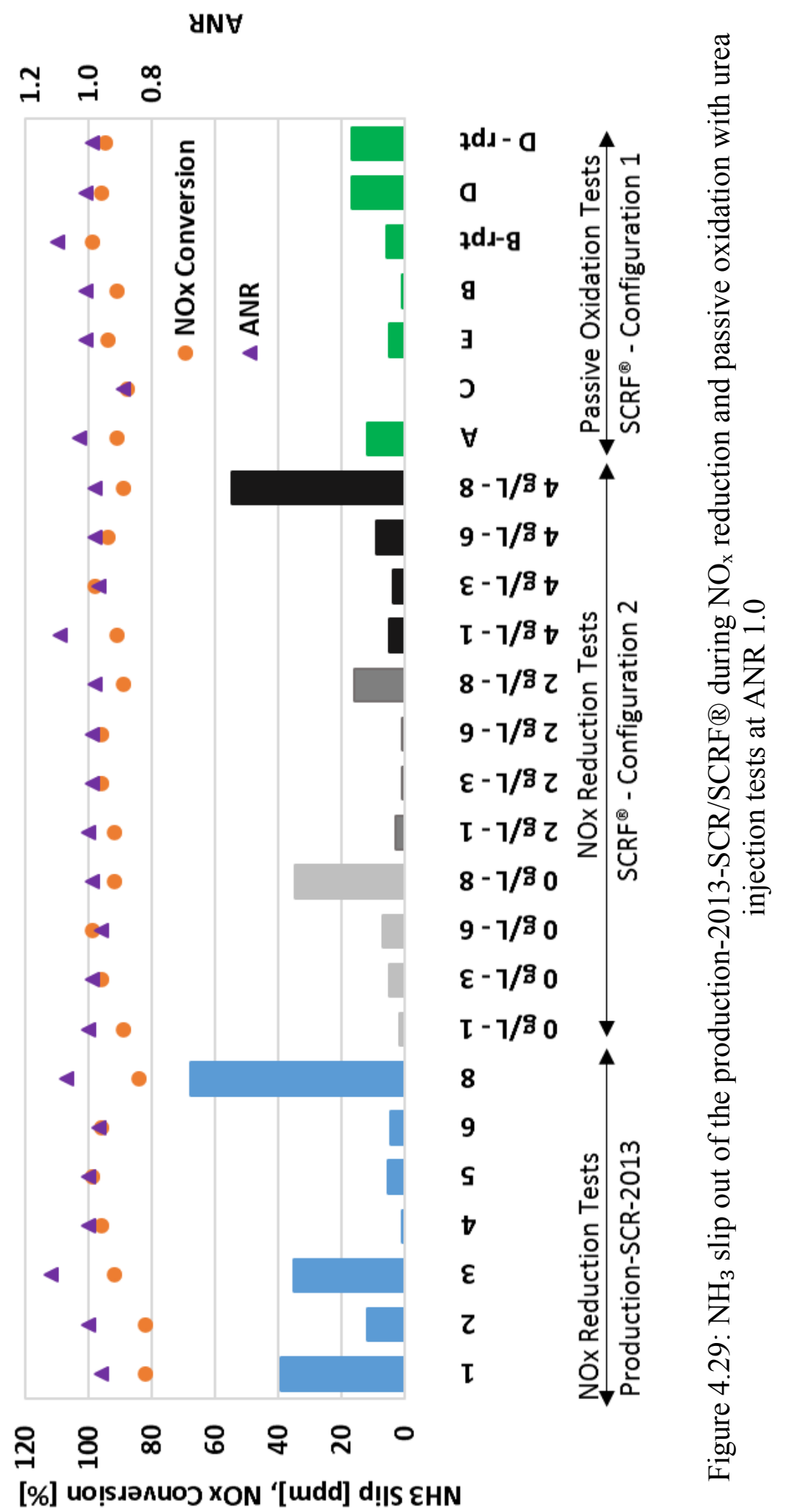




\subsection{2 $\mathrm{NH}_{3}$ Storage}

The $\mathrm{NH}_{3}$ storage at various inlet temperatures for the production-SCR and the SCRF® (with and without PM loading) were estimated using the $\mathrm{NO}_{\mathrm{x}}$ concentrations at the inlet and the outlet of the production-2013-SCR/SCRF® and $\mathrm{NH}_{3}$ concentration at the inlet of the production-2013-SCR/SCRF® at 1.2 ANR, estimated using equation 3.8.

The $\mathrm{NO}_{\mathrm{x}}$ converted and the $\mathrm{NH}_{3}$ slip out of the SCRF® were subtracted from the inlet $\mathrm{NH}_{3}$ to estimate the $\mathrm{NH}_{3}$ consumed in the production-2013-SCR/SCRF® as described in equation 4.6. The $\mathrm{NH}_{3}$ consumed values were subtracted from the inlet $\mathrm{NH}_{3}$ to obtain the $\mathrm{NH}_{3}$ stored on the catalyst as indicated in Figure 4.29. The $\mathrm{NH}_{3}$ storage stabilizes as the $\mathrm{NO}_{x}$ conversion and $\mathrm{NH}_{3}$ slip out of the production-2013-SCR/SCRF® stabilize. The $\mathrm{NH}_{3}$ storage was calculated until the curve stabilized. The $\mathrm{NH}_{3}$ storage on the catalyst was estimated using equation 4.7.

$\mathrm{NH}_{3}$ Consumed $=$ Inlet $\mathrm{NH}_{3}-\left(\right.$ Inlet $\mathrm{NO}_{\mathrm{x}}-$ Outlet $\left.\mathrm{NO}_{\mathrm{x}}\right)-\mathrm{NH}_{3}$ Slip

Eqn. 4.6

Where, $\mathrm{NH}_{3}$ consumed, inlet $\mathrm{NH}_{3}$, inlet $\mathrm{NO}_{x}$, outlet $\mathrm{NO}_{\mathrm{x}}$ and $\mathrm{NH}_{3}$ slip are in ppm.

\section{$\mathrm{NH}_{3}$ Storage}

$=\frac{\int_{\mathrm{t} 1}^{\mathrm{t} 2} \mathrm{Yi} * \text { exhaust flow rate } * \mathrm{dt}}{\text { molecular wt. of air } * \text { total volume of the SCR/SCRF } \mathbb{R}}$

Where $\mathrm{NH}_{3}$ storage is in ( $\mathrm{gmol} / \mathrm{m}^{3}$ of substrate), $Y_{i}$ is the $\mathrm{NH}_{3}$ concentration stored on the catalyst (ppm) (Inlet $\mathrm{NH}_{3}-\mathrm{NH}_{3}$ consumed), $\mathrm{t} 1$ is the start of urea injection (minutes), $\mathrm{t} 2$ is the time at which $\mathrm{NH}_{3}$ stored curve stabilizes (minutes), as shown in Figure 4.29, exhaust flow rate is in ( $\mathrm{kg} /$ minute), molecular weight of air is $28.96(\mathrm{~g} / \mathrm{gmol})$ and total volume of the production-2013-SCR/SCRF® 17.04 (L). It is also assumed that the 
production-2013-SCR and the SCRF® catalyst loading is represented by the total volume of the substrates i.e $17.04 \mathrm{~L}$.

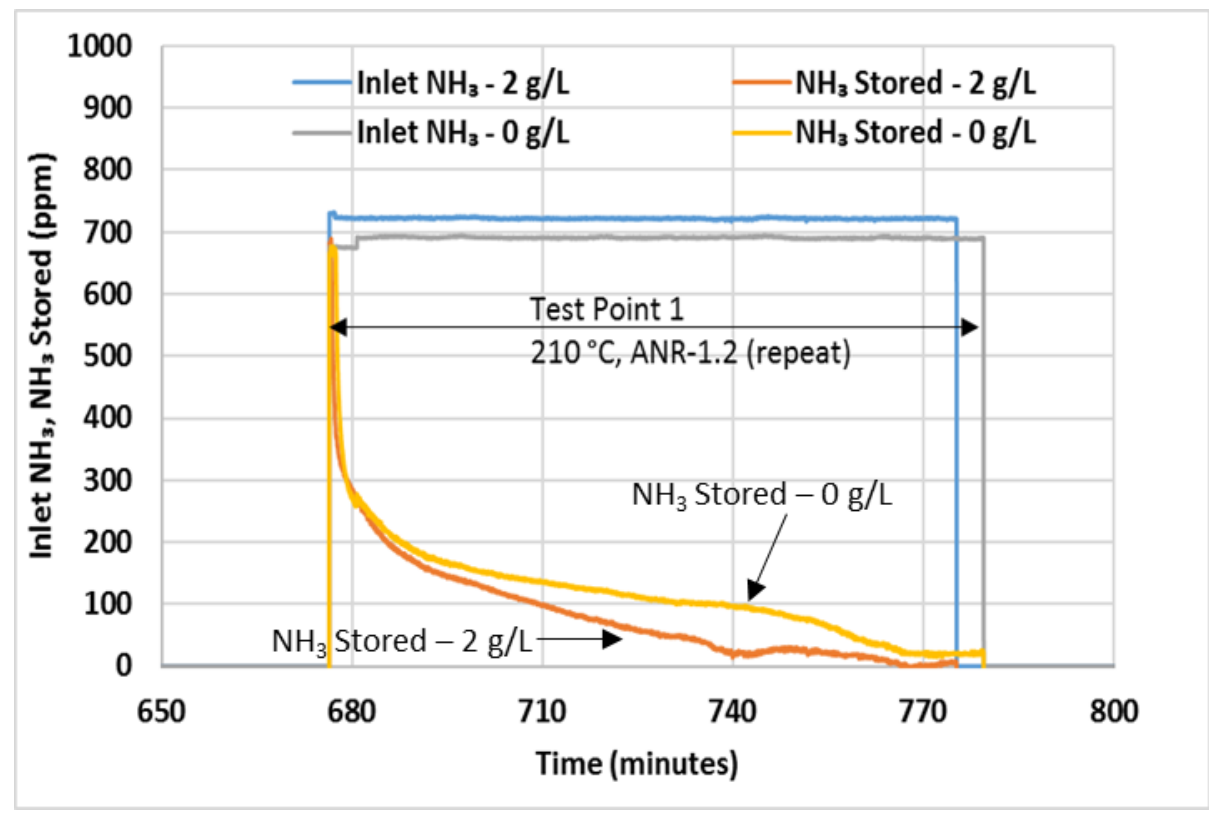

Figure 4.30: Inlet $\mathrm{NH}_{3}$ and $\mathrm{NH}_{3}$ stored in the $\mathrm{SCRF}{ }^{\circledR}$ at Test Point 1 at ANR 1.2 repeat, without and with PM loading in the $\operatorname{SCRF}{ }^{\circledR}(0$ and $2 \mathrm{~g} / \mathrm{L}), \mathrm{SV}=13.7 \mathrm{k} / \mathrm{hr}, \mathrm{SCRF} \circledast$ inlet temperature $=210^{\circ} \mathrm{C}$

Equation 3.8, for estimation of inlet $\mathrm{NH}_{3}$ assumes that all the DEF injected into the system is converted to $\mathrm{NH}_{3}$. However, the DEF to $\mathrm{NH}_{3}$ conversion reactions are dependent on temperature. The results from reference [85] as shown in Figure 4.30 were used to obtain the fraction of DEF converted into $\mathrm{NH}_{3}$ at various temperatures. The $\mathrm{NH}_{3}$ storage $\left(\mathrm{gmol} / \mathrm{m}^{3)}\right.$ values were multiplied by the temperature based fraction, to obtain the actual $\mathrm{NH}_{3}$ stored on the production-SCR/SCRF®. 
Trend of urea thermolysis considered to calculate $\mathrm{NH}_{3}$ storage in the $\mathrm{SCRF}^{\circledR}$ at various temperatures

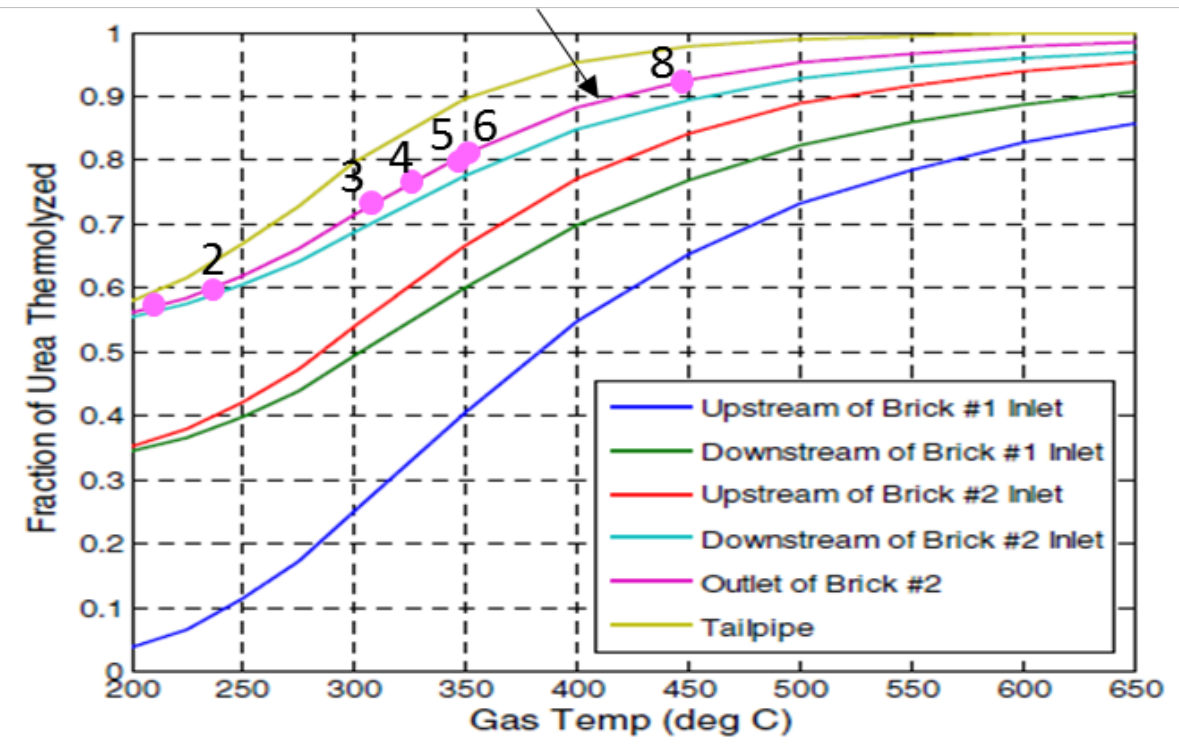

Figure 4.31: Fraction of Urea thermolyzed at various locations, $\mathrm{SV}=30 \mathrm{k} / \mathrm{hr}$ [85]

From Figure 4.31 it can be observed that the SCR-2010, the production-2013-SCR and the SCRF ${ }^{\circledR}$ (without PM) have approximately same ammonia storage capability at lower and higher temperatures. However, the SCRF® (without PM) demonstrated lower ammonia storage at temperatures around $300^{\circ} \mathrm{C}$, when compared to the production-2013SCR and the SCR-2010 from reference [9]. Also, the ammonia storage capability of the SCRF ${ }^{\circledR}$ with the PM loading of $2 \mathrm{~g} / \mathrm{L}$, decreases by approximately $30 \%$ at lower temperatures $\left(200-250^{\circ} \mathrm{C}\right)$, when compared to the ammonia storage in the SCRF® without PM. The reduced $\mathrm{NH}_{3}$ storage in the $\mathrm{SCRF}{ }^{\circledR}$ with PM loading in the SCRF® is also evident from Figure 4.29. The difference reduces as the substrate temperature increases. Further PM loading on the SCRF ${ }^{\circledR}$ to $4 \mathrm{~g} / \mathrm{L}$ had negligible effect on ammonia storage. Similar results related to the ammonia storage were observed by Tan et al. [70]. 


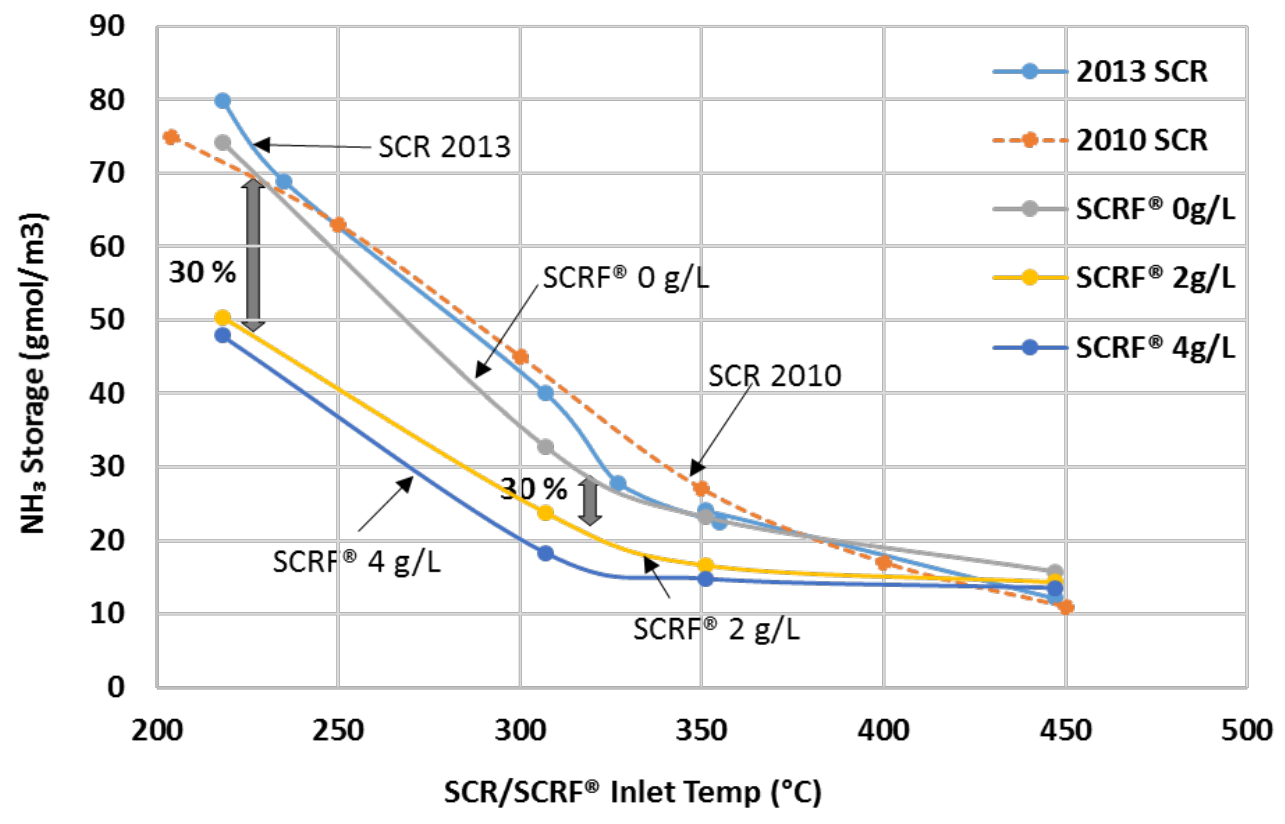

Figure 4.32: $\mathrm{NH}_{3}$ storage in the production-SCR and the SCRF® at various temperatures

\subsection{Calculation of ANR's for Configuration 3: SCRF® + SCR}

The experimental data for the SCRF® were studied and analyzed to calculate the targeted ANR to be maintained during the passive oxidation stage of Test Points A, B, C, D and E and $\mathrm{NO}_{\mathrm{x}}$ reduction stage of Test Point 1. The data for Test Points $\mathrm{A}$ and $\mathrm{E}$ obtained from passive oxidation tests with urea injection as a part of configuration 1 are shown in Table 4.23. The $\mathrm{NO}_{\mathrm{x}}$ and $\mathrm{NH}_{3}$ concentrations at the inlet and outlet of the $\mathrm{SCRF}{ }^{\circledR}, \mathrm{NO}_{\mathrm{x}}$ conversion efficiency and ANR were used to calculate the targeted ANR for configuration 3 such that maximum $\mathrm{NO}_{x}$ reduction and minimum $\mathrm{NH}_{3}$ slip could be achieved at the outlet of the SCRF® and SCRF® and SCR-A substrate together. 
Table 4.23: Performance of the SCRF® during the passive oxidation tests with urea injection in configuration 1 [1]

\begin{tabular}{|c|c|c|c|c|c|c|c|}
\hline $\begin{array}{c}\text { Test } \\
\text { Points }\end{array}$ & $\begin{array}{c}\text { SCRF® } \\
\text { Inlet } \\
\mathbf{N O}_{\mathbf{x}}\end{array}$ & $\begin{array}{c}\mathbf{S C R F}^{\circledR} \\
\text { Inlet }_{\mathbf{N}}\end{array}$ & $\mathbf{A N R}$ & $\begin{array}{c}\mathbf{S C R F}{ }^{\circledR} \\
\text { Outlet } \\
\mathbf{N O}_{\mathbf{x}}\end{array}$ & $\begin{array}{c}\mathbf{N H}_{\mathbf{3}} \\
\text { Slip }\end{array}$ & $\begin{array}{c}\mathbf{N O}_{\mathbf{x}} \\
\mathbf{C o n v} . \\
\text { Eff. }\end{array}$ & $\begin{array}{c}\text { Nitrogen } \\
\text { Balance }\end{array}$ \\
\hline$[-]$ & {$[\mathbf{p p m}]$} & {$[\mathbf{p p m}]$} & {$[-]$} & {$[\mathbf{p p m}]$} & {$[\mathbf{p p m}]$} & {$[\mathbf{\%}]$} & {$[\mathbf{\%}]$} \\
\hline $\mathrm{A}$ & 590 & 607 & 1.03 & 55 & 12 & 91 & 90 \\
\hline $\mathrm{E}$ & 1450 & 1465 & 1.01 & 80 & 5 & 94 & 94 \\
\hline
\end{tabular}

From Table 4.23 it is observed that for Test Point A, $\mathrm{NO}_{\mathrm{x}}$ concentration of $55 \mathrm{ppm}$ and $\mathrm{NH}_{3}$ slip of $12 \mathrm{ppm}$ were measured at the outlet of the SCRF®. The $\mathrm{NO}_{\mathrm{x}}$ concentration of $55 \mathrm{ppm}$ could be reduced in the SCRF® if additional SCRF® inlet $\mathrm{NH}_{3}$ concentration of 67 ppm were available (considering 90\% nitrogen balance) during the test. Hence, the targeted ANR to be performed for Test Point $\mathrm{A}$ in configuration 3 (SCRF®) with a downstream SCR) would be 1.13. The calculations for Test Point A are shown in Figure 4.32 .

$$
\begin{aligned}
& \mathrm{SCRF}^{\oplus} \text { outlet } \mathrm{NO}_{\mathrm{x}} / \text { Nitrogen balance }=\text { Additional } \mathrm{SCRF}^{\circledast} \text { inlet } \mathrm{NH}_{3} \\
& 55 \text { / } 0.90=61 \\
& \left(\mathrm{SCRF}^{\oplus} \text { inlet } \mathrm{NH}_{3}+\text { Additional } \mathrm{SCRF}^{\circledast} \text { inlet } \mathrm{NH}_{3}\right) / \mathrm{SCRF}^{\oplus} \text { inlet } \mathrm{NO}_{\mathrm{x}}=\text { Targeted ANR } \\
& (607+61) \quad / \quad 590=1.13
\end{aligned}
$$

Figure 4.33: Sample calculations to estimate the targeted ANR for Test Point A

Similarly, for Test Point E, $\mathrm{NO}_{\mathrm{x}}$ concentration of $80 \mathrm{ppm}$ could be reduced in the SCRF® if additional SCRF® inlet $\mathrm{NH}_{3}$ concentration of $85 \mathrm{ppm}$ were available (considering 94\% nitrogen balance) during the test. Hence, the targeted ANR to be performed for Test Point $\mathrm{E}$ in configuration 3 would be 1.07. The calculations for Test Point E are shown in Figure 4.33. 


$$
\begin{aligned}
& \mathrm{SCRF}^{\circledast} \text { outlet } \mathrm{NO}_{\mathrm{x}}(\mathrm{ppm}) / \text { Nitrogen balance }=\text { Additional } \mathrm{SCRF}^{\circledR} \text { inlet } \mathrm{NH}_{3}(\mathrm{ppm}) \\
& 80 \\
& \text { / } 0.94= \\
& 85 \\
& \left(\mathrm{SCRF}^{\circledast} \text { inlet } \mathrm{NH}_{3}+\text { Additional } \mathrm{SCRF}^{\oplus} \text { inlet } \mathrm{NH}_{3}\right) / \mathrm{SCRF}^{\circledast} \text { inlet } \mathrm{NO}_{\mathrm{x}}=\text { Targeted } \mathrm{ANR} \\
& \left(\begin{array}{lll}
1465 & + & -1450=1.07
\end{array}\right.
\end{aligned}
$$

Figure 4.34: Sample calculations to estimate the targeted ANR for Test Point E 


\section{Chapter 5. Summary and Conclusions}

One of the goals of this research was to investigate the effect of temperature and space velocity on the $\mathrm{NO}_{\mathrm{x}}$ reduction performance of the SCRF®, with and without PM loading in the SCRF® and compare it with the performance of the production-2013-SCR. Also, there was a goal to determine the effects of PM loading at 0,2 and $4 \mathrm{~g} / \mathrm{L}$ as a function of ANR on the outlet $\mathrm{NO}, \mathrm{NO}_{2}$ and $\mathrm{NH}_{3}$ and the $\mathrm{NOx}$ reduction as affected by the temperature and space velocity. Another goal of this research was to determine the $\mathrm{NH}_{3}$ storage for the production-2013-SCR and the SCRF®, to study the effect of PM loading on the $\mathrm{NH}_{3}$ storage. The goals have been met through experimental studies on the production-2013-SCR and the SCRF® coupled with the 1-D SCR model calibration. The important findings and accomplishments from the study and the recommendation for the future work are discussed in this chapter.

\subsection{Summary}

The test procedures were developed and the test conditions were determined to evaluate the performance of the production-2013-SCR and the SCRF®. Seven $\mathrm{NO}_{\mathrm{x}}$ reduction tests were completed to evaluate the $\mathrm{NO}_{\mathrm{x}}$ reduction and $\mathrm{NH}_{3}$ slip performance for production2013-SCR. Seven passive oxidation and twelve $\mathrm{NO}_{\mathrm{x}}$ reduction tests were completed in configurations 1 and 2 respectively, to evaluate the $\mathrm{NO}_{\mathrm{x}}$ reduction and $\mathrm{NH}_{3}$ slip performance of the SCRF®, with 0, 2 and $4 \mathrm{~g} / \mathrm{L}$ PM loading in the SCRF® as a function of temperature and space velocities for ANR 0.8, 1.0 and 1.2.

\section{NO $_{x}$ Reduction in Production-2013-SCR and 1-D SCR Model Calibration}

The $\mathrm{NO}_{\mathrm{x}}$ reduction and $\mathrm{NH}_{3}$ slip characteristics of the $\mathrm{Cu}$-zeolite based production-2013SCR were determined at steady state engine operating conditions. During the seven different test conditions, SCR inlet temperatures varied from 208 to $447{ }^{\circ} \mathrm{C}$, space velocity varied from 12.0 to $44.7 \mathrm{k} / \mathrm{hr}, \mathrm{NO}_{\mathrm{x}}$ varied from 280 to $1730 \mathrm{ppm}$ and $\mathrm{NO}_{2} / \mathrm{NO}_{\mathrm{x}}$ varied from 0.2 to 0.5 . The $\mathrm{NO}_{\mathrm{x}}$ conversion efficiency and $\mathrm{NH}_{3}$ slip performance of the 
production-2013-SCR was considered as the baseline performance and was compared with the $\mathrm{NO}_{\mathrm{x}}$ reduction in the $\mathrm{SCRF}{ }^{\circledR}$. Nitrogen balance was performed using the $\mathrm{NO}_{\mathrm{x}}$ and $\mathrm{NH}_{3}$ concentrations at the inlet and outlet of the production-2013-SCR, to validate the consistency of the experimental data. The nitrogen balance of $100 \pm 10 \%$ was observed for the seven tests, indicating a good agreement between the concentrations at the inlet and outlet of the production-2013-SCR. $\mathrm{NH}_{3}$ storage on the production-2013SCR was calculated using the experimental data.

The 1-D SCR model was calibrated to the engine experimental data obtained from the production-2013-SCR. A unique set of model calibration parameters were determined for Test Points with SCR inlet temperatures in the range of 250 to $450^{\circ} \mathrm{C}$. However, a different set of parameters were used for Test Point 1, which has the SCR inlet temperature $\sim 205^{\circ} \mathrm{C}$. The calibrated model was validated by comparing the experimental and simulated data using $\mathrm{NO}, \mathrm{NO}_{2}$ and $\mathrm{NH}_{3}$ concentrations at the $\mathrm{SCR}$ outlet.

\section{NO $_{\mathrm{x}}$ Reduction in SCRF ${ }^{\circledR}$ - with and without PM - Configurations 1}

\section{and 2}

Seven passive oxidation tests with urea injection were conducted in configuration 1 to study the effect of $\mathrm{NO}_{\mathrm{x}}$ reduction reactions on the $\mathrm{NO}_{2}$ assisted $\mathrm{PM}$ oxidation. The $\mathrm{SCRF}{ }^{\circledR}$ was loaded to $1.8 \pm 0.4 \mathrm{~g} / \mathrm{L}$ before start of the passive oxidation stage. The urea injection was performed to achieve a constant ANR of 1.0 during the passive oxidation stage. The $\mathrm{NO}_{\mathrm{x}}$ reduction and $\mathrm{NH}_{3}$ slip data for the $\mathrm{SCRF}{ }^{\circledR}$ were analyzed and the nitrogen balance was performed to validate the consistency of the experimental data.

The Test Points 1, 3, 6 and 8 from Table 3.15 were run in configuration 2, to collect the experimental data to determine the $\mathrm{NO}_{\mathrm{x}}$ reduction and $\mathrm{NH}_{3}$ slip performance of the SCRF®, with and without PM loading in the SCRF® (total twelve tests). The four Test Points cover the SCRF® inlet temperatures in the range of 200 to $450^{\circ} \mathrm{C}$, space velocities from 13 to $48 \mathrm{k} / \mathrm{hr}$, SCRF ${ }^{\circledR}$ inlet $\mathrm{NO}_{\mathrm{x}}$ from 280 to $1600 \mathrm{ppm}$. During $\mathrm{NO}_{\mathrm{x}}$ reduction tests for the SCRF® without PM loading, the CPF was placed upstream of the SCRF® to filter the PM entering into the SCRF®. Hence, using the data from four tests without PM 
loading in the $\mathrm{SCRF}{ }^{\circledR}, \mathrm{NO}_{\mathrm{x}}$ reduction performance of the clean $\mathrm{SCRF}{ }^{\circledR}$ was determined. During $\mathrm{NO}_{\mathrm{x}}$ reduction tests for the $\mathrm{SCRF}{ }^{\circledR}$ with $\mathrm{PM}$ loading, the $\mathrm{CPF}$ was replaced with a spacer, so that the engine-out PM was filtered and deposited on the SCRF® to achieve the target PM loading of 2 and $4 \mathrm{~g} / \mathrm{L}$. The urea dosing cycle was performed to achieve the ANR of $0.8,1.0,1.2$ and 1.2 repeat to study the $\mathrm{NO}_{x}$ reduction and $\mathrm{NO}, \mathrm{NO}_{2}$ and $\mathrm{NH}_{3}$ slip from the SCRF®, with 0,2 and $4 \mathrm{~g} / \mathrm{L}$ PM loading. $\mathrm{NH}_{3}$ storage on the SCRF®, with and without PM loading on the SCRF® was calculated using the experimental data from the twelve $\mathrm{NO}_{\mathrm{x}}$ reduction tests in the configuration 2 .

$\mathrm{NO}_{x}$ reduction, $\mathrm{NH}_{3}$ slip and $\mathrm{NH}_{3}$ storage data for the SCRF®, obtained from configurations 1 and 2 were compared to the baseline data for the production-2013-SCR.

\subsection{Conclusions}

The experimental data obtained from the tests conducted with the production-2013-SCR and the SCRF® (configurations 1 and 2, with and without PM loading) were analyzed to determine the $\mathrm{NO}_{x}$ conversion efficiency, $\mathrm{NH}_{3}$ storage and $\mathrm{NH}_{3}$ slip characteristics of the production-2013-SCR and the SCRF®. The 1-D SCR model was calibrated using the experimental data obtained from the seven tests with the production-2013-SCR. The conclusions with respect to the goals and objectives of this study are discussed in the following sections.

\section{$\mathrm{NO}_{\mathrm{x}}$ Reduction, $\mathrm{NH}_{3}$ storage and 1-D SCR Model Calibration - Production-2013-SCR}

1. The production-2013-SCR can achieve $90-95 \% \mathrm{NO}_{\mathrm{x}}$ reduction with $\mathrm{NH}_{3}$ slip $<40 \mathrm{ppm}$ at ANR 1.0, for the inlet temperature range of $300-350^{\circ} \mathrm{C}$. However, the $\mathrm{NO}_{\mathrm{x}}$ reduction performance decreases to $80-85 \%$ at ANR 1.0, with $\mathrm{NH}_{3}$ slip $<20$

and $<70 \mathrm{ppm}$ for inlet temperatures below $250^{\circ} \mathrm{C}$ and above $450^{\circ} \mathrm{C}$ respectively.

2. Maximum $\mathrm{NH}_{3}$ storage of $75 \mathrm{gmol} / \mathrm{m} 3$ of substrate at $200{ }^{\circ} \mathrm{C}$ was observed on the production-2013-SCR. The $\mathrm{NH}_{3}$ storage values for the production-2013-SCR 
were within $\pm 5 \mathrm{gmol} / \mathrm{m} 3$ when compared to the production-SCR-2010, for the inlet temperature range of $200-450^{\circ} \mathrm{C}$.

3. The 1-D SCR model was calibrated to $\pm 20 \mathrm{ppm}$ of the experimental data, for NO and $\mathrm{NO}_{2}$ gaseous concentrations at the outlet of the production-2013-SCR. The model was also calibrated to $\pm 30 \mathrm{ppm}$ of the experimental data, for $\mathrm{NH}_{3}$ slip out of the production-2013-SCR.

\section{$\mathrm{NO}_{\mathrm{x}}$ Reduction - SCRF®: Configuration 1}

1. The $\mathrm{NO}_{\mathrm{x}}$ reduction $>90 \%$ and $\mathrm{NH}_{3}$ slip $<20 \mathrm{ppm}$ at ANR 1.0, can be achieved with the SCRF®, with PM loading of $2 \mathrm{~g} / \mathrm{L}$ in the SCRF®, for the inlet temperature range of 260 to $370{ }^{\circ} \mathrm{C}$.

2. The $\mathrm{SCRF}{ }^{\circledR}$ exhibits potential for the $\mathrm{NO}_{\mathrm{x}}$ reduction $>95 \%$ at ANR between 1.05 - 1.10, since the $\mathrm{NH}_{3}$ slip values for the seven passive oxidation tests with urea injection were $<20$ ppm at ANR 1.0.

\section{$\mathrm{NO}_{\mathrm{x}}$ Reduction and $\mathrm{NH}_{3}$ storage $-\mathrm{SCRF}{ }^{\circledR}$ : Configuration 2}

1. The $\mathrm{NO}_{\mathrm{x}}$ reduction $>90 \%$ and $\mathrm{NH}_{3}$ slip $<50 \mathrm{ppm}$ at ANR 1.0, can be achieved with the SCRF®, with and without PM loading in the SCRF®, for the inlet temperature range of 200 to $450{ }^{\circ} \mathrm{C}$ and inlet $\mathrm{NO}_{2} / \mathrm{NO}_{\mathrm{x}}$ ratio in the range of 0.2 to 0.5. Maximum $\mathrm{NO}_{\mathrm{x}}$ reduction of $95 \%$ at $\mathrm{ANR} 1.0$ was observed, for the inlet temperature range of 300 to $400{ }^{\circ} \mathrm{C}$.

2. The $\mathrm{SCRF}{ }^{\circledR}$ (with and without PM loading) provides 5-7\% improvement in the $\mathrm{NO}_{\mathrm{x}}$ reduction when compared to the production-2013-SCR at the inlet temperatures below $250{ }^{\circ} \mathrm{C}$ and above $400{ }^{\circ} \mathrm{C}$

3. The SCRF® outlet $\mathrm{NO}_{2} / \mathrm{NO}_{\mathrm{x}}$ ratio decreases above $300{ }^{\circ} \mathrm{C}$ with increase in $\mathrm{PM}$ loading on the SCRF® from 0 to $2 \mathrm{~g} / \mathrm{L}$ and from 2 to $4 \mathrm{~g} / \mathrm{L}$. This decrement in $\mathrm{NO}_{2} / \mathrm{NO}_{\mathrm{x}}$ ratio is due to the consumption of $\mathrm{NO}_{2}$ via passive oxidation of PM. Hence, the effective $\mathrm{NO}_{2} / \mathrm{NO}_{\mathrm{x}}$ ratio on the SCR catalyst in the SCRF® could be 
significantly lower than the inlet $\mathrm{NO}_{2} / \mathrm{NO}_{\mathrm{x}}$ ratio, having effects on the $\mathrm{NO}_{\mathrm{x}}$ reduction in the SCRF®.

4. The impact of $\mathrm{PM}$ loading on the $\mathrm{NO}_{\mathrm{x}}$ reduction in the $\mathrm{SCRF}{ }^{\circledR}$ was insignificant below $300{ }^{\circ} \mathrm{C}$. The $\mathrm{NO}_{\mathrm{x}}$ reduction decreased by $3-5 \%$ above $350{ }^{\circ} \mathrm{C}$ with the increase in PM loading from 0 to 2 and $4 \mathrm{~g} / \mathrm{L}$, due to consumption of $\mathrm{NO}_{2}$ via passive oxidation of PM.

5. $\mathrm{NH}_{3}$ storage on the $\mathrm{SCRF}{ }^{\circledR}$ without $\mathrm{PM}$ loading is similar to the production2013-SCR. Maximum storage of $75 \mathrm{gmol} / \mathrm{m} 3$ of substrate was observed at $200{ }^{\circ} \mathrm{C}$ for the $S C R F \circledast$.

6. The SCRF® showed $20-30 \%$ reduction in $\mathrm{NH}_{3}$ storage when comparing $0 \mathrm{~g} / \mathrm{L}$ loading to 2 and $4 \mathrm{~g} / \mathrm{L}$ PM loading for the temperature range of 200 to $350{ }^{\circ} \mathrm{C}$. The decrease in the $\mathrm{NH}_{3}$ storage with PM loading was insignificant for the SCRF® inlet temperatures above $350^{\circ} \mathrm{C}$. The increase in PM loading from 2 to 4 $\mathrm{g} / \mathrm{L}$ has minimal impact on the $\mathrm{NH}_{3}$ storage. 


\section{References}

[1] E. Gustafson, "An Experimental Investigation into $\mathrm{NO}_{2}$ Assisted Passive Oxidation with and without Urea Dosing and Active Regeneration of Particulate Matter for a SCR Catalyst on a DPF," MS Thesis, Michigan Technological University, 2016.

[2] "DieselNet, www.dieselnet.com," [Online].

[3] K. Raghavan, "An Experimental Investigation into the Effect of $\mathrm{NO}_{2}$ and Temperature on the Passive Oxidation and Active Regeneration of Particulate Matter in a Diesel Particulate Filter," MS Thesis, Michigan Technological University, 2015.

[4] M. Colombo, I. Nova and E. Tronconi, "A comparative study of the $\mathrm{NH}_{3}-\mathrm{SCR}$ reactions over a $\mathrm{Cu}$-zeolite and a Fe-zeolite catalyst," Catalysis Today 2010;151:223-230, 2010.

[5] H. Surenahalli, "Dynamic Model Based State Estimation In a Heavy Duty Diesel Aftertreatment System For Onboard Diagnostics And Controls," PhD Dissertation, Michigan Technological University, 2013.

[6] J. Pidgeon, "An Experimental Investigation into the Effects of Biodiesel Blends on Particulate Matter Oxidation in a Catalyzed Particulate Filter during Active Regeneration," MS Thesis, Michigan Technological University, 2013.

[7] C. Hutton, "An Experimental Investigation into the Passive Oxidation of Particulate Matter in a Catalyzed Particulate Filter," MS Thesis, Michigan Technological University, 2010.

[8] X. Song, J. Naber, J. Johnson and G. Parker, "An Experimental and Modeling Study of Reaction Kinetics for a Cu-Zeolite SCR Catalyst Based on Engine Experiments," SAE Technical Paper 2013-01-1054, doi:10.4271/2013-01-1054, 2013.

[9] X. Song, "A SCR Model based on Reactor and Engine Experimental Studies for a Cu-zeolite Catalyst," PhD Dissertation, Michigan Technological University, 2013.

[10] T. Ballinger, . J. Cox, M. Konduru and D. De, "Evaluation of SCR Catalyst Technology on Diesel Particulate Filters," SAE Int. J. Fuels Lubr. 2(1):369-374, doi:10.4271/2009-01-0910, 2009. 
[11] Y. He, D. Brown, S. Lu, M. Paratore and J. Li, "Opportunities and Challenges for Blended 2-Way SCR/DPF Aftertreatment Technologies," SAE Technical Paper 2009-01-0274, 2009.

[12] X. Song, J. Johnson and J. Naber, "A review of the literature of selective catalytic reduction catalysts integrated into diesel particulate filters," International Journal of Engine Research, doi:10.1177/1468087414545094, 2014.

[13] B. Mahadevan, J. Johnson and M. Shahbakhti, "Development of a Catalyzed Diesel Particulate Filter Multi-zone Model for Simulation of Axial and Radial Substrate Temperature and Particulate Matter Distribution," Emission Control Science and Technology, DOI 10.1007/s40825-015-0015-x, 2015.

[14] J. Chowng, I. Nam and S. Ham, "Effect of promoters including tungsten and barium on the thermal stability of $\mathrm{V} 2 \mathrm{O} 5 /$ sulfated $\mathrm{TiO}_{2}$ catalyst for $\mathrm{NO}$ reduction by $\mathrm{NH}_{3}$," Catal. Today 111, 242-247, 2009.

[15] M. Vargas, M. Casanova, A. Trovarelli and G. Busca, "An IR study of thermally stable $\mathrm{V} 2 \mathrm{O} 5-\mathrm{WO}_{3}-\mathrm{TiO}_{2} \mathrm{SCR}$ catalysts modified with silica and rare-earths $(\mathrm{Ce}, \mathrm{Tb}$, Er)," Appl. Catal. B: Environ. 75, 303-311, 2007.

[16] J. Spengler, D. Trandal and S. Iretskaya, "Development of Vanadia-Based SCR for High-Temperature Application," IAV MinNO Conference, Berlin, June 2014.

[17] I. Nova and E. Tronconi, "Urea-SCR technology for deNO ${ }_{x}$ after treatment of diesel exhausts," Fundamental and Applied Catalysis 2014.

[18] M. Castagnola, J. Caserta, S. Chatterjee and H. Chen, "Engine Performance of Cuand Fe-Based SCR Emission Control Systems for Heavy Duty Diesel Applications," SAE Technical Paper 2011-01-1329, doi:10.4271/2011-01-1329, 2011.

[19] G. Cavataio, J. Girard, G. Cabaralo and C. Lambert, "Laboratory Testing of UreaSCR Formulations to Meet Tier 2 Bin 5 Emissions," SAE Technical Paper 2007-01$1575,2007$.

[20] J. Girard, R. Snow, G. Cabaralo and C. Lambert, "The Influence of Ammonia to $\mathrm{NO}_{\mathrm{x}}$ Ratio on SCR Performance," SAE Technical Paper 2007-01-1581, 2007.

[21] S. Schmieg and J. Lee, "Evaluation of Supplier Catalyst Formulations for the Selective Catalytic Reduction of $\mathrm{NO}_{x}$ with Ammonia," SAE Technical Paper 200501-3881, 2005. 
[22] H. Nishiyama, Y. Tanaka, T. Adachi and S. Kawamura, "A Study on the Improvement of $\mathrm{NO}_{x}$ Reduction Efficiency for a Urea SCR System," SAE Technical Paper 2015-01-2014, 2015.

[23] K. Kamasamudram, N. Currier, T. Szailer and A. Yezerets, "Why Cu- and FeZeolite SCR Catalysts Behave Differently at Low Temperatures," SAE Technical Paper 2010-01-1182, 2010.

[24] B. Shakya, M. Harold and V. Balakotaiah, "Simulations and optimization of combined Fe- and Cu-zeolite SCR monolith catalysts," Chemical Engineering Journal, Volume 278, 2015.

[25] S. Hirose, H. Yamamoto, H. Suenobu and H. Sakamoto, "Development of High Porosity Cordierite Honeycomb Substrate for SCR Application to Realize High $\mathrm{NO}_{\mathrm{x}}$ Conversion Efficiency and System Compactness," SAE Int. J. Mater. Manf. 7(3):682-687, doi:10.4271/2014-01-1528, 2014.

[26] J. Pless, M. Naseri, W. Klink and G. Spreitzer, "Development of SCR on High Porosity Substrates for Heavy Duty and Off-Road Applications," SAE Int. J. Commer. Veh. 7(1):177-185, doi:10.4271/2014-01-1521, 2014.

[27] T. Zhang, R. Qu, W. Su and J. Li, "A novel Ce-Te mixed oxide catalyst for the selective catalytic reduction of $\mathrm{NO}_{x}$ with $\mathrm{NH}_{3}, "$ Applied Catalysis B: Environmental 2015 .

[28] P. Li, Y. Xin, Q. Li, Z. Wang, Z. Zhang and L. Zheng, "Ce-Ti Amorphous Oxides for Selective Catalytic Reduction of NO with NH3: Confirmation of Ce-O-Ti Active Sites," Environ. Sci. Technol. 46, 9600-9605, 2012.

[29] Y. Peng, R. Qu, X. Zhang and J. Li, "The relationship between structure and activity of $\mathrm{MoO}_{3}-\mathrm{CeO}_{2}$ catalysts for NO removal: influences of acidity and reducibility," Chem. Commun. 49, 6215-6217, DOI: 10.1039/C3CC42693A, 2013.

[30] Z. Liu, Y. Yi, J. Li, S. Woo, B. Wang, X. Cao and Z. Li, "A superior catalyst with dual redox cycles for the selective reduction of $\mathrm{NO}_{\mathrm{x}}$ by ammonia," Chem. Commun. 49, 7726-7728, DOI: 10.1039/C3CC43041C, 2013.

[31] G. Busca, L. Lietti, G. Ramis and F. Berti, "Chemical and mechanistic aspects of the selective catalytic reduction of $\mathrm{NO}_{\mathrm{x}}$ by ammonia over oxide catalysts," Appl. Catal. B 18, 1-36, doi:10.1016/S0926-3373(98)00040-X, 1998.

[32] F. Liu, A. He, W. Shan, X. Shi and C. Zhang, "Influence of sulfation on iron titanate catalyst for the selective catalytic reduction of $\mathrm{NO}_{x}$ with $\mathrm{NH}_{3}, "$ Appl. Catal. B 103, 
369-377, doi:10.1016/j.apcatb.2011.01.044, 2011.

[33] D. Pappas, T. Boningari, P. Boolchand and P. Smirniotis, "Novel manganese oxide confined interweaved titania nanotubes for the low-temperaature Selective Catalytic reduction of $\mathrm{NO}_{x}$ by $\mathrm{NH}_{3}$," Journal of Catalysis, Volume 334,

doi:10.1016/j.jcat.2015.11.013, 2016.

[34] T. Boningari and P. Smirinotis, "Nickel-doped $\mathrm{Mn} / \mathrm{TiO}_{2}$ as an efficient catalyst for the low-temperature $\mathrm{SCR}$ of $\mathrm{NO}$ with $\mathrm{NH}_{3}$ : Catalytic evaluation and characterizations," Journal of Catalysis, volume 288, doi:10.1016/j.jcat.2012.01.003, 2012.

[35] K. Zhuang, J. Qiu, F. Tang, B. Xu and Y. Fan, "The structure and catalytic activity of anatase and rutile titania supported manganese oxide catalysts for selective catalytic reduction of NO by NH3," Phys. Chem. Chem. Phys 13, 4463, 2011.

[36] A. Schuler, M. Votsmeier, P. Kiwic, J. Giwshoff, W. Hautpmann, A. Drochner and H. Vogel, "NH$H_{3}-\mathrm{SCR}$ on Fe zeolite catalysts - From model setup to $\mathrm{NH}_{3}$ dosing," Chemical Engineering Journal, volume 154, 2009.

[37] J. Chi, "Control Challenges for Optimal $\mathrm{NO}_{x}$ Conversion Efficiency from SCR Aftertreatment Systems," SAE Technical Paper 2009-01-0905, doi:10.4271/200901-0905, 2009.

[38] E. Faghihi and A. Shamekhi, "Development of a neural network model for selective catalytic reduction (SCR) catalytic converter and ammonia dosing optimization using multi objective genetic algorithm," Chemical Engineering Journal, vol. 165, 2010.

[39] P. Gaynor, B. Reid, G. Hargrave and T. Lockyer, "An Experimental Investigation into DEF Dosing Strategies for Heavy Duty Vehicle Applications," SAE Int. J. Engines 8(3):1196-1206, doi:10.4271/2015-01-1028, 2015.

[40] H. Dong, S. Shuai and J. Wang, "Effect of Urea Thermal Decomposition on Diesel $\mathrm{NO}_{\mathrm{x}}$-SCR Aftertreatment Systems," SAE Technical Paper 2008-01-1544, doi:10.4271/2008-01-1544, 2008.

[41] B. Guan, "Southwest Research Institute, "Review of state of the art technologies of selective catalytic reduction of $\mathrm{NO}_{\mathrm{x}}$ from diesel engine exhaust," Applied Thermal Engineering, volume 66, 1359-4311, 2014.

[42] G. Bartley, C. Chadwell, T. Kostek and R. Zhan, "SCR Deactivation Kinetics for Model-Based Control and Accelerated Aging Applications," SAE Technical Paper 
2012-01-1077, doi:10.4271/2012-01-1077, 2012.

[43] J. Theis, J. Ura and R. McCabe, "The Effects of Sulfur Poisoning and Desulfation Temperature on the $\mathrm{NO}_{\mathrm{x}}$ Conversion of LNT+SCR Systems for Diesel Applications," SAE Int. J. Fuels Lubr. 3(1):1-15, doi:10.4271/2010-01-0300, 2010.

[44] M. Pereira, A. Nicolle and D. Berthout, "Hydrothermal aging effects on Cu-zeolite $\mathrm{NH}_{3}$-SCR catalyst," Catalysis Today, Volume 258, 2015.

[45] J. Kwak, D. Tran, S. Burton, J. Szanyi, J. Lee and C. Peden, "Effects of hydrothermal aging on $\mathrm{NH}_{3}$-SCR reaction over $\mathrm{Cu}$ /zeolites," Journal of Catalysis, Volume 284, 2012.

[46] J. Luo, H. An, K. Kamasamudram and N. Currier, "Impact of Accelerated Hydrothermal Aging on Structure and Performance of Cu-SSZ-13 SCR Catalysts," SAE Int. J. Engines 8(3):1181-1186, doi:10.4271/2015-01-1022, 2015.

[47] Y. Huang, Y. Cheng and C. Lambert, "Deactivation of Cu/Zeolite SCR Catalyst Due to Reductive Hydrothermal Aging," SAE Int. J. Fuels Lubr. 1(1):466-470, doi:10.4271/2008-01-1021, 2009.

[48] G. Cavataio, H. Jen, J. Warner and J. Girard, "Enhanced Durability of a Cu/Zeolite Based SCR Catalyst," SAE Int. J. Fuels Lubr. 1(1):477-487, 2009, doi:10.4271/2008-01-1025, 2009.

[49] J. Fedeyko, H. Chen, T. Ballinger and E. Weigert, "Development of Thermally Durable Cu/SCR Catalysts," SAE Technical Paper 2009-01-0899, doi:10.4271/2009-01-0899, 2009.

[50] G. Cruciani, "Zeolites upon heating: Factors governing their thermal stability and structural changes," Journal of Physics and Chemistry of Solids, Volume 67:19731994, 2006.

[51] J. Luo, A. Yezerets, C. Henry and H. Hess, "Hydrocarbon Poisoning of Cu-Zeolite SCR Catalysts," SAE Technical Paper 2012-01-1096, doi:10.4271/2012-01-1096, 2012 .

[52] C. Montreuil and C. Lambert, "The effect of hydrocarbons on the selective catalyzed reduction of $\mathrm{NO}_{x}$ over low and high temperature catalyst formulations," $S A E$ Technical Paper 2008-01-1030, 2008.

[53] J. Girard, R. Snow and G. Cavataio, "Influence of hydrocarbon storage on the 
durability of SCR catalysts," SAE Technical Paper 2008-01-0767, 2008.

[54] E. Japkea, M. Casapua, M. Truoilletb, O. Deutschmanna and J. Grunwaldta, "Soot and hydrocarbon oxidation over vanadia based SCR catalysts," Catalysis Today, Volume 258, doi:10.1016/j.cattod.2015.04.020, 2015.

[55] N. Ottinger, B. Foley, Y. Xi and Z. Liu, "Impact of Hydrocarbons on the Dual (Oxidation and SCR) Functions of Ammonia Oxidation Catalysts," SAE Int. J. Engines 7(3):1262-1268, doi:10.4271/2014-01-1536, 2014.

[56] S. Shwan, J. Jansson, L. Olsson and M. Skoglundh, "Chemical deactivation of FeBEA as $\mathrm{NH}_{3}$-SCR catalyst - Effect of phosphorous," Applied Catalyst B: Environmental 147, 2014.

[57] G. Cavataio, H. Jen, D. Dobson and J. Warner, "Laboratory Study to Determine Impact of $\mathrm{Na}$ and $\mathrm{K}$ Exposure on the Durability of DOC and SCR Catalyst Formulations," SAE Technical Paper 2009-01-2823, doi:10.4271/2009-01-2823, 2009.

[58] J. Chi and H. DaCosta, "Modeling and Control of a Urea-SCR Aftertreatment System," SAE Technical Paper 2005-01-0966, doi:10.4271/2005-01-0966, 2005.

[59] E. Abu-Ramadan, K. Saha and X. Li, "Numerical Modeling of the Impingement Process of Urea-Water Solution Spray on the Heated Walls of SCR Systems," SAE Technical Paper 2012-01-1301, 2012.

[60] M. Koebel, M. Elsener and M. Kleemmann, "Urea-SCR: a promising technique to reduce $\mathrm{NO}_{\mathrm{x}}$ emissions from automotive diesel engines," Catal. Today 56 (2000) 335 345,2000 .

[61] H. Fang and $\mathrm{H}$. DaCosta, "Urea thermolysis and $\mathrm{NO}_{\mathrm{x}}$ reduction with and without SCR catalysts," Appl. Catal. B: Environ. 46, 14-34, 2003.

[62] J. Lee, M. Paratore and D. Brown, "Evaluation of Cu-Based SCR/DPF Technology for Diesel Exhaust Emission Control," SAE Int. J. Fuels Lubr. 1(1):96-101, doi:10.4271/2008-01-0072, 2009.

[63] Y. Yang, G. Cho and C. Rutland, "Model Based Study of DeNO ${ }_{x}$ Characteristics for Integrated DPF/SCR System over Cu-Zeolite," SAE Technical Paper 2015-01-1060, doi:10.4271/2015-01-1060, 2015. 
[64] E. Tronconi, "Interaction of $\mathrm{NO}_{\mathrm{x}}$ Reduction and Soot Oxidation in a DPF with CuZeolite SCR Coating," Emission Control Science and Technology, DOI 10.1007/s40825-015-0014-y, 2015.

[65] M. Naseri, S. Chatterjee, M. Castagnola and H. Chen, "Development of SCR on Diesel Particulate Filter System for Heavy Duty Applications," SAE Int. J. Engines 4(1):1798-1809, doi:10.4271/2011-01-1312, 2011.

[66] J. Czerwinski, Y. Zimmerli, A. Mayer and J. Lemaire, "Investigations of SDPF Diesel Particle Filter with SCR Coating for HD-Applications," SAE Technical Paper 2015-01-1023, doi:10.4271/2015-01-1023, 2015.

[67] T. Watling, "Development, validation and application of a model for an SCR catalyst coated diesel particulate filter," Catal. Today, doi:10.1016/j.cattod. 2012.02.007, 2012.

[68] S. Park, K. Narayanaswamy, S. Schmieg and C. Rutland, "A Model Development for Evaluating Soot-NOx Interactions in a Blended 2-Way Diesel Particulate Filter/Selective Catalytic Reduction," Ind. Eng. Chem. Res., 2012..

[69] W. Tang, D. Youndren, M. SantaMaria and S. Kumar, "On-Engine Investigation of SCR on Filters (SCRoF) for HDD Passive Applications," SAE Int. J. Engines 6(2):862-872, doi:10.4271/2013-01-1066, 2013.

[70] J. Tan, C. Solbrig and S. Schmieg, "The Development of Advanced 2-Way SCR/DPF Systems to Meet Future Heavy-Duty Diesel Emissions," SAE Technical Paper 2011-01-1140, doi:10.4271/2011-01-1140, 2011.

[71] F. Schrade, M. Brammer, J. Schaeffner and K. Langeheinecke, "Physico-Chemical Modeling of an Integrated SCR on DPF (SCR/DPF) System," SAE Int. J. Engines 5(3):958-974, doi:10.4271/2012-01-1083, 2012.

[72] J. Czerwinski, Y. Zimmerli, A. Mayer, G. D'Urbano and D. Zurcher, "Emission Reduction with Diesel Particle Filter with SCR Coating (SDPF)," Emission Control Science and Technology, Volume 1, 2015.

[73] G. Cavataio, J. Girard and C. Lambert, "Cu/Zeolite SCR on High Porosity Filters: Laboratory and Engine Performance Evaluations," SAE Technical Paper 2009-010897, doi:10.4271/2009-01-0897, 2009. 
[74] K. Johansen, H. Bentzer, A. Kustov and K. Larsen, "Integration of Vanadium and Zeolite Type SCR Functionality into DPF in Exhaust Aftertreatment Systems Advantages and Challenges," SAE Technical Paper 2014-01-1523, doi:10.4271/2014-01-1523, 2014.

[75] R. Conway, S. Chatterjee, M. Naseri and C. Aydin, "Demonstration of SCR on a Diesel Particulate Filter System on a Heavy Duty Application," SAE Technical Paper, doi:10.4271/2015-01-1033, 2015.

[76] H. Kojima, M. Fischer, H. Haga and N. Ohya, "Next Generation All in One CloseCoupled Urea-SCR System," SAE Technical Paper 2015-01-0994, doi:10.4271/2015-01-0994, 2015.

[77] K. Rappe, "Integrated Selective Catalytic Reduction-Diesel Particulate Filter Aftertreatment: Insights into Pressure Drop, $\mathrm{NO}_{\mathrm{x}}$ Conversion, and Passive Soot Oxidation Behavior," Industrial and Engineering Chemistry Research, 2014.

[78] M. Naseri, R. Conway, H. Hess and C. Aydin, "Development of Emission Control Systems to Enable High $\mathrm{NO}_{\mathrm{x}}$ Conversion on Heavy Duty Diesel Engines," $S A E$ Technical Paper 2014-01-1525, doi:10.4271/2014-01-1525, 2014.

[79] V. Strots, A. Kishi, S. Adelberg and L. Kramer, "Application of Integrated $\mathrm{SCR} / \mathrm{DPF}$ Systems in Commercial Vehicles," JSAE Annual Congress, 45420145174, 2014.

[80] K. Premchand, "Development of a 1-D Catalyzed Diesel Particulate Filter Model for Simulation of the Performance and the Oxidation of Particulate Matter and Nitrogen Oxides using Passive Oxidation and Active Regeneration Engine Experimental Data," PhD Dissertation, Michigan Technological University, 2013.

[81] R. Foley, "Experimental Investigation into Particulate Matter Distribution in Catalyzed Particulate Filters using a 3D Terahertz Wave Scanner," MS Thesis, Michigan Technological University, 2013.

[82] K. Shiel, "A Study of the Effect of Biodiesel Fuel on Passive Oxidation in a Catalyzed Particulate Filter," MS Thesis, Michigan Technological University, 2012.

[83] J. Pidgeon, "An Experimental Investigation into the Effects of Biodiesel Blends on Particulate Matter Oxidation in a Catalyzed Particulate Filter during Active Regeneration," MS Thesis, Michigan Technological University, 2013.

[84] K. Chilumukuru, R. Arasappa, J. Johnson and J. Naber, "An Experimental Study of Particulate Thermal Oxidation in a Catalyzed Filter During Active Regeneration," SAE Technical Paper 2009-01-1474, doi:10.4271/2009-01-1474, 2009. 
[85] T. McKinley and A. Alleyne, "A Urea Decomposition Modeling Framework for SCR Systems," SAE Int. J. Fuels Lubr. 2(1):612-626, doi:10.4271/2009-01-1269, 2009.

[86] S. Gupta, "An Experimental Investigation into the Effect of Particulate Matter on $\mathrm{NO}_{\mathrm{x}}$ Reduction in a SCR Catalyst on a DPF," MS Report, Michigan Technological University, 2016. 


\section{Appendix A. MS Start up, Shut down and Calibration Procedures}

The MS is ON and in STANDBY mode during the daily operation. In case the MS is turned OFF for the repair or any other purpose for more than 4 hours, the MS is to be switched $\mathrm{ON}$ at least 5 hours before its use for emission measurement. During the warmup period, the system is stabilized for the data collection, since the sensitivity of the cold analyzer is unstable and the measurements may not be reliable due to inaccurate calibration. It also can cause the MS to drift while measuring emission concentrations during the test. The emission data and the system operation parameters can be monitored, recorded and controlled through the V\&F Viewer software installed in a desktop computer. Ensure that the computer is turned $\mathrm{ON}$ and the analyzer is connected to the computer via a LAN cable. To initiate the start-up process, open the valve on the xenon gas bottle located inside the MS. Purging the analyzer with xenon removes the oxygen that may have leaked into the analyzer. The oxygen in the gas lines and analyzer may cause damage to the filament which generates electrons. Now switch ON the MS and confirm that the red LEDs are displayed on the RF generator, indicating the status of the MS. The LEDs will turn orange and green in color as the MS has warmed up and stabilized. Open the V\&F Viewer and connect to the MS. Select the measurement method "SCR" from the drop-down list in the software. Put the MS in the STANDBY mode when not in use. Refrain from moving the MS when it is turned ON, to avoid any possible damage to the turbo-pump.

In this study, the MS was used to measure the concentration of $\mathrm{NO}, \mathrm{NO}_{2}, \mathrm{NH}_{3}$ and $\mathrm{O}_{2}$ in the exhaust flow. The MS needs to be calibrated before each test, using the gas bottles for each species of known concentration. The $\mathrm{N}_{2}$ gas with purity of $99.999 \%$ was used as the zero gas. The details of calibration gases are given in Table 3.10. The calibration can be performed either automatically, using the calibration option in the software, or manually, by adjusting the concentration measurement to that of the calibration gas. For the automatic calibration, open the valves on all the calibration gas bottles and $\mathrm{N}_{2}$. Click on 
"Calibrate" option in the side menu and select all the species to be calibrated. Press "Start" to initiate the calibration process. It takes about $8-10$ minutes to complete the procedure. After the calibration procedure, put the MS in the "Measure" mode till the end of the test.

To perform the manual calibration, plug the calibration gas bottle of the species to be calibrated into the quick connect valve on the front panel of the MS. Unplug the other gases and release the pressure in the line, to prevent their interference during the calibration, due to leakage of the gas through the quick connect valve or the gas lines of the analyzer. Put the MS in the "Measure" mode. Select the quick connect valve from the "Sample inlet" function (the top right section of the software) and the MS starts measuring the calibration gas. Now zero the MS by selecting "inert gas" from the list. Perform zeroing of MS in automatic mode by selecting only "inert gas" in the list. After completion of zeroing step, select other gases of interest. After the measurement has stabilized, select the gas type from the "molecule list" displayed on the right side of the software. Then select channel calibration and enter the concentration mentioned on the gas bottle in the open window. Observe the change in the measurement. If the updated concentration measurement is not correct, re-enter the concentration value, else click OK to accept the calibration. Then repeat the procedure for each species to be calibrated. The calibration procedure was also performed during the test to confirm the accuracy of the data.

To turn OFF the analyzer, select "turn off analyzer" from tools menu of the V\&F software. This prevents loss of data and ensures proper shut down of the analyzer. Then turn OFF the power switch located on the rear panel of the analyzer. Then close the valves on the source gas and calibration gas bottles to prevent any possible leakage. Wait for $30 \mathrm{mins}$ if the system is to be accessed for replacement/repair of components. This provides time for the turbofan to stop completely and the system to cool down. 


\section{Appendix B. Calibration of NH 3Sensor using the MS}

$\mathrm{NH}_{3}$ slip from the $\mathrm{SCR} / \mathrm{SCRF}{ }^{\circledR}$ was measured using the MS and the $\mathrm{NH}_{3}$ sensor as described in the Chapter 3. It was observed from the experimental results that the $\mathrm{NH}_{3}$ slip measured by the MS were lower than the values measured by the $\mathrm{NH}_{3}$ sensor. In order to compare the $\mathrm{NH}_{3}$ slip measurements from the $\mathrm{NH}_{3}$ sensor and the MS, it is important to know the empirical relation between the two values. The IMR-MS is calibrated before each test using the calibration gas of known concentration as explained in Appendix A.

To determine the empirical relation between the $\mathrm{NH}_{3}$ sensor and the IMR-MS, a test was conducted. The test condition and results of the $\mathrm{NH}_{3}$ sensor calibration are given in Table B.1. The engine was stabilized at the baseline condition as explained in the Chapter 3 . During the test, the DEF injection rate was varied to achieve the ANR of 1.2, 1.5, 1.8 and 2.0. At each ANR the $\mathrm{NH}_{3}$ slip was measured by the MS and the $\mathrm{NH}_{3}$ sensor at the same time, until the $\mathrm{NH}_{3}$ measurements from both the instruments reached the steady state for 5 minutes. Then the steady state $\mathrm{NH}_{3}$ slip measurements from both the instruments were compared to estimate the ratio of $\mathrm{NH}_{3}$ slip from the sensor to the $\mathrm{NH}_{3}$ slip from the MS. The average of the ratios can be used as the $\mathrm{NH}_{3}$ sensor calibration factor during calibration of the SCR-F model.

Table B.1: Results of $\mathrm{NH}_{3}$ sensor calibration

\begin{tabular}{|c|c|c|c|c|c|c|c|}
\hline Speed & Load & $\begin{array}{c}\text { Exhaust } \\
\text { Flow } \\
\text { Rate }\end{array}$ & $\begin{array}{c}\text { SCRF® } \\
\text { Inlet } \\
\text { Temp. }\end{array}$ & ANR & $\begin{array}{c}\mathbf{N H}_{3} \\
\text { Sensor }\end{array}$ & $\begin{array}{c}\mathbf{N H}_{3} \\
\text { MS }\end{array}$ & Ratio \\
\hline$[$ RPM] $]$ & {$[$ N.m] } & {$[\mathbf{k g} / \mathbf{m i n}]$} & {$\left[{ }^{\circ} \mathbf{C}\right]$} & {$[-]$} & {$[\mathbf{p p m}]$} & {$[\mathbf{p p m}]$} & {$[-]$} \\
\hline 1661 & 478 & 8.1 & 325 & 0.0 & 0 & 0 & - \\
\hline 1662 & 477 & 8.1 & 323 & 1.2 & 81 & 71 & 1.15 \\
\hline 1661 & 479 & 8.1 & 323 & 1.5 & 252 & 220 & 1.15 \\
\hline 1662 & 479 & 8.1 & 321 & 1.8 & 420 & 360 & 1.17 \\
\hline 1662 & 478 & 8.1 & 320 & 2.0 & 556 & 469 & 1.19 \\
\hline 1662 & 477 & 8.1 & 321 & 0.0 & 0 & 6 & - \\
\hline
\end{tabular}




\section{Appendix C. Calibration of the DEF Injector}

The ANR and the $\mathrm{NH}_{3}$ concentration at the $\mathrm{SCR} / \mathrm{SCRF} ®$ inlet is estimated from the $\mathrm{DEF}$ injection rate, exhaust flow rate and urea properties. Hence, it is important to accurately control the DEF injection rate. The DEF injection rate is controlled by entering the targeted DEF injection rate into the Cummins proprietary software "Calterm", which communicates the command to the engine ECM. The DEF injector calibration procedure is described below.

1) Remove the DEF injector mounted on the decomposition tube.

2) Position a $500 \mathrm{ml}$ measuring cylinder under the DEF injector.

3) Start the DEF injection and continue injecting for 10 minutes. For flow rates below $0.1 \mathrm{ml} / \mathrm{s}$, perform $\mathrm{DEF}$ injection for 20 minutes or higher to reduce the error.

4) Stop the DEF injection and remove the measuring cylinder. Place it on a flat surface and wait until no bubbles can be seen in the DEF collected.

5) Record the volume of the DEF collected in the measuring cylinder. Pour the DEF back into the DEF tank.

The relationship between the targeted DEF flow rate (command sent to the ECM) and the actual DEF flow rate (obtained from Calterm) are plotted in Figure C.1. The linear trend line characterizes the relationship between the targeted and the actual DEF flow rate. The actual DEF flow rate was obtained from the Calterm parameter "V_UIM_flm_EstUreaInjRate" and was used to calculate the $\mathrm{NH}_{3}$ concentrations and ANR at the inlet of the SCRF®. 


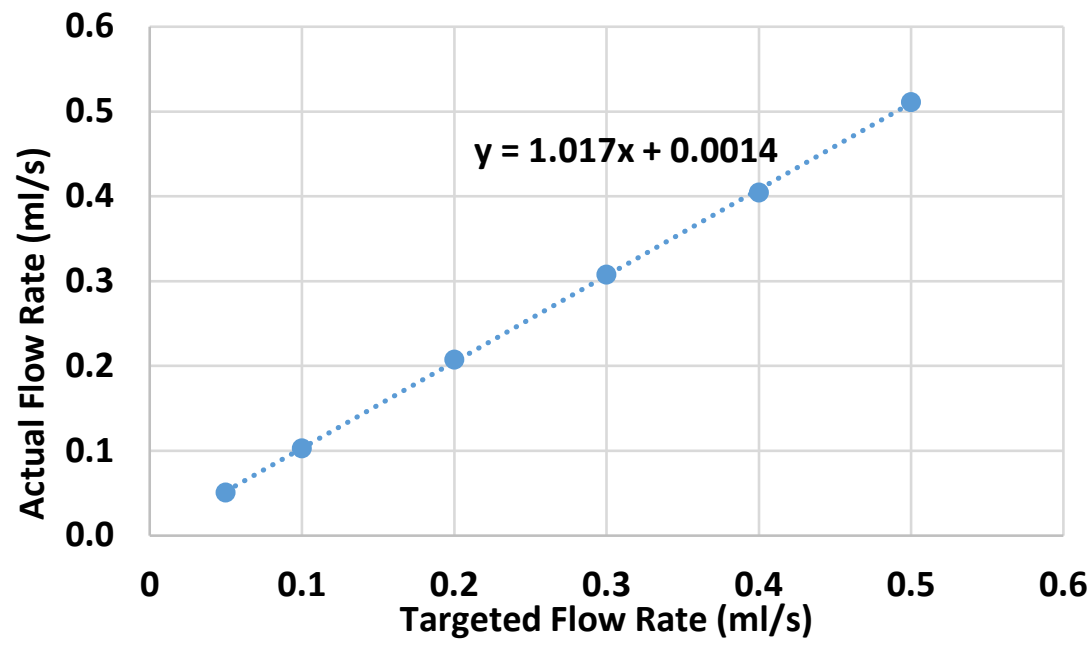

Figure C.1: Calibration curve for the DEF injection 


\section{Appendix D. Production-2013-SCR Experimental Results, 1-D SCR Model Calibration Procedure and Simulation Results}

The $\mathrm{NO}, \mathrm{NO}_{2}$ and $\mathrm{NH}_{3}$ concentrations and the $\mathrm{NO}_{\mathrm{x}}$ reduction performance of the production-2013-SCR at ANR of 0.3, 0.5, 0.8, 1.0 (repeat) and 0.8 (repeat) are given in Tables D.1 through D.5.

Table D.1: $\mathrm{NO}_{\mathrm{x}}$ reduction performance of the production-2013-SCR at target ANR of 0.3

\begin{tabular}{|c|c|c|c|c|c|c|c|c|c|c|}
\hline $\begin{array}{c}\text { Test } \\
\text { Points }\end{array}$ & $\begin{array}{c}\text { SCR } \\
\text { Inlet } \\
\text { Temp. }\end{array}$ & NO [ & pm] & & $\begin{array}{l}\mathrm{P}_{2} \\
\mathrm{~m}]\end{array}$ & & $\mathrm{H}_{3}$ & ANR & $\begin{array}{c}\text { NO }_{\mathrm{x}} \\
\text { Conv. } \\
\text { Efficiency }\end{array}$ & $\begin{array}{c}\text { Nitrogen } \\
\text { Balance }\end{array}$ \\
\hline$[-]$ & {$\left[{ }^{\circ} \mathrm{C}\right]$} & In & Out & In & Out & In & Out & {$[-]$} & {$[\%]$} & {$[\%]$} \\
\hline 1 & 219 & 470 & 347 & 178 & 125 & 177 & 0 & 0.27 & 25 & 99 \\
\hline 2 & 238 & 177 & 142 & 102 & 78 & 72 & 1 & 0.26 & 22 & 83 \\
\hline 3 & 307 & 199 & 139 & 91 & 67 & 87 & 0 & 0.30 & 30 & 97 \\
\hline 4 & 327 & 185 & 122 & 158 & 127 & 93 & 0 & 0.27 & 28 & 101 \\
\hline 5 & 354 & 325 & 203 & 227 & 179 & 165 & 0 & 0.30 & 29 & 103 \\
\hline 6 & 352 & 1045 & 647 & 685 & 578 & 476 & 32 & 0.28 & 31 & 113 \\
\hline 8 & 447 & 443 & 336 & 99 & 53 & 163 & 0 & 0.30 & 27 & 94 \\
\hline
\end{tabular}

Table D.2: $\mathrm{NO}_{\mathrm{x}}$ reduction performance of the production-2013-SCR at target ANR of 0.5

\begin{tabular}{|c|c|c|c|c|c|c|c|c|c|c|}
\hline $\begin{array}{c}\text { Test } \\
\text { Points }\end{array}$ & $\begin{array}{c}\text { SCR } \\
\text { Inlet } \\
\text { Temp. }\end{array}$ & \multicolumn{2}{|c|}{ NO [ppm] } & \multicolumn{2}{|c|}{$\begin{array}{c}\mathbf{N O}_{\mathbf{2}} \\
\text { [ppm] }\end{array}$} & \multicolumn{2}{|c|}{$\begin{array}{c}\mathbf{N H}_{\mathbf{3}} \\
\text { [ppm] }\end{array}$} & ANR & $\begin{array}{c}\mathbf{N O}_{\mathbf{x}} \\
\text { Conv. } \\
\text { Efficiency }\end{array}$ & $\begin{array}{c}\text { Nitrogen } \\
\text { Balance }\end{array}$ \\
\hline$[-]$ & {$\left[{ }^{\circ} \mathbf{C}\right]$} & In & Out & In & Out & In & Out & {$[-]$} & {$[\%]$} & {$[\%]$} \\
\hline $\mathbf{1}$ & 219 & 470 & 289 & 178 & 78 & 301 & 1 & 0.46 & 42 & 94 \\
\hline $\mathbf{2}$ & 238 & 177 & 113 & 102 & 34 & 126 & 1 & 0.45 & 41 & 106 \\
\hline $\mathbf{3}$ & 307 & 199 & 105 & 91 & 38 & 148 & 1 & 0.51 & 51 & 100 \\
\hline $\mathbf{4}$ & 327 & 185 & 86 & 158 & 92 & 156 & 0 & 0.45 & 48 & 106 \\
\hline $\mathbf{5}$ & 354 & 325 & 142 & 227 & 122 & 271 & 0 & 0.49 & 51 & 106 \\
\hline $\mathbf{6}$ & 352 & 1045 & 474 & 685 & 405 & 802 & 0 & 0.46 & 50 & 106 \\
\hline $\mathbf{8}$ & 447 & 443 & 252 & 99 & 12 & 276 & 0 & 0.51 & 50 & 101 \\
\hline
\end{tabular}

Table D.3: $\mathrm{NO}_{\mathrm{x}}$ reduction performance of the production-2013-SCR at target ANR of 0.8 


\begin{tabular}{|c|c|c|c|c|c|c|c|c|c|c|}
\hline $\begin{array}{c}\text { Test } \\
\text { Points }\end{array}$ & $\begin{array}{c}\text { SCR } \\
\text { Inlet } \\
\text { Temp. }\end{array}$ & \multicolumn{2}{|c|}{ NO [ppm] } & \multicolumn{2}{|c|}{$\begin{array}{c}\mathbf{N O}_{\mathbf{2}} \\
\text { [ppm] }\end{array}$} & \multicolumn{2}{c|}{$\begin{array}{c}\mathbf{N H}_{\mathbf{3}} \\
{[\mathbf{p p m}]}\end{array}$} & ANR & $\begin{array}{c}\mathbf{N O}_{\mathbf{x}} \\
\text { Conv. } \\
\text { Efficiency }\end{array}$ & $\begin{array}{c}\text { Nitrogen } \\
\text { Balance }\end{array}$ \\
\hline$[-]$ & {$\left[{ }^{\circ} \mathbf{C}\right]$} & In & Out & In & Out & In & Out & {$[-]$} & {$[\%]$} & {$[\%]$} \\
\hline $\mathbf{1}$ & 219 & 470 & 217 & 178 & 27 & 481 & 1 & 0.74 & 61 & 84 \\
\hline $\mathbf{2}$ & 238 & 177 & 82 & 102 & 23 & 205 & 1 & 0.73 & 63 & 85 \\
\hline $\mathbf{3}$ & 307 & 199 & 50 & 91 & 3 & 238 & 0 & 0.82 & 82 & 100 \\
\hline $\mathbf{4}$ & 327 & 185 & 40 & 158 & 41 & 254 & 0 & 0.74 & 76 & 103 \\
\hline $\mathbf{5}$ & 354 & 325 & 61 & 227 & 38 & 435 & 0 & 0.79 & 82 & 104 \\
\hline $\mathbf{6}$ & 352 & 1045 & 244 & 685 & 139 & 1291 & 0 & 0.75 & 78 & 104 \\
\hline $\mathbf{8}$ & 447 & 443 & 124 & 99 & 1 & 442 & 15 & 0.82 & 77 & 98 \\
\hline
\end{tabular}

Table D.4: $\mathrm{NO}_{\mathrm{x}}$ reduction performance of the production-2013-SCR at target ANR of 1.0 (Repeat)

\begin{tabular}{|c|c|c|c|c|c|c|c|c|c|c|}
\hline $\begin{array}{c}\text { Test } \\
\text { Points }\end{array}$ & $\begin{array}{c}\text { SCR } \\
\text { Inlet } \\
\text { Temp. }\end{array}$ & \multicolumn{2}{|c|}{ NO [ppm] } & \multicolumn{2}{|c|}{$\begin{array}{c}\mathbf{N O}_{\mathbf{2}} \\
{[\mathbf{p p m}]}\end{array}$} & \multicolumn{2}{|c|}{$\begin{array}{c}\mathbf{N H}_{\mathbf{3}} \\
{[\mathbf{p p m}]}\end{array}$} & ANR & $\begin{array}{c}\mathbf{N O}_{\mathbf{x}} \\
\text { Conv. } \\
\text { Efficiency }\end{array}$ & $\begin{array}{c}\text { Nitrogen } \\
\text { Balance }\end{array}$ \\
\hline$[-]$ & {$\left[{ }^{\circ} \mathbf{C}\right]$} & In & Out & In & Out & In & Out & {$[-]$} & {$[\%]$} & {$[\%]$} \\
\hline $\mathbf{1}$ & 219 & 470 & 110 & 178 & 0 & 606 & 39 & 0.94 & 2 & 95 \\
\hline $\mathbf{2}$ & 238 & 177 & 30 & 102 & 0 & 260 & 12 & 0.93 & 89 & 100 \\
\hline $\mathbf{3}$ & 307 & 199 & 24 & 91 & 0 & 293 & 35 & 1.01 & 92 & 103 \\
\hline $\mathbf{4}$ & 327 & 185 & 6 & 158 & 4 & 316 & 1 & 0.92 & 97 & 106 \\
\hline $\mathbf{5}$ & 354 & 325 & 3 & 227 & 0 & 539 & 6 & 0.98 & 100 & 103 \\
\hline $\mathbf{6}$ & 352 & 1045 & 85 & 685 & 1 & 1713 & 5 & 0.99 & 95 & 96 \\
\hline $\mathbf{8}$ & 447 & 443 & 89 & 99 & 0 & 554 & 68 & 1.02 & 83 & 94 \\
\hline
\end{tabular}

Table D.5: $\mathrm{NO}_{\mathrm{x}}$ reduction performance of the production-2013-SCR at target ANR of 0.8 (repeat)

\begin{tabular}{|c|c|c|c|c|c|c|c|c|c|c|}
\hline $\begin{array}{c}\text { Test } \\
\text { Points }\end{array}$ & $\begin{array}{c}\text { SCR } \\
\text { Inlet } \\
\text { Temp. }\end{array}$ & \multicolumn{2}{|c|}{ NO [ppm] } & \multicolumn{2}{|c|}{$\begin{array}{c}\mathbf{N O}_{\mathbf{2}} \\
{[\mathbf{p p m}]}\end{array}$} & \multicolumn{2}{|c|}{$\begin{array}{c}\mathbf{N H}_{\mathbf{3}} \\
{[\mathbf{p p m}]}\end{array}$} & ANR & $\begin{array}{c}\mathbf{N O}_{\mathbf{x}} \\
\text { Conv. } \\
\text { Efficiency }\end{array}$ & $\begin{array}{c}\text { Nitrogen } \\
\text { Balance }\end{array}$ \\
\hline$[-]$ & {$\left[{ }^{\circ} \mathbf{C}\right]$} & In & Out & In & Out & In & Out & {$[-]$} & {$[\%]$} & {$[\%]$} \\
\hline $\mathbf{1}$ & 219 & 470 & 144 & 178 & 0 & 483 & 6 & 0.75 & 77 & 106 \\
\hline $\mathbf{2}$ & 238 & 177 & 67 & 102 & 2 & 206 & 3 & 0.74 & 75 & 103 \\
\hline $\mathbf{3}$ & 307 & 199 & 49 & 91 & 1 & 232 & 1 & 0.80 & 83 & 104 \\
\hline $\mathbf{4}$ & 327 & 185 & 40 & 158 & 33 & 253 & 0 & 0.74 & 79 & 107 \\
\hline $\mathbf{5}$ & 354 & 325 & 70 & 227 & 33 & 437 & 0 & 0.79 & 81 & 103 \\
\hline $\mathbf{6}$ & 352 & 1045 & 274 & 685 & 124 & 1300 & 0 & 0.75 & 78 & 102 \\
\hline $\mathbf{8}$ & 447 & 443 & 131 & 99 & 0 & 443 & 13 & 0.82 & 75 & 96 \\
\hline
\end{tabular}

The experimental data acquired from the seven $\mathrm{NO}_{\mathrm{x}}$ reduction Test Points that cover a range of SCR inlet temperatures, space velocities and inlet $\mathrm{NO}_{\mathrm{x}}$ concentrations were used 
to prepare the time varying inputs and calibrate the model. The time varying inputs required for the model are:

I. Exhaust mass flow rate

II. Concentration of chemical species $\left(\mathrm{NO}, \mathrm{NO}_{2}, \mathrm{NH}_{3}, \mathrm{H}_{2} \mathrm{O}, \mathrm{CO}_{2}\right.$ at the inlet of the SCR)

III. SCR inlet temperature and pressure

The primary objective of the calibration procedure was to determine a single set of parameters that could simulate the $\mathrm{NO}_{\mathrm{x}}$ reduction performance of the production-2013SCR for the seven Test Points. The SCR model parameters used for calibrating the model to the engine experimental data from the Cummins ISB 2010 engine, were used as the starting values. The simulation data from the model were compared with the experimental data, to determine the difference and evaluate the performance of the 1-D SCR model. The model parameters were changed manually to reduce the cost function. The cost function value for each species is defined as the accumulative absolute error between the model prediction and the experimental measurement divided by the simulation time. The equation calculating the cost function value for each species is given in Equation D.1. The Equation D.1 is from reference [9].

$$
\operatorname{Cos} t_{i}=\frac{\sum_{t_{0}}^{t_{\text {end }}}\left|C_{i, \operatorname{Sim}}-C_{i, E x p}\right|}{t_{\text {end }}}
$$

Where Cost $\mathrm{t}_{\mathrm{i}}$ is the cost function for gas species $i\left(i=\mathrm{NO}, \mathrm{NO}_{2}, \mathrm{NH}_{3}\right) . t_{\mathrm{o}}$ and $t_{\text {end }}$ are the start and stop time in seconds for the simulation. $\mathrm{C}_{i, \operatorname{Sim}}$ and $\mathrm{C}_{i, \text { Exp }}$ are the model simulated and experimentally measured gas concentrations for the gas species $i$ respectively [9].

\section{Manual Optimization}


The manual optimization procedure illustrated in Figure D. 1 is explained in the following steps:

I. Run the model with the input file and the initial set of parameters. Initial parameters for engine data were taken from Table 5.1 in reference [9].

II. The model simulated data and the experimental data were plotted to determine the difference in concentrations of $\mathrm{NO}, \mathrm{NO}_{2}$ and $\mathrm{NH}_{3}$ at the production-2013SCR outlet location. The difference in concentration during steady state operation was used to estimate the parameter to be optimized.

III. The parameter is changed to reduce the difference.

IV. The parameters were changed based on the cost function. The parameters were also tuned to reduce the difference between the experimental and simulated data during transient and steady state conditions. Then step 2 was repeated.

V. The step III and IV were repeated till the model was calibrated to within \pm 20 ppm for $\mathrm{NO}$ and $\mathrm{NO}_{2}$, and \pm 30 ppm for $\mathrm{NH}_{3}$ concentrations.

The activation energy for the twelve reactions in the MY2013 production-2013-SCR were assumed to be same as that of MY2010 production. The pre-exponential factor for R1, R2, R7 and R9 described in Chapter 2, which are labelled as "A_ads1", "A_des1", " A_std" and "A_fst" respectively, were calibrated based on trial-and-error method since only these factors affected the simulation results significantly. The modified preexponential values are highlighted in Table 4.5. The plot of reaction rate constant vs $1000 / T$ is shown in Figure D.2. It is observed from Figure D.2 that the reaction rate constant for each reaction followed a linear trend in the Arrhenius form, meaning that the effect of the temperature on the reaction rates was well captured by the model. The slope $\mathrm{m}$ and the interception $\mathrm{c}$ of each fit trend line were used to calculate the pre-exponential constant and the activation energy of each reaction. Comparison of the simulation of SCR outlet concentrations of $\mathrm{NO}, \mathrm{NO}_{2}$ and $\mathrm{NH}_{3}$ data to the experimental data for Test Points 2, 3, 4, 6 and 8 are shown in Figures D.3 to D.7. 


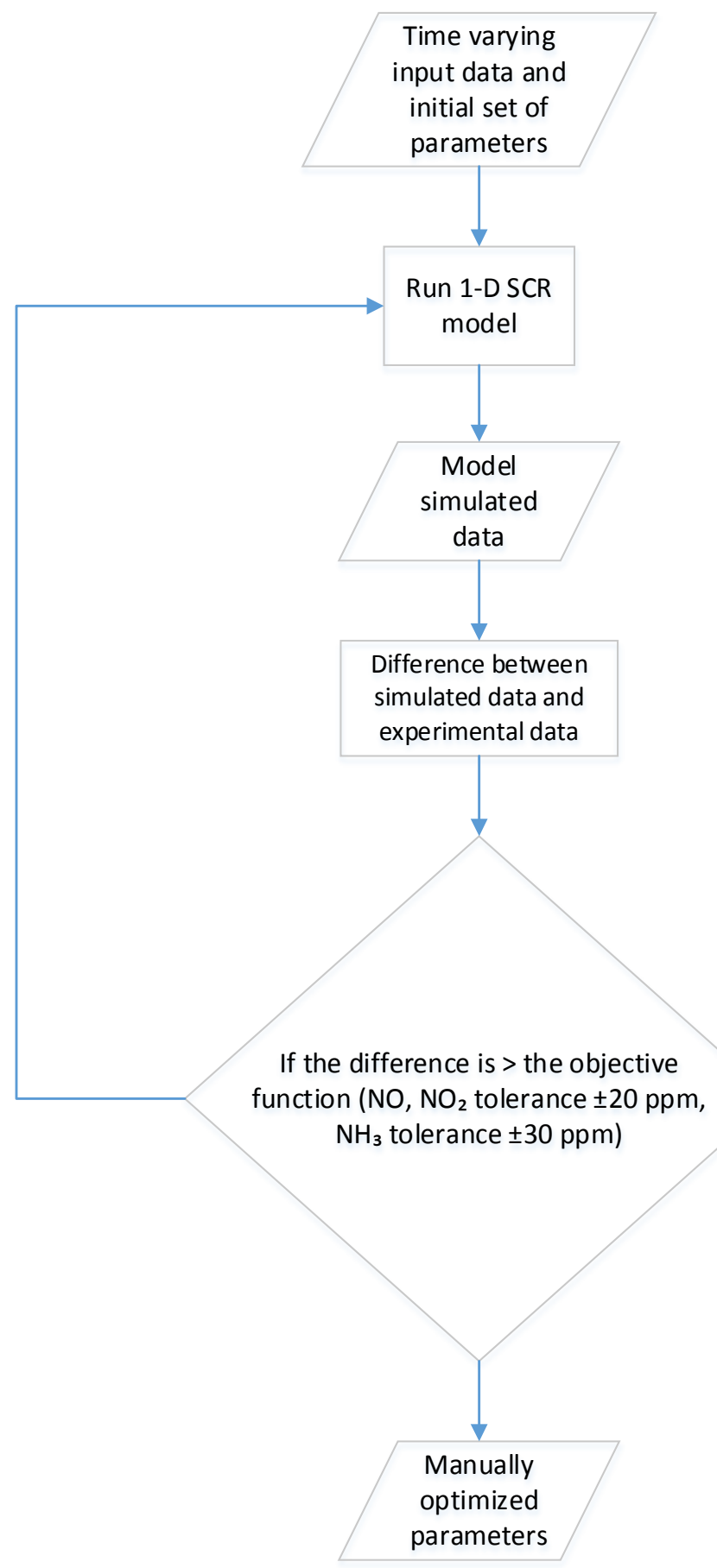

Figure D.1: Flow chart of manual optimization procedure to calibrate 1-D SCR model 


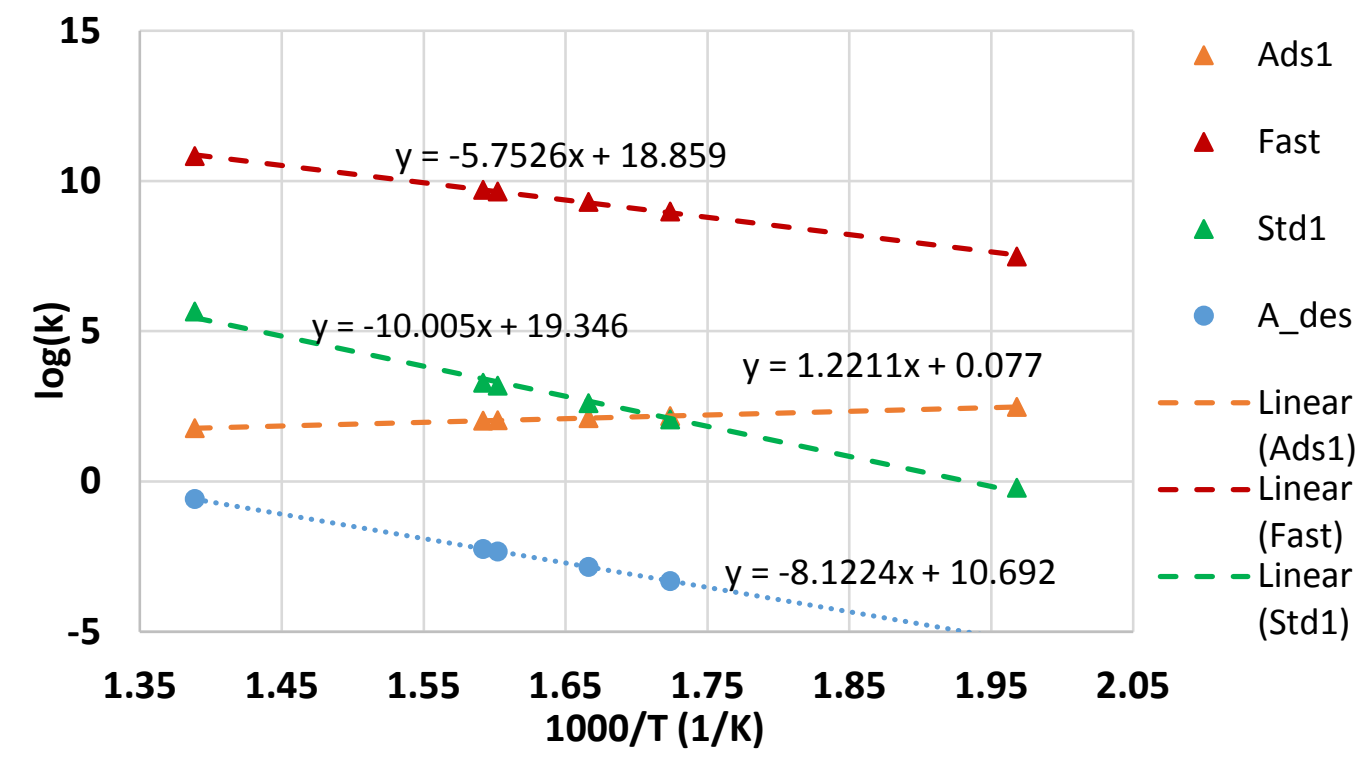

Figure D.2: Arrhenius plots of reaction rate constants for reactions R1, R2, R7 and R9



Figure D.3: Comparison of the SCR outlet gaseous concentrations between simulation results and experimental measurements for Test Point 2 (SCR inlet temperature $235^{\circ} \mathrm{C}$, SV $17.2 \mathrm{k} / \mathrm{hr}$ 


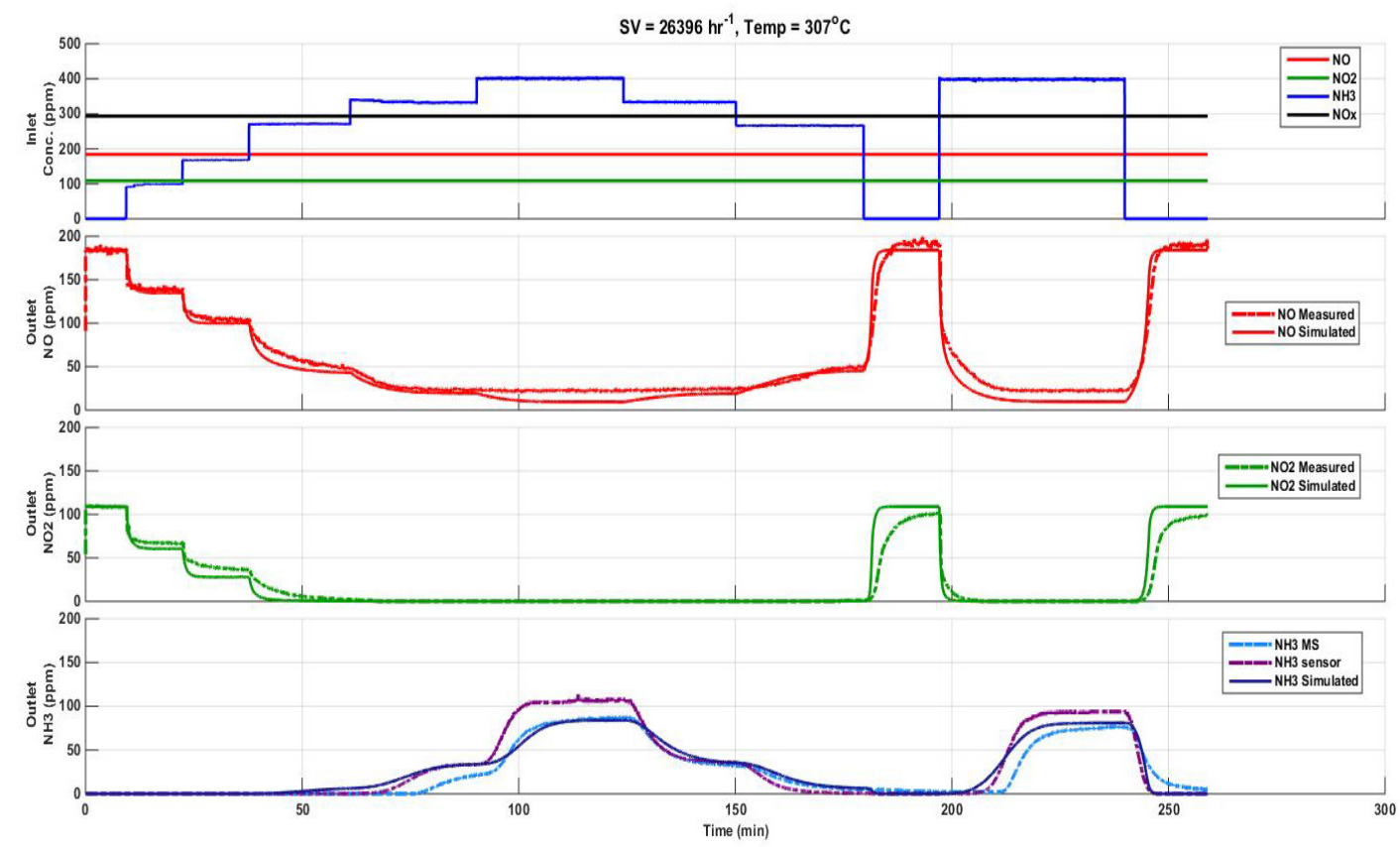

Figure D.4: Comparison of the SCR outlet gaseous concentrations between simulation results and experimental measurements for Test Point 3 (SCR inlet temperature $307^{\circ} \mathrm{C}$, SV $26.4 \mathrm{k} / \mathrm{hr}$

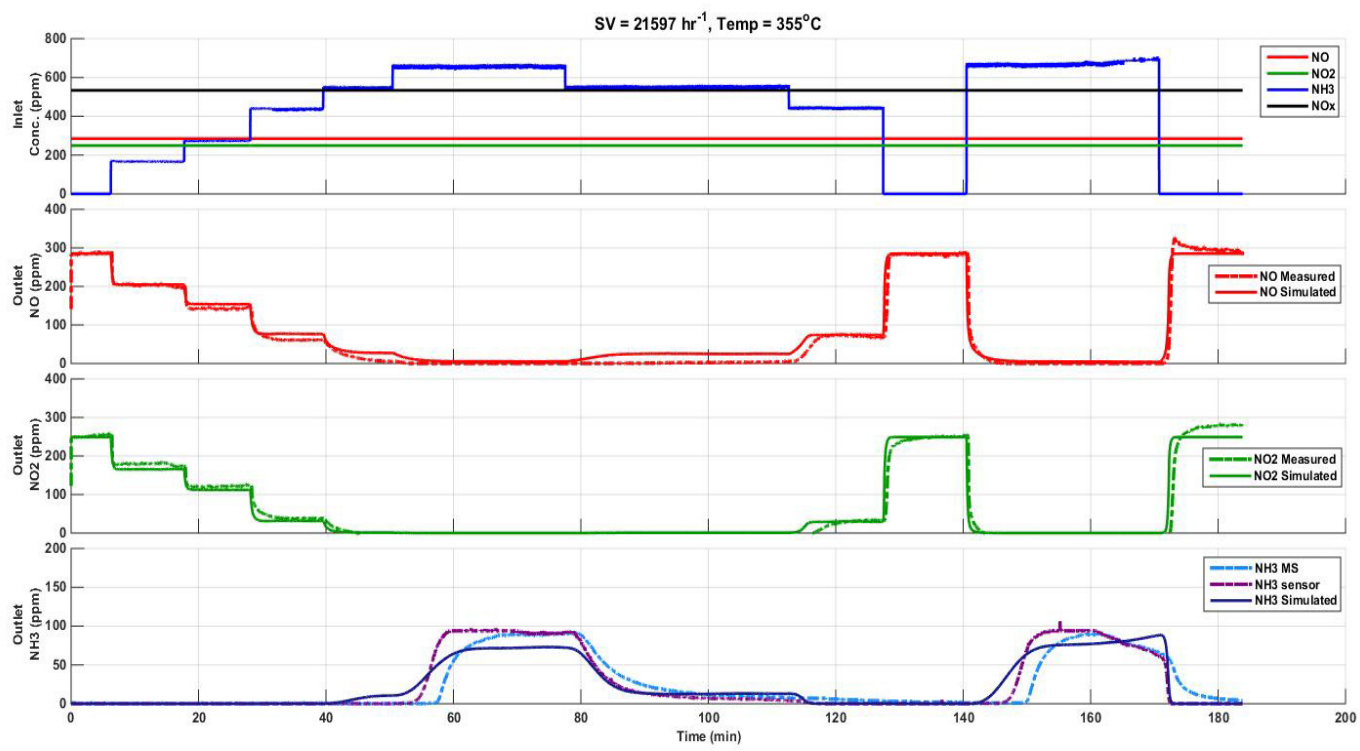

Figure D.5: Comparison of the SCR outlet gaseous concentrations between simulation results and experimental measurements for Test Point 5 (SCR inlet temperature $355^{\circ} \mathrm{C}$, SV $21.6 \mathrm{k} / \mathrm{hr}$ 


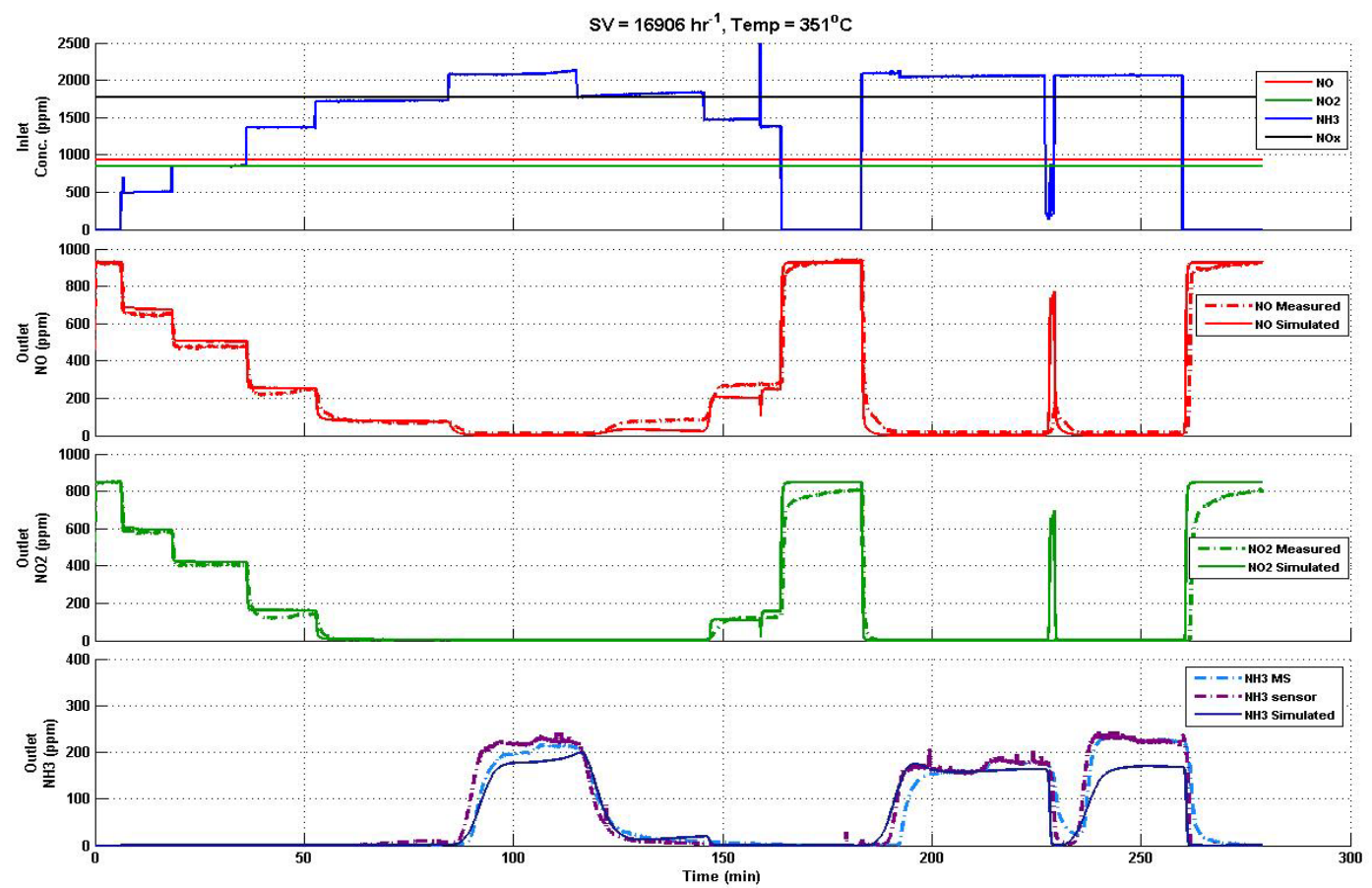

Figure D.6: Comparison of the SCR outlet gaseous concentrations between simulation results and experimental measurements for Test Point 6 (SCR inlet temperature $351^{\circ} \mathrm{C}$, SV $16.9 \mathrm{k} / \mathrm{hr}$

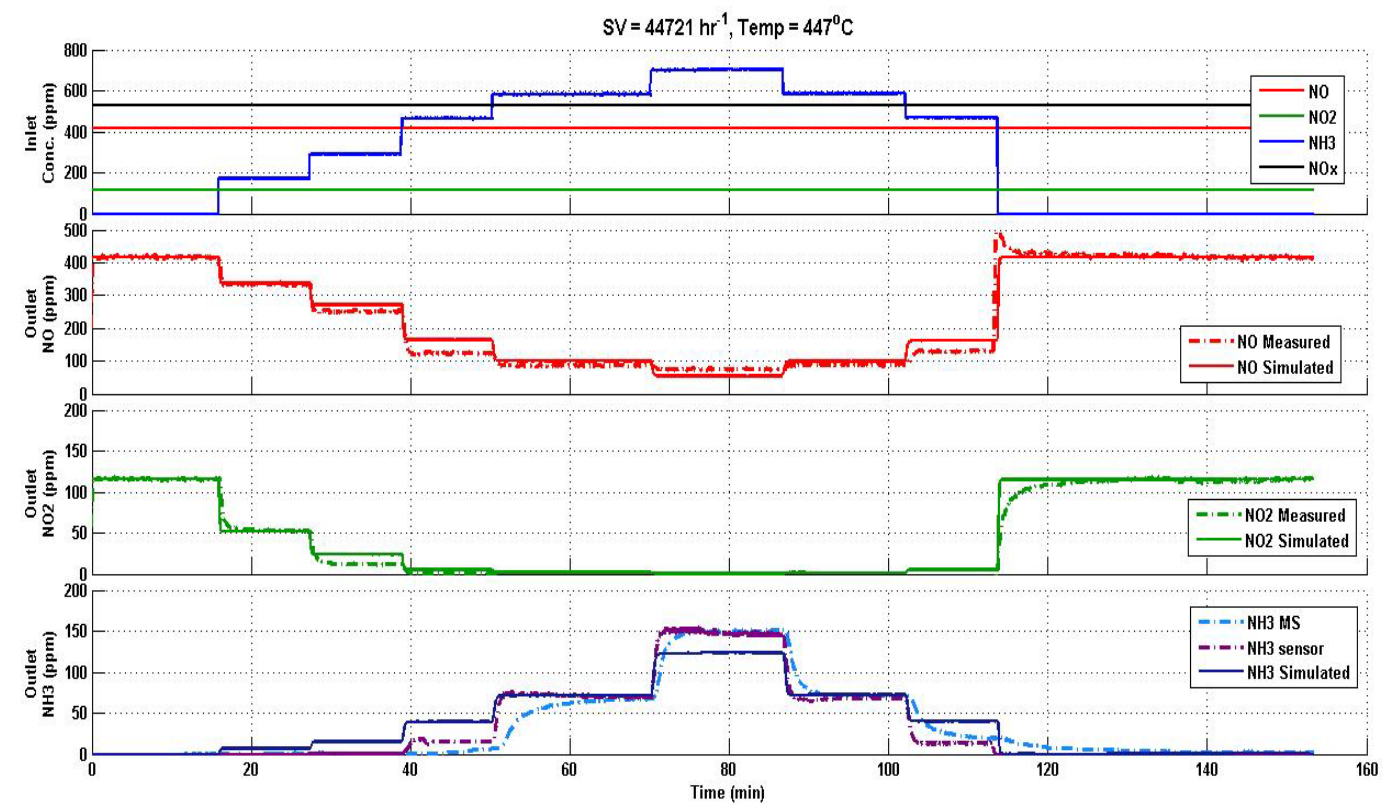

Figure D.7: Comparison of the SCR outlet gaseous concentrations between simulation results and experimental measurements for Test Point 8 (SCR inlet temperature $447^{\circ} \mathrm{C}$, SV $44.7 \mathrm{k} / \mathrm{hr}$ 


\section{Appendix E. Engine, Exhaust conditions and PM Mass Balance for each Stage - Configuration 2 (with PM loading)}

The engine conditions, exhaust conditions at the inlet of the SCRF® and PM mass balance across the SCRF® for stages 1 and 2 and $\mathrm{NO}_{\mathrm{x}}$ reduction stages are presented in this appendix. The engine speed, load, the engine out and SCRF® inlet (temperature, $\mathrm{NO} / \mathrm{NO}_{2} / \mathrm{NO}_{\mathrm{x}}$ concentration, $\mathrm{PM}$ concentration) conditions are analyzed and compared for deviation in Table E.1, E.2, E.5, and E.6. The filtration efficiency of the SCRF® and PM oxidation in the SCRF® is summarized in Table E.3, E.4, E.7, and E.8.

\section{Stage 1 and Stage 2 for PM Loading $2 \mathrm{~g} / \mathrm{L}$}

It is seen from Table E.1 and E.2 that the species concentration $\left(\mathrm{NO}, \mathrm{NO}_{2}\right.$ and $\left.\mathrm{NO}_{\mathrm{x}}\right)$ and engine out PM are consistent for all Test Points. The speed and load values were kept at constant values of $2400 \mathrm{RPM}$ and $200 \mathrm{Nm}$ and have very small deviation. The average engine-out particulate matter is $11.4 \mathrm{mg} / \mathrm{scm}$ (milligrams /standard cubic meter) and is consistent for all tests with a standard deviation of $0.5 \mathrm{mg} / \mathrm{scm}$ and $0.3 \mathrm{mg} / \mathrm{scm}$ for stage 1 and stage 2 respectively.

The parameters such as $\mathrm{PM}$ concentration into $\mathrm{SCRF}{ }^{\circledR}, \mathrm{NO}_{2} / \mathrm{PM}$ ratio, temperature into SCRF® and loading duration which affected the PM deposition and oxidation in the SCRF ${ }^{\circledR}$ are given in Table E.3 and E.4. The Test Point 3 (2401 rpm engine speed, 203 $\mathrm{Nm}$ load) has least PMRetained of 27.9 grams in the SCRF® for the high PM concentration coming into the $\mathrm{SCRF}{ }^{\circledR}$ and hence high $\mathrm{PM}_{\text {Available }}$ for oxidation. Another reason was that the Test Point 3 was run for least time period of approximately 300 minutes.

PM oxidized (percentage) in stage 1 as shown in Table E. 3 has the similar trend to that of PM oxidized (percentage) in stage 2 as shown in Table E.4. This is because mass loaded in stage 1 is estimated assuming the same rate of loading as in stage 2 . The filtration 
efficiency for stage 2 is obtained using the upstream and downstream SCRF® PM samples collected during stage 2 . 


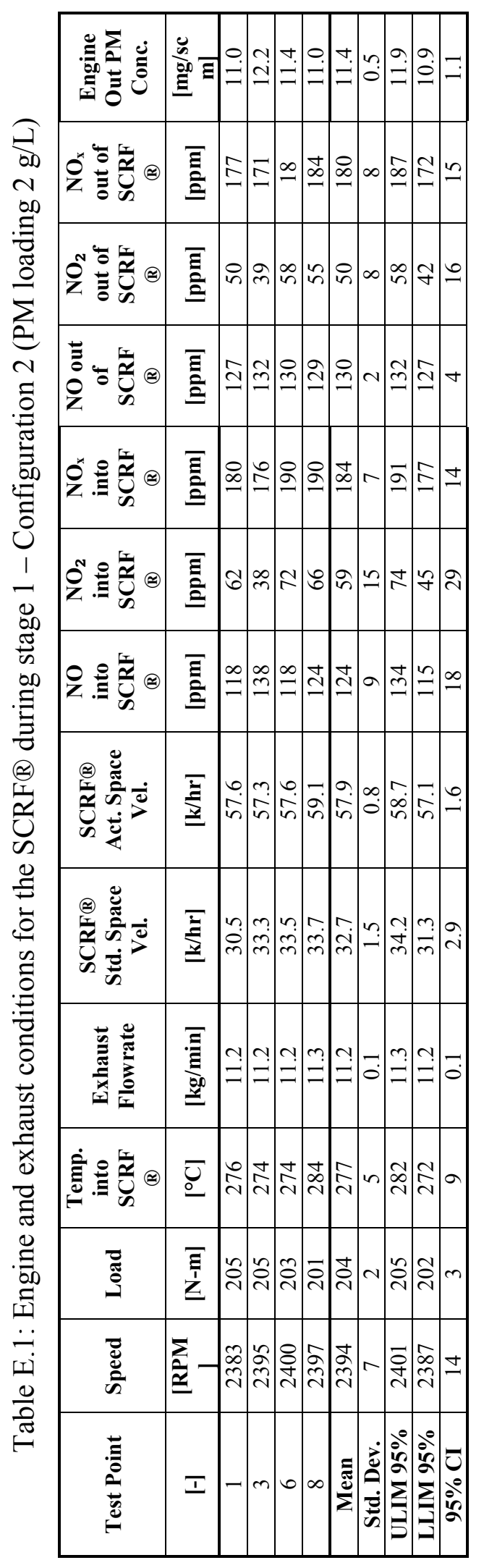

\begin{tabular}{|c|c|c|c|c|c|c|c|c|}
\hline 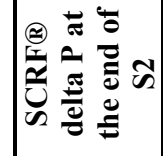 & $\begin{array}{l}\bar{\pi} \\
\stackrel{\Xi}{\Xi}\end{array}$ & \begin{tabular}{l|l} 
\\
$\vdots$
\end{tabular} & & $\stackrel{f}{6}$ & ֻี & ? & ઼ָ & ? \\
\hline 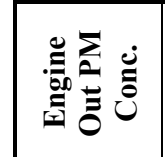 & 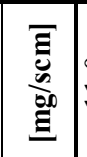 & & & $\stackrel{f}{=}$ & 3 & 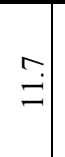 & $\stackrel{\circ}{\exists}$ & $\hat{0}$ \\
\hline 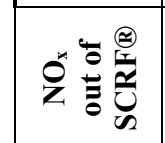 & 可 & $\stackrel{\infty}{\stackrel{\infty}{2}}$ & & $\infty$ & $\nabla$ & $\stackrel{\alpha}{-}$ & $\stackrel{\widetilde{\infty}}{=}$ & $r$ \\
\hline 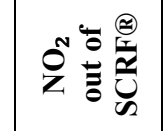 & 氞 & & & 4 & $r$ & $\approx$ & ले & $\cong$ \\
\hline 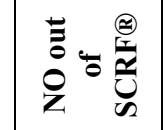 & 氞 & & & I & $r$ & $\begin{array}{l}0 \\
\pm\end{array}$ &  & $\leadsto$ \\
\hline రి & 可 & & & $\bar{a}$ & 0 & $\bar{\sigma}$ & $\stackrel{\infty}{\infty}$ & $\Rightarrow$ \\
\hline 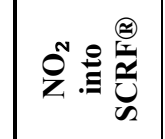 & 馬 & & 38 & $\infty$ & $=$ & $\approx$ & in & $\bar{\lambda}$ \\
\hline 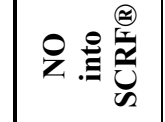 & 可 & & & $\approx$ & $r$ & $\bar{m}$ & $\stackrel{0}{=}$ & $\approx$ \\
\hline 国 & $\bar{E}$ & & & iि & $\stackrel{+}{0}$ & 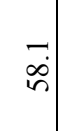 & $\stackrel{m}{i}$ & $\stackrel{\infty}{\circ}$ \\
\hline 䧽 & $\underset{\underline{E}}{\underline{\underline{E}}}$ & & & $\hat{\dot{m}}$ & 0 & $\begin{array}{l}\infty \\
\stackrel{0}{0}\end{array}$ & 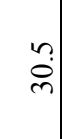 & $?$ \\
\hline  & 疍 & & & $\stackrel{?}{=}$ & 0 & $\stackrel{m}{=}$ & $\stackrel{N}{=}$ & 0 \\
\hline 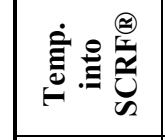 & $\bar{J}$ & & & 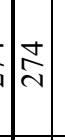 & $\nabla$ & $\stackrel{\infty}{\stackrel{\infty}{\sim}}$ & $\stackrel{?}{N}$ & $\infty$ \\
\hline 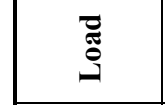 & $\underline{z}$ & & & $\stackrel{\overbrace{}}{a}$ & - & 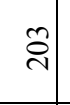 & $\overrightarrow{\mathrm{i}}$ & $N$ \\
\hline $\begin{array}{l}\bar{\Xi} \\
\overline{\omega^{2}}\end{array}$ & $\begin{array}{l}\bar{\sum} \\
\underline{\underline{\underline{\Xi}}}\end{array}$ & & तेंबे & $\begin{array}{l}\text { a } \\
\vdots \\
⿱ 亠 乂 \\
\end{array}$ & - & 勇 & ळ్సి & $\mathrm{N}$ \\
\hline 粍言 & $I$ & & & & & & & î \\
\hline
\end{tabular}




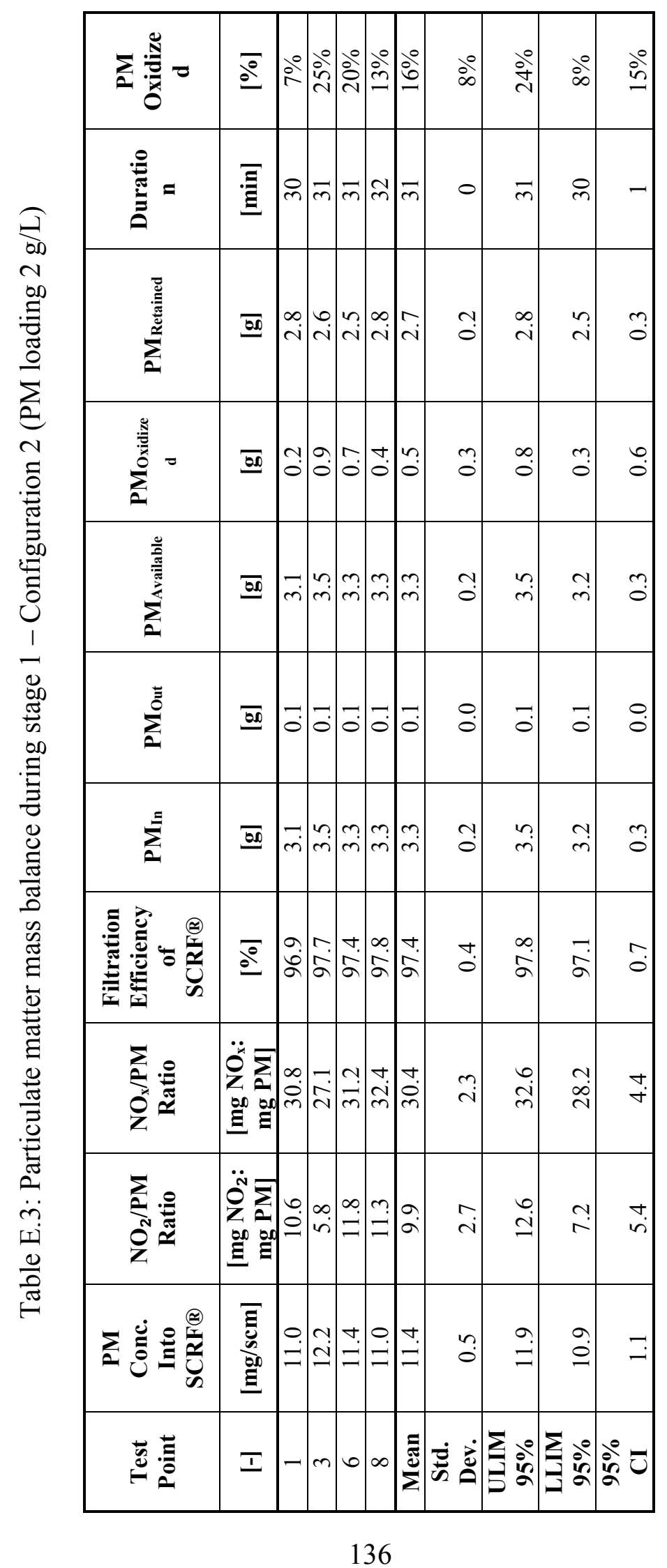




\begin{tabular}{|c|c|c|c|c|c|c|c|c|c|c|}
\hline 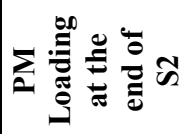 & $\underset{\underline{\sigma_{0}}}{\bar{T}}$ & $\left|\begin{array}{l}0 \\
i\end{array}\right|$ & $\mid \begin{array}{l}-0 \\
-\end{array}$ & $\stackrel{\infty}{-}$ & $\rightarrow$ & $\stackrel{\infty}{-}$ & $\overrightarrow{0}$ & $\stackrel{\circ}{i}$ & 9 & ? \\
\hline 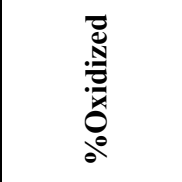 & $e^{\circ}$ & $\stackrel{0}{\infty}$ & $\left|\begin{array}{l}0 \\
\vec{v}\end{array}\right|$ & ठें & ले & 㤐 & $\dot{b}$ & ลें & ลे & $\stackrel{\circ}{\beth}$ \\
\hline & $\bar{\Xi}$ & లి & $\left|\begin{array}{|c|}\vec{\partial} \\
\vec{ల}\end{array}\right|$ & 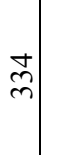 & లి & $\widetilde{\approx}$ & 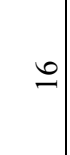 & ले & $\stackrel{\infty}{\infty}$ & $\vec{m}$ \\
\hline 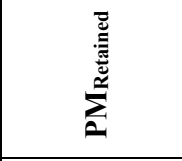 & 50 & $\stackrel{m}{m}$ & $\stackrel{.}{\grave{\sim}}$ & $\overrightarrow{0}$ & $\begin{array}{l}n \\
\tilde{n}\end{array}$ & $\frac{\circ}{\dot{m}}$ & $\tilde{i}$ & $\stackrel{\vec{m}}{m}$ & $\begin{array}{l}n \\
0 \\
\dot{\sim}\end{array}$ & $\stackrel{\rho}{\dot{r}}$ \\
\hline 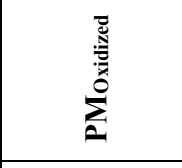 & 50 & \begin{tabular}{|c|}
0 \\
$\dot{r}$
\end{tabular} & $\stackrel{\stackrel{\sim}{\sim}}{\sim}$ & \begin{tabular}{c|c}
0 \\
$\infty$
\end{tabular} & $\begin{array}{c}\infty \\
+ \\
+\end{array}$ & $\begin{array}{c}\infty \\
\dot{r} \\
\dot{r}\end{array}$ & $\stackrel{+}{i}$ & $\vec{\infty}$ & $\stackrel{n}{n}$ & $\stackrel{\odot}{+}$ \\
\hline 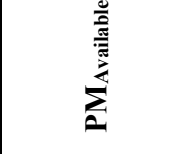 & 50.0 & $\underset{m}{\stackrel{\sim}{m}}$ & $\left|\begin{array}{c|}-1 \\
\dot{6} \\
m\end{array}\right|$ & $\vec{m}$ & $\overrightarrow{0}$ & 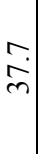 & $?$ & $\begin{array}{c}\hat{a} \\
\infty \\
\infty\end{array}$ & $\begin{array}{l}+ \\
\dot{0} \\
\end{array}$ & $\tilde{i}$ \\
\hline$\sum_{\text {E }}^{\overline{\bar{E}}}$ & 50 & $\Rightarrow$ & $\left|\begin{array}{l}\infty \\
0 \\
0\end{array}\right|$ & $\stackrel{\circ}{-}$ & $\stackrel{\infty}{0}$ & $\dot{o}$ & -1 & $\stackrel{\circ}{-}$ & $\begin{array}{l}\infty \\
0 \\
0\end{array}$ & $?$ \\
\hline$\sum_{E}^{E}$ & 50 & \begin{tabular}{|l|} 
\\
$\dot{m}$ \\
\end{tabular} & $\begin{array}{l}n \\
m \\
m\end{array}$ & $\begin{array}{l}0 \\
\dot{0} \\
\dot{n}\end{array}$ & $m$ & $\begin{array}{l}0 \\
\dot{n} \\
m\end{array}$ & $?$ & rֶ. & ले & $\dddot{\sim}$ \\
\hline 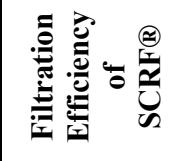 & $e^{\overline{0}}$ & aें & م. & $\begin{array}{l}\vec{\Delta} \\
\dot{a}\end{array}$ &  & $\frac{⿱}{\dot{a}}$ & $\stackrel{+}{0}$ & $\begin{array}{l}\infty \\
\stackrel{\leftrightarrow}{a} \\
\text {. }\end{array}$ & $\vec{a}$ & $\hat{0}$ \\
\hline$\underset{z}{\sum_{0}}$ & 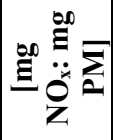 & $m$ & $\begin{array}{l}\infty \\
\infty \\
\grave{i}\end{array}$ &  & $\overrightarrow{\mathrm{n}}$ & $\stackrel{i}{m}$ & $\stackrel{\infty}{-}$ & $\stackrel{n}{m}$ & $\begin{array}{l}0 \\
\dot{m}\end{array}$ & $\dddot{m}$ \\
\hline 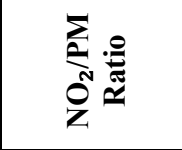 & 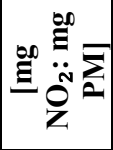 & $\stackrel{-}{ \pm}$ & $\because$ & $\begin{array}{l}0 \\
\stackrel{0}{0}\end{array}$ & $\stackrel{0}{=}$ & $\stackrel{?}{=}$ & $\vec{i}$ & $\stackrel{+}{\stackrel{\sim}{2}}$ & $\stackrel{\sim}{\sigma}$ & $\stackrel{\mathcal{F}}{f}$ \\
\hline 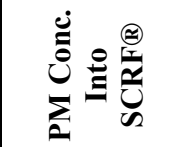 & 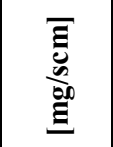 & $\stackrel{\circ}{=}$ & $\stackrel{\infty}{=}$ & $\stackrel{\nabla}{=}$ & $\stackrel{\sim}{\exists}$ & $\stackrel{\nabla}{=}$ & $?$ & 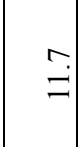 & $\stackrel{\circ}{=}$ & $\hat{o}$ \\
\hline 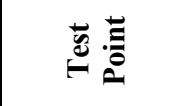 & $I$ & - & $m$ & 6 & $\infty$ & $\equiv$ & $\dot{\vec{\Delta}} \dot{\vec{\Delta}}$ & $\sum^{\circ}$ & בू & ن̃ \\
\hline
\end{tabular}




\section{Stage 1 and Stage 2 at $4 \mathrm{~g} / \mathrm{L}$ Loading}

Table E.5 and E.6 give the consistent values for engine speed, load, SCRF® inlet species concentration and engine out PM concentration for all Test Points. The average engineout particulate matter is $18.7 \mathrm{mg} / \mathrm{scm}$ and $19.4 \mathrm{mg} / \mathrm{scm}$ for stage 1 and stage 2 respectively.

Table E. 8 shows that the PM oxidized (percentage) for stage 2 is consistent for all Test Points with mean oxidation $24 \%$. The PMRetained in the SCRF® is $4 \mathrm{~g}$ and $69.4 \mathrm{~g}$ for stage 1 and stage 2 respectively. The filtration efficiency of $99.1 \%$ is obtained using the samples collected during stage 2 which is considered to be same for stage 1 . 


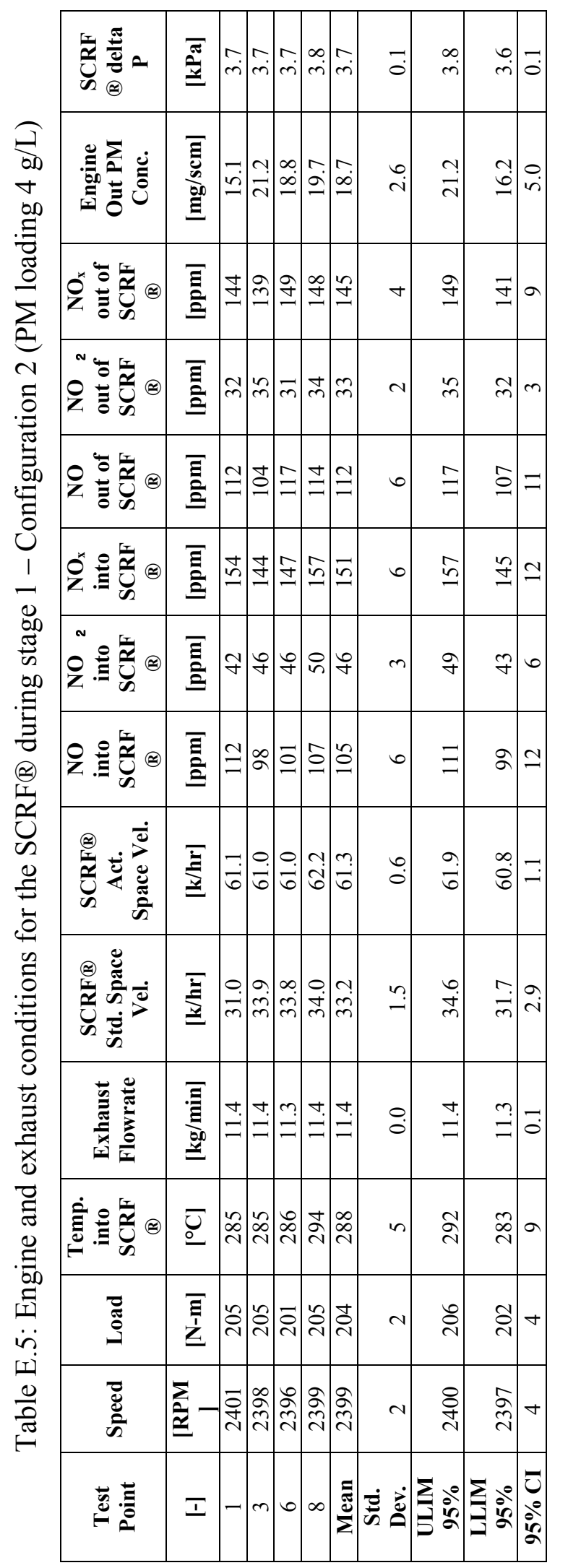

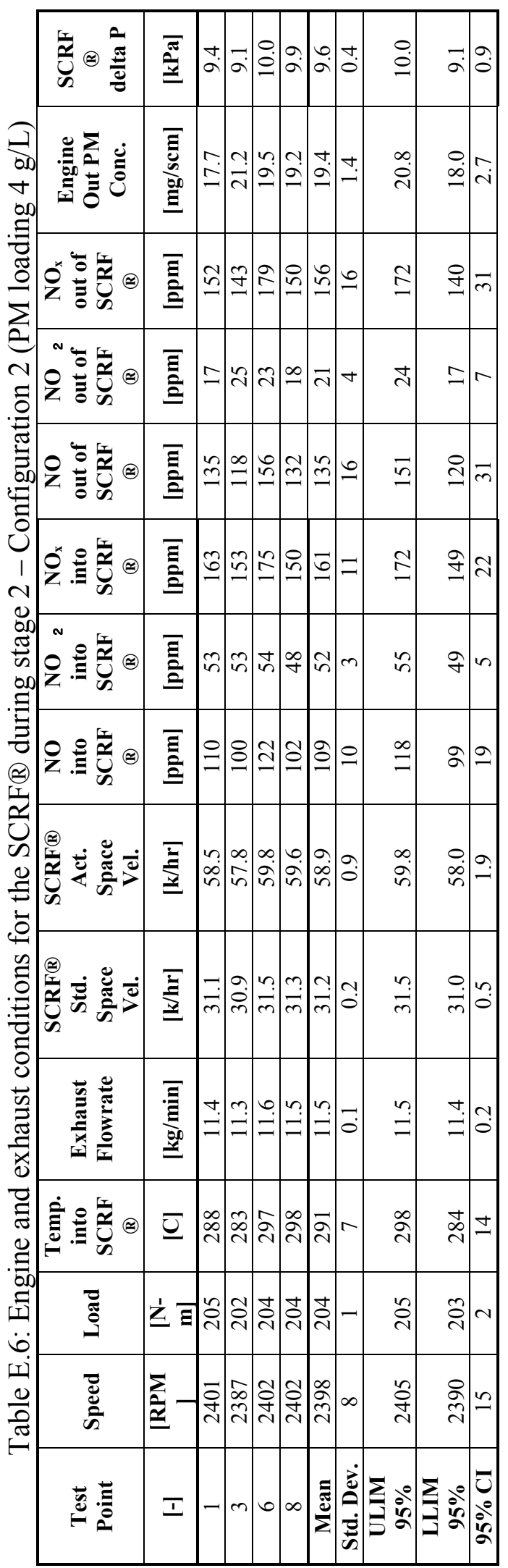




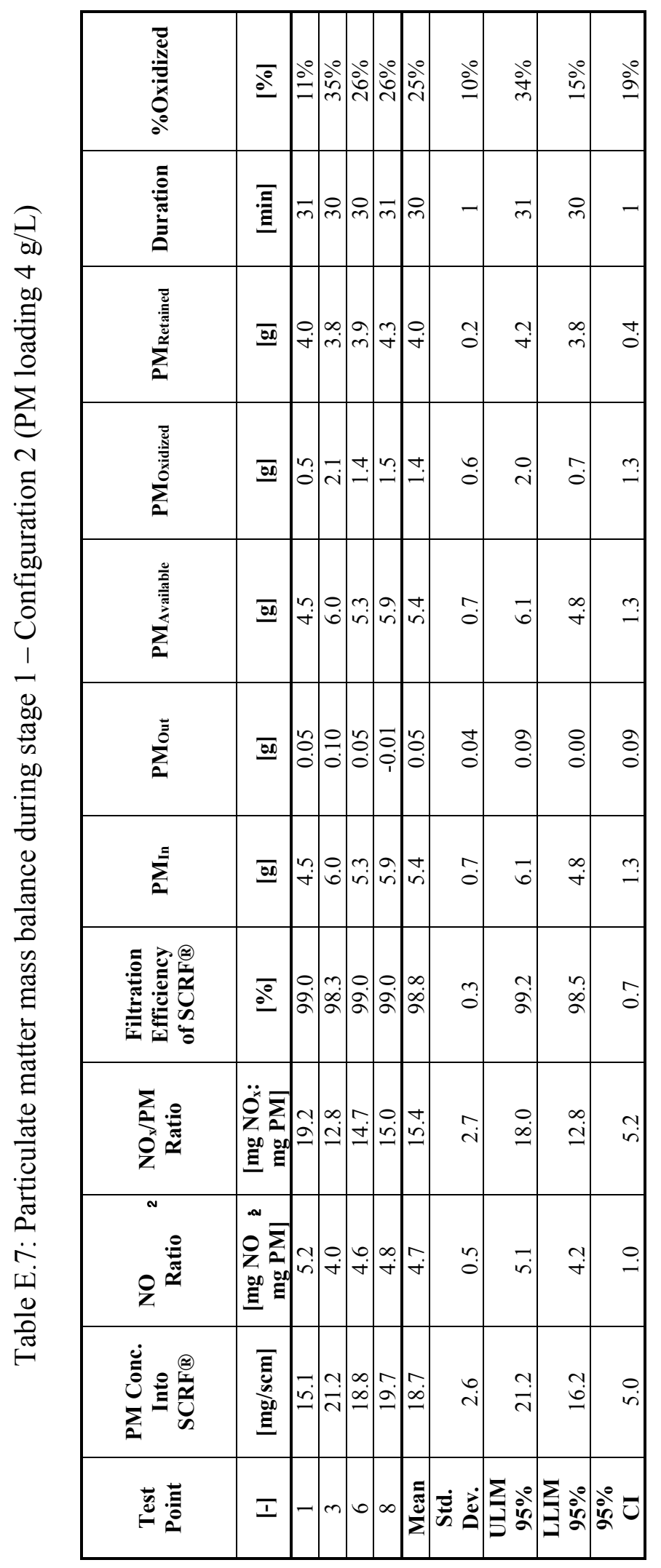




\begin{tabular}{|c|c|c|c|c|c|c|c|c|c|}
\hline 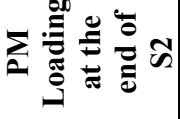 & $\overline{\bar{B}_{0.0}}$ & $\overrightarrow{\dot{\tau}}$ & 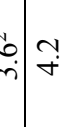 & $\stackrel{\nabla}{+}$ & $\overrightarrow{+}$ & $?$ & $\stackrel{+}{+}$ & $\vec{n}$ & $\ddot{0}$ \\
\hline 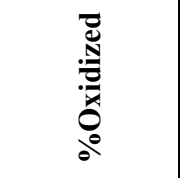 & $\underline{e}$ & $\stackrel{\circ}{\stackrel{\circ}{\sim}}$ & $\frac{\partial}{2} \stackrel{\circ}{\circ}$ & $\stackrel{\stackrel{\circ}{+}}{\sim}$ & $\stackrel{\circ}{\stackrel{0}{\sim}}$ & लें & 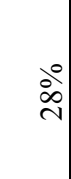 & $\frac{\partial}{\vec{v}}$ & $\stackrel{0}{\circ}$ \\
\hline 栉 & 畐 & $\bar{n} \bar{n}$ & $\begin{array}{lll}0 \\
b \\
b\end{array}$ & $\frac{0}{n}$ & $\hat{a}$ & $\approx$ & तี & 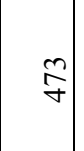 & $q$ \\
\hline 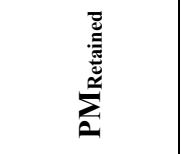 & $\overline{00}$ & 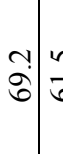 & 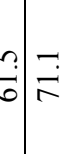 & in & $\begin{array}{l}+ \\
\dot{6} \\
\dot{6}\end{array}$ & $\dot{s}$ & $\begin{array}{l}\stackrel{2}{n} \\
\end{array}$ & $\begin{array}{l}0 \\
\text { రై }\end{array}$ & $\stackrel{0}{=}$ \\
\hline & 50 &  & $\stackrel{m}{m} \stackrel{m}{\stackrel{n}{n}}$ & $\stackrel{\sim}{\stackrel{N}{\sim}}$ & $\underset{\sim}{\stackrel{\sim}{\sim}}$ & $\begin{array}{l}0 \\
\dot{n}\end{array}$ & ָे & $\stackrel{\infty}{\grave{\sim}}$ & $\exists$ \\
\hline 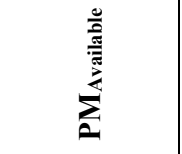 & $\overline{000}$ & : & ণ্: & $\begin{array}{l}\infty \\
\dot{\alpha}\end{array}$ & $\left|\begin{array}{c}0 \\
\vdots \\
\hat{a}\end{array}\right|$ & $\stackrel{\sim}{+}$ & 홍 & $\stackrel{\dot{\sigma}}{\ddot{\sigma}}$ & $\begin{array}{l}3 \\
\infty\end{array}$ \\
\hline$\sum_{\bar{E}}^{\overline{\bar{E}}}$ & $\underline{00}$ & $\dot{\partial}=$ & & $\vec{\varphi}$ & $\begin{array}{l}\infty \\
0\end{array}$ & $\ddot{0}$ & $\underline{n}$ & $\overrightarrow{0}$ & $\stackrel{+}{-}$ \\
\hline$\sum_{\underline{\Omega}}^{\Xi}$ & $\overline{E 00}$ & 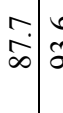 & مُ & $\begin{array}{l}n \\
a\end{array}$ & $\begin{array}{c}0 \\
\end{array}$ & $\stackrel{\sim}{\sim}$ & r. & $\stackrel{+}{\grave{\infty}}$ & $\begin{array}{c}m \\
\infty\end{array}$ \\
\hline 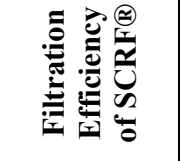 & $e^{\bar{e}}$ & $\begin{array}{l}\dot{\sigma} \\
\dot{\sigma}\end{array}$ & $\begin{array}{l}2 \\
2\end{array}$ & $\begin{array}{l}3 . \\
\dot{0} \\
\sigma\end{array}$ & $\left|\begin{array}{l}\infty \\
\infty \\
\infty \\
\alpha\end{array}\right|$ & $?$ & ๙ุ & $\begin{array}{l}n \\
\infty \\
\infty \\
0\end{array}$ & $\stackrel{1}{0}$ \\
\hline 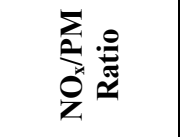 & 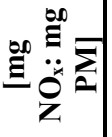 & $\stackrel{?}{=}$ & : & $\stackrel{\Im}{\dot{\Xi}}$ & $\left|\begin{array}{l}0 \\
\ddot{2}\end{array}\right|$ & $\stackrel{\infty}{-}$ & $\stackrel{?}{=}$ & $\stackrel{.}{2}$ & $\dot{r}$ \\
\hline$\overbrace{z}^{\stackrel{\varrho}{\pi}}$ & 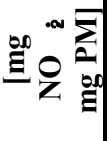 & & $\dot{f}$ is & $\stackrel{r}{\forall}$ & : & $\stackrel{+}{0}$ & 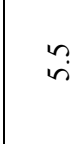 & $\stackrel{0}{+}$ & 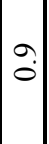 \\
\hline 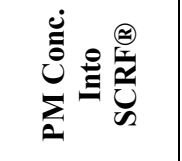 & 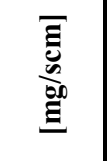 & $\stackrel{\overbrace{}}{=}$ & 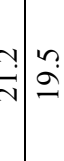 & $\stackrel{2}{2}$ & $\ddot{\square}$ & $\stackrel{+}{-}$ & $\stackrel{\infty}{\stackrel{\sim}{े}}$ & $\begin{array}{l}0 \\
\infty \\
-1\end{array}$ & $\vec{i}$ \\
\hline 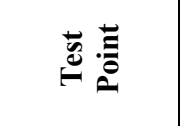 & $I$ & $-\pi$ & & $\infty$ & $\Xi$ & $\dot{\vec{\Delta}}$ & in & ¿a & $\begin{array}{c}7 \\
0 \\
0 \\
2\end{array}$ \\
\hline
\end{tabular}


The $\mathrm{PM}_{\text {Retained }}$ in the $\mathrm{SCRF}{ }^{\circledR}$ at the end of the stage 1, stage 2 and $\mathrm{NO}_{\mathrm{x}}$ reduction stage are given in Table E.9. The PMRetained are calculated using the equations described in section 3.6.7 of this thesis. From Table E.9 it is observed that for the $\mathrm{NO}_{\mathrm{x}}$ experimental tests with target PM loading of 2 and $4 \mathrm{~g} / \mathrm{L}$, the PMRetained at the end of stage 1 and stage 2 were consistent and PM loading of $2 \pm 0.2 \mathrm{~g} / \mathrm{L}$ and $4 \pm 0.4 \mathrm{~g} / \mathrm{L}$ were achieved for all the tests except for Test Point 3. The stage 2 duration for Test Point 3 was 30 minutes shorter than the other Test Points. It is also observed that the $\mathrm{PM}_{\text {Retained }}$ at the end of $\mathrm{NO}_{\mathrm{x}}$ reduction stage for Test Point 1 is $23-24$ grams higher that the $P M_{\text {Retained }}$ at the end of stage 2 for PM loading of 2 and $4 \mathrm{~g} / \mathrm{L}$. This could be due to higher $\mathrm{NH}_{3}$ storage in the SCRF® and water adsorption in the SCRF since Test Point 1 is a low temperature test condition $\left(\sim 213^{\circ} \mathrm{C}\right)$. The $\mathrm{NH}_{3}$ stored in the SCRF® for all Test Points, with PM loading of 2 and $4 \mathrm{~g} / \mathrm{L}$ are given in Table E.10. It is also observed that the Test Points 6 and 8 indicated significant PM oxidation during $\mathrm{NO}_{\mathrm{x}}$ reduction stage with PM loading of $2 \mathrm{~g} / \mathrm{L}$, since the $\mathrm{PM}_{\text {Retained }}$ at the end of $\mathrm{NO}_{\mathrm{x}}$ reduction stage is lower than the $\mathrm{PM}_{\text {Retained }}$ at the end of stage 2. However, the $\mathrm{PM}_{\text {Retained }}$ at the end of $\mathrm{NO}_{\mathrm{x}}$ reduction stage is higher than the $\mathrm{PM}_{\text {Retained }}$ at the end of stage 2 for Test Points 6 and 8 with PM loading of $4 \mathrm{~g} / \mathrm{L}$. This appears to be an error in the mass measurement of the SCRF® substrate at the end of $\mathrm{NO}_{\mathrm{x}}$ reduction stage.

Table E.9: $\mathrm{PM}_{\text {Retained }}$ in the SCRF® at the end of the stage 1, stage 2 and $\mathrm{NO}_{\mathrm{x}}$ reduction stage for Test Points in configuration 2

\begin{tabular}{|c|c|c|c|c|c|c|c|}
\hline \multirow{3}{*}{$\begin{array}{c}\text { Test } \\
\text { Points }\end{array}$} & \multirow{3}{*}{$\begin{array}{c}\text { SCRF }^{\circledR} \\
\text { inlet } \\
\text { Temp. }\end{array}$} & \multicolumn{6}{|c|}{ Configuration 2 - PM Retained, (grams) } \\
\hline & & \multicolumn{3}{|c|}{ Target PM Loading - 2 g/L } & \multicolumn{3}{|c|}{ Target PM Loading - $4 \mathrm{~g} / \mathrm{L}$} \\
\hline & & Stage 1 & Stage 2 & $\begin{array}{c}\text { NO }_{\mathbf{x}} \text { Reduction } \\
\text { Stage }\end{array}$ & Stage 1 & Stage 2 & $\begin{array}{c}\mathbf{N O}_{\mathbf{x}} \text { Reduction } \\
\text { Stage }\end{array}$ \\
\hline 1 & 213 & 2.8 & 33.3 & 56.2 & 4.0 & 69.2 & 93.1 \\
\hline 3 & 301 & 2.6 & $27.9^{1}$ & 24.6 & 3.8 & $61.5^{1}$ & 59.8 \\
\hline 6 & 345 & 2.5 & 30.1 & 25.9 & 3.9 & 71.1 & $82.7^{2}$ \\
\hline 8 & 443 & 2.8 & 32.5 & 10.1 & 4.3 & 75.7 & $80.8^{2}$ \\
\hline
\end{tabular}


Table E.10: $\mathrm{NH}_{3}$ stored (grams) in the SCRF® for various Test Points in configuration 2

\begin{tabular}{|c|c|c|c|c|c|}
\hline Test Point & {$[-]$} & $\mathbf{1}$ & $\mathbf{3}$ & $\mathbf{6}$ & $\mathbf{8}$ \\
\hline SCRF® inlet Temp. & {$\left[{ }^{\circ} \mathbf{C}\right]$} & 213 & 301 & 345 & 443 \\
\hline $\mathbf{N H}_{\mathbf{3}}$ stored - PM Loading 2 $\mathbf{~ g / L}$ & {$[\mathbf{g}]$} & 14.6 & 6.9 & 4.8 & 4.2 \\
\hline $\mathbf{N H}_{\mathbf{3}}$ stored - PM Loading 4 g/L & {$[\mathbf{g}]$} & 13.9 & 5.3 & 4.3 & 3.9 \\
\hline
\end{tabular}




\section{Appendix F. Gaseous Emissions by Stage}

This appendix describes the emission concentrations during stage 1 and stage 2 of $\mathrm{NO}_{\mathrm{x}}$ reduction tests with PM loading of 2 and $4 \mathrm{~g} / \mathrm{L}$ in the SCRF® from Tables F.1 through F.4. The emission concentrations for $\mathrm{NO}_{\mathrm{x}}$ reduction at ANRs 0.8, 1.0 and 1.2 are discussed in Chapter 4 and the emission concentrations at ANR of 1.2 (repeat) are summarized in this section in Tables F.6. All the measurements presented in the Tables F.1 through F.5 were measured using a mass spectrometer. The positive and negative values of NO conversion efficiency shows reduction and increment in NO concentration across the components (DOC, SCRF®) respectively.

Due to problems with the Mass Spectrometer emission analyzer, the $\mathrm{NO}_{2}$ concentrations were not available correctly at the upstream DOC location for some the Test Points. After the repair of the MS, the correct concentrations upstream DOC were obtained for $\mathrm{NO}_{\mathrm{x}}$ reduction tests with PM loading of $4 \mathrm{~g} / \mathrm{L}$. The $\mathrm{NO}_{\mathrm{x}}$ is determined as the sum of $\mathrm{NO}$ and $\mathrm{NO}_{2}$ concentrations at the respective locations. The effect of $\mathrm{PM}$ loading on $\mathrm{NO}_{\mathrm{x}}$ reduction efficiency for the four Tests points at ANR-1.2 (repeat) is shown in Figure F.1. 


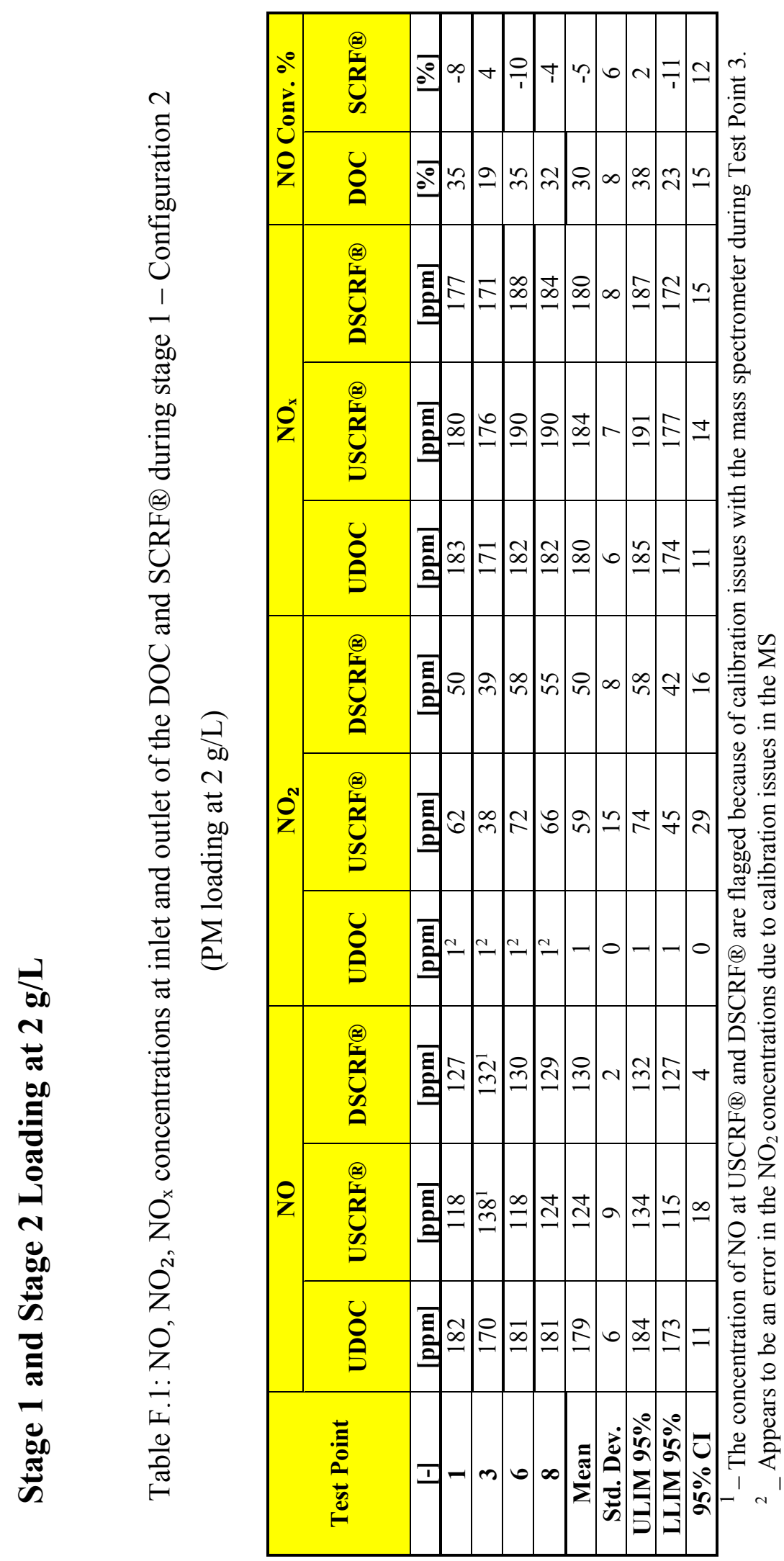




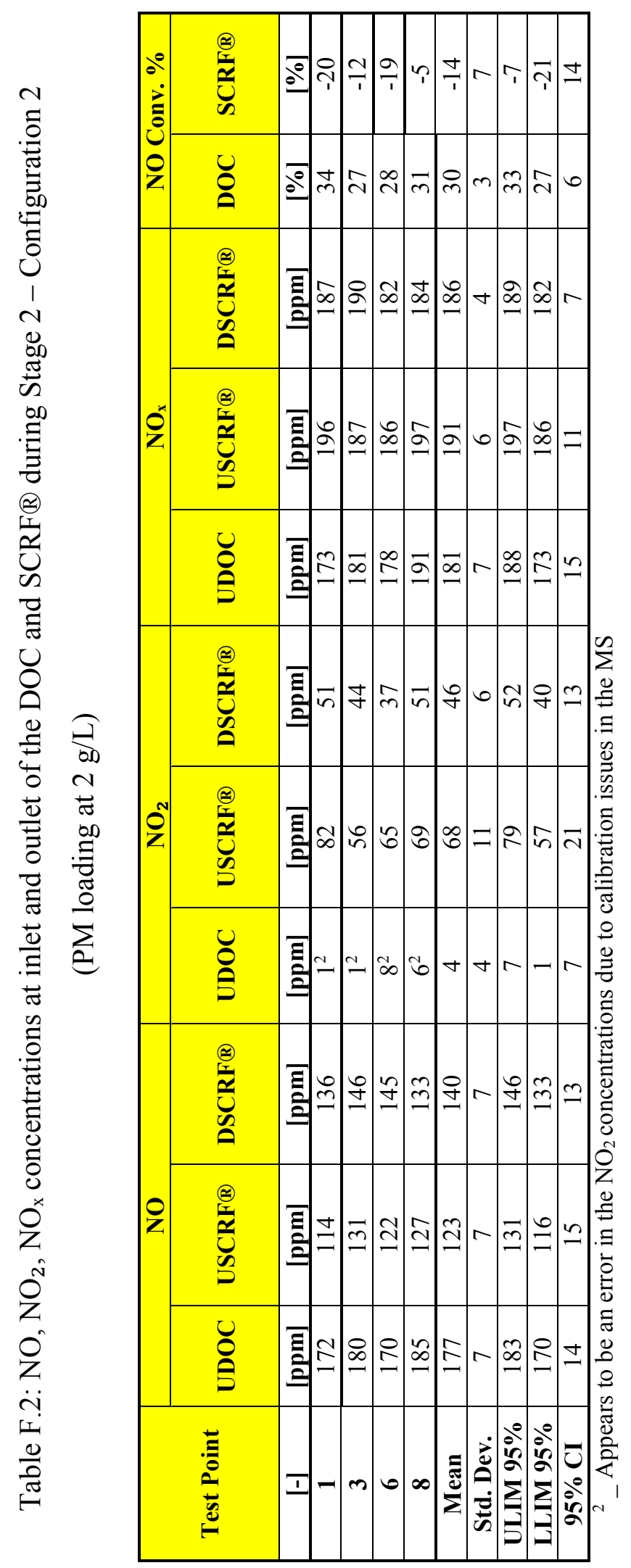




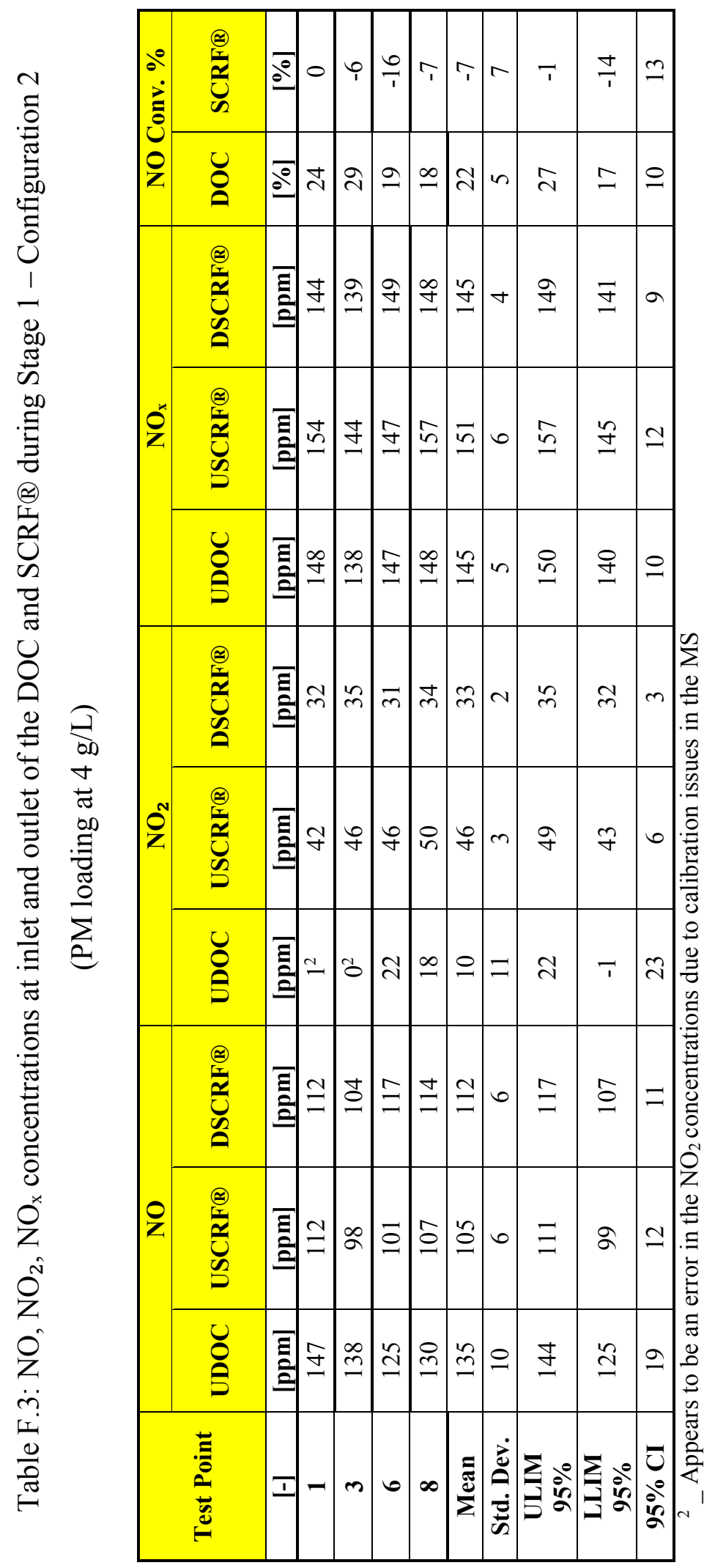




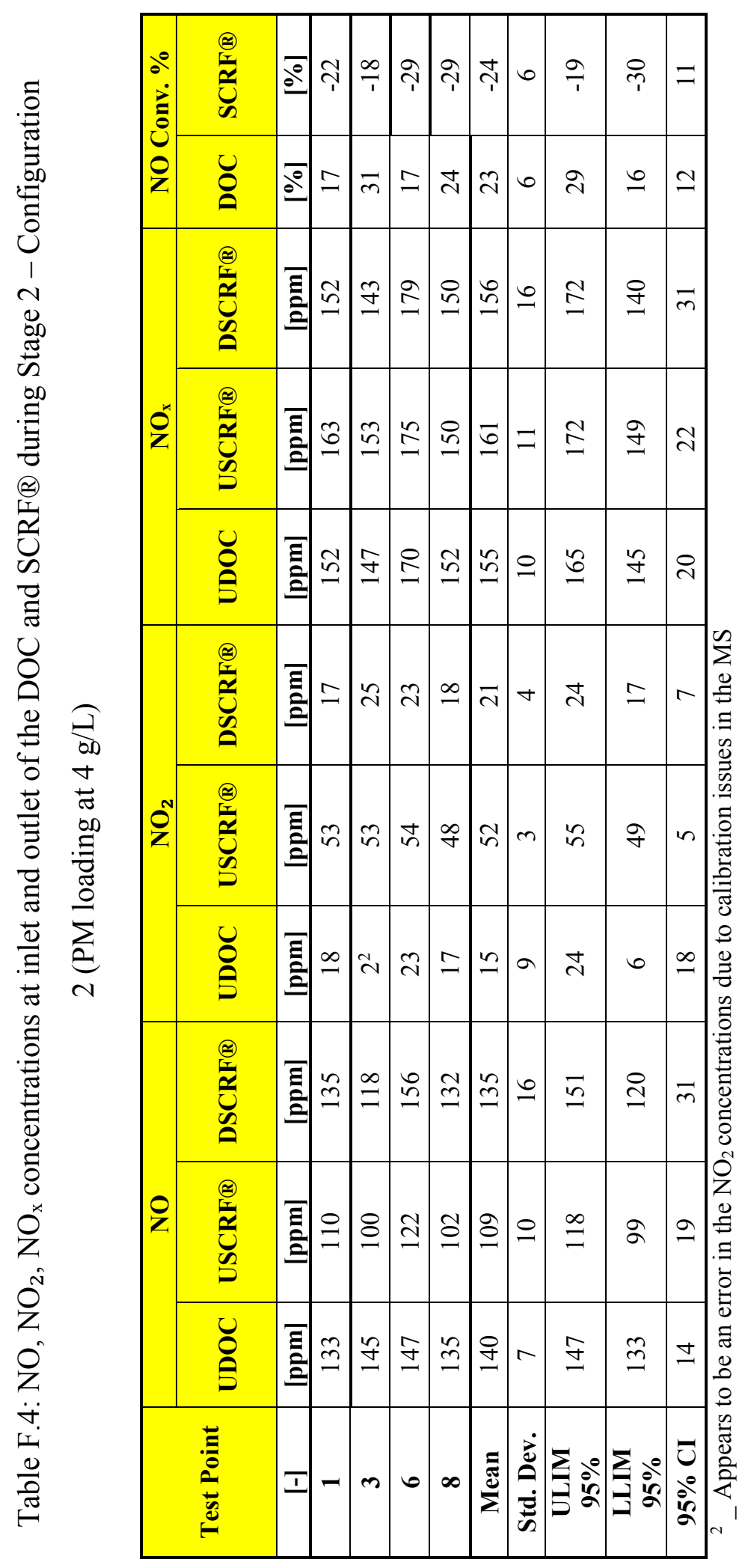




\section{NOx Reduction Stage}

Table F.5: $\mathrm{NO}$ and $\mathrm{NO}_{2}$ concentrations at inlet and outlet of the $\mathrm{SCRF}{ }^{\circledR}$ for $\mathrm{NO}_{\mathrm{x}}$ reduction Test Points, at ANR - 0

\begin{tabular}{|c|c|c|c|c|c|c|c|c|c|c|c|c|}
\hline \multirow{3}{*}{$\begin{array}{l}\text { Test } \\
\text { Point }\end{array}$} & \multicolumn{6}{|c|}{ NO [ppm] } & \multicolumn{6}{|c|}{$\mathrm{NO}_{2}[\mathrm{ppm}]$} \\
\hline & \multicolumn{2}{|c|}{ SCRF®- ${ }^{\circledR}$} & \multicolumn{2}{|c|}{ SCRF®- 2} & \multicolumn{2}{|c|}{ SCRF®- 4} & \multicolumn{2}{|c|}{ SCRF®- 0} & \multicolumn{2}{|c|}{ SCRF®- 2} & \multicolumn{2}{|c|}{ SCRF®- 4} \\
\hline & In & Out & In & Out & In & Out & In & Out & In & Out & In & Out \\
\hline 1 & 345 & 352 & 403 & 387 & 411 & 401 & 213 & 200 & 203 & 205 & 141 & 116 \\
\hline 3 & 158 & 160 & 161 & 198 & 198 & 249 & 121 & 116 & 131 & 88 & 124 & 75 \\
\hline 6 & 795 & 808 & 743 & 967 & 793 & 1151 & 674 & 688 & 644 & 426 & 588 & 231 \\
\hline 8 & 411 & 415 & 424 & 457 & 415 & 502 & 140 & 139 & 125 & 52 & 115 & 22 \\
\hline
\end{tabular}




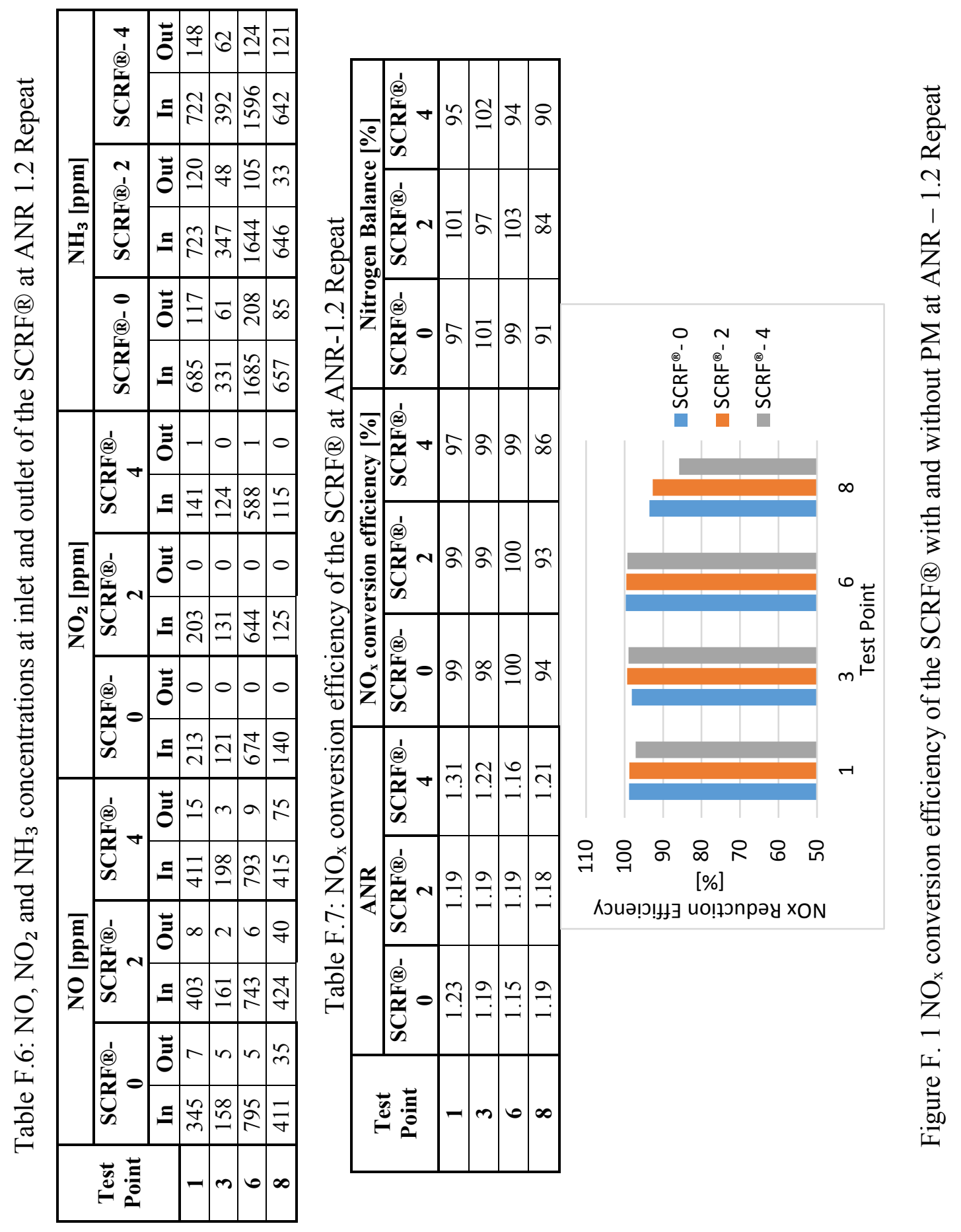




\section{Appendix G. Pressure Drop Across the SCRF® - Configuration 2 (with and without PM loading)}

The pressure drop across the SCRF® for each Test Point, with and without PM loading in the SCRF® is discussed in this section. Figures G.1, G.2, G.3 and G.4 show that the pressure drop remains constant for the tests without PM loading $(0 \mathrm{~g} / \mathrm{L})$ in the SCRF®. This happens because a CPF was placed upstream of the SCRF®. Hence, there is little PM deposition or oxidation phenomenon occurring in the SCRF®.

Figures G.5 and G.6 show the pressure drop across the SCRF® with PM loading of $2 \mathrm{~g} / \mathrm{L}$ in the SCRF®. PM Retained in the SCRF® at the end of the stages are indicated on the pressure drop plots. The Test Point 8 has high SCRF® inlet temperatures and therefore the $\mathrm{SCRF}{ }^{\circledR}$ was loaded again in between $\mathrm{NO}_{\mathrm{x}}$ reduction test denoted by repeat loadings as shown in Figures H.6 for $2 \mathrm{~g} / \mathrm{L}$ loading. Similar repeat loadings were done for the same Test Points for PM loading of $4 \mathrm{~g} / \mathrm{L}$ as shown in Figures G.9 and G.10.

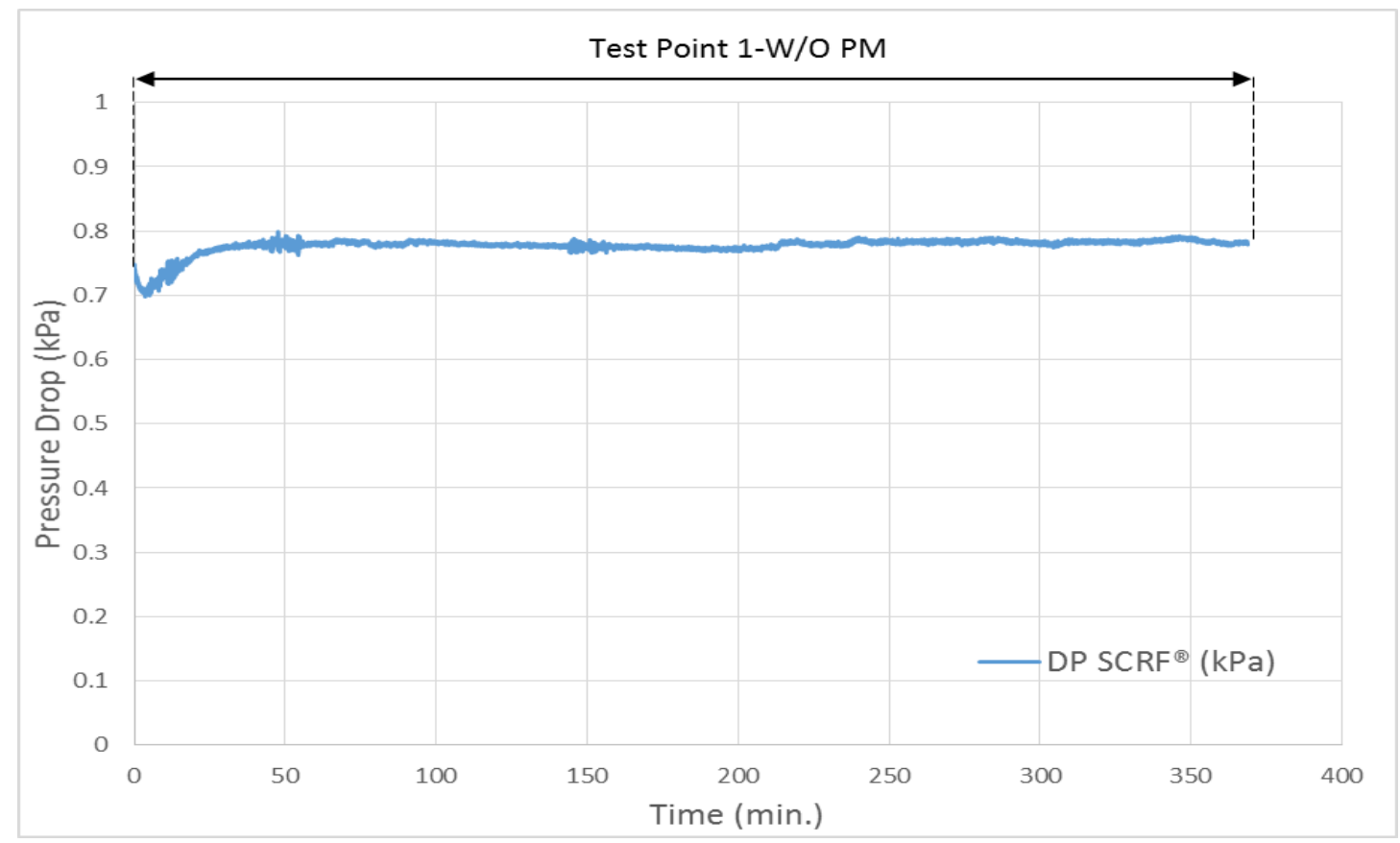

Figure G.1: Pressure drop across the SCRF® for the Test Point 1, PM loading $0 \mathrm{~g} / \mathrm{L}$ 




Figure G.2: Pressure drop across the SCRF® for the Test Point 3, PM loading $0 \mathrm{~g} / \mathrm{L}$

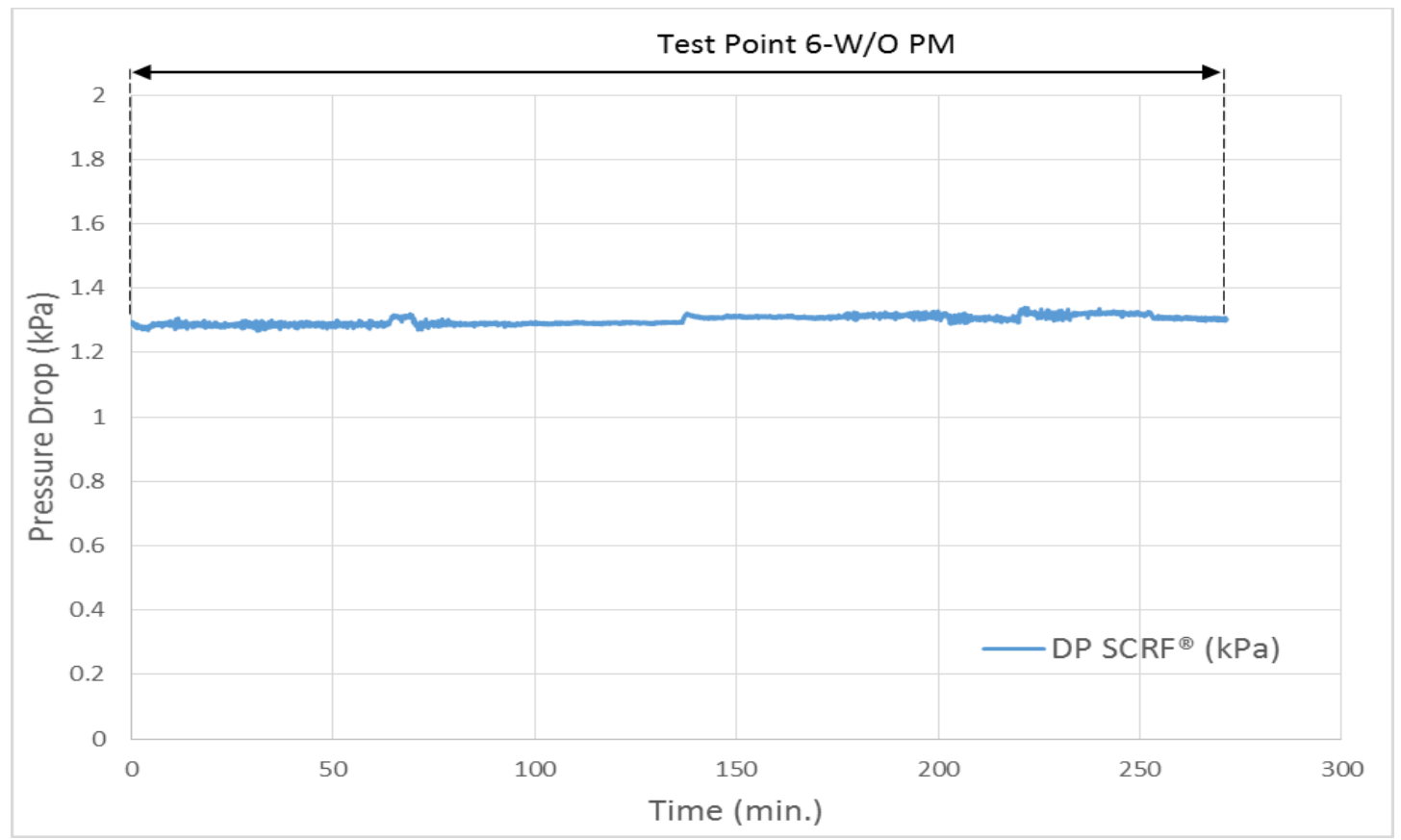

Figure G.3: Pressure drop across the SCRF® for the Test Point 6, PM loading $0 \mathrm{~g} / \mathrm{L}$ 


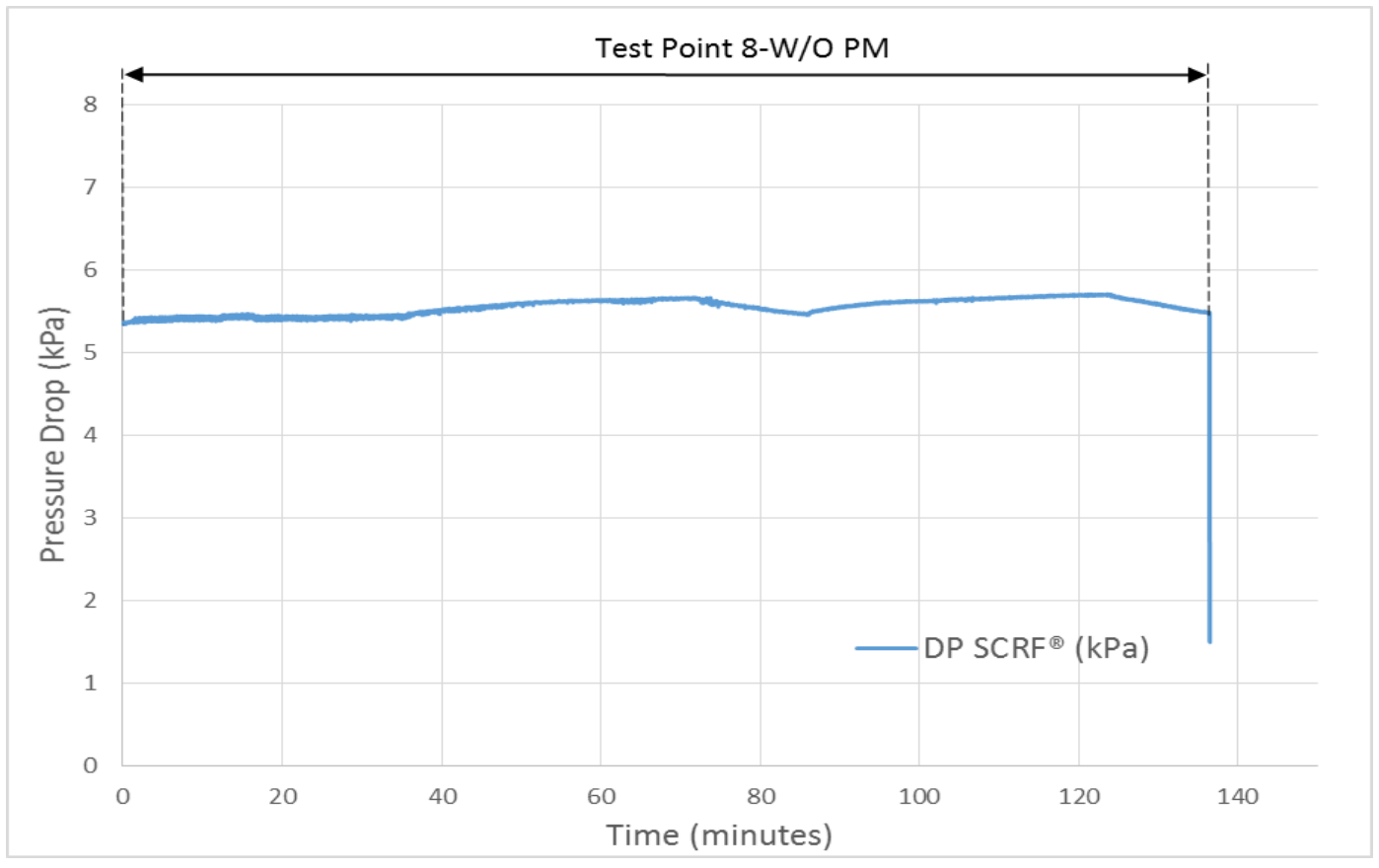

Figure G.4: Pressure drop across the SCRF® for the Test Point 8, PM loading $0 \mathrm{~g} / \mathrm{L}$ PM Loading at $4 \mathrm{~g} / \mathrm{L}$



Figure G.5: Pressure drop across the SCRF® for the Test Point 3, with PM loading $2 \mathrm{~g} / \mathrm{L}$ 


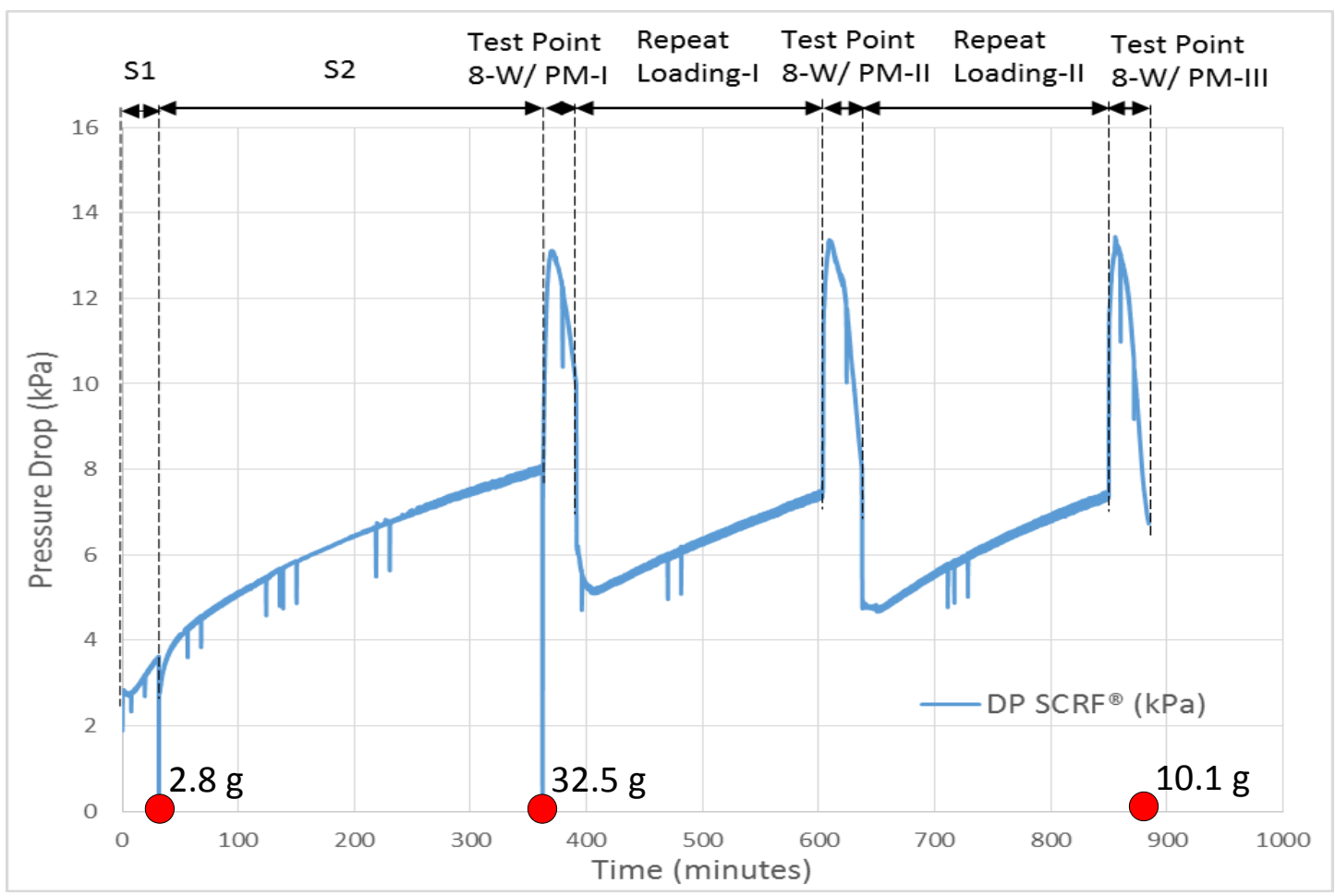

Figure G.6: Pressure drop across the SCRF® for the Test Point 8, with PM loading 2 g/L PM Loading at $4 \mathrm{~g} / \mathrm{L}$

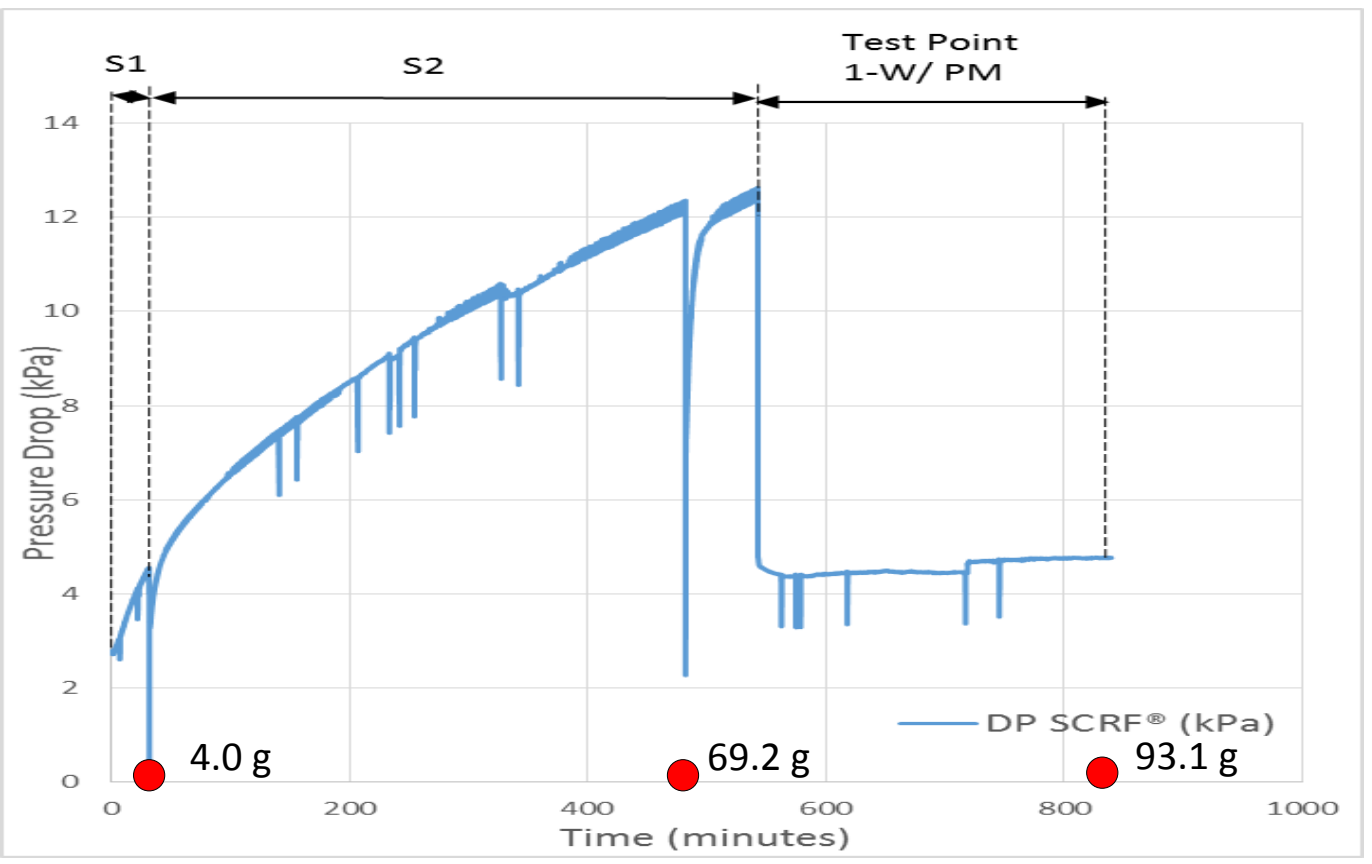

Figure G.7: Pressure drop across the SCRF® for the Test Point 1, with PM loading $4 \mathrm{~g} / \mathrm{L}$ 




Figure G.8: Pressure drop across the SCRF® for the Test Point 3, with PM loading 4 g/L

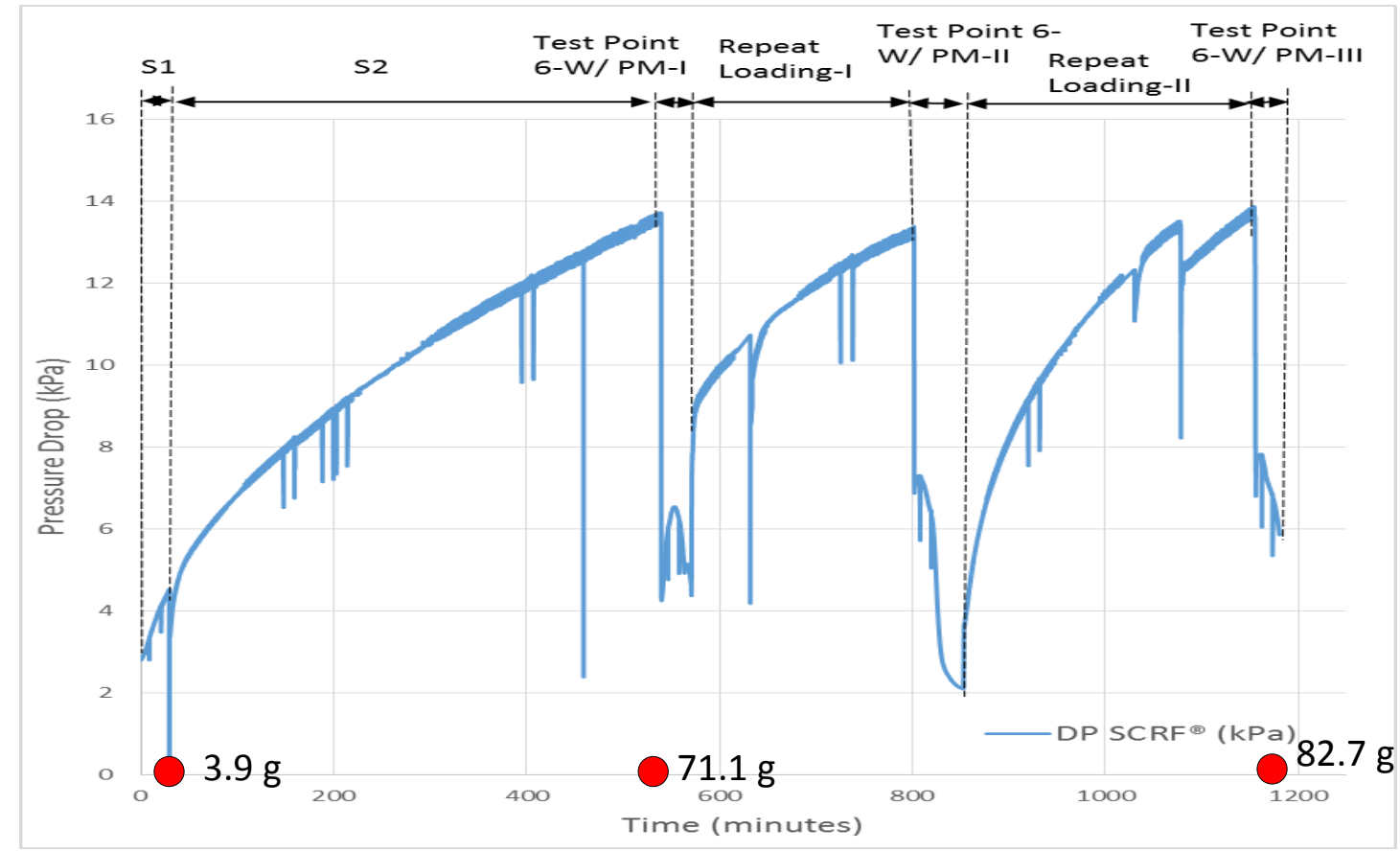

Figure G.9: Pressure drop across the SCRF® for the Test Point 6, with PM loading 4 g/L 




Figure G.10: Pressure drop across the SCRF® for the Test Point 8, with PM loading 4 $\mathrm{g} / \mathrm{L}$ 


\section{Appendix H. Temperature Distribution in the SCRF® - Configuration 2 (with and without PM loading)}

In this section, the gas temperature distribution in the radial and axial positions in the $\mathrm{SCRF}{ }^{\circledR}$ during the $\mathrm{NO}_{\mathrm{x}}$ reduction stage, with and without PM loading is discussed. The study of the gas temperature distribution obtained from experimental data is critical since the experimental data will be used to calibrate the SCR-F model being developed at MTU. Figure H.1 shows the thermocouple arrangement in the SCRF® at various radial and axial locations. Twenty thermocouples are labeled from S1 to S20. The thermocouples $\mathrm{S} 1$ to $\mathrm{S} 10$ were inserted into the $\mathrm{SCRF}{ }^{\circledR}$ through the inlet channels of the SCRF® and the thermocouples S11 to S20 were inserted through the outlet channels of the SCRF®.

The gas temperatures in the SCRF® were monitored, recorded and studied using the Ktype thermocouples for the loading and $\mathrm{NO}_{\mathrm{x}}$ reduction stages, with or without $\mathrm{PM}$ loading in the SCRF®. The temperature distribution in the SCRF® during the loading stages performed in configuration 2 are discussed in reference [86].

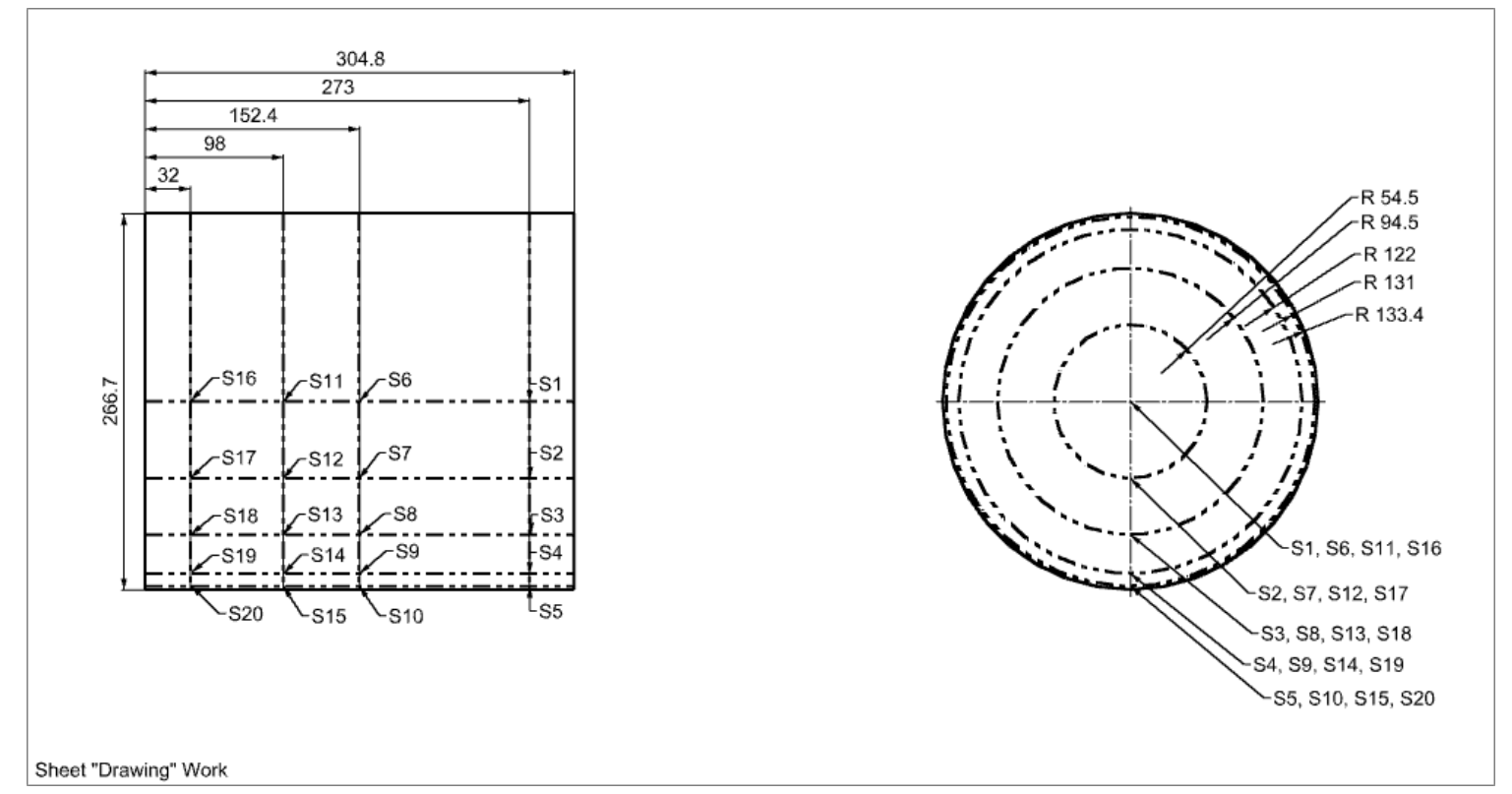

Figure H.1: Thermocouple arrangement in the $\mathrm{SCRF}{ }^{\circledR}$ (all dimensions in $\mathrm{mm}$ ) 


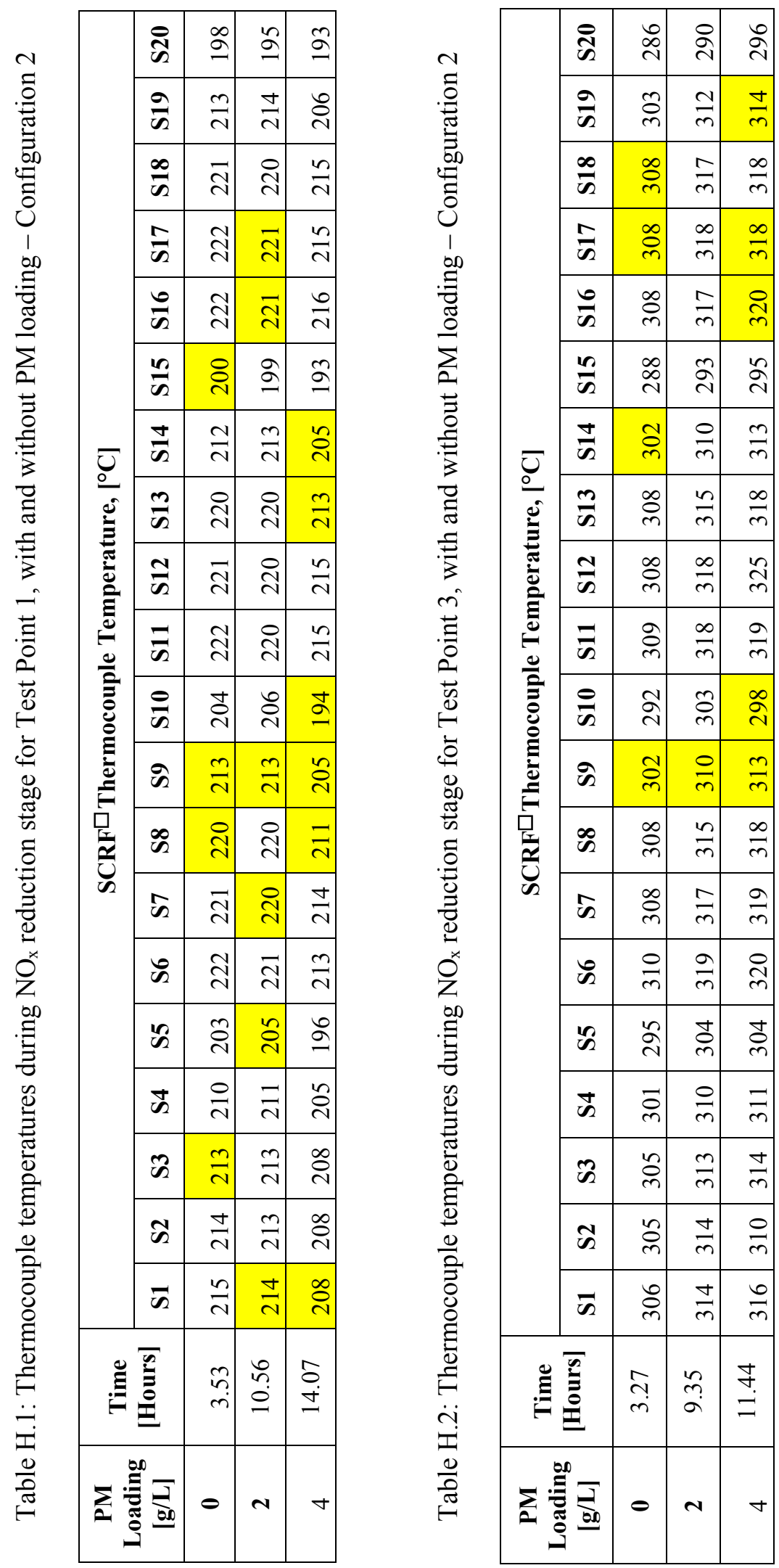




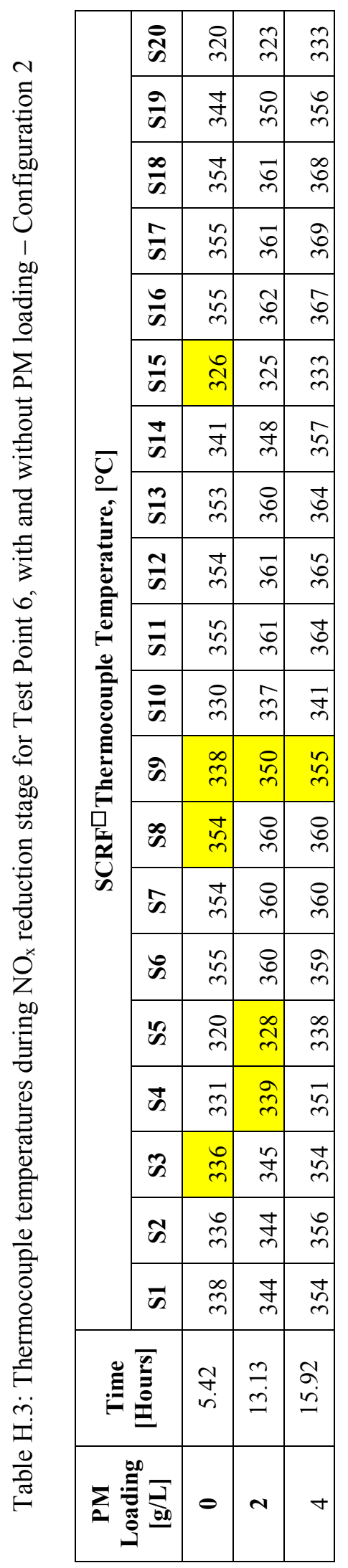

\begin{tabular}{|c|c|c|c|c|}
\hline \multirow{20}{*}{  } & ळิ & สี & & $\underset{\mathcal{f}}{ }$ \\
\hline & $\overrightarrow{\bar{s}}$ & $\stackrel{?}{f}$ & $\mathcal{F}$ & f \\
\hline & $\frac{\infty}{\infty}$ & gे & $\stackrel{\infty}{f}$ & $\begin{array}{l}+ \\
\sigma \\
\sigma\end{array}$ \\
\hline & $\bar{n}$ & gे & f & $\stackrel{n}{q}$ \\
\hline & $\frac{0}{\infty}$ & 守 & f & 蒋 \\
\hline & $\frac{n}{\infty}$ & 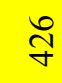 & $\stackrel{\infty}{\forall}$ & $\underset{f}{\mathscr{f}}$ \\
\hline & $\vec{n}$ & $\stackrel{P}{f}$ & $\vec{f}$ & $\stackrel{\infty}{+}$ \\
\hline & $\frac{m}{\infty}$ & 守 & $\begin{array}{l}0 \\
+\end{array}$ & gे \\
\hline & $\tilde{a}$ & 守 & $\begin{array}{l}0 \\
\dot{q}\end{array}$ & 菊 \\
\hline & $\bar{\omega}$ & 离 & $\frac{v}{f}$ & $\begin{array}{l}\stackrel{+}{y} \\
\dot{y}\end{array}$ \\
\hline & $\frac{\theta}{\infty}$ & $\stackrel{\odot}{\vartheta}$ & 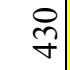 & ণ্ণ \\
\hline & के & $\stackrel{\vartheta}{\vartheta}$ & f & f \\
\hline & $\infty$ & $\stackrel{\infty}{f}$ & $\stackrel{q}{f}$ & $\tilde{n}$ \\
\hline & in & $\stackrel{\infty}{f}$ & $\begin{array}{l}0 \\
+ \\
+\end{array}$ & $\tilde{n}$ \\
\hline & \& & $\overline{5}$ & f & 孛 \\
\hline & $\ddot{n}$ & $\stackrel{\overbrace{}}{ซ}$ & भे & $\tilde{\tilde{\gamma}}$ \\
\hline & I & $\hat{q}$ & $\hat{\tilde{F}}$ & $\underset{7}{\ddagger}$ \\
\hline & $\infty$ & f & $\vec{f}$ & f \\
\hline & ஜू & $\stackrel{f}{f}$ & $\underset{7}{\&}$ & $\stackrel{\infty}{+}$ \\
\hline & $\bar{\omega}$ & 寺 & $\bar{f}$ & 守 \\
\hline \multicolumn{2}{|c|}{ 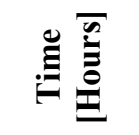 } & 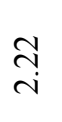 &  & $\begin{array}{l}\tilde{\delta} \\
\stackrel{0}{0}\end{array}$ \\
\hline \multicolumn{2}{|c|}{ 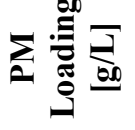 } & 0 & $N$ & $\nabla$ \\
\hline
\end{tabular}




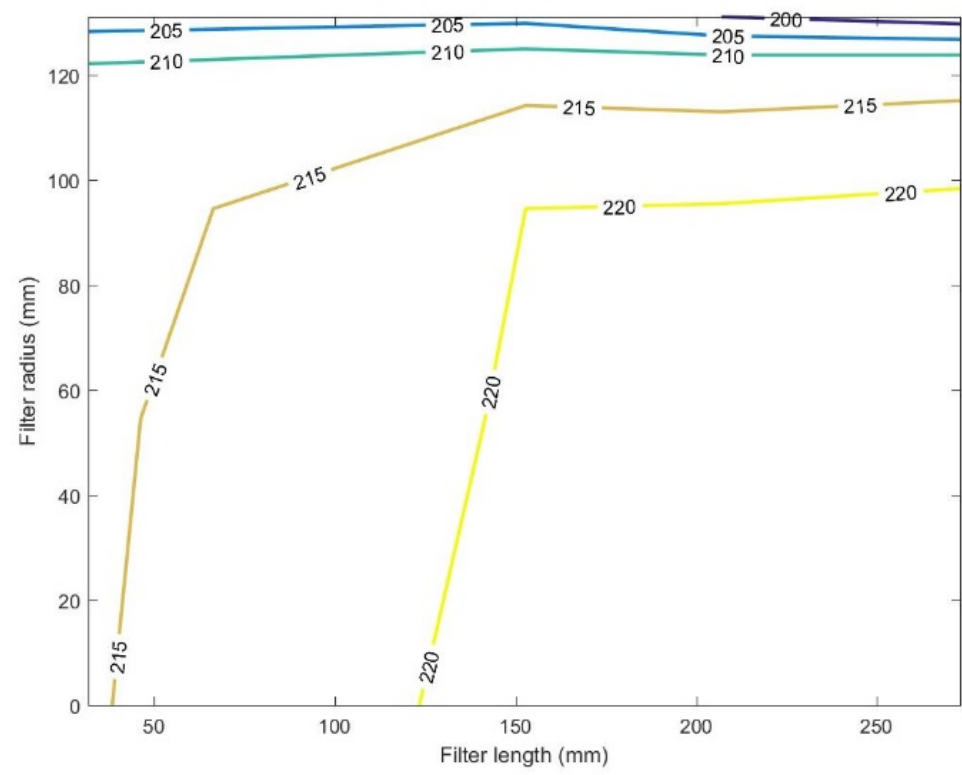

Figure H.2: Temperature distribution in the $\mathrm{SCRF}{ }^{\circledR}$ during $\mathrm{NO}_{\mathrm{x}}$ reduction stage for Test Point 1 without PM loading, at ANR 1.0



Figure H.3: Temperature distribution in the $\mathrm{SCRF}{ }^{\circledR}$ during $\mathrm{NO}_{\mathrm{x}}$ reduction stage for Test Point 1 with $2 \mathrm{~g} / \mathrm{L}$ PM loading, at ANR 1.0 




Figure H.4: Temperature distribution in the $\mathrm{SCRF}{ }^{\circledR}$ during $\mathrm{NO}_{\mathrm{x}}$ reduction stage for Test Point 1 with $4 \mathrm{~g} / \mathrm{L}$ PM loading, at ANR 1.0

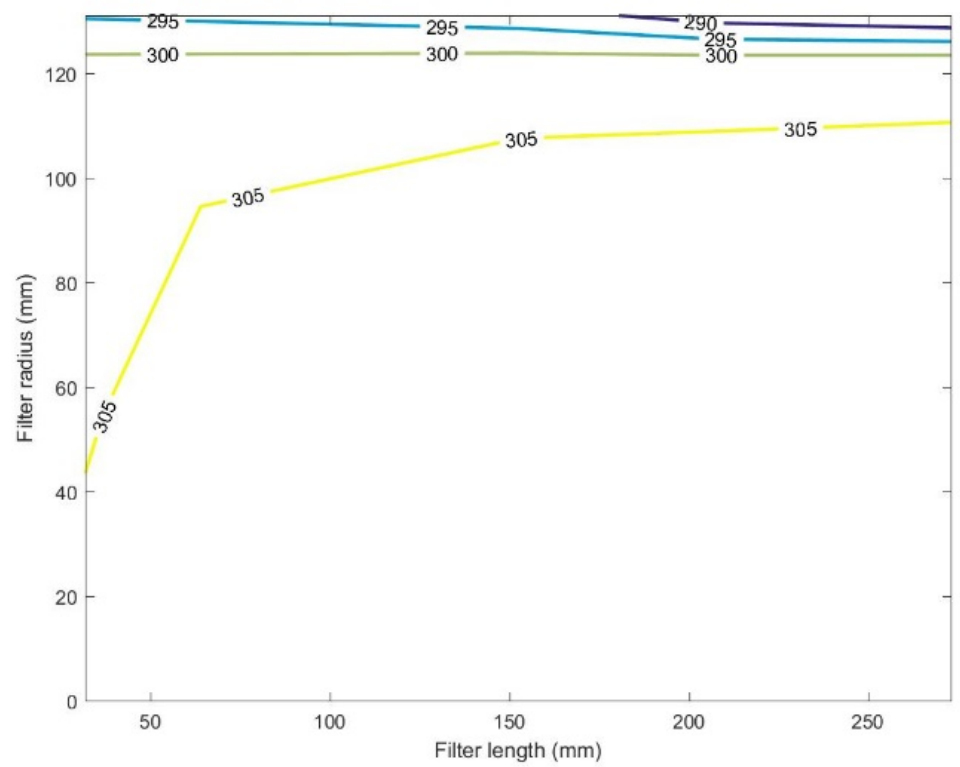

Figure H.5: Temperature distribution in the $\mathrm{SCRF}{ }^{\circledR}$ during $\mathrm{NO}_{\mathrm{x}}$ reduction stage for Test Point 3 without PM loading, at ANR 1.0 


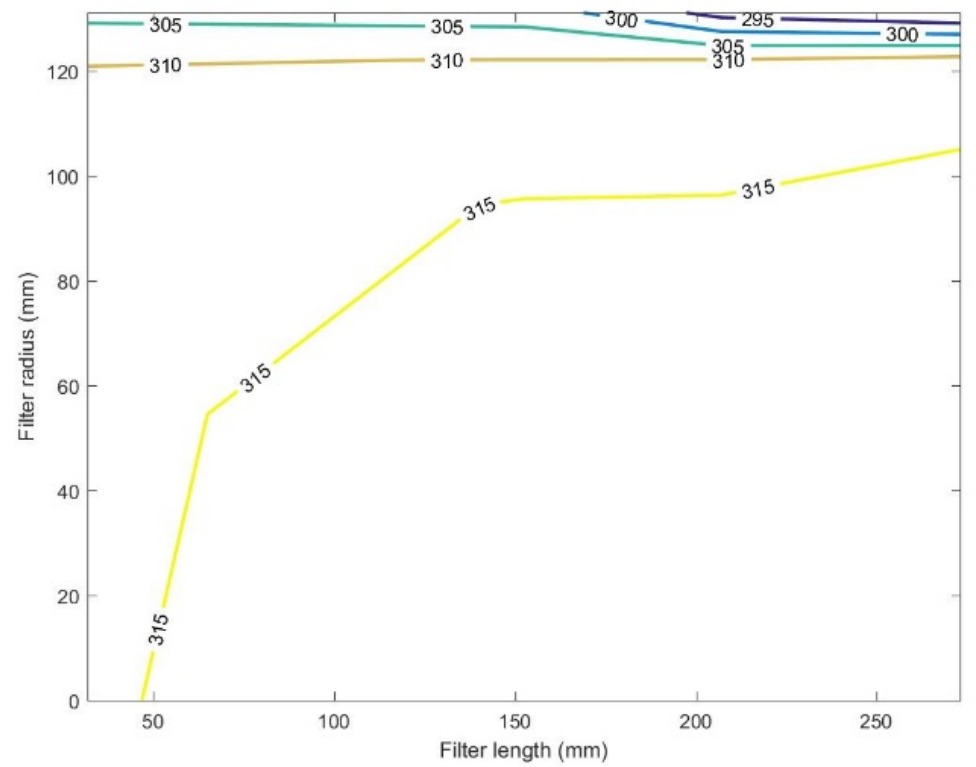

Figure H.6: Temperature distribution in the $\mathrm{SCRF}{ }^{\circledR}$ during $\mathrm{NO}_{\mathrm{x}}$ reduction stage for Test Point 3 with $2 \mathrm{~g} / \mathrm{L}$ PM loading, at ANR 1.0

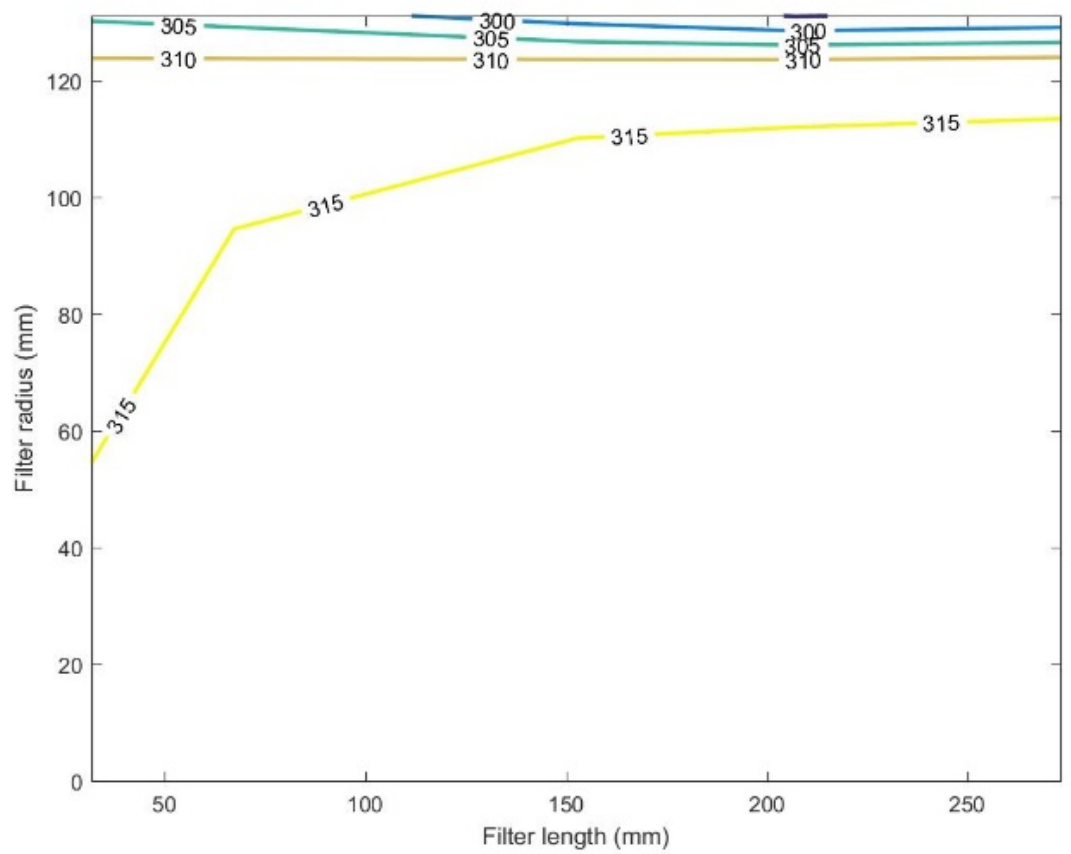

Figure H.7: Temperature distribution in the SCRF® during $\mathrm{NO}_{\mathrm{x}}$ reduction stage for Test Point 3 with $4 \mathrm{~g} / \mathrm{L}$ PM loading, at ANR 1.0 


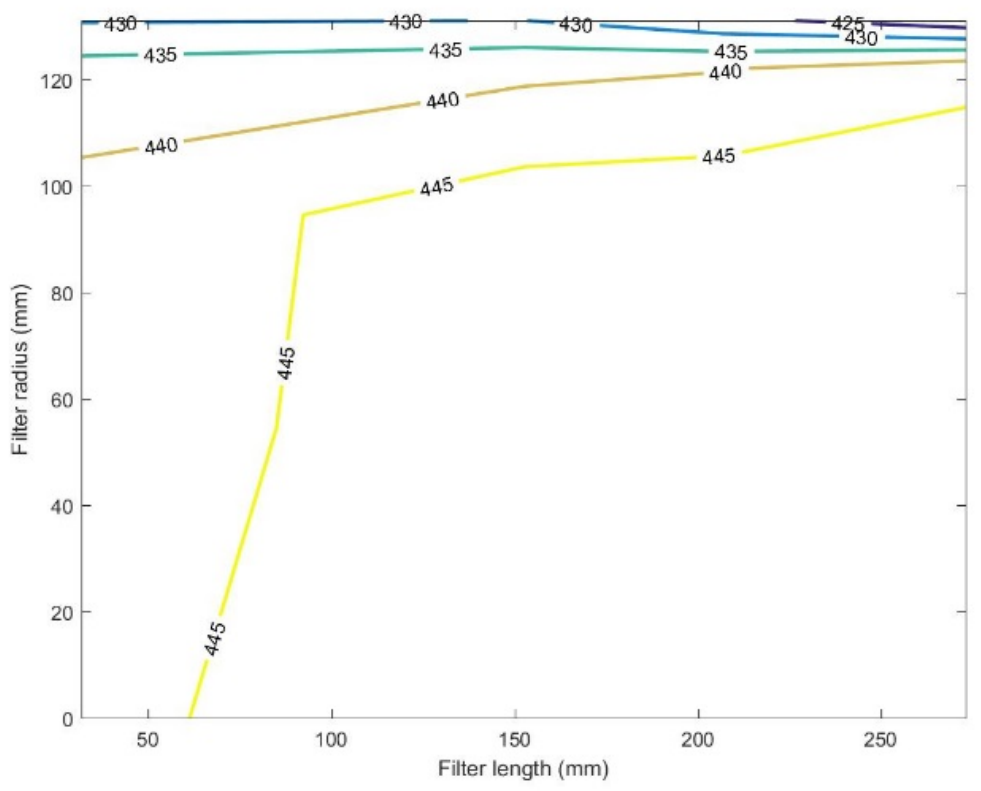

Figure H.8: Temperature distribution in the $\mathrm{SCRF}{ }^{\circledR}$ during $\mathrm{NO}_{\mathrm{x}}$ reduction stage for Test Point 8 without PM loading, at ANR 1.0



Figure H.9: Temperature distribution in the SCRF® during $\mathrm{NO}_{\mathrm{x}}$ reduction stage for Test Point 8 with 2 g/L PM loading, at ANR 1.0 




Figure H.10: Temperature distribution in the $\mathrm{SCRF}{ }^{\circledR}$ during $\mathrm{NO}_{\mathrm{x}}$ reduction stage for Test Point 8 with $4 \mathrm{~g} / \mathrm{L}$ PM loading at ANR 1.0

The temperature factor calculated using Equation H.1 [13] for all Test Points in configuration 2, with and without PM loading in the SCRF® are shown in Figures H.11, H.12 and H.13.

$$
\text { Temperautre Factor, } C=\frac{T_{S}-T_{r}}{T_{s}-T_{m}}
$$

Where $T_{m}$ is mean exhaust gas temperature, $T_{s}$ is wall inner surface temperature, $T_{r}$ temperature at a given radial location, y Axial location.

The diameter ratio is the ratio of SCRF® diameter at a given measurement location to the maximum SCRF® diameter [13]. From Figures H.11, H.12 and H.13 it is observed that the temperature factor is almost constant up to the SCRF® diameter ratio of 0.7 (indicating uniform temperature) and drops to 0 value (minimum temperature) at the SCRF® diameter ratio of 1.0 (outer radius of the filter). The maximum gradient in the temperature factor is observed at the $\mathrm{SCRF}{ }^{\circledR}$ diameter ratio of 0.7 to 1.0 , showing that 
more than $90 \%$ of the radial temperature reduction is in the $30 \%$ of the filter section closest to the outer radius of the filter.

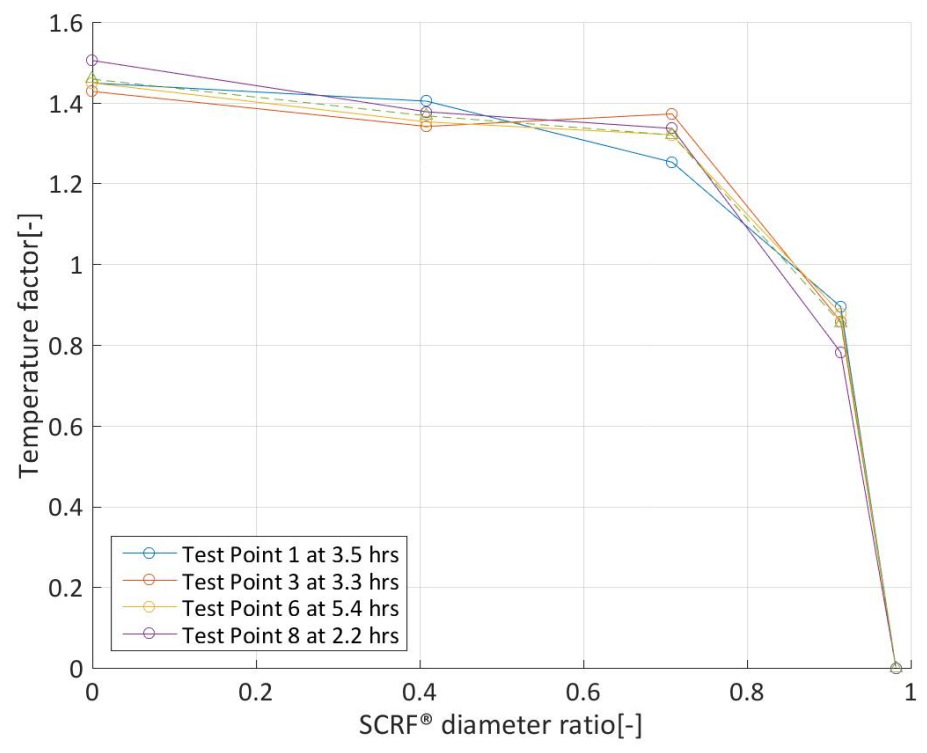

Figure H.11: Temperature factor profile at the $\mathrm{SCRF}{ }^{\circledR}$ inlet during $\mathrm{NO}_{\mathrm{x}}$ reduction stage without PM loading, at ANR 1.0

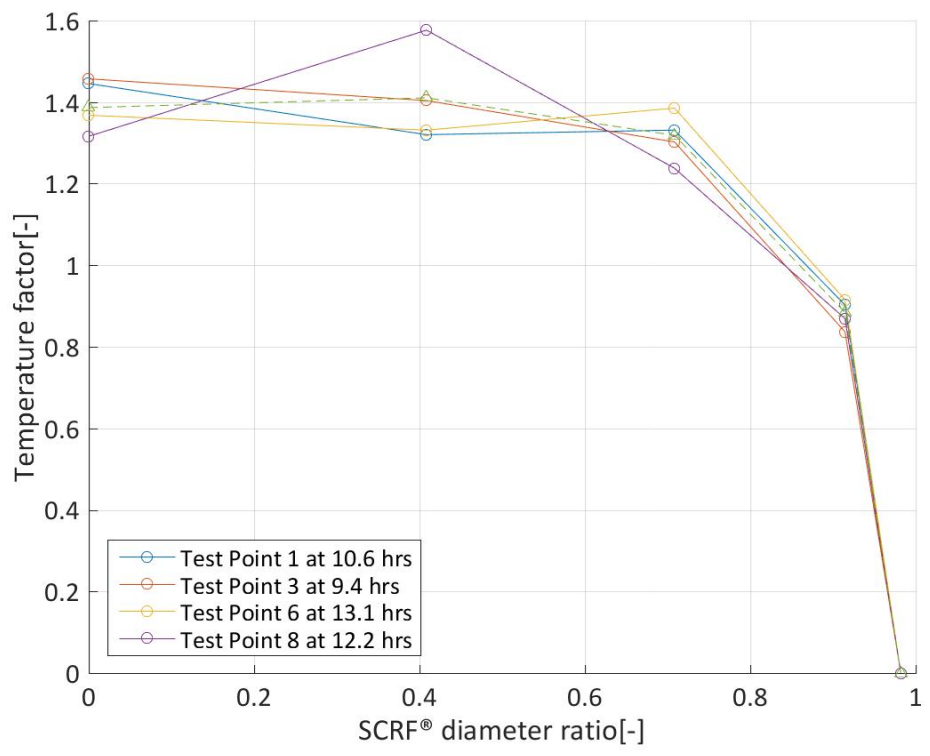

Figure H.12: Temperature factor profile at the $\mathrm{SCRF}{ }^{\circledR}$ inlet during $\mathrm{NO}_{\mathrm{x}}$ reduction stage with $2 \mathrm{~g} / \mathrm{L}$ PM loading, at ANR 1.0 


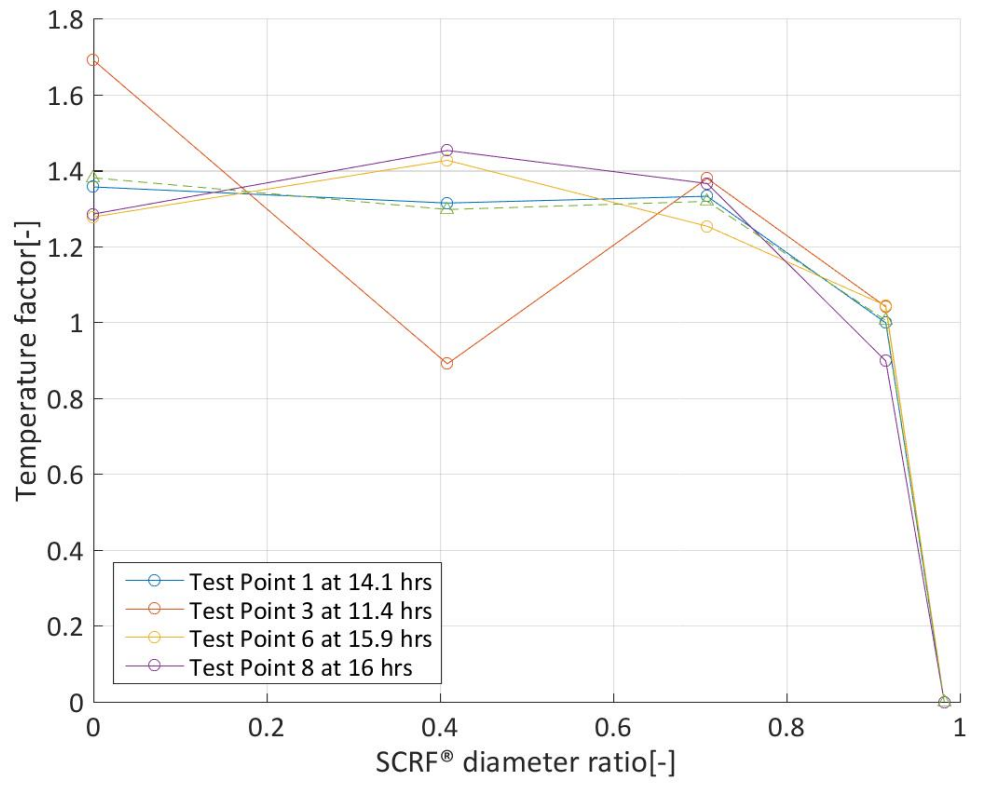

Figure H.13: Temperature factor profile at the $\mathrm{SCRF}{ }^{\circledR}$ inlet during $\mathrm{NO}_{\mathrm{x}}$ reduction stage with $4 \mathrm{~g} / \mathrm{L}$ PM loading, at ANR 1.0 


\section{Appendix I. Permissions to Use Copyrighted Material}

The permission letter below is for Figure 2.1

Dear Mr. vaibhav kadam,

Thank you for placing your order through Copyright Clearance Center's RightsLink service. Elsevier has partnered with RightsLink to license its content. This notice is a confirmation that your order was successful.

Your order details and publisher terms and conditions are available by clicking the link below:

http://s100.copyright.com/CustomerAdmin/PLF.jsp?ref=638d9123-c178-4953-b7ca$\mathrm{e} 5 \mathrm{c} 345 \mathrm{f} 9 \mathrm{c} 206$

\section{Order Details}

Licensee: vaibhav kadam

License Date: Aug 17, 2016

License Number: 3931510428725

Publication: Applied Catalysis B: Environmental

Title: A novel Ce-Ta mixed oxide catalyst for the selective catalytic reduction of NOx with NH3

The permission letter below is for Figure 2.2.

Dear Mr. vaibhav kadam,

Thank you for placing your order through Copyright Clearance Center's RightsLink service. Elsevier has partnered with RightsLink to license its content. This notice is a confirmation that your order was successful.

Your order details and publisher terms and conditions are available by clicking the link below:

http://s100.copyright.com/CustomerAdmin/PLF.jsp?ref=ea897345-2b3e-4876-aada$\underline{40 \mathrm{e} 51 \mathrm{fcee} 96 \mathrm{e}}$

\section{Order Details}

Licensee: vaibhav kadam 
License Date: Aug 17, 2016

License Number: 3931510836920

Publication: Journal of Catalysis

Title: Novel manganese oxide confined interweaved titania nanotubes for the lowtemperature Selective Catalytic Reduction (SCR) of NOx by NH3

The permission letter below is for Figures 2.4 and 2.5.

Dear Vaibhav Kadam,

Thank you very much for your permission request.

Enclosed you will find the permission letter. Kindly abide the outlined conditions for the usage.

\section{Springer reference}

\section{Emission Control Science and Technology}

May 2015, Volume 1, Issue 2, pp. 134-151

First online: 08 May 2015

\section{Interaction of NO $x$ Reduction and Soot Oxidation in a DPF with Cu-Zeolite SCR}

Coating

Authors: E. Tronconi, I. Nova, F. Marchitti, G. Koltsakis, D. Karamitros, B. Maletic, N. Markert, D.

Chatterjee, M. Hehle

(C) Springer SIP, AG 2015

Materials to be reused: Figure 7 and Figure 14

DOI 10.1007/s40825-015-0014-y

Print ISSN 2199-3629

Online ISSN 2199-3637

Journal no. 40825

\section{Your project}

Requestor: Vaibhav Kadam

GRA. Michigan Tech

vkadam@mtu.edu

University: Michigan Tech

Purpose: Dissertation/Thesis

Sincerely,

Rights and Permissions

Springer Science+Business Media 
Tiergartenstr. 17

69121 Heidelberg

Germany

Hello,

Attached please find a Microsoft Word document with a request to use a total of 2 figures in my Master's thesis (Master's student at Michigan Tech) from 1 publication in the Emission Control Science and Technology, May 2015, Volume 1, Issue 2.

If you have any questions, please do not hesitate to contact me at the information listed below.

Thank you

Vaibhav Kadam

GRA. Michigan Tech

vkadam@,mtu.edu

The permission letter below is for Figures 1.1, 3.3, 3.4, 3.5 and 3.6

Hi Vaibhav,

Please feel free to use any material from my thesis as required. All the best for your thesis!

Regards,

Krishnan Raghavan

Krishnan,

I am planning to use Figures 1.1, 3.1 and 3.3 from your thesis (original or modified version) for my thesis. Please provide me your permission to use the copyrighted material.

Thank you,

Vaibhav Kadam

GRA, Michigan Tech

vkadam@mtu.edu 
The permission letter below is for Figure 3.8.

Hi Vaibhav,

Yes, you have my permission. All the best for your thesis.

Warm Regards,

Erik Gustafson

Hi Erik,

I am planning to use Figure 1.1, 3.1 and 3.3 from your thesis (original or modified version) for my thesis. Please provide me your permission to use the copyrighted material.

Thank you,

Vaibhav Kadam

Figures 2.3 and 2.6. are reprinted with permission from SAE International.

Dear Vaibhav,

Thank you for your patience during processing of your request.

Please be advised, reproduction use of Figure 1, page 2 of SAE 2009-01-0274 and Figure 12, page 8 of SAE 2014-01-1523, is hereby granted, and subject to the following terms and conditions:

-Permission is granted for non-exclusive English language rights, and for the specific use as indicated in your email;

-Permission is required for new requests, or for further use of the material;

-The SAE material must be clearly identified and include the following statement "Reprinted with Permission from SAE International";

-We also request that you include a complete reference to the SAE document within the reference section for each figure replicated; 
-This permission does not cover any third-party copyrighted work which may appear in the material requested;

-Licensor's use of this material, in whole or in part, is entirely its responsibility, and SAE International does not warrant or is not responsible for any use of the material.

Thank you.

Best Regards,

Nikole Aston

IP Compliance Specialist

SAE INTERNATIONAL

400 Commonwealth Drive

Warrendale, PA 15096 USA

Hello,

Attached please find a Microsoft Word document with a request to use a total of 2 figures from 2 different S.A.E. publications in my Master's thesis.

Figure 1 from article: He, Y., Brown, D., Lu, S., Paratore, M. et al., "Opportunities and Challenges for Blended 2-Way SCR/DPF Aftertreatment Technologies," SAE Technical Paper 2009-01-0274, 2009, doi:10.4271/2009-01-0274.

Figure 12 from article: Johansen, K., Bentzer, H., Kustov, A., Larsen, K. et al., "Integration of Vanadium and Zeolite Type SCR Functionality into DPF in Exhaust Aftertreatment Systems - Advantages and Challenges," SAE Technical Paper 2014-011523, 2014, doi:10.4271/2014-01-1523.

Please provide me permission to use the copyright material.

Thank you

Vaibhav Kadam

GRA, Michigan Tech

vkadam@mtu.edu 